\title{
Análise de segunda ordem global em edifícios com estrutura de concreto armado
}

\begin{abstract}
Dissertação apresentada à Escola de Engenharia de São Carlos da Universidade de São Paulo como parte dos requisitos para obtenção do título de Mestre em Ciências, Programa de Engenharia Civil (Estruturas).
\end{abstract}

Versão corrigida. A original encontra-se na Escola de Engenharia de São Carlos da Universidade de São Paulo, EESC-USP.

Linha de pesquisa:

Estruturas de concreto e alvenaria

Orientador: Libânio Miranda Pinheiro 
AUTORIZO A REPRODUÇÃO E DIVULGAÇÃO TOTAL OU PARCIAL DESTE TRABALHO, POR QUALQUER MEIO CONVENCIONAL OU ELETRÔNICO, PARA FINS DE ESTUDO E PESQUISA, DESDE QUE CITADA A FONTE.

Ficha catalográfica preparada pela Seção de Tratamento da Informação do Serviço de Biblioteca - EESC/USP

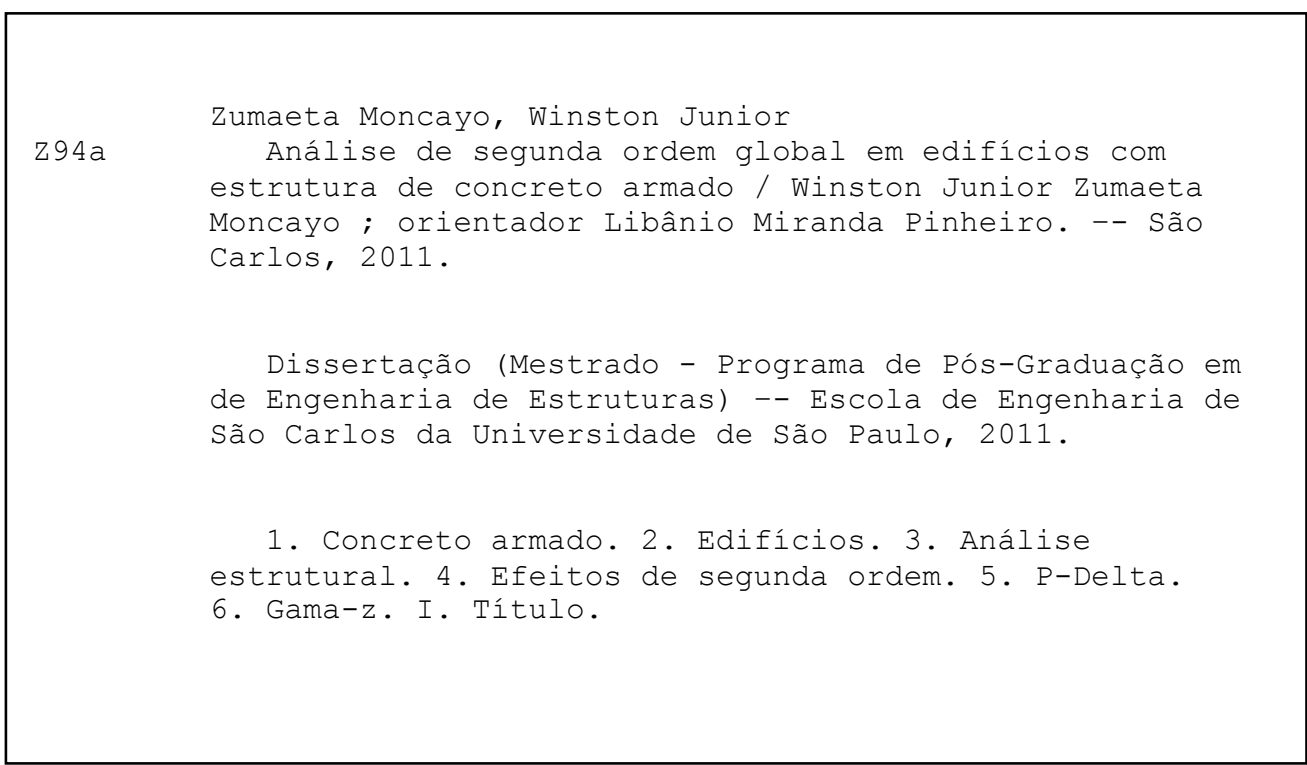




\section{FOLHA DE JULGAMENTO}

Candidato: Engenheiro WINSTON JUNIOR ZUMAETA MONCAYO.

Dissertação defendida e julgada em 15/03/2011 perante a Comissão Julgadora:

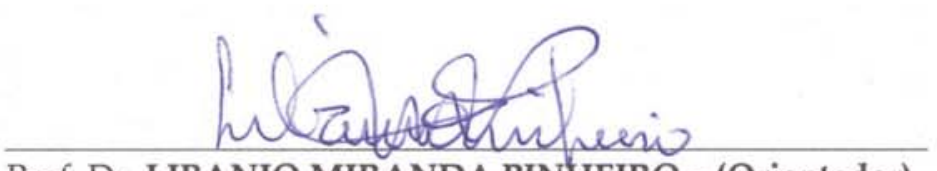

Prof. Dr. LIBANIO MIRANDA PINHEIRO - (Orientador)

(Escola de Engenharia de São Carlos/USP)

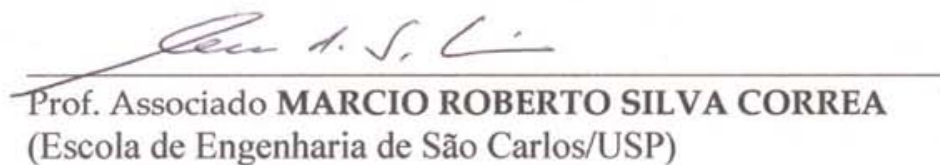

APROVADO

(Escola de Engenharia de São Carlos/USP)
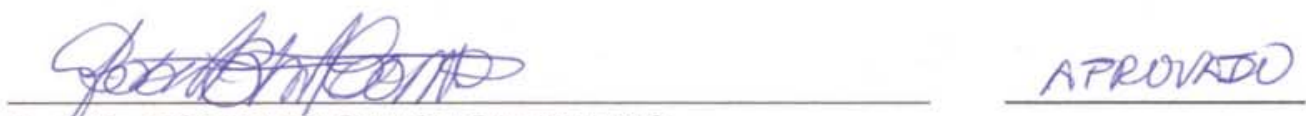

Prof. Dr. ROBERTO CHUST CARVALHO

(Universidade Federal de São Carlos/UFSCar)

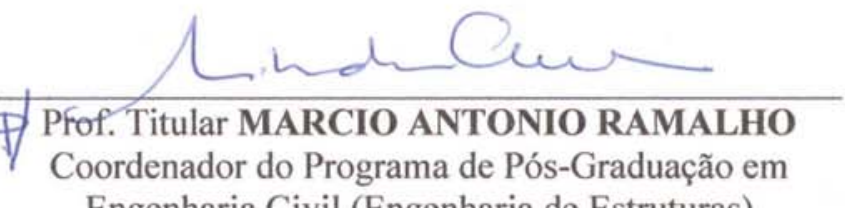

Engenharia Civil (Engenharia de Estruturas)

Ana nucia H. c. E7 Debs, Profa. Dra

Vige Goordenadora da Área de

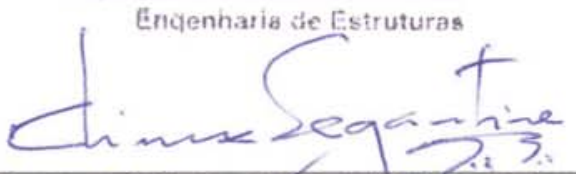

Prof. Associado PAULO CÊSAR LIMA SEGANTINE

Presidente da Comissão de Pós-Graduação 

Aos meus pais, Winston e Martha, pelo apoio e incentivo. Aos meus irmãos, Emerson, Gladys e Vivian, pela amizade e companheirismo. 

A Deus, meu pai e minha mãe, pois sem eles eu não teria chegado até aqui.

Ao prof. Libânio Miranda Pinheiro pela brilhante orientação, pela grande amizade e pela confiança depositada em mim desde o início do mestrado.

À Universidade Federal do Amazonas por ter me formado em dois cursos de graduação: Engenharia Civil e Matemática.

Aos professores da Universidade Federal do Amazonas do Departamento de Construção, Vilar Fiúza da Câmara Jr., Marcus Vinicius de Vasconcelos Paiva, Flávio Alberto Cantisani de Carvalho e Raimundo Pereira de Vasconcelos, por terem sido os responsáveis por eu gostar tanto da área de Engenharia de Estruturas.

Ao prof. Francisco Anastácio Cantisani de Carvalho por ter me dado a oportunidade de trabalhar em seu escritório e poder aprender um pouco da área de projeto de edifícios.

Aos professores da pós-graduação José Samuel Giongo e Márcio Roberto Silva Corrêa pela ajuda com referências bibliográficas.

Aos engenheiros Alio Ernesto Kimura e Nelson Covas pelo esclarecimento de algumas dúvidas relacionadas ao Sistema TQS.

Ao Departamento de Engenharia de Estruturas da Escola de Engenharia de São Carlos pela infraestrutura disponibilizada para a realização do mestrado.

A todos os meus amigos do Departamento que tornaram mais agradáveis esses dois anos de mestrado.

Aos funcionários do Departamento de Engenharia de Estruturas da Escola de Engenharia de São Carlos.

Aos engenheiros Hugo Forni Ferriani e Rodrigo Aparecido Falcucci pelos edifícios concedidos para análise.

À minha namorada Juliane Henriques de Melo pelo amor, carinho, paciência e compreensão.

À CAPES pela bolsa concedida. 

ZUMAETA MONCAYO, W. J. (2011). Análise de segunda ordem global em edifícios com estrutura de concreto armado. 221p. Dissertação (Mestrado) Escola de Engenharia de São Carlos, Universidade de São Paulo, São Carlos, 2011.

A análise de segunda ordem global de edifícios é indispensável nos dias atuais, em que as estruturas são cada vez mais esbeltas. No mercado, há diversos sistemas computacionais que realizam essa análise, e alguns dos novos engenheiros estruturais podem não saber os conceitos em que ela se baseia. Portanto, este trabalho pretende: avaliar os efeitos de segunda ordem em edifícios por meio dos coeficientes $\gamma_{z}$ e $F A V t$, este desenvolvido pela TQS, e por meio do processo P-Delta; mostrar como este processo P-Delta funciona e como o sistema computacional CAD/TQS o considera; e analisar também os esforços de segunda ordem calculados a partir dos de primeira ordem multiplicados por $0,95 \gamma_{z}$. Em relação à avaliação da estabilidade global, serão comparados os resultados obtidos com os parâmetros $\alpha, \gamma_{z}, F A V t$ e $R M 2 M 1$, este último gerado a partir do processo P-Delta. Pretende-se, assim, fornecer subsídios para que os novos engenheiros tenham condições de atuar com base conceitual bem fundamentada, tanto na escolha do método quanto na análise dos resultados.

Palavras-chave: concreto armado, edifícios, análise estrutural, efeitos de segunda ordem, P-Delta, Gama-z. 

ZUMAETA MONCAYO, W. J. (2011). Overall second-order analysis in buildings with reinforced concrete structure. 221p. Dissertation (Master) Escola de Engenharia de São Carlos, Universidade de São Paulo, São Carlos, 2011.

The overall second-order analysis of buildings is essential nowadays, in which the structures are each time more slender. In the market, there are several computer systems that perform this analysis, and some new structural engineers can not know the concepts on which it rests. Therefore, this study aims: to evaluate the second-order effects in buildings making use of the coefficients $\gamma_{z}$, and FAVt, this developed by TQS, and using P-Delta process; to show how this P-Delta process works and how the computer system CAD/TQS considers it; and also analyze the second order efforts obtained from the firstorder ones multiplied by $0,95 \gamma_{z}$. Regarding the evaluation of overall stability, will be compared the results obtained with the parameters $\alpha, \gamma_{z}, F A V t$, and $R M 2 M 1$, the latter generated from the P-Delta process. It is intended, therefore, to provide subsidies for new engineers to be able to work with well-founded conceptual base, both in the choice of method and analysis of results.

Keywords: reinforced concrete, buildings, structural analysis, second-order effects, P-Delta, Gamma-z. 



\section{SUMÁRIO}

1. I NTRODUÇÃO ................................................................. 17

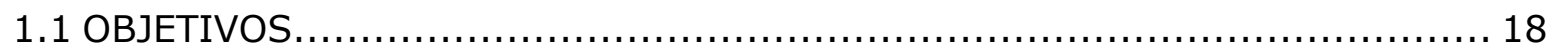

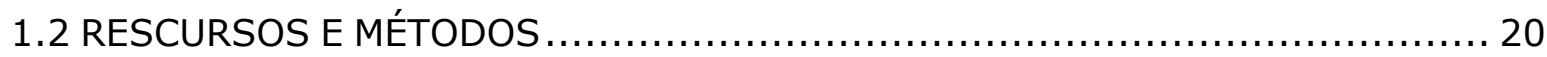

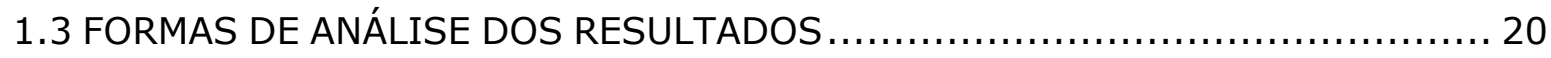

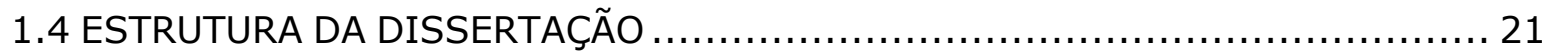

2. PARÂMETROS DE ESTABI LI DADE GLOBAL ....................... 23

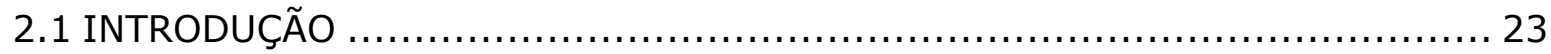

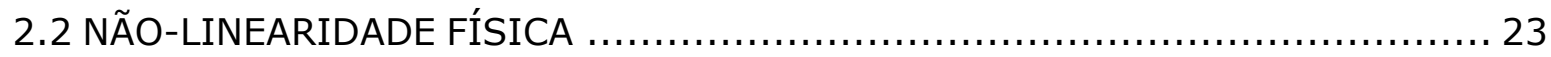

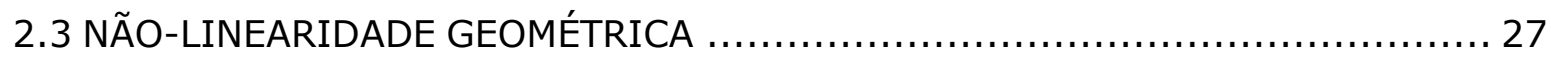

2.4 PARÂMETROS DE ESTABILIDADE E EFEITOS DE SEGUNDA ORDEM ............. 30

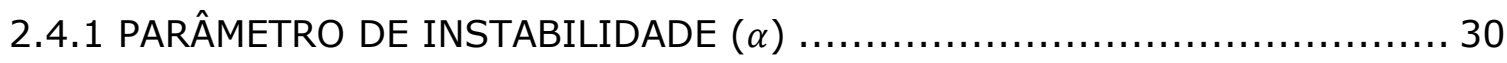

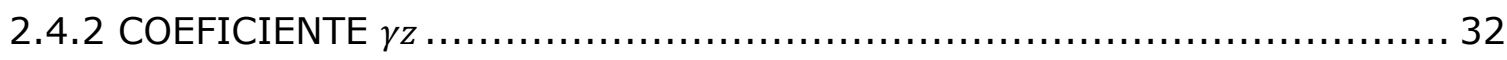

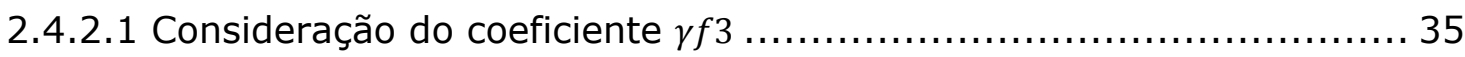

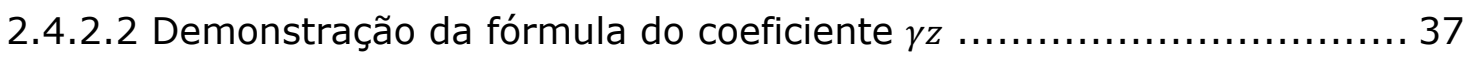

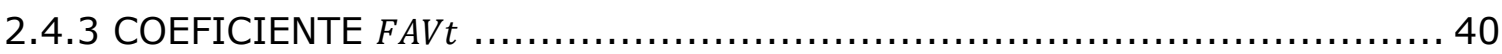

2.5 EXEMPLOS DE APLICAÇÃO DOS COEFICIENTES $F A V t$ E $\gamma z \ldots \ldots \ldots \ldots \ldots \ldots \ldots . \ldots 4$

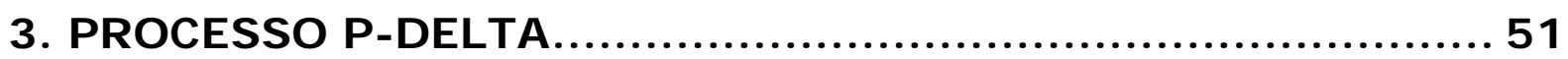

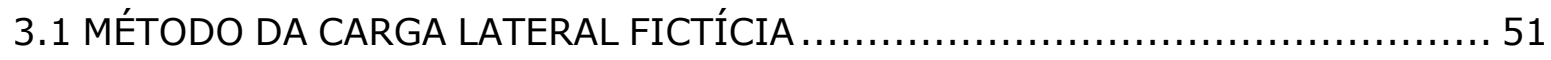

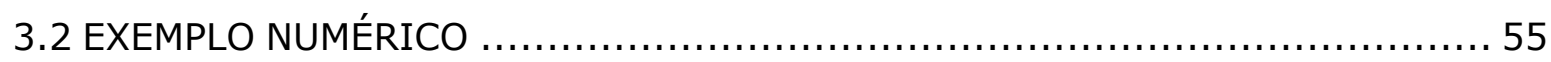

3.2.1 ANÁLISE PELO PROCESSO P-Delta ..................................... 55

3.2.2 ANÁLISE PELO MÉTODO SIMPLIFICADO DO Gama-z .................... 61

3.2.3 COMPARAÇÃO ENTRE O PROCESSO P-Delta E O Gama-z ....................63

3.3 CONSIDERAÇÕES SOBRE O PROCESSO P-DELTA NO SOFTWARE TQS .......... 65

\section{TÓPI COS RELACI ONADOS À ESTABI LI DADE ...................... 71}

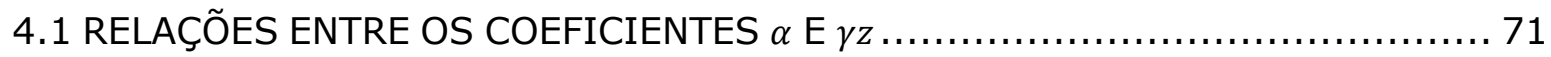

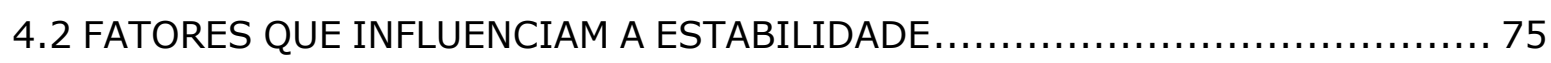

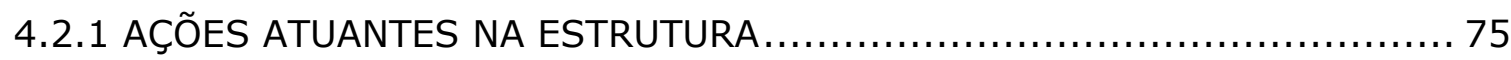

4.2.1.1 Ações horizontais .................................................... 75

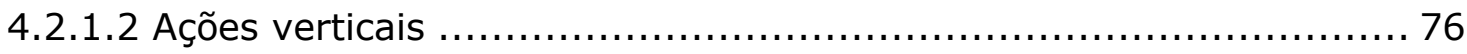

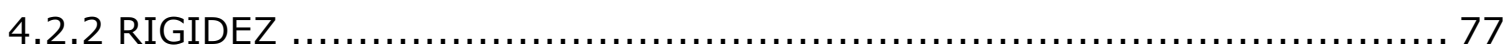


4.2.3 ANÁLISES COM REDISTRIBUIÇÃO DE ESFORÇOS $\ldots \ldots \ldots \ldots \ldots \ldots \ldots \ldots \ldots . \ldots \ldots$

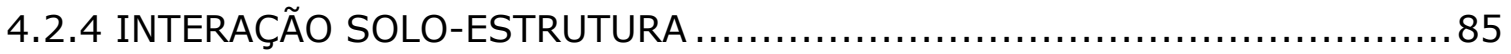

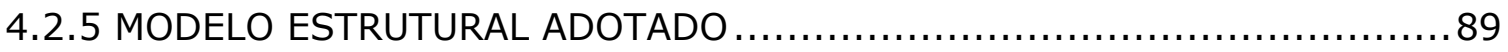

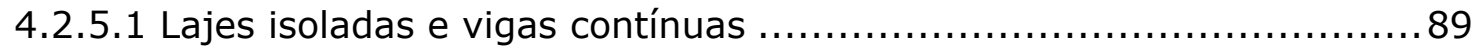

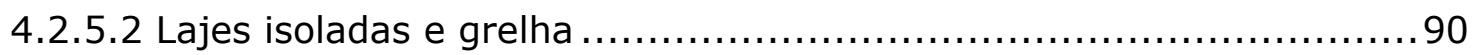

4.2.5.3 Lajes e vigas consideradas como grelha equivalente ...................90

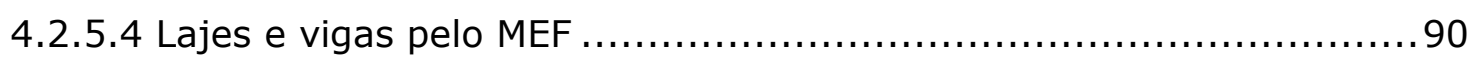

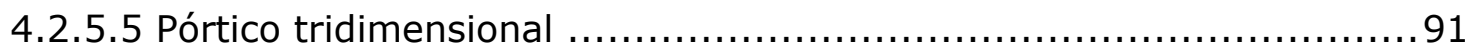

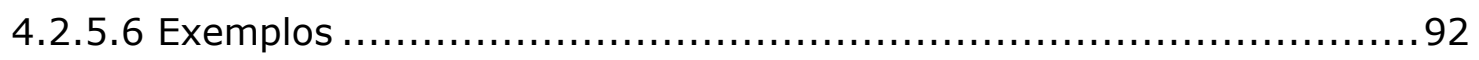

5. AÇÕES ATUANTES NA ESTRUTURA $\ldots \ldots \ldots \ldots \ldots \ldots \ldots \ldots \ldots \ldots \ldots \ldots \ldots$

5.1 AÇÕES DEVIDAS ÀS IMPERFEIÇÕES GEOMÉTRICAS GLOBAIS $\ldots \ldots \ldots \ldots \ldots \ldots . . \ldots 7$

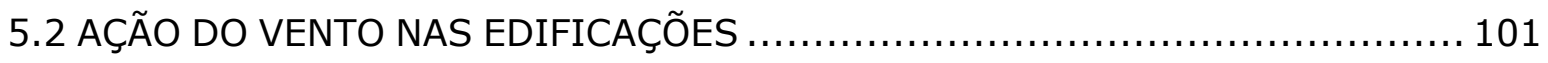

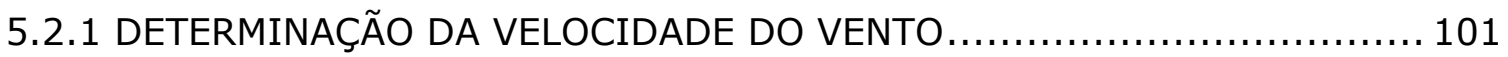

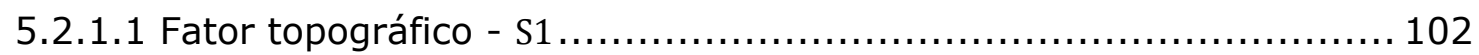

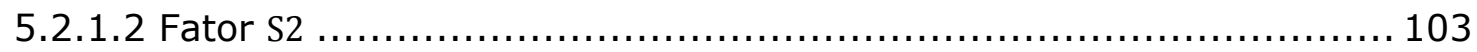

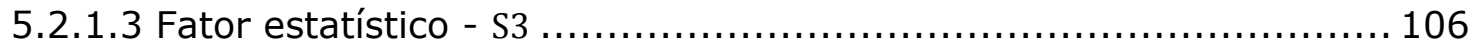

5.2.2 FORÇA DE ARRASTO E COEFICIENTE DE ARRASTO $\ldots \ldots \ldots \ldots \ldots \ldots \ldots \ldots \ldots$

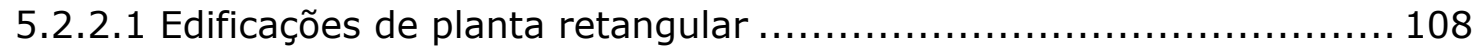

5.2.3 ANÁLISE DE VENTO NO SISTEMA COMPUTACIONAL CAD/TQS ............ 111

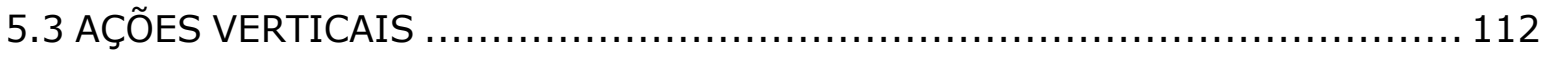

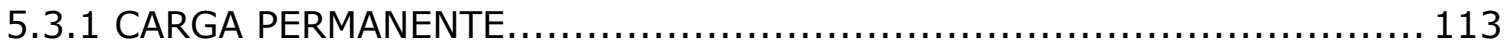

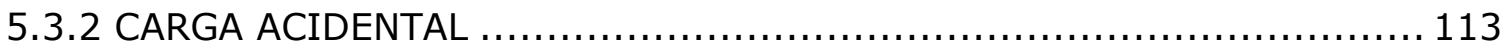

6. ANÁLI SE DE DOIS EDI Fí CI OS ....................................... 115

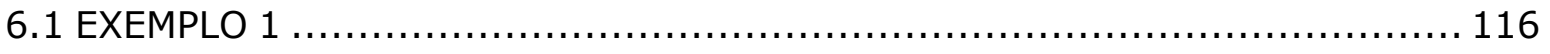

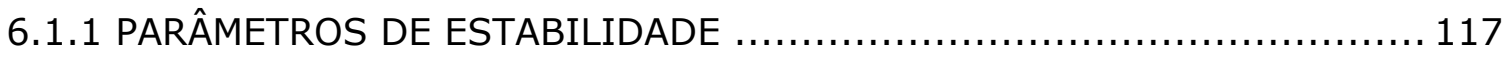

6.1.2 ANÁLISE DE SEGUNDA ORDEM GLOBAL ............................... 119

6.1.3 ALTERNATIVA PARA CONSIDERAR A NÃO-LINEARIDADE FÍSICA ......... 126

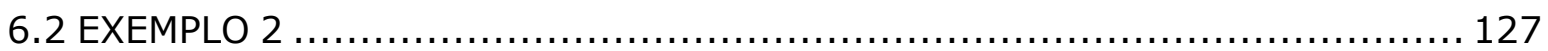

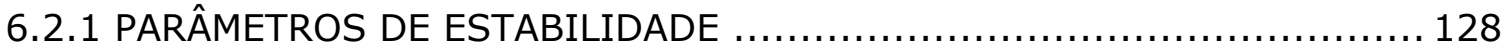

6.2.2 ANÁLISE DE SEGUNDA ORDEM GLOBAL ............................... 129

6.2.3 ALTERNATIVA PARA CONSIDERAR A NÃO-LINEARIDADE FÍSICA ......... 137

7. ANÁLI SE DE CI NCO EDI FÍ CI OS ..................................... 139

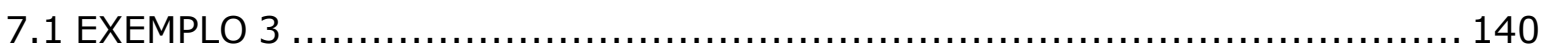

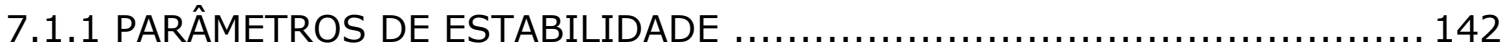


7.1.2 ANÁLISE DE SEGUNDA ORDEM GLOBAL.................................. 143

7.1.3 ALTERNATIVA PARA CONSIDERAR A NÃO-LINEARIDADE FÍSICA .......... 148

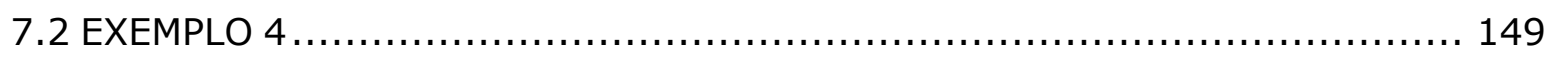

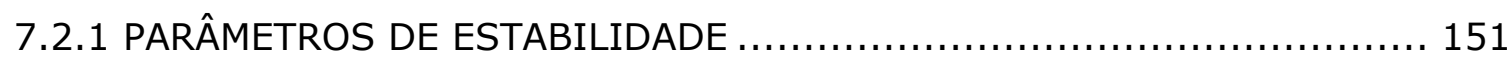

7.2.2 ANÁLISE DE SEGUNDA ORDEM GLOBAL..................................... 152

7.2.3 ALTERNATIVA PARA CONSIDERAR A NÃO-LINEARIDADE FÍSICA.......... 152

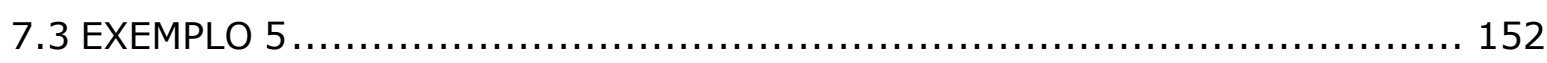

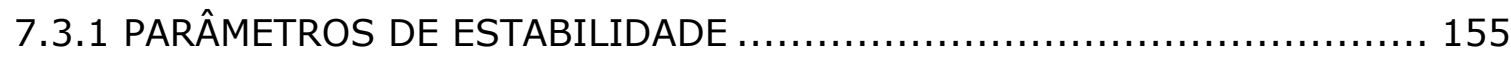

7.3.2 ANÁLISE DE SEGUNDA ORDEM GLOBAL.................................. 155

7.3.3 ALTERNATIVA PARA CONSIDERAR A NÃO-LINEARIDADE FÍSICA .......... 155

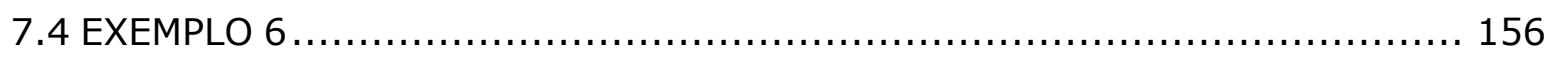

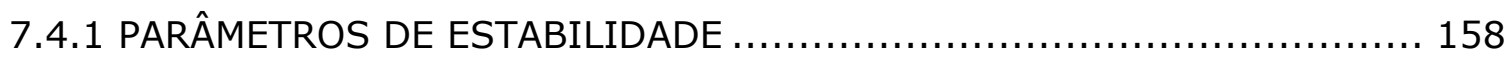

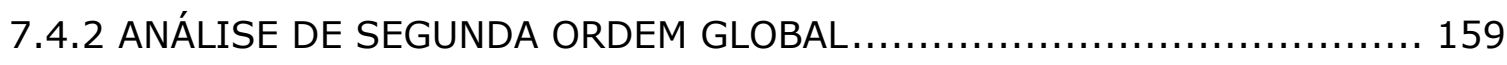

7.4.3 ALTERNATIVA PARA CONSIDERAR A NÃO-LINEARIDADE FÍSICA........... 159

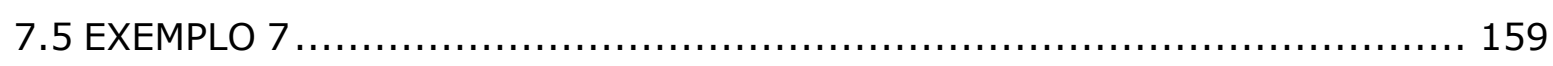

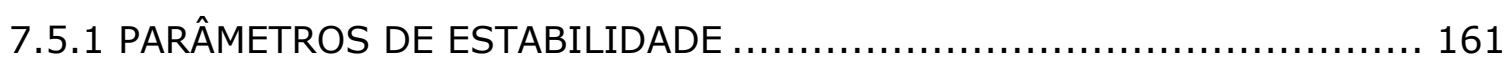

7.5.2 ANÁLISE DE SEGUNDA ORDEM GLOBAL.................................... 162

7.5.3 ALTERNATIVA PARA CONSIDERAR A NÃO-LINEARIDADE FÍSICA .......... 169

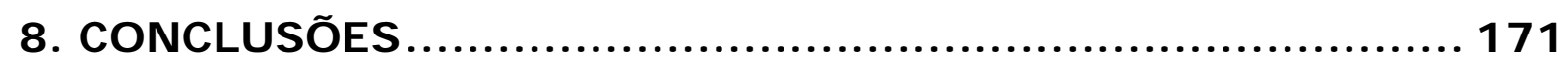

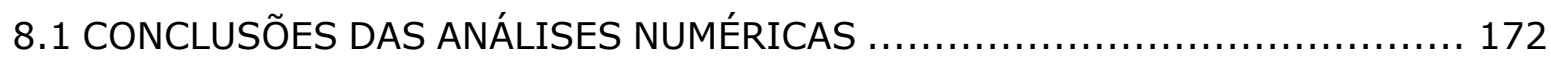

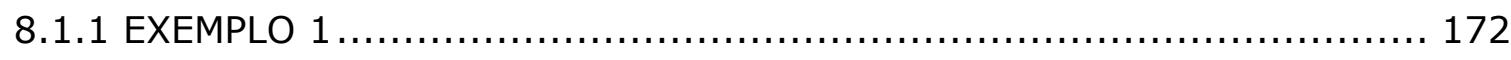

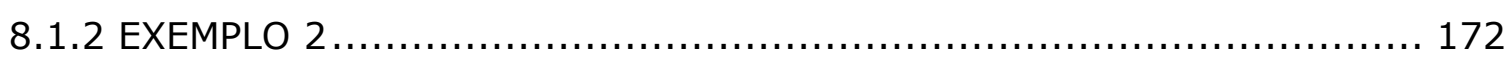

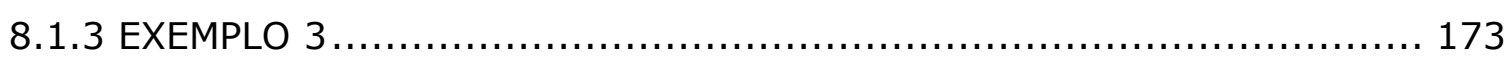

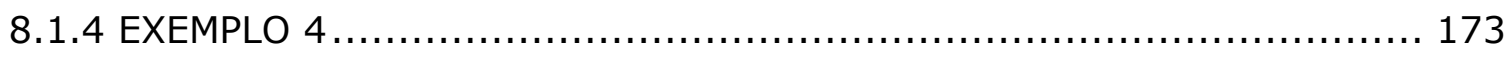

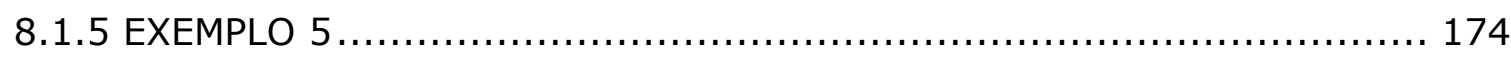

8.1.6 EXEMPLO 6

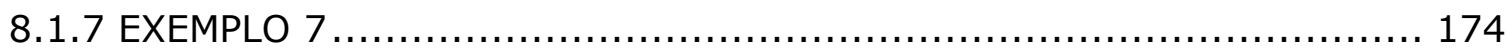

8.1.8 CONSIDERAÇÕES FINAIS DAS ANÁLISES ................................... 175

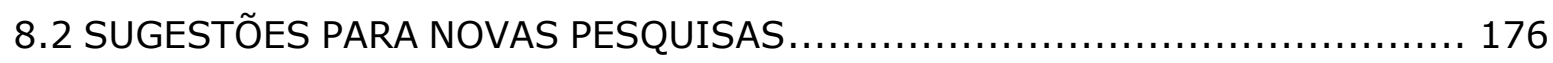

REFERÊNCI AS BI BLI OGRÁFI CAS ........................................ 177

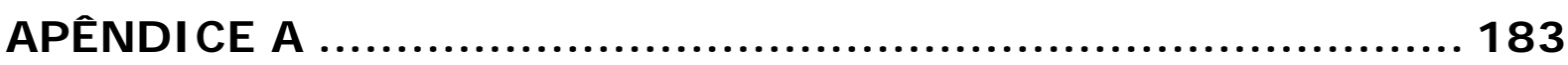

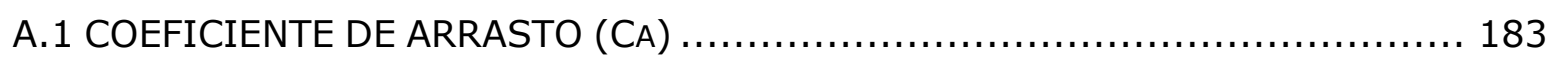

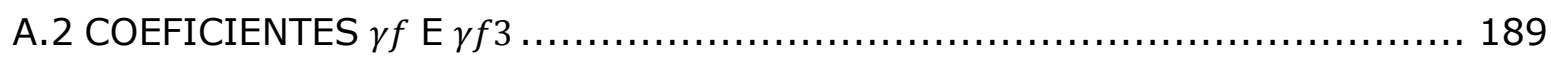

A.3 IMPERFEIÇÕES GEOMÉTRICAS GLOBAIS (DESAPRUMO) ….................... 191 
A.4 COEFICIENTES PARA CONSIDERAÇÃO DA NÃO-LINEARIDADE FÍSICA ........ 194

A.5 ESFORÇOS PARA CÁLCULO DO GAMA-Z ................................... 196

A. 6 CONSIDERAÇÃO DO GAMA-Z NA TRANSFERÊNCIA DE ESFORÇOS .............. 199

A.7 CARGAS VERTICAIS PARA CÁLCULO DOS MOMENTOS DE 2a ORDEM .......... 201

A.8 DESLOCAMENTOS HORIZONTAIS DEVIDOS A CARGAS VERTICAIS ............ 202

A.9 NÚMERO MÍNIMO DE PISOS PARA APLICAÇÃO DE GAMA-Z $\ldots \ldots \ldots \ldots \ldots \ldots \ldots . \ldots \ldots$

A.10 COEFICIENTE PARA CLASSIFICAR A DESLOCABILIDADE $\ldots \ldots \ldots \ldots \ldots \ldots \ldots . \ldots \ldots$

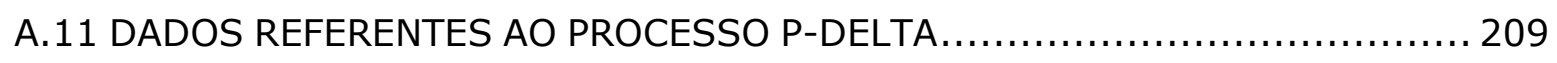

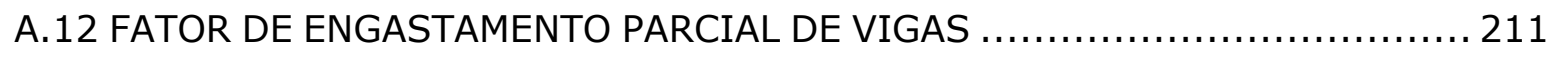

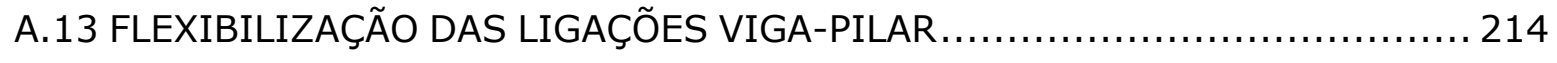

A.14 LIMITES DOS DESLOCAMENTOS HORIZONTAIS DO EDIFÍCIO .............. 216

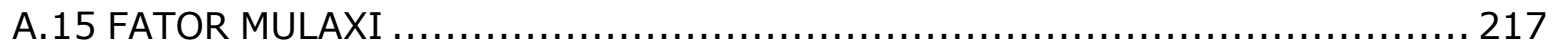

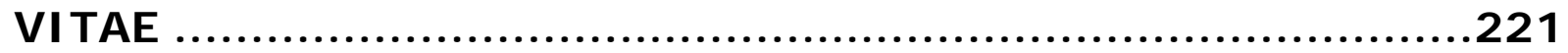




\section{NTRODUÇÃO}

A análise de segunda ordem global de edifícios é indispensável nos dias atuais, diferente de outras épocas. Entre os vários motivos pode-se citar que a tecnologia do concreto sofreu grandes avanços e tornou possível a execução de concretos de elevada resistência, que podem ultrapassar os $50 \mathrm{MPa}$, ocasionando estruturas mais esbeltas. Há poucas décadas, a resistência usual em estruturas de concreto era em torno de $15 \mathrm{MPa}$ a $20 \mathrm{MPa}$.

Tratando-se de pilares, quanto mais esbeltos, mais necessária se torna a análise de segunda ordem global, pois são eles os maiores responsáveis por manter a estabilidade global dos edifícios.

Alguns dos novos engenheiros estruturais podem não saber os conceitos em que se baseiam esses tipos de análise de segunda ordem, pois com o avanço da informática, todos os cálculos complexos e inviáveis para serem realizados no dia a dia dos escritórios são realizados de maneira muito simples, com apenas o apertar de um botão, e devido a essa facilidade de se realizar processamentos, muitos não se preocupam em se aprofundar em tais assuntos, ou por falta de tempo pela correria dos escritórios, ou por achar que não é necessário obter tal conhecimento, porque o computador "faz tudo", o que é um grande erro.

Toda essa complexidade que está por trás da análise de efeitos de segunda ordem deve-se ao fato de o concreto armado apresentar um comportamento não-linear em relação à sua constituição, chamado de nãolinearidade física, assim como, também, por apresentar comportamento nãolinear em relação à sua geometria, denominado não-linearidade geométrica. Tais efeitos podem ser determinados através de uma análise na qual se considera a estrutura na sua configuração final de equilíbrio (PINTO, 1997).

$\mathrm{Na}$ análise de estabilidade de estruturas devem ser consideradas ações horizontais que são originadas principalmente pelas ações do vento e pelas imperfeições geométricas. 
Segundo Franco (1985), há vários métodos de cálculo para análise de estruturas de nós móveis, variando dos mais simples aos mais complexos. As não-linearidades são consideradas diferentemente por cada um deles, e a escolha do método apropriado dependerá das características da obra e de sua sensibilidade aos efeitos de segunda ordem.

O $\gamma_{z}$ (Gama-z) é um processo simplificado de avaliação da estabilidade global e dos efeitos de segunda ordem mediante multiplicação dos momentos de primeira ordem por um coeficiente $\gamma_{z}$. Baseia-se na hipótese de que as sucessivas linhas elásticas, devidas às ações verticais aplicadas numa estrutura com os nós deslocados, sucedem-se segundo uma progressão geométrica. Há casos excepcionais em que não se deve aplicar esse processo simplificado, por exemplo, quando se tem vigas de transição, quando se tem estruturas que já possuem deslocamentos devidos a carregamentos verticais, entre outros (VASCONCELOS, 2000).

O Processo P-Delta tradicional é um dos que pode ser utilizado para a análise de segunda ordem, com aplicação relativamente simples e que oferece estimativas satisfatórias desses efeitos. Pode ser encontrado em alguns trabalhos como Método da Carga Lateral Fictícia. Ele consiste em um cálculo iterativo onde o efeito dos deslocamentos sucessivos é transformado em forças horizontais equivalentes (LOPES, SANTOS \& SOUZA, 2005).

Primeiramente é feita uma análise de primeira ordem, considerando o carregamento horizontal e o vertical. Os deslocamentos dos nós $(\Delta)$ obtidos para cada pavimento serão transformados em forças horizontais fictícias a serem consideradas na estrutura para nova análise (BUENO, 2009).

\subsection{OBJ ETIVOS}

O objetivo principal deste trabalho é a análise estrutural de edifícios, dedicando maior atenção aos efeitos de segunda ordem global obtidos por meio do coeficiente $\gamma_{z}$. Os resultados serão comparados aos de análises baseadas no processo P-Delta, relativa aos mesmos edifícios que servirão de base para este trabalho. Será mostrado como este processo P-Delta funciona e como o sistema computacional CAD/TQS o considera. 
Outro objetivo consiste em fazer uma comparação com o coeficiente desenvolvido pela TQS Informática: o coeficiente $F A V t$, calculado pela mesma formulação do coeficiente $\gamma_{z}$, em que se consideram os deslocamentos horizontais provocados pelas forças verticais. Também, será avaliada a estabilidade global dos edifícios analisados.

Pretende-se, assim, fornecer subsídios para que os novos engenheiros tenham condições de atuar com base conceitual bem fundamentada, tanto na escolha do método quanto na análise dos resultados.

Após o estudo desta dissertação, pretende-se que o leitor esteja apto para realizar uma boa análise de estabilidade global de edifícios, pois irá adquirir uma boa fundamentação teórica e será capaz de responder às seguintes perguntas:

$>$ O que é estabilidade global? Para que serve?

$>0$ que são efeitos de segunda ordem?

$>$ Quando os efeitos de segunda ordem devem ser considerados?

$>$ Os efeitos de segunda ordem podem gerar resultados muito diferentes, quando considerados ou não?

$>$ A ação do vento influencia diretamente na estabilidade global?

Para que serve o coeficiente de arrasto (Ca) do vento? Como ele é calculado?

Do que se trata uma análise não-linear?

Qual a diferença entre não-linearidade física e não-linearidade geométrica? Em que situações elas devem ser consideradas?

> Estarão sendo cometidos erros se for realizada uma análise puramente linear?

$>0$ que são parâmetros de estabilidade global?

> Para que serve o parâmetro de instabilidade alfa?

$>0$ que é Gama-z? Para que serve? Como é calculado?

$>0$ que é P-Delta? Para que serve? Como é calculado?

$>$ O que é o parâmetro FAVt? Para que serve?

Quais fatores influenciam diretamente na estabilidade do edifício? 


\subsection{RESCURSOS E MÉTODOS}

Inicialmente, será apresentada uma revisão bibliográfica sobre análise de segunda ordem global de edifícios com estrutura de concreto armado, com ênfase no coeficiente $\gamma_{z}$ e no processo P-Delta.

Em seguida, será feita a análise estrutural de sete edifícios, considerando as alternativas: lajes maciças e lajes nervuradas.

Em dois deles serão considerados, também, núcleos rígidos junto à escada e ao elevador.

Para isso, será utilizado um sistema computacional disponível no mercado, - CAD/TQS versão 15.5, por ser ele bastante empregado nos principais escritórios de projeto estrutural do país.

Será apresentado um apêndice contendo todos os passos realizados no sistema computacional, para obtenção dos resultados de tais análises de segunda ordem global.

Com a leitura do trabalho, além de adquirir alguns conhecimentos sobre a teoria e os conceitos fundamentais relacionados com o assunto, pretende-se, com o citado apêndice, que os interessados possam aplicar, de maneira simples e prática, parte significativa do conhecimento utilizado no sistema CAD/TQS.

Esse sistema está disponível no Departamento de Engenharia de Estruturas (SET) da Escola de Engenharia de São Carlos (EESC/USP).

\subsection{FORMAS DE ANÁLI SE DOS RESULTADOS}

Todas as análises serão realizadas respeitando-se as prescrições da norma vigente (NBR-6118:2003).

Os resultados das análises de segunda ordem obtidos pelos coeficientes $\gamma_{z}$ e FAVt serão comparados aos obtidos pelo processo P-Delta.

Será avaliada também a eficiência dos esforços de segunda ordem obtidos pela majoração dos esforços horizontais de primeira ordem por $0,95 \gamma_{z}$.

Para a análise da estabilidade global, serão comparados os resultados obtidos por meio dos parâmetros $\alpha, \gamma_{z}, F A V t$ e do coeficiente RM2M1, que é gerado a partir do processo P-Delta.

Ressalta-se que o caso de possível torção em relação ao eixo vertical do edifício não será comentado neste trabalho. 


\subsection{ESTRUTURA DA DI SSERTAÇÃO}

O trabalho consiste em descrever todo o processo e considerações que se devem seguir para realizar uma boa análise global de edifícios. Os capítulos deste trabalho apresentam os conteúdos descritos a seguir.

Capítulo 1: apresentação do trabalho, introduzindo 0 assunto da estabilidade global, mostrando os objetivos, os recursos e métodos e a forma de análise dos resultados.

Capítulo 2: revisão bibliográfica sobre as não-linearidades consideradas nos projetos de edifícios e os parâmetros de estabilidade global que são utilizados com mais frequência nos escritórios de projeto estrutural do Brasil.

Capítulo 3: revisão bibliográfica sobre o processo P-Delta e como ele é considerado pelo sistema computacional CAD/TQS, usado neste trabalho.

Capítulo 4: tópicos relacionados à estabilidade global, correlação entre os parâmetros de estabilidade e fatores que influenciam diretamente na estabilidade do edifício.

Capítulo 5: ações horizontais e verticais que poderão atuar na edificação ao longo de sua vida útil.

Capítulo 6: análise numérica de dois edifícios e resultados.

Capítulo 7: análise numérica de mais cinco edifícios e resultados.

Capítulo 8: conclusões e sugestões para novas pesquisas. 



\section{PARÂMETROS DE ESTABI LI DADE GLOBAL}

\subsection{NTRODUÇÃO}

A verificação da estabilidade global é um requisito importante na elaboração de projetos de edifícios de concreto armado, e visa garantir a segurança da estrutura perante o estado limite último de instabilidade, situação que representa a perda da capacidade resistente da estrutura, causada pelo aumento das deformações.

Para tal verificação existem alguns coeficientes chamados de parâmetros de estabilidade global. Porém, antes de estudá-los, para o bom entendimento de tais parâmetros, é necessário comentar sobre a análise não-linear, que é extremamente importante, pois na realidade o concreto armado possui um comportamento não-linear. $\mathrm{Na}$ engenharia de estruturas existem basicamente três tipos de não-linearidades que podem gerar um comportamento não-linear, à medida que o carregamento é aplicado: não-linearidade física (NLF), nãolinearidade geométrica (NLG) e a não-linearidade de contato (NLC).

$\mathrm{Em}$ projetos de edifícios de concreto armado moldados no local, consideram-se somente as não-linearidades física e geométrica, já que a nãolinearidade de contato não é comum, pois se trata de alterações nas condições de contorno (apoio, engaste) durante o processo de deformação da estrutura, ou seja, vínculos inicialmente inexistentes podem passar a existir, ou então, vínculos inicialmente existentes podem desaparecer. Por outro lado, forças inicialmente prescritas, externamente aplicadas ao contorno, podem ter sua ação alterada em função do processo de deformação da estrutura (PROENÇA, 2010). As não-linearidades física e geométrica serão tratadas nos próximos itens.

\subsection{NÃO-LI NEARI DADE FÍ SI CA}

Quando se refere à não-linearidade física, está sendo considerada a que é causada pelo comportamento do material, que neste caso é o concreto armado. Os efeitos da fissuração, da fluência, do escoamento da armadura, todos eles conferem ao concreto armado um comportamento não-linear (PINTO, 1997). 
Na figura 2.1-(a) pode-se ver o diagrama que relaciona a tensão e a deformação de maneira linear (uma reta), e na figura 2.1-(b), o diagrama relativo a um comportamento não-linear (uma curva).

Agora, em termos práticos, qual a diferença entre ser ou não ser considerada a não-linearidade física? A principal diferença está relacionada ao módulo de elasticidade do concreto. Pode-se observar isso na figura 2.1-(a), na qual, para qualquer intensidade de tensão, por exemplo, $\sigma_{1}, \sigma_{2}$ e $\sigma_{3}$, a resposta do concreto é a mesma, ou seja, o módulo de elasticidade $E_{c}$ é constante.

Na figura 2.1-(b), para as tensões $\sigma_{1}, \sigma_{2}$ e $\sigma_{3}$, a resposta do concreto não é a mesma, pois para estas tensões encontra-se $E_{c_{1}}, E_{c_{2}}$ e $E_{c_{3}}$ respectivamente. Portanto, percebe-se que o módulo de elasticidade não é constante (único). Observa-se que, na figura 2.1, apenas se está destacando o módulo de elasticidade, e não o ângulo formado entre o gráfico e a abscissa, pois o ângulo seria $\operatorname{Arctg} E_{c}$.

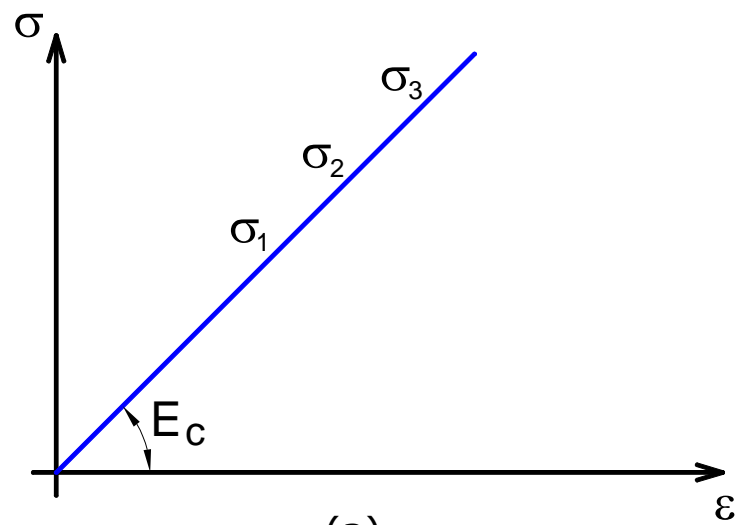

(a)

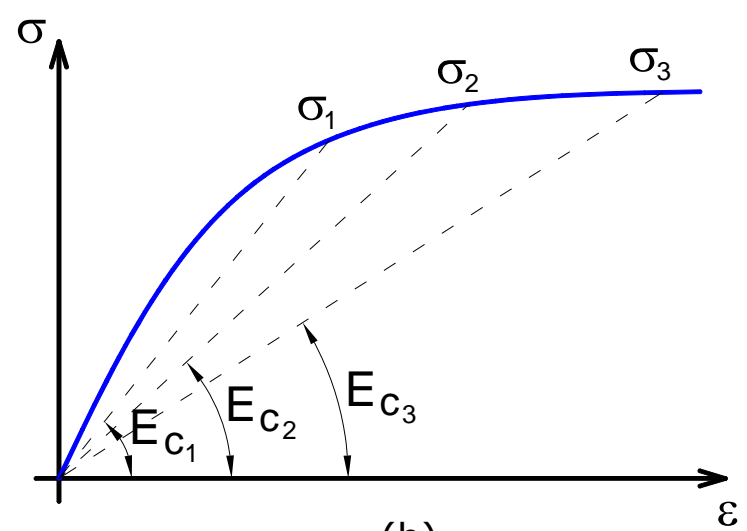

(b)

Figura 2.1. Diagrama tensão-deformação do concreto: (a) linear; (b) não-linear.

No dia-a-dia, usualmente o projetista analisa sua estrutura baseando-se em momentos fletores, e não em tensões. Por isso é possível utilizar um diagrama chamado momento-curvatura $(M-1 / r)$, indicado na figura 2.2 , que pode ser utilizado na análise não-linear de pavimentos, no cálculo de flechas, e o diagrama normal-momento-curvatura ( $N-M-1 / r)$, mostrado na figura 2.3, que é empregado no cálculo de elementos submetidos a esforço normal, por exemplo, para o cálculo de vigas submetidas à flexão composta e, principalmente, para o cálculo de pilares. 


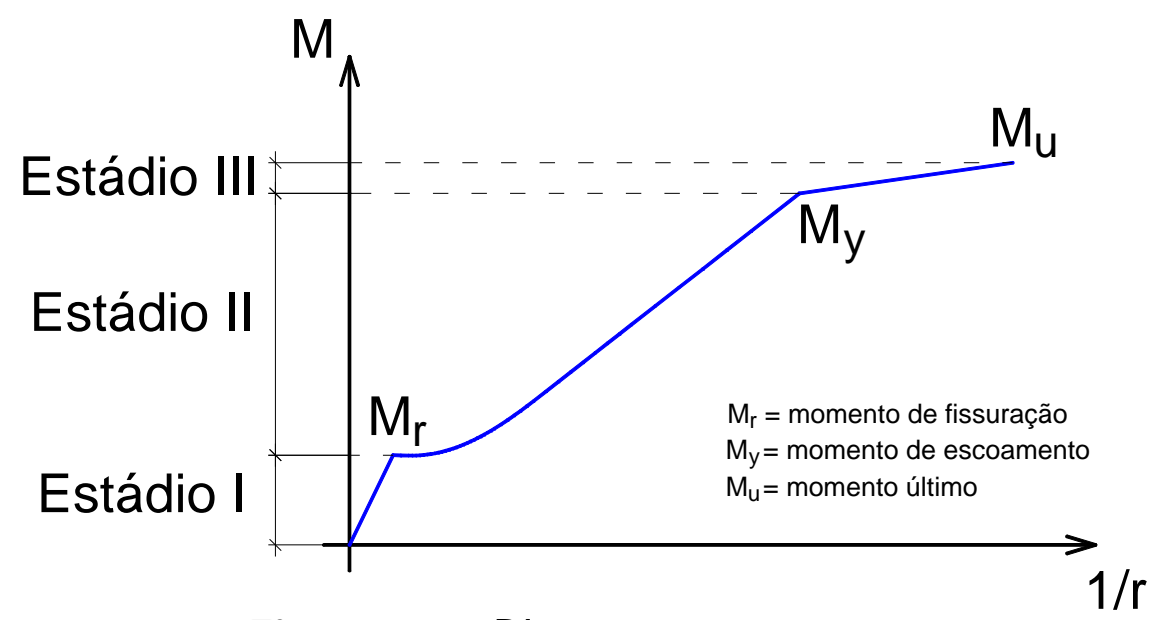

Figura 2.2. Diagrama momento-curvatura.

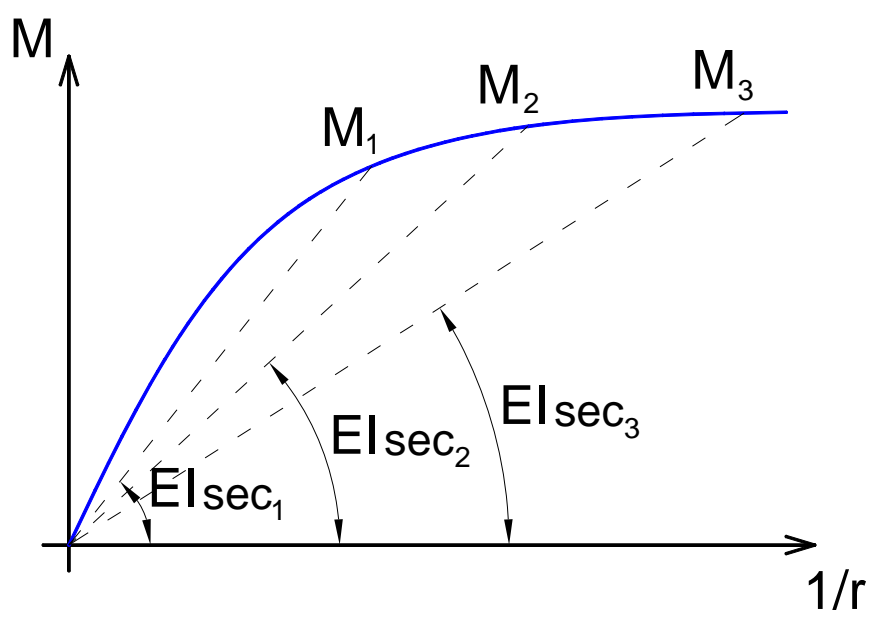

Figura 2.3. Diagrama normal-momento-curvatura.

Observa-se que o diagrama da figura 2.3 é gerado para uma dada força normal e para um determinado valor da taxa de armadura, e que o efeito da fluência não está sendo considerado.

Tem-se uma grande vantagem em utilizar a relação momento-curvatura, pois analogamente ao diagrama tensão-deformação, em que se pode obter o módulo de elasticidade, no diagrama momento-curvatura pode-se obter diretamente a rigidez $E I$, que é de extrema importância para a análise estrutural. Mais detalhes podem ser encontrados em Kimura (2007).

A NBR 6118:2003, no item 15.3.1, faz comentários a respeito das relações momento-curvatura. Sem a ajuda de um computador, a consideração desses diagramas em projetos de edifícios torna-se inviável, pois a construção dos diagramas é extremamente trabalhosa. Devido a essa dificuldade a Norma permite que se faça uma análise linear, porém com os devidos ajustes. 
E que ajustes seriam esses? Para o caso de uma análise em serviço, cálculo de flechas, por exemplo, que sejam consideradas a fissuração e a fluência, pois tais considerações são obrigatórias segundo o item 14.6.4.1 da NBR 6118:2003.

Para o caso da análise global de uma edificação, pode-se considerar um valor constante (único) para a rigidez EI, porém utilizando-se um coeficiente redutor. Tal coeficiente tem a função de simular a variação da rigidez e estimar de forma aproximada os efeitos da não-linearidade física.

Há coeficientes redutores diferenciados para lajes, vigas e pilares. Tais coeficientes estão no item 15.7.3 da NBR 6118:2003, e valem somente para estruturas reticuladas com no mínimo quatro andares. São eles:

$>$ Para lajes: $(E I)_{s e c}=0,3 \cdot E_{c i} I_{c}$

Para vigas: $(E I)_{s e c}=0,4 \cdot E_{c i} I_{c}$ para $A_{S}{ }_{S} \neq A_{s} \mathrm{e}$

$$
(E I)_{s e c}=0,5 \cdot E_{c i} I_{c} \text { para } A_{s}^{\prime}=A_{s}
$$

Para pilares: $(E I)_{s e c}=0,8 \cdot E_{c i} I_{c}$

$I_{c}$ é o momento de inércia da seção bruta de concreto, incluindo, quando for o caso, as mesas colaborantes (seção T).

$A^{\prime}{ }_{S}$ é a armadura de compressão, no caso de vigas com armadura dupla.

$A_{s}$ é a armadura de tração.

Em projetos de edifícios usuais, é muito difícil ter vigas armadas com $A^{\prime}{ }_{s}=A_{s}$. Portanto, na maioria dos casos utiliza-se $(E I)_{s e c}=0,4 \cdot E_{c i} I_{c}$. Cabe destacar que essa consideração vale para vigas com armadura dupla ou simples.

Há também mais uma consideração para a redução de rigidez, quando forem respeitadas duas condições: a estrutura de contraventamento (estrutura responsável pela estabilidade do edifício) for composta exclusivamente por vigas e pilares, ou seja, sem a consideração de núcleos de elevadores, que em geral são pilares-parede de grandes dimensões, em formato de $U$, e $\gamma_{z}$ (será estudado mais adiante) for menor que 1,3 . Nessas situações, permite-se calcular a rigidez das vigas e pilares por:

$$
>(E I)_{s e c}=0,7 \cdot E_{c i} I_{c}
$$


As lajes continuariam com $(E I)_{s e c}=0,3 \cdot E_{c i} I_{c}$, e não se pode esquecer que esses valores de rigidez reduzida são aproximados, pois, por exemplo, na realidade não se tem $0,7 \cdot E_{c i} I_{c}$ ou $0,8 \cdot E_{c i} I_{c}$ para cada lance de pilar, ao longo da altura do edifício. Os lances possuem diferentes valores de rigidez, mas se adotam tais valores como uma média que representa bem a rigidez dos pilares do edifício como um todo. Portanto, por esse motivo, são utilizados somente para análise global, e não podem ser usados para uma análise local.

Para esses casos de análise local, considera-se a não-linearidade física de maneira diferenciada, por exemplo, através de um dos seguintes métodos: curvatura aproximada, kapa aproximado, kapa acoplado a diagrama $\mathrm{N}-\mathrm{M}-1 / \mathrm{r}$ e método geral. Esses métodos que são descritos na NBR 6118:2003, nos itens 15.8.3.3.2, 15.8.3.3.3, 15.8.3.3.4 e 15.8.3.2 respectivamente.

E como foi dito anteriormente, as reduções para a análise global valem somente para estruturas reticuladas de no mínimo quatro pavimentos, podendo surgir uma pergunta: por que essa limitação?

A resposta é a falta de estudos para estruturas reticuladas com menos de quatro andares, ou seja, não se sabe ainda quais valores de coeficientes redutores podem ser utilizados para as rigidezes de pilares em edifícios com três pavimentos ou menos, mas se sabe que há grandes possibilidades de serem menores, por exemplo $(E I)_{s e c}=0,6 \cdot E_{c i} I_{c}$ ou $(E I)_{s e c}=0,5 \cdot E_{c i} I_{c}$. Portanto, são necessárias pesquisas específicas para sejam analisados coeficientes redutores para edifícios com menos de quatro andares.

\subsection{NÃO-LI NEARI DADE GEOMÉTRICA}

Quando se menciona a não-linearidade geométrica, está sendo considerada aquela causada pela mudança da geometria da estrutura, ou seja, mudança da posição da estrutura no espaço (PINTO, 1997). Pergunta-se: quando a estrutura muda de posição no espaço? Ela muda de posição quando se deforma, como pode ser visto na figura 2.4, em que uma barra vertical engastada na base e livre no topo, ao estar submetida a uma ação horizontal no topo, muda de configuração, indo para a posição da linha cheia. 


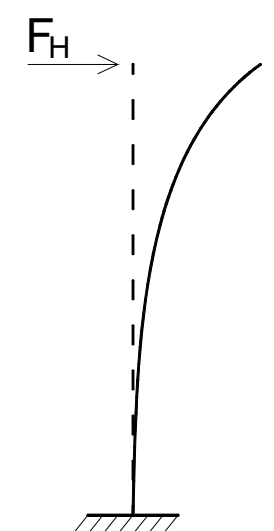

Figura 2.4. Barra vertical com mudança de posição no espaço.

Os efeitos da não-linearidade geométrica são determinados quando se analisa o equilíbrio na posição deformada, ou seja, quando se realiza a análise com a barra na posição da linha cheia (Figura 2.4).

Para que os conceitos da não-linearidade geométrica fiquem mais claros, analisa-se a barra vertical, mostrada na figura 2.5 , submetida às forças vertical e horizontal.

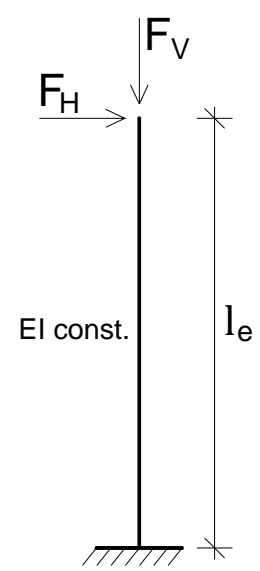

Figura 2.5. Barra vertical submetida a ações vertical e horizontal.

Para que tal estrutura esteja em equilíbrio na posição indeformada, ou seja, na posição inicial, aparecem reações na base da barra, como mostrado na figura 2.6, sendo uma delas o momento fletor de primeira ordem $M_{1}$, que recebe este nome (de primeira ordem) pelo fato de ter sido obtido na análise do equilíbrio da barra na posição indeformada (inicial). 


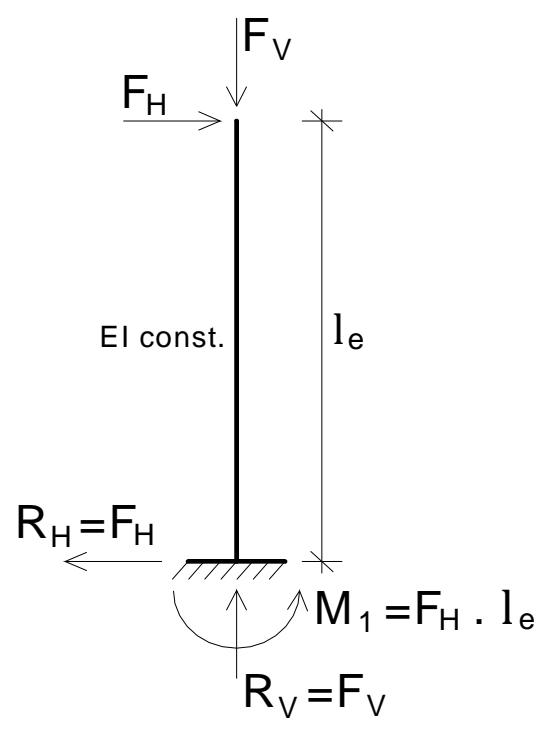

Figura 2.6. Reações na barra vertical indeformada.

Agora, se o equilíbrio for considerado na posição deformada, ou seja, na posição deslocada de um valor $u$ devido à ação horizontal, será gerado um acréscimo de momento na base igual a $\Delta M=F_{V} \cdot u$, fazendo com que o valor do momento de primeira ordem $M_{1}$ aumente, resultando o momento de $1^{\text {a }}$ ordem mais $2^{\mathrm{a}}$ ordem, chamado $M_{2}$, que pode ser visto na figura 2.7.

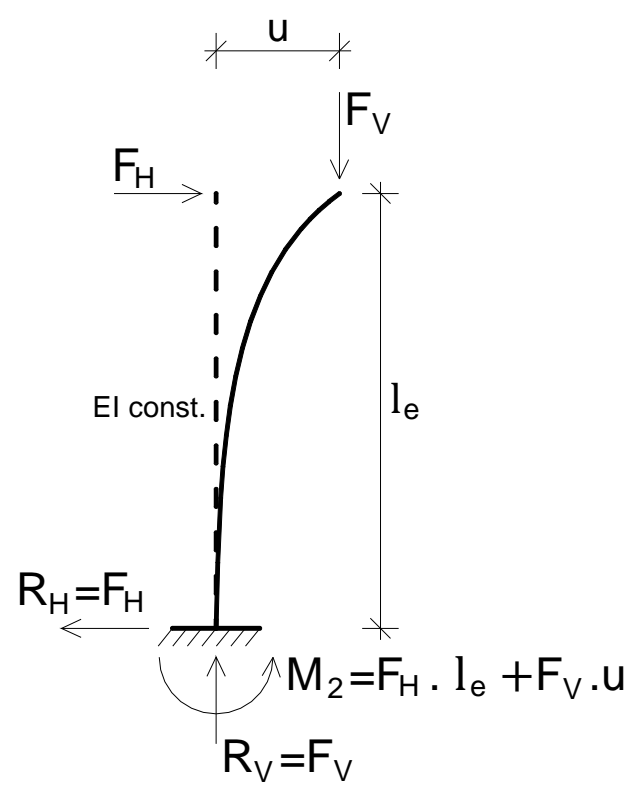

Figura 2.7. Reações na barra vertical deformada. 
O acréscimo de momento é um efeito de segunda ordem, pois foi um esforço que surgiu com a análise do equilíbrio da estrutura na sua posição deformada. Portanto, somente se esse esforço for levado em conta na análise é que a não-linearidade geométrica da estrutura estará sendo considerada.

\subsection{PARÂMETROS DE ESTABI LI DADE E EFEI TOS DE SEGUNDA ORDEM}

A avaliação da estabilidade global de edifícios pode ser realizada mediante o cálculo dos chamados parâmetros de estabilidade. Alguns deles, além de avaliar a estabilidade, podem estimar os efeitos de segunda ordem.

Segundo a NBR 6118:2003, no item 15.2, os efeitos de segunda ordem podem ser desprezados sempre que não representarem acréscimo superior a $10 \%$ nas reações e nas solicitações relevantes da estrutura, ou seja, tais efeitos podem ser desprezados se não representarem acréscimo superior a $10 \%$ em relação aos efeitos de primeira ordem (efeitos que surgem quando o equilíbrio da estrutura é estudado na configuração geométrica inicial).

Para efeito de cálculo, as estruturas são consideradas de nós fixos ou de nós móveis. São consideradas de nós fixos quando os efeitos globais de segunda ordem são desprezíveis (inferiores a $10 \%$ dos respectivos esforços de primeira ordem). São considerados de nós móveis quando os efeitos de segunda ordem são importantes (superiores a $10 \%$ dos respectivos esforços de primeira ordem) e devem ser considerados. Duas observações devem ser feitas: as estruturas de nós fixos na realidade não são fixas, ou seja, são deslocáveis, mas possuem deslocamentos horizontais muito pequenos, que podem ser desprezados; e as estruturas de nós móveis não são estruturas que se movimentam de forma significativa, mas diferentemente das de nós fixos, seus deslocamentos precisam ser considerados no cálculo dos esforços.

\subsubsection{PARÂMETRO DE INSTABI LI DADE $(\alpha)$}

O parâmetro $\alpha$ é um meio para avaliar a estabilidade global de estruturas de concreto, porém não é capaz de estimar os efeitos de segunda ordem. Ele foi deduzido em 1967 por Beck e König, baseado na teoria de Euler, e foi definido como parâmetro de instabilidade por Franco (1985). 
A estrutura é considerada um meio elástico, e portanto não se leva em conta a fissuração dos elementos.

Segundo a NBR 6118:2003, item 15.5.2, seu valor é calculado pela fórmula:

$$
\alpha=H_{t o t} \cdot \sqrt{\frac{N_{k}}{\left(E_{c s} \cdot I_{c}\right)}}
$$

$H_{\text {tot }}$ é a altura da estrutura, medida a partir do topo da fundação ou de um nível pouco deslocável do subsolo;

$N_{k}$ é o somatório de todas as cargas verticais atuantes na estrutura (a partir do nível considerado para o cálculo de $\left.H_{t o t}\right)$, com seu valor característico;

$E_{c S} I_{c}$ é o somatório dos valores de rigidez de todos os pilares na direção considerada; no caso de estruturas de pórticos, de treliças ou mistas, ou com pilares de rigidez variável ao longo da altura, pode ser considerado o valor da expressão $E_{c s} I_{c}$ de um pilar equivalente de seção constante.

O valor de $\alpha$ é comparado a um valor $\alpha_{1}$, de modo que, se $\alpha<\alpha_{1}$, a estrutura é considerada de nós fixos, e se $\alpha \geq \alpha_{1}$, de nós móveis.

Sendo $n$ o número de níveis de barras horizontais (andares) acima da fundação ou de um nível pouco deslocável do subsolo, o valor de $\alpha_{1}$ é dado por:

$$
\begin{array}{ll}
\alpha_{1}=0,2+0,1 \cdot n & \text { se: } n \leq 3 \\
\alpha_{1}=0,6 & \text { se: } n \geq 4
\end{array}
$$

Esse valor limite $\alpha_{1}=0,6$ prescrito para $n \geq 4$ é, em geral, aplicável às estruturas usuais de edifícios. Pode ser adotado para associações de pilaresparede e para pórticos associados a pilares-parede. Pode ser aumentado para $\alpha_{1}=0,7$ no caso de contraventamento constituído exclusivamente por pilaresparede, e deve ser reduzido para $\alpha_{1}=0,5$ quando só houver pórticos.

No estudo do parâmetro $\alpha$, embora não seja considerada a fissuração dos elementos, a não-linearidade física do concreto é levada em conta na dedução do limite $\alpha_{1}$, pois o comportamento não-linear não surge apenas devido à fissuração, pois o concreto submetido à compressão já possui um comportamento puramente não-linear. 
Em Franco (1985) observa-se que, na dedução de $\alpha_{1}$, foi levada em conta uma carga vertical de cálculo $N_{d}=1,4 \cdot N_{k}$ e a rigidez reduzida igual a $0,7 \cdot E_{c s} I_{c}$. Isto explica porque no cálculo do parâmetro $\alpha$ utilizam-se esforços característicos e rigidez integral da seção. O cálculo do coeficiente $\gamma_{\mathrm{z}}$, que será estudado a seguir, é realizado de maneira diferente, pois se utilizam esforços de cálculo e rigidez reduzida para contemplar de forma aproximada a não-linearidade física. Tais reduções são feitas de acordo com o item 2.2 deste trabalho.

O valor de $I_{c}$ deve ser calculado considerando as seções brutas dos pilares, e o valor do módulo de elasticidade $E_{c s}=0,85 \cdot E_{c i}$ pode ser substituído pelo valor de $E_{c i}=5600 \cdot \sqrt{f_{c k}}$, com $f_{c k}$ em MPa.

O parâmetro $\alpha$ não se aplica a estruturas significativamente assimétricas, ou que apresentem deslocamentos horizontais apreciáveis sob ação das cargas verticais. Tais deslocamentos serão vistos com mais detalhes no item 2.4.3 deste trabalho.

Na prática ele é bem menos utilizado que o coeficiente $\gamma_{\mathrm{z}}$, pois com este coeficiente, além de se avaliar a estabilidade global, pode-se estimar os esforços de segunda ordem e assim obter os esforços globais finais, o que não é possível com o parâmetro $\alpha$, como foi dito anteriormente.

\subsubsection{COEFICI ENTE $\gamma_{z}$}

O coeficiente $\gamma_{z}$ é um parâmetro que avalia, de forma simples e bastante eficiente, a estabilidade global de um edifício com estrutura de concreto armado. Também é capaz de estimar os esforços de segunda ordem por uma simples majoração dos esforços de primeira ordem. Esse coeficiente foi criado por Franco e Vasconcelos (1991).

Valores coerentes de $\gamma_{z}$ são números um pouco maiores do que 1,0 . Franco e Vasconcelos (1991) estabeleceram um limite de 1,20 para o valor de $\gamma_{z}$. Porém, Carmo (1995), após análises em seu trabalho, concluiu que é possível avançar além do valor 1,20 , podendo chegar até $\gamma_{z}$ igual a 1,30 .

Pinto (1997) concluiu que valores superiores a 1,20 devem ser evitados, e chegou a essa conclusão comparando os valores de $\gamma_{z}$ aos resultados obtidos com um método que considera a NLG de maneira mais refinada, através de alterações incrementais na matriz de rigidez. 
Em relação aos esforços obtidos com o $\gamma_{z}$, percebeu que para valores entre 1,15 e 1,20 começam a aparecer diferenças de 3\% contra a segurança, acima de 1,20 as diferenças tendem a aumentar para mais de $5 \%$, e para $\gamma_{z}$ superior a 1,30 aparecem diferenças da ordem de 7\% contra a segurança. Lima (2001) também concluiu que o limite 1,20 está mais compatível que 1,30. Pinto, Corrêa e Ramalho (2005) chegaram a uma nova conclusão, em que o limite de 1,20 pode ser um pouco conservador, podendo se estender o limite do coeficiente $\gamma_{z}$ para 1,25, devendo ser evitados valores acima disso.

De acordo com a NBR 6118:2003, o limite do coeficiente $\gamma_{z}$ é 1,30, e como já se pode perceber, valores acima disso revelam que a estrutura possui um grau de instabilidade elevado, ou seja, é uma estrutura instável e impraticável. Valores inferiores a 1,0 , ou mesmo negativos, são incoerentes e indicam que a estrutura é totalmente instável.

Na prática as estruturas costumam ser projetadas com um limite de 1,20. Acima desse valor é comum utilizar-se o processo P- $\Delta$, que consiste em uma análise não-linear geométrica e que será estudada em detalhes no capítulo 3 . Cabe destacar que o coeficiente $\gamma_{z}$ consiste em uma análise linear, que considera de forma aproximada os efeitos da não-linearidade geométrica.

Pode-se relacionar a parte decimal do valor obtido de $\gamma_{z}$ com a magnitude dos efeitos globais de segunda ordem na estrutura, por exemplo:

$>1,05$ - Efeitos de segunda ordem em torno de 5\% dos de primeira;

$>1,10$ - Efeitos de segunda ordem em torno de $10 \%$ dos de primeira;

$>1,15$ - Efeitos de segunda ordem em torno de $15 \%$ dos de primeira.

Segundo a NBR 6118:2003, item 15.5.3, o valor de $\gamma_{z}$ para cada combinação de carregamento é dado pela expressão:

$$
\begin{aligned}
& \gamma_{z}=\frac{1}{1-\frac{\Delta M_{t o t, d}}{M_{1, t o t, d}}} \\
& \Delta \mathrm{M}_{\text {tot,d }} \quad \text { é a soma dos produtos de todas as forças verticais atuantes na } \\
& \text { estrutura, na combinação considerada, com seus valores de } \\
& \text { cálculo, pelos deslocamentos horizontais de seus respectivos } \\
& \text { pontos de aplicação, obtidos da análise de primeira ordem; }
\end{aligned}
$$


$\mathrm{M}_{1, \text { tot,d }}$ é o momento de tombamento, ou seja, a soma dos momentos de todas as forças horizontais da combinação considerada, com seus valores de cálculo, em relação à base da estrutura.

Considera-se que a estrutura é de nós fixos se for obedecida a condição $\gamma_{z} \leq 1,1$, e de nós móveis se $1,1<\gamma_{z} \leq 1,3$.

Segundo o item 15.7.2 da NBR 6118:2003, com o valor de $\gamma_{z}$ é possível estimar os esforços finais $\left(1^{a}+2^{a}\right.$ ordem) por uma simples multiplicação dos esforços horizontais de primeira ordem, da combinação de carregamento considerada, por $0,95 \cdot \gamma_{z}$, sendo válido esse processo somente para $\gamma_{z} \leq 1,3$.

Carmo (1995) concluiu que majorar os esforços horizontais de primeira ordem somente por $\gamma_{z}$ é satisfatório, como já havia sido mostrado por Franco e Vasconcelos (1991). Pinto (1997) também concluiu que a majoração somente por $\gamma_{z}$ gera resultados satisfatórios até o limite de 1,20. Lima (2001) concluiu que a majoração por $0,95 \cdot \gamma_{z}$ não conduz a bons resultados, principalmente nos pavimentos inferiores, pois a variação dos efeitos de segunda ordem é bastante significativa ao longo da altura da edificação. A majoração com $\gamma_{z}$, por outro lado, mostrou-se bastante satisfatória e mais eficiente que a feita $\operatorname{com} 0,95 \cdot \gamma_{z}$, e sugeriu a adoção de $\gamma_{z}$ como majorador dos esforços. Pinto, Corrêa e Ramalho (2005) obtiveram apenas um novo limite para $\gamma_{z}$, igual a 1,25, como já foi comentado, porém a majoração apenas por $\gamma_{z}$ ainda foi satisfatória.

Para edifícios de alvenaria estrutural, Campoó, Corrêa e Ramalho (2005) concluíram que a majoração por $\gamma_{z}$ mostrou-se bastante satisfatória, em comparação com os resultados do processo P-Delta. Marin (2009), estudando estruturas de concreto pré-moldado de múltiplos pavimentos, também concluiu que a majoração por $\gamma_{z}$ gera melhores resultados que os obtidos com $0,95 \cdot \gamma_{z}$.

O coeficiente $\gamma_{z}$ é válido para estruturas reticuladas de no mínimo quatro andares. Tal limitação se deve aos mesmos motivos citados no item 2.2 deste trabalho, em que se comenta que, abaixo de quatro andares, ainda não se sabe qual o coeficiente redutor da rigidez de pilares que deve ser utilizado para a consideração da não-linearidade física de forma aproximada.

Outro motivo é que o cálculo do $\gamma_{z}$ pressupõe estruturas com pavimentos tipos idênticos e regularidade dos elementos estruturais de um piso ao outro, regularidade essa que é menos comum em edifícios com até quatro pavimentos. 
Portanto, para edificações com menos de quatro pavimentos, sugere-se a utilização do parâmetro $\alpha$ para verificação da estabilidade do edifício, e o processo P- $\Delta$ para a avaliação do efeito global de segunda ordem.

\subsubsection{Consideração do coeficiente $\gamma_{f 3}$}

Uma consideração da NBR 6118:2003, no item 15.3.1, pode ser levada em conta no cálculo do $\gamma_{z}$.

A Norma indica que pode ser considerada também a formulação de segurança em que se calculam os efeitos de segunda ordem das cargas majoradas por $\gamma_{f} / \gamma_{f 3}$, que posteriormente são majoradas por $\gamma_{f 3}$, $\operatorname{com} \gamma_{f 3}=1,1$.

Segundo o item 11.7 da NBR 6118:2003, as ações devem ser multiplicadas por $\gamma_{f}$, ponderador que é obtido pela multiplicação de três parcelas $\gamma_{f}=\gamma_{f 1} \cdot \gamma_{f 2} \cdot \gamma_{f 3}$, sendo que $\gamma_{f 1}$ leva em conta a variabilidade das ações, $\gamma_{f 2}$, a simultaneidade das ações e $\gamma_{f 3}$, as aproximações feitas em projeto (KIMURA, 2007).

Com a consideração do item 15.3.1 da NBR 6118:2003, omite-se a parcela $\gamma_{f 3}$ do coeficiente de segurança, pois ao se majorar com $\frac{\gamma_{f}}{\gamma_{f 3}}=\frac{\gamma_{f 1} \cdot \gamma_{f 2} \cdot \gamma_{f 3}}{\gamma_{f 3}}$ o resultado é o mesmo que se obtém com $\gamma_{f 1} \cdot \gamma_{f 2}$, e para obter o resultado final majora-se com $\gamma_{f 3}$. Aí se pergunta: não seria obtido o mesmo resultado se fosse empregado diretamente o majorador $\gamma_{f}$ ? A resposta é não, porque a análise de segunda ordem não possui uma resposta linear, e sim uma resposta não-linear. Portanto, ao se majorar com $\gamma_{f 3}$ no final, obtém-se um resultado um pouco menor, nos casos usuais. Deve-se lembrar que a NBR 6118:2003 é bem clara e diz "que pode ser considerada", e não "que deve ser considerada". Portanto, essa consideração é opcional.

No Sistema Computacional TQS os esforços são multiplicados por $\frac{\gamma_{f}}{\gamma_{f 3}}$. Caso se queira considerar esse item da Norma, basta adotar o valor de $\gamma_{f 3}=1,1$; no caso contrário, basta admitir o valor de $\gamma_{f 3}=1,0$, pois $\frac{\gamma_{f}}{\gamma_{f 3}}=\frac{\gamma_{f}}{1,0}=\gamma_{f}$. No apêndice deste trabalho será mostrado onde o valor de $\gamma_{f 3}$ pode ser alterado, dentro do Sistema Computacional. 
Para que fique mais clara a consideração desse item da Norma, será reproduzido um exemplo que costuma ser mostrado no curso de cálculo de pilares ministrado pelo eng. Alio E. Kimura.

Suponha-se uma estrutura com resposta $S(F)$ não-linear representada pela curva em azul na figura 2.8. Pode-se observar que para os valores de $F$ iguais a 5,10 e 15 resultam valores de $S$ iguais a 20, 45 e 100 respectivamente. Se a resposta fosse linear, como representado pela linha tracejada, os valores de $S$ seriam outros.

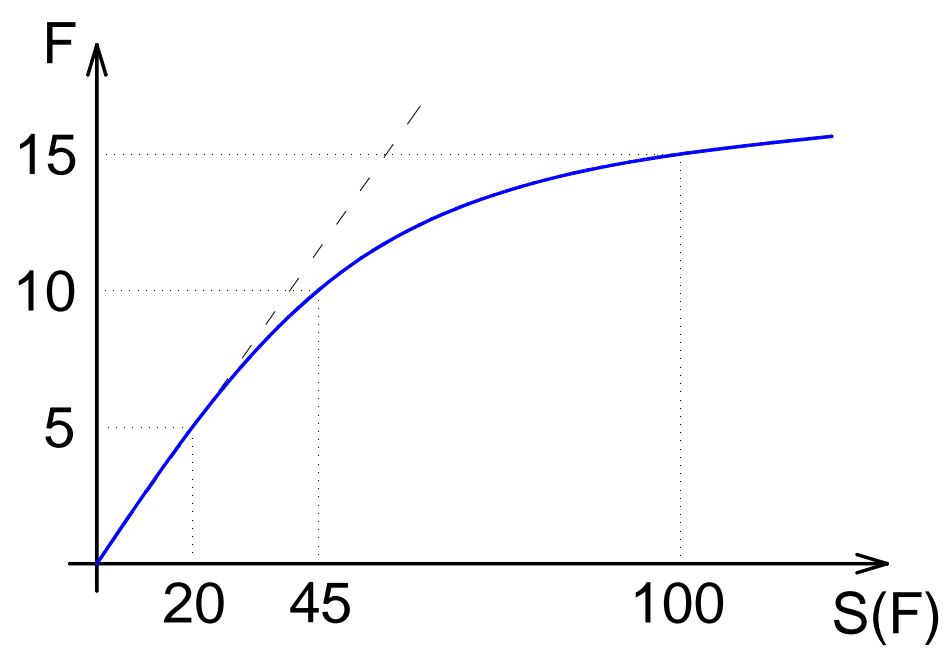

Figura 2.8. Resposta da estrutura representada de maneira não-linear.

Se o valor da ação característica a ser aplicada for $F_{k}=10$, obtém-se $S_{k}=45$. Majorando-se o valor de $F_{k} \operatorname{com} \gamma_{f}=1,4$, tem-se $F_{d}=1,4 \cdot 10=14$, o que representa uma resposta $S_{d}=85$, como pode ser visto na figura 2.9.

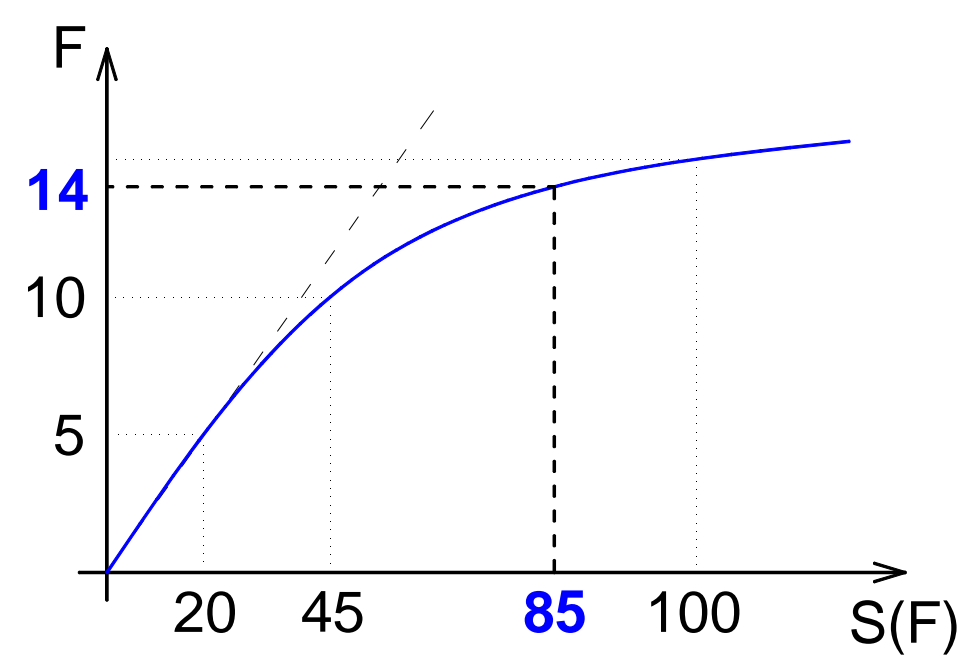

Figura 2.9. Resposta da estrutura para uma ação $F_{d}=14$. 
Utilizando-se a formulação de segurança da NBR 6118:2003 e majorandose $F_{k}=10 \operatorname{com} \frac{\gamma_{f}}{\gamma_{f 3}}=\frac{1,4}{1,1}=1,27$, obtém-se $F_{d}=1,27 \cdot 10=12,7$, o que corresponde a uma resposta $S_{d}=72$, como pode ser visto na figura 2.10. Porém, lembrando que se deve no final da análise multiplicar por $\gamma_{f 3}=1,1$, resulta $S_{d \text {,final }}=72 \cdot 1,1=79,2$, menor que o valor $S_{d}=85$ obtido na análise anterior. Portanto, observa-se que com a formulação de segurança obtém-se uma resposta menor.

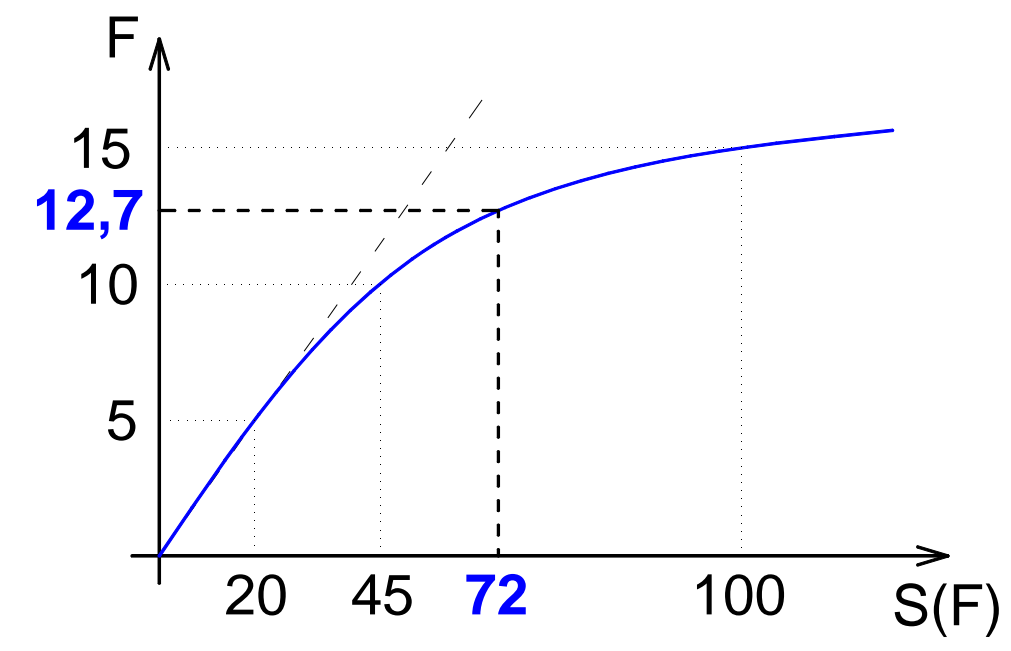

Figura 2.10. Resposta da estrutura para uma ação $F_{d} \cong 12,7$.

\subsubsection{Demonstração da fórmula do coeficiente $\gamma_{z}$}

A formulação do $\gamma_{z}$ pode ser concebida de maneira simples e prática e será demonstrada a seguir, de modo bem didático. Partindo de uma análise linear, com a aplicação das ações horizontais, são calculados os momentos de primeira ordem $M_{1}$ em relação à base do edifício e os deslocamentos horizontais da estrutura, análogo ao que se mostrou no item 2.3, ao considerar os efeitos da não-linearidade geométrica. Esses deslocamentos fazem com que a força vertical atuante gere acréscimos de momento fletor na base, resultando um momento $M_{2}$, isso na segunda iteração de uma sucessão de várias. Cada iteração gera acréscimos de momento que vão diminuindo até se tornarem praticamente nulos, obtendo-se um momento final $M$, se a estrutura for estável.

$\mathrm{Na}$ figura 2.11, pode-se observar um gráfico que relaciona o momento gerado na estrutura e o número de iterações. Verifica-se no gráfico que o fim da curva tende a ser uma reta, ou seja, tende a convergir a um único valor, igual ao momento final $M$. 
Esse momento final $M$ é a soma dos momentos de primeira e de segunda ordem, ou seja, é a soma do momento $M_{1}$ com os acréscimos de momentos a cada iteração:

$$
M=M_{1}+\Delta M_{1}+\Delta M_{2}+\Delta M_{3}+\cdots+\Delta M_{i}
$$

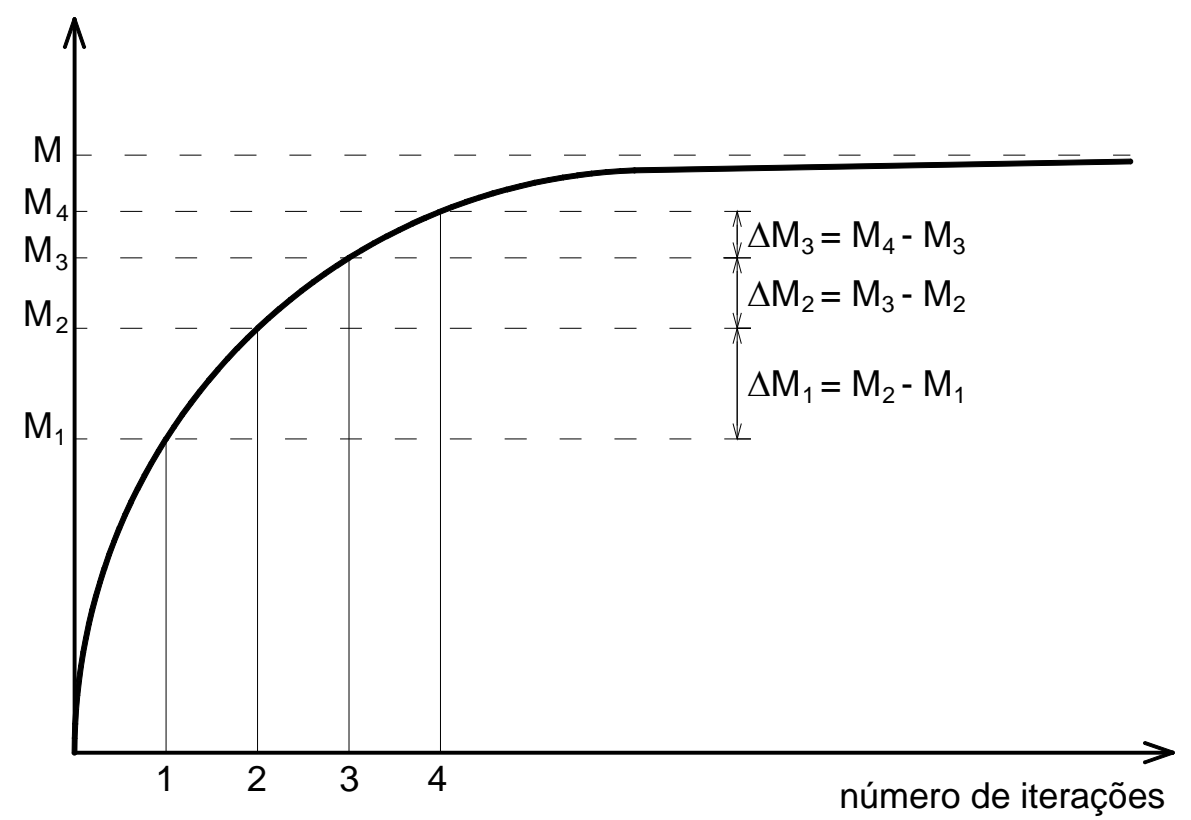

Figura 2.11. Determinação de momento final $M$ (adaptada: CEB-1978).

Segundo o CEB-1978, as parcelas do momento final estão em uma progressão geométrica decrescente de razão menor que 1 , e a razão pode ser obtida dividindo-se um termo pelo seu anterior, ou seja:

$$
r=\frac{\Delta M_{1}}{M_{1}}=\frac{\Delta M_{2}}{\Delta M_{1}}=\frac{\Delta M_{3}}{\Delta M_{2}}=\cdots=\frac{\Delta M_{i}}{\Delta M_{i-1}}<1
$$

Da expressão anterior obtêm-se:

$$
\begin{aligned}
& \Delta M_{1}=M_{1} \cdot r \\
& \Delta M_{2}=\Delta M_{1} \cdot r=\left(M_{1} \cdot r\right) \cdot r=M_{1} \cdot r^{2} \\
& \Delta M_{3}=\Delta M_{2} \cdot r=\left[\Delta M_{1} \cdot r\right] \cdot r=\left[\left(M_{1} \cdot r\right) \cdot r\right] \cdot r=M_{1} \cdot r^{3} \\
& \vdots \\
& \Delta M_{i}=\Delta M_{i-1} \cdot r=M_{1} \cdot r^{i}
\end{aligned}
$$

Substituindo na equação 2.1 , resulta:

$$
\begin{aligned}
& M=M_{1}+\Delta M_{1}+\Delta M_{2}+\Delta M_{3}+\cdots+\Delta M_{i} \\
& M=M_{1}+M_{1} \cdot r+M_{1} \cdot r^{2}+M_{1} \cdot r^{3}+\cdots+M_{1} \cdot r^{i}
\end{aligned}
$$


Colocando-se $M_{1}$ em evidência na equação 2.4, obtém-se:

$M=\left(1+r+r^{2}+r^{3}+\cdots+r^{i}\right) \cdot M_{1}$

Percebe-se que a somatória das parcelas dentro dos parênteses, no segundo membro da equação 2.5 , é uma soma dos termos de uma progressão geométrica infinita de razão $r$, cuja formulação já foi deduzida e pode ser encontrada em qualquer livro de matemática do ensino médio. Tal formulação permite que se diga que a soma dos termos de uma PG infinita de razão $q$, com $-1<q<1$, é dada por:

$S_{\infty}=\frac{a_{1}}{1-q}$

$>a_{1}$ é o primeiro termo da soma;

$>q$ é a razão $(-1<q<1)$.

No estudo das progressões geométricas impõe-se como restrição para a razão o intervalo $(-1<q<1)$, pois o universo de estudo são os números reais $(\mathbb{R})$. Na demonstração do coeficiente $\gamma_{z}$ impõe-se como restrição para a razão apenas $(q<1)$, pois nunca resultará razão negativa, isso porque um momento obtido numa determinada iteração nunca será menor que o obtido na iteração anterior. Caso isto ocorra, algum erro foi cometido na análise.

Portanto, obtém-se o seguinte resultado:

$$
M=\left(\frac{1}{1-r}\right) \cdot M_{1}
$$

Sabe-se que o $\gamma_{z}$ é obtido por meio de uma análise linear e que com ele pode-se considerar de forma aproximada a análise não-linear geométrica.

Tal análise é realizada por sucessivas análises lineares, uma após a outra, ou seja, a cada iteração realiza-se uma análise linear para que no final se possa obter um resultado que represente os efeitos da não-linearidade geométrica.

Portanto, considerando-se apenas a primeira análise linear, o que corresponde à primeira e à segunda iteração, tem-se:

$r=\frac{\Delta M}{M_{1}}$

E em valores de cálculo:

$$
r=\frac{\Delta M_{d}}{M_{1 d}}
$$


Portanto, substituindo-se (2.8) em (2.6) resulta:

$$
M=\left(\frac{1}{1-\frac{\Delta M_{d}}{M_{1 d}}}\right) \cdot M_{1}
$$

A parcela que majora (multiplica) o momento $M_{1}$ foi definida por Franco e Vasconcelos (1991) como o coeficiente $\gamma_{z}$. Portanto:

$$
\gamma_{z}=\frac{1}{1-\frac{\Delta M_{d}}{M_{1 d}}}
$$

Generalizando-se para o caso de edifícios, onde se tem carregamentos verticais com diferentes pontos de aplicação na estrutura, obtém-se a formulação da NBR 6118:2003:

$$
\gamma_{z}=\frac{1}{1-\frac{\Delta M_{t o t, d}}{M_{1, t o t, d}}}
$$

\subsubsection{COEFICIENTE FAVt}

O coeficiente FAVt (Fator de amplificação de esforços horizontais ou de vento) também pode ser considerado um parâmetro que avalia a estabilidade global. Bueno (2009) estudou esse parâmetro, porém chamando-o de $\gamma_{z}^{\prime}$. Comparou seus resultados com os do processo P- $\Delta$ e encontrou valores satisfatórios, mas concluiu que para esse parâmetro ser consolidado como parâmetro de estabilidade são necessários mais estudos. Além dessa função ele pode ser utilizado como estimador dos esforços de segunda ordem, similar ao $\gamma_{z}$.

Esse coeficiente FAVt é exclusivo do Sistema CAD/TQS. É calculado utilizando-se exatamente a mesma formulação do coeficiente $\gamma_{z}$. A diferença é que os deslocamentos horizontais provocados pelas cargas verticais são considerados, ou seja, a única parcela que é calculada de uma maneira diferente em relação ao $\gamma_{z}$ é o $\Delta M_{t o t, d}$ (esforços de segunda ordem).

Ao fim do capítulo será apresentado um exemplo prático que mostrará a diferença entre esses dois coeficientes. 
Portanto a formulação do FAVt é a seguinte:

$$
F A V t=\frac{1}{1-\frac{\Delta M_{t o t, d}}{M_{1, t o t, d}}}
$$

Agora, em que casos podem ocorrer deslocamentos horizontais devidos a cargas verticais?

Tais deslocamentos são provenientes do fato da estrutura não ser simétrica (caso mais geral), por exemplo, um edifício no alto da orla da praia, com todas as sacadas voltadas para o mar, sendo que do outro lado não existe nenhuma sacada.

Essas sacadas constituem balanços que geram um momento em cada piso, o que provoca o deslocamento horizontal devido às cargas verticais.

Podem-se encontrar também tais deslocamentos em edifícios com vigas de transição, com pilares que mudam de seção no meio da edificação sem simetria, planta não simétrica, taxas de armadura diferentes entre pilares, desaprumo etc.

Para ficar mais claro, pode-se observar na figura 2.12 um exemplo de estrutura não simétrica, composta à direita por grandes balanços, sem nenhum balanço à esquerda, o que caracteriza a falta de simetria, como comentado no exemplo anterior, do edifício no alto da orla da praia.

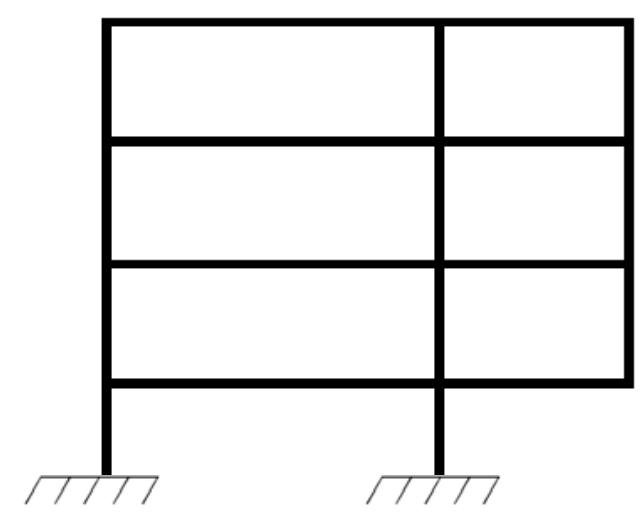

Figura 2.12. Estrutura não simétrica.

Após a aplicação de um carregamento vertical na estrutura da figura 2.12, como mostrado na figura 2.13, obtém-se a configuração deformada indicada na figura 2.14, onde se pode observar claramente o deslocamento horizontal de toda a estrutura, devido ao carregamento vertical aplicado $\left(u_{h, v}\right)$. 


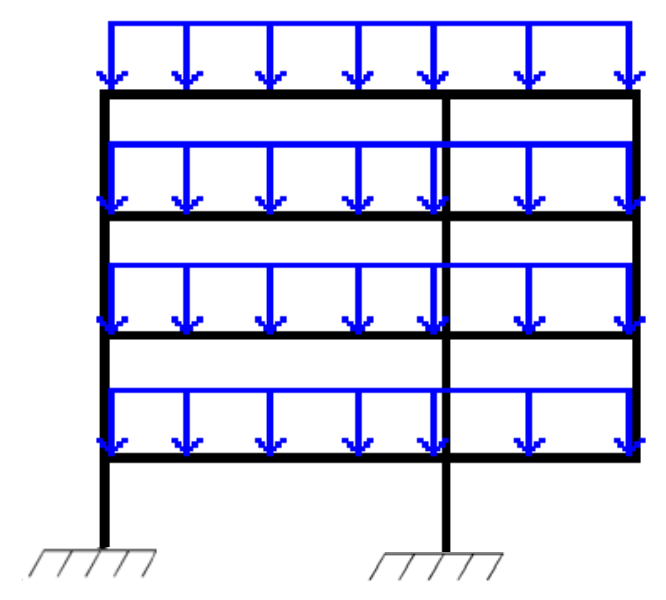

Figura 2.13. Carregamento vertical aplicado na estrutura.

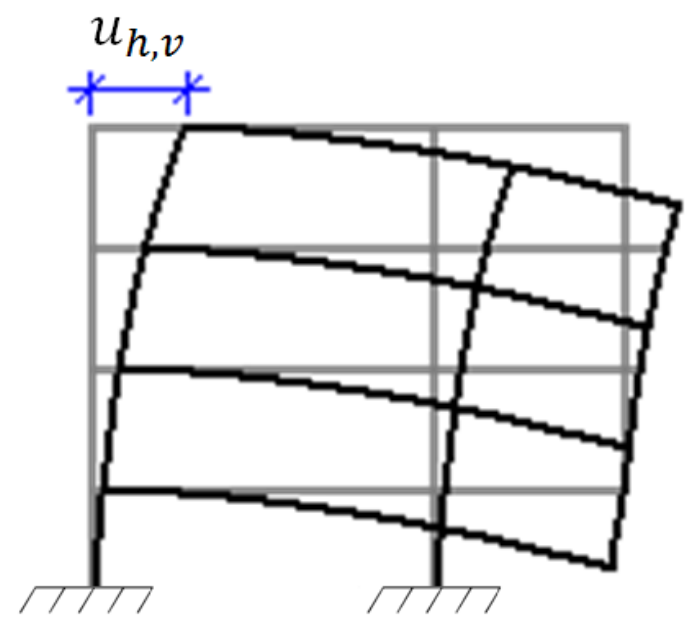

Figura 2.14. Deslocamento horizontal devido à carga vertical.

O cálculo do FAVt é feito principalmente para aplicação do método aproximado para avaliação dos efeitos de globais de segunda ordem $\left(0,95 \cdot \gamma_{\mathrm{z}}\right)$ proposto pela NBR 6118:2003, que pode ser chamado de $(0,95 \cdot F A V t)$ neste caso. Quando os deslocamentos horizontais provocados pelas cargas verticais atuam no sentido do vento, FAVt é maior que $\gamma_{\mathrm{z}}$. Em situações contrárias, isto é, quando os deslocamentos oriundos das cargas verticais atuam em sentido oposto ao do vento (favorecendo a estabilidade), FAVt é menor que $\gamma_{\mathrm{z}}$.

O Sistema CAD/TQS opta pelo coeficiente FAVt como o majorador de esforços de primeira ordem, e quando se recai neste último caso em que os deslocamento devidos às cargas verticais ocorrem no sentido oposto ao do vento, o Sistema adota automaticamente o $\gamma_{\mathrm{z}}$ como majorador de esforços, descartando o FAVt. 
Quando o edifício é perfeitamente simétrico, o $\gamma_{\mathrm{z}}$ e o FAVt são idênticos, porque neste caso o deslocamento horizontal devido ao carregamento vertical não irá existir. Caso contrário, esses valores não são iguais.

Em relação ao deslocamento horizontal estar no sentido do vento, para que isso fique mais claro, pode-se ver na figura 2.15-(a) uma estrutura não simétrica com um carregamento $P$ concentrado na extremidade do balanço. Com a aplicação desse carregamento a estrutura sofre um deslocamento $\left(u_{h, v}\right)$, e o vento ao atuar no mesmo sentido do deslocamento irá aumentá-lo, resultando um deslocamento horizontal final $\left(u_{h, f}\right)$ maior que $\left(u_{h, v}\right)$, como pode ser visto na figura 2.15-(b). Isso explica o valor do FAVt ser maior que o de $\gamma_{\mathrm{z}}$ para este caso.

vento
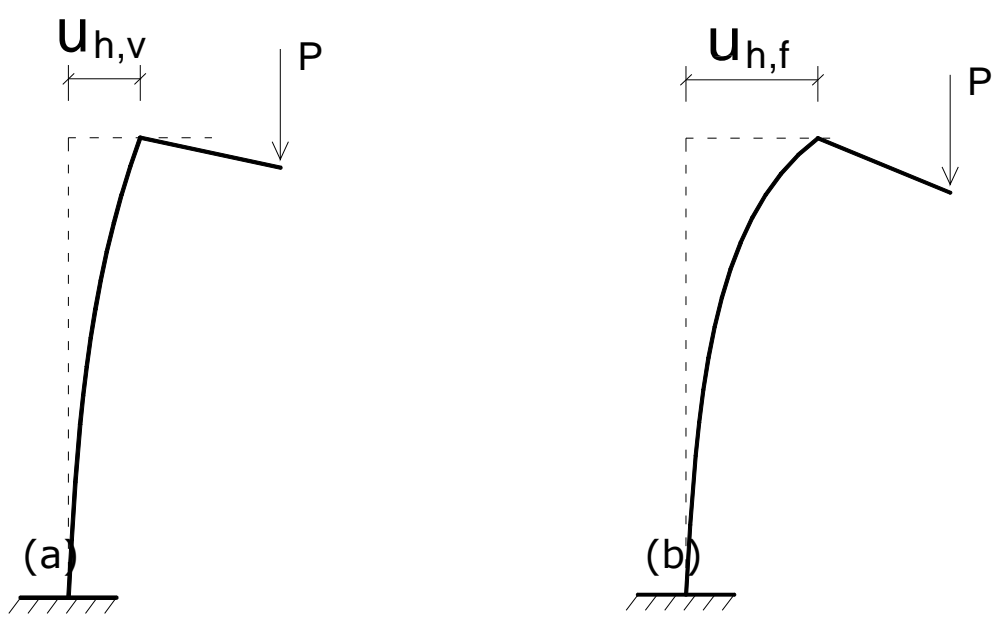

Figura 2.15. Vento no sentido do deslocamento horizontal devido à carga vertical.

Para o caso em que o sentido do vento é oposto ao do deslocamento horizontal, pode-se ver na figura 2.16-(a) a mesma estrutura com a carga concentrada $\mathrm{P}$ aplicada na extremidade do balanço gerando um deslocamento $\left(u_{h, v}\right)$, e o vento, ao atuar no sentido oposto ao do deslocamento da estrutura, irá diminuí-lo, resultando um deslocamento final $\left(u_{h, f}\right)$ menor que $\left(u_{h, v}\right)$, como pode ser visto na figura 2.16-(b). Isso explica o fato do valor do FAVt ser menor que o de $\gamma_{\mathrm{z}}$ para este caso. 
Sabe-se que para o cálculo do $\gamma_{\mathrm{z}}$, foram utilizados apenas os deslocamentos gerados pelo vento, e também que os deslocamentos $\left(u_{h, v}\right)$ indicados nas figuras foram exagerados para facilitar sua visualização.

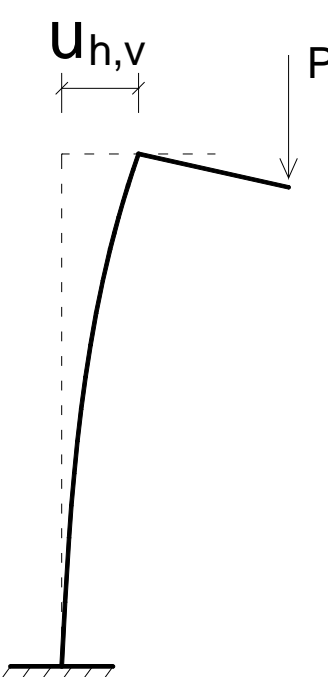

(a)

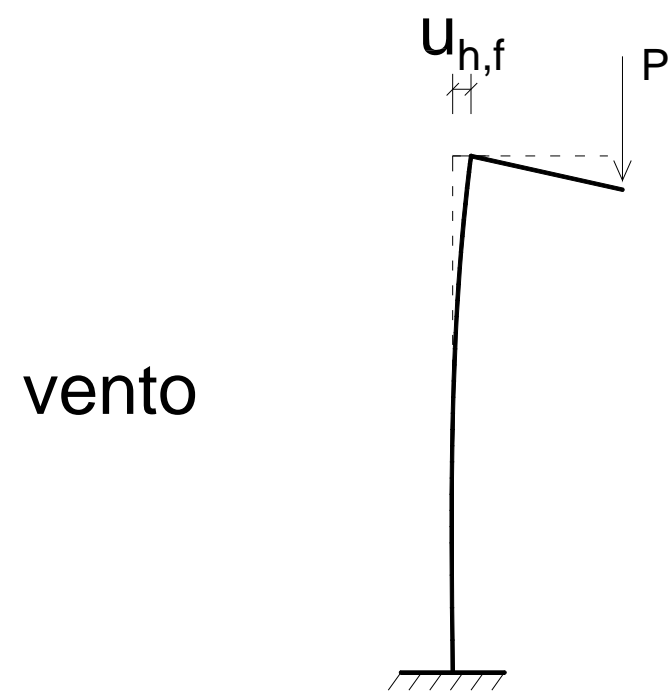

(b)

Figura 2.16. Vento no sentido oposto ao do deslocamento horizontal devido à carga vertical.

Existe outra questão a ser equacionada nesses casos. À medida que a edificação vai sendo construída, e consequentemente inclinando-se, o construtor vai colocando o prédio no prumo novamente, isto é, fazendo as fôrmas inclinadas para o lado contrário. Em função disso, o deslocamento horizontal devido às cargas verticais até então atuantes (peso próprio principalmente) não é o total calculado elasticamente, por isso o Sistema CAD/TQS permite que seja fornecido um valor para considerar esse efeito, ou seja, não é preciso considerar $100 \%$ do deslocamento horizontal devido às cargas verticais. No arquivo de critérios existe um campo para isso, que será mostrado no apêndice deste trabalho.

Depois que a estrutura estiver pronta e forem gradativamente colocadas outras cargas, como alvenarias, revestimentos etc., aí sim o deslocamento aproxima-se do valor total. Vale ressaltar, que o peso próprio é significativo em edifícios altos, o que acarreta a importância deste critério.

No próximo item, será resolvido um exercício para mostrar a aplicação dos dois coeficientes: o $\gamma_{\mathrm{z}}$ e o FAVt. 


\subsection{EXEMPLOS DE APLICAÇÃO DOS COEFICIENTES FAVt E $\gamma_{z}$}

Exemplo 1: Calcular os valores dos coeficientes $\gamma_{z}$ e FAVt para a estrutura mostrada na figura 2.17, sabendo-se que o concreto possui $f_{c k}=25 \mathrm{MPa}$ e o peso próprio da estrutura foi desprezado.

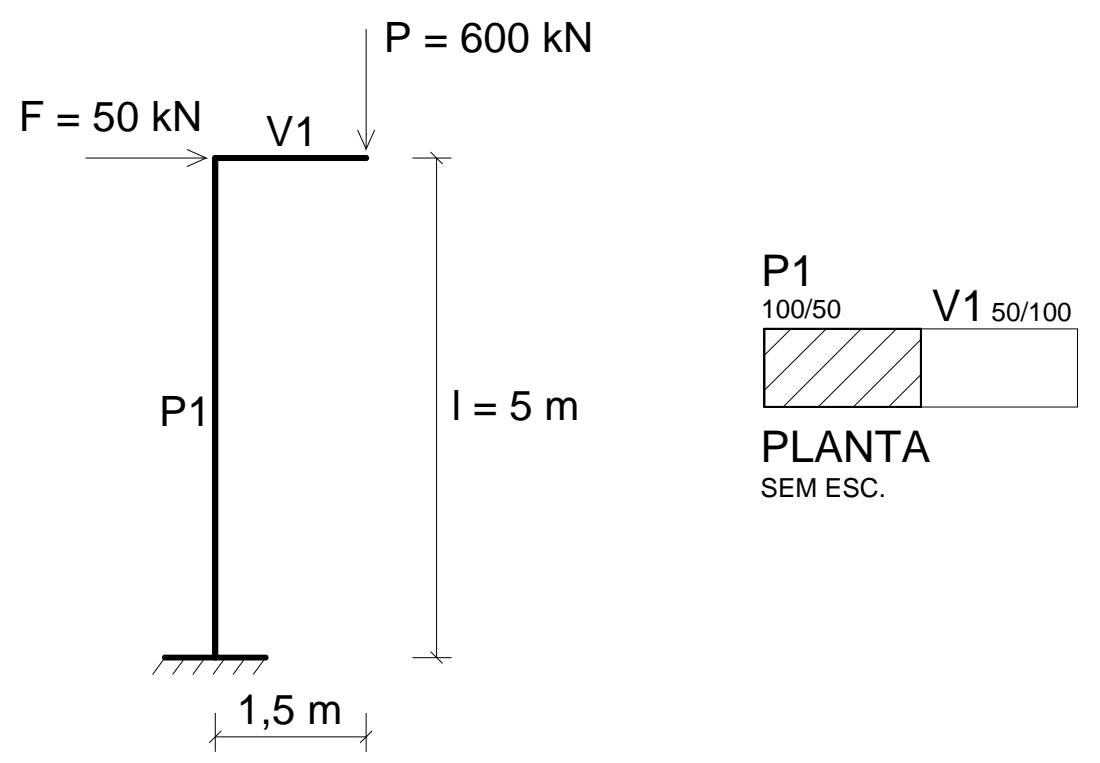

Figura 2.17. Estrutura formada por um pilar e uma viga.

Módulo de Elasticidade:

O módulo necessário é o modulo de elasticidade tangente inicial.

$E_{c i}=5600 \cdot \sqrt{f_{c k}}=5600 \cdot \sqrt{25}=28.000 \mathrm{MPa}=28.000 .000 \mathrm{kN} / \mathrm{m}^{2}$

Inércia do Pilar:

$$
I_{c, p i l}=\frac{b \cdot h^{3}}{12}=\frac{0,5 \cdot 1,0^{3}}{12}=0,04166 \mathrm{~m}^{4}
$$

Deslocamento horizontal devido à ação horizontal:

Como pode ser observado na figura 2.18, o deslocamento horizontal devido à ação horizontal $\left(u_{h, h}\right)$, que pode ser obtido em qualquer tabela de linhas elásticas nos livros de Resistência dos Materiais, é igual a $u_{h, h}=\frac{F_{d} \cdot l^{3}}{3 \cdot(E I)_{s e c}}$, sendo $F_{d}$ uma ação de cálculo concentrada na extremidade livre de uma barra vertical engastada na base e livre no topo, $l$ o comprimento da barra e $(E I)_{s e c}$ a rigidez secante. 
Será considerado, de acordo com o item 15.7.3 da NBR 6118:2003, o valor de $(E I)_{s e c}=0,7 E_{c i} I_{c}$ para contemplar a não-linearidade física de forma aproximada.

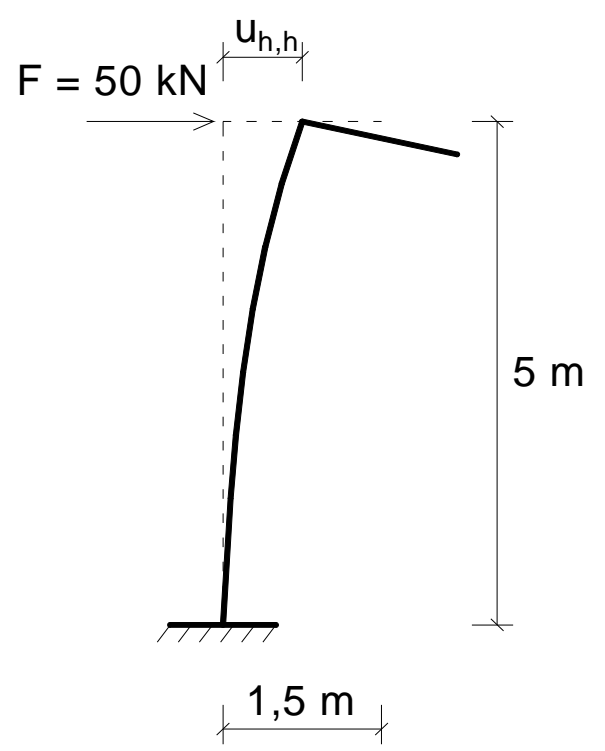

Figura 2.18. Deslocamento horizontal devido à ação horizontal.

$$
\begin{aligned}
& u_{h, h}=\frac{F_{d} \cdot l^{3}}{3 \cdot(E I)_{s e c}}=\frac{F_{d} \cdot l^{3}}{3 \cdot\left(0,7 E_{c i} I_{c, p i l}\right)}=\frac{(50 \cdot 1,4) \cdot 5^{3}}{3 \cdot(0,7 \cdot 28000000 \cdot 0,04166)} \\
& u_{h, h}=0,0036 \mathrm{~m}
\end{aligned}
$$

\section{Cálculo do Gama-z:}

Para o cálculo do Gama-z, utiliza-se apenas o deslocamento horizontal devido à ação horizontal.

$$
\begin{aligned}
& \gamma_{z}=\frac{1}{1-\frac{\Delta M_{t o t, d}}{M_{1, t o t, d}}} \\
& \gamma_{z}=\frac{1}{1-\frac{P_{d} \cdot u_{h, h}}{F_{d} \cdot l}} \\
& \gamma_{z}=\frac{1}{1-\frac{(600 \cdot 1,4) \cdot 0,0036}{(50 \cdot 1,4) \cdot 5}}=\frac{1}{1-\frac{0,30}{35}} \\
& \gamma_{z} \cong 1,009
\end{aligned}
$$




\section{Deslocamento horizontal devido à ação vertical:}

Como pode ser observado na figura 2.19, o deslocamento horizontal devido à ação vertical $\left(u_{h, v}\right)$, que também pode ser obtido em tabelas de livros de Resistência dos Materiais, é igual a $u_{h, v}=\frac{M_{d} \cdot l^{2}}{2 \cdot(E I)_{s e c}}$, sendo $M_{d}$ um momento de cálculo concentrado na extremidade livre de uma barra vertical engastada na base e livre no topo, $l$ o comprimento da barra e $(E I)_{s e c}$ a rigidez secante. 0 momento $M$ concentrado na extremidade livre é obtido transferindo-se a carga $\mathrm{P}$ aplicada na extremidade livre da viga para a extremidade livre do pilar, ao se transferir obtém-se um momento $M=P \cdot 1,5=600 \cdot 1,5=900 \mathrm{kN} . \mathrm{m}$, como pode ser observado na figura 2.20 .

Como no deslocamento devido à ação horizontal, aqui também será considerado, de acordo com o item 15.7.1 da NBR 6118:2003, o valor de $(E I)_{s e c}=0,7 E_{c i} I_{c}$ para contemplar a não-linearidade física de forma aproximada.

$$
\begin{aligned}
& u_{h, v}=\frac{M_{d} \cdot l^{2}}{2 \cdot(E I)_{s e c}}=\frac{M_{d} \cdot l^{2}}{2 \cdot\left(0,7 E_{c i} I_{c, p i l}\right)}=\frac{(900 \cdot 1,4) \cdot 5^{2}}{2 \cdot(0,7 \cdot 28000000 \cdot 0,04166)} \\
& u_{h, v}=0,0193 \mathrm{~m}
\end{aligned}
$$

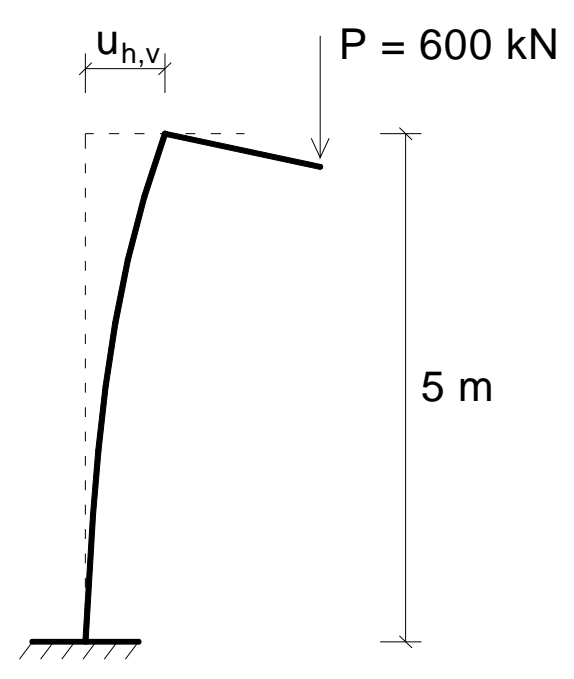

$1,5 \mathrm{~m}$

Figura 2.19. Deslocamento horizontal devido à ação vertical. 


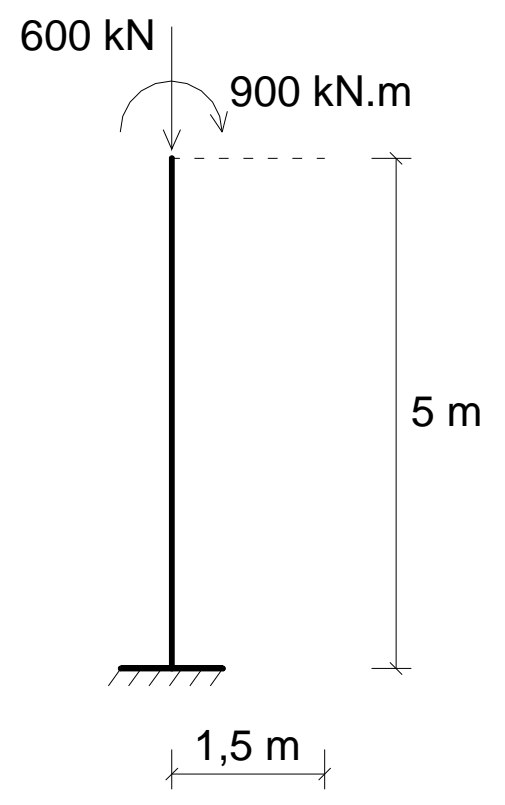

Figura 2.20. Transferência da carga P para a extremidade livre do pilar.

\section{Cálculo do FAVt:}

Para o cálculo do FAVt, utiliza-se o deslocamento horizontal total $\left(u_{h, t o t}\right)$, como pode ser observado na figura 2.21 , o qual é a soma dos deslocamentos horizontais devidos à ação horizontal e à ação vertical, diferentemente do cálculo do Gama-z, no qual se utiliza somente o deslocamento horizontal devido à ação horizontal.

$$
\begin{aligned}
& F A V t=\frac{1}{1-\frac{\Delta M_{t o t, d}}{M_{1, t o t, d}}} \\
& F A V t=\frac{1}{1-\frac{P_{d} \cdot\left(u_{h, t o t}\right)}{F_{d} \cdot l}} \\
& F A V t=\frac{1}{1-\frac{P_{d} \cdot\left(u_{h, h}+u_{h, v}\right)}{F_{d} \cdot l}} \\
& F A V t=\frac{1}{1-\frac{(600 \cdot 1,4) \cdot(0,0036+0,0193)}{(50 \cdot 1,4) \cdot 5}}=\frac{1}{1-\frac{1,92}{35}}
\end{aligned}
$$

$F A V t=1,058$ 


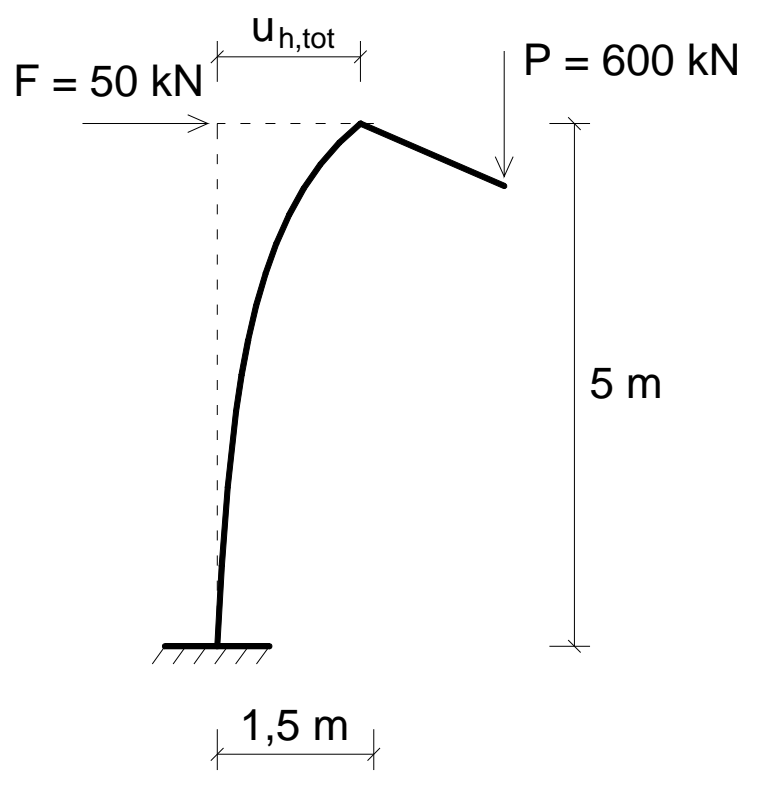

Figura 2.21. Deslocamento horizontal total.

Conclusão:

Para este exemplo, obteve-se $\gamma_{z} \cong 1,009$ e $F A V t=1,058$, ou seja, para o caso de utilizá-los como majorador de esforços de primeira ordem, com o coeficiente $F A V t$ obteve-se um acréscimo de aproximadamente 4,86\%.

$$
\frac{1,058-1,009}{1,009} \cdot 100 \cong 4,86 \%
$$

Lembra-se que este exemplo teve a única finalidade de mostrar a diferença do cálculo dos dois coeficientes. 

Os esforços de primeira e de segunda ordem global podem ser obtidos por meio do processo P-Delta. Porém, como ele não é um parâmetro de estabilidade, a avaliação da estabilidade global é realizada após a análise. O P-Delta nada mais é do que um processo de análise não-linear geométrica.

Segundo Lopes (2005), P-Delta é um efeito que ocorre em qualquer estrutura onde os elementos estão submetidos a forças axiais, ou seja, forças na direção longitudinal da peça. Pode-se dizer que é um processo que relaciona a carga axial $(P)$ com o deslocamento horizontal $(\Delta)$. Na literatura, há diversos métodos que levam em conta este processo, tais como: Método de Dois Ciclos Iterativos, Método da Carga Lateral Fictícia, Método da Carga de Gravidade Iterativa e Método da Rigidez Negativa.

Neste trabalho será dada ênfase apenas ao Método da Carga Lateral Fictícia, por ele ser o mais conhecido entre todos, e no item 3.3 deste capítulo, será mostrado como o Sistema Computacional TQS considera o processo P-Delta.

\subsection{MÉTODO DA CARGA LATERAL FI CTÍ CI A}

Este método também pode ser chamado de P- $\Delta$ iterativo ou, em inglês, de "Iterative Method". Após a análise de primeira ordem, iniciam-se as iterações até que se chegue numa posição de equilíbrio, como pode ser visto na figura 3.1.

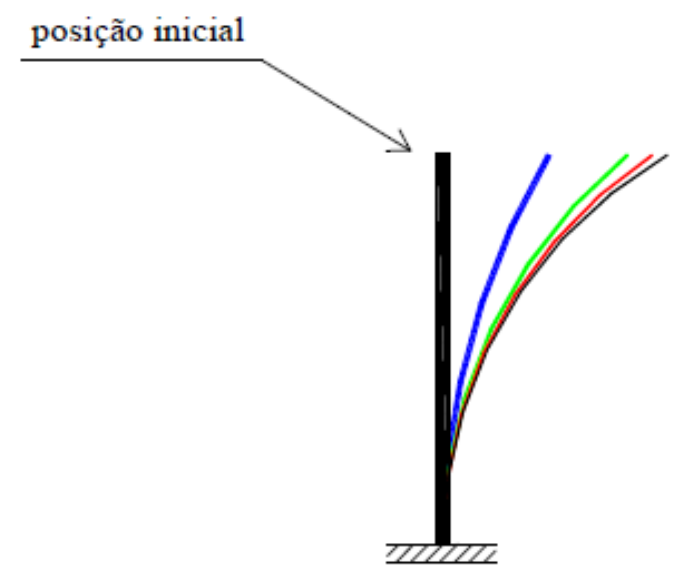

$-1^{\mathrm{a}}$ ordem
$-1^{\mathrm{a}}$ iteração
$-2^{\mathrm{a}}$ iteração

Figura 3.1. Iterações do processo P-Delta. Fonte: LIMA (2001). 
A cada iteração obtém-se uma nova força lateral fictícia e, com essa nova força, volta-se a realizar a mesma análise, até atingir a posição de equilíbrio, como foi dito anteriormente.

Como foi visto na figura 3.1, o processo P-Delta foi mostrado para uma barra simples na vertical, engastada na base e livre no topo. Porém, esse processo pode ser aplicado a edifícios de múltiplos andares, como mostra a figura 3.2 .

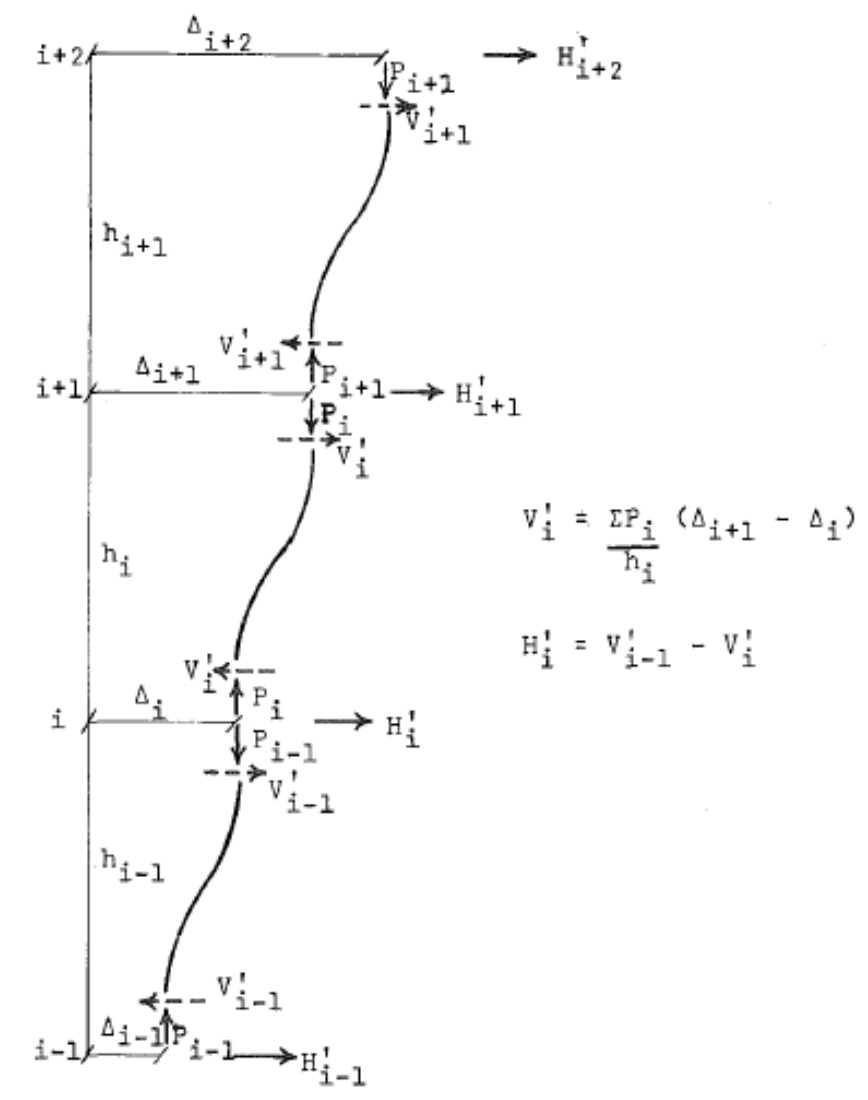

Figura 3.2. Cargas fictícias $\left(H^{\prime}\right)$ em edifícios de múltiplos andares.

Fonte: GAIOTTI (1989).

Para quem está estudando o processo P-Delta pela primeira vez, a figura 3.2 pode parecer um pouco confusa. Portanto, para tentar explicar melhor, serão consideradas algumas etapas, sendo a primeira a de aplicação de carregamento vertical, surgindo, logo após, os esforços horizontais fictícios (cortante fictícia, $V^{\prime}$, e a carga lateral fictícia, $\left.H^{\prime}\right)$.

Os esforços cortantes fictícios podem ser obtidos pela seguinte expressão:

$$
V_{i}^{\prime}=\frac{\sum P_{i}}{h_{i}} \cdot\left(\Delta_{i+1}-\Delta_{i}\right)
$$


E a carga lateral fictícia $H^{\prime}$ de um andar (i) pode ser obtida subtraindo-se a cortante fictícia desse andar (i) do valor relativo ao andar inferior (i - 1), ou seja:

$$
H^{\prime}{ }_{i}=V^{\prime}{ }_{i-1}-V^{\prime}{ }_{i}
$$

$\mathrm{Na}$ figura 3.3, pode-se observar a face indeformada do edifício e a face deformada, sendo esta representada pela linha mais escura.

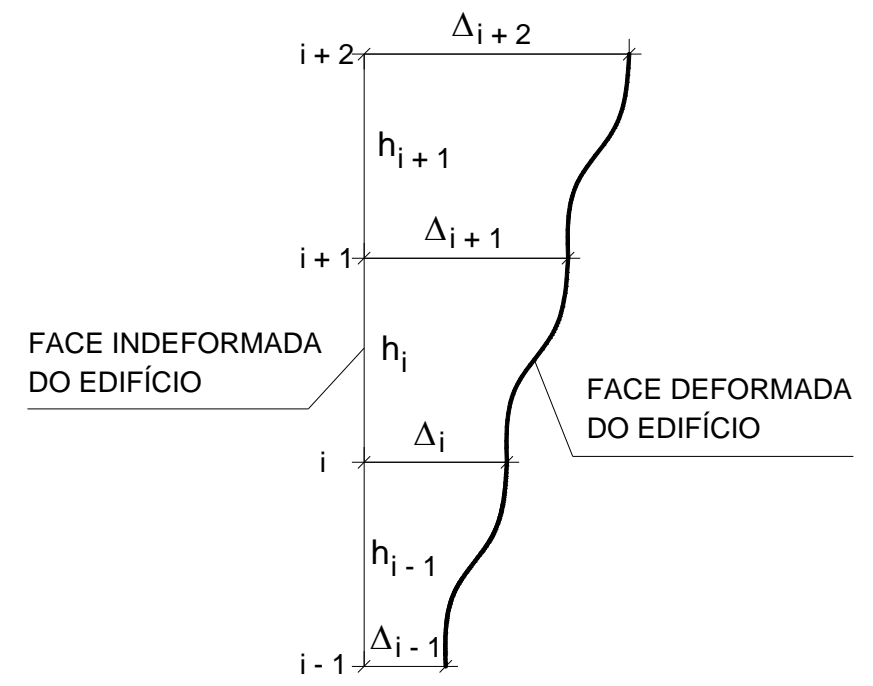

Figura 3.3. Deslocamentos dos pavimentos.

Na figura 3.4 são indicados os deslocamentos horizontais entre os pavimentos.

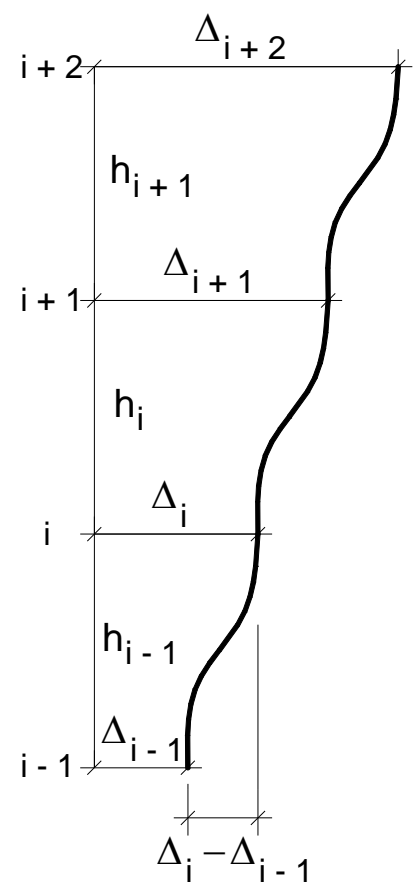

(a)

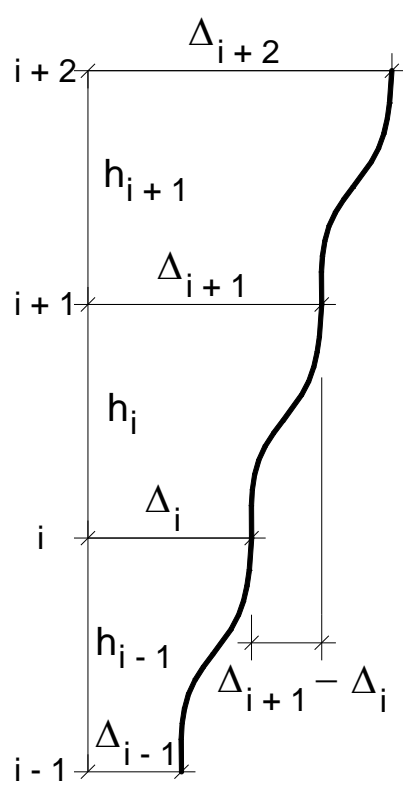

(b)

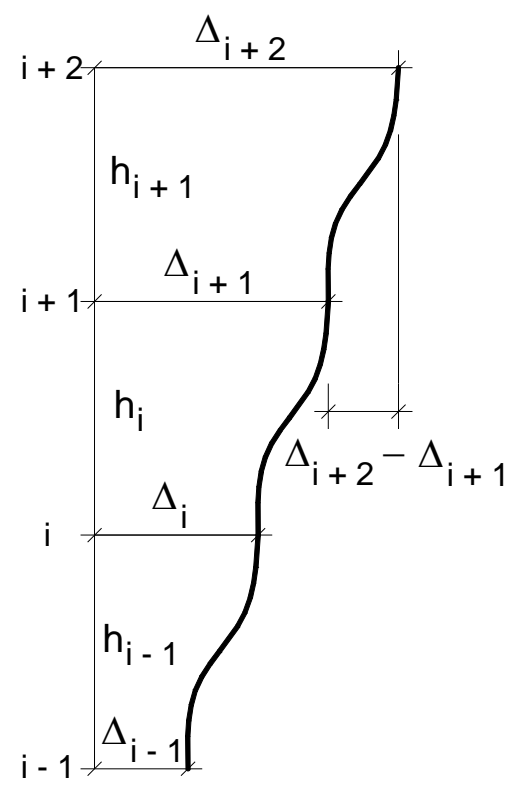

(c)

Figura 3.4. Deslocamentos horizontais entre os pavimentos. 
Com a aplicação das cargas verticais, como mostrado na figura 3.5-(a), surgirão momentos, por causa dos deslocamentos horizontais entre os pavimentos.

Por exemplo, utilizando-se os deslocamentos entre os pavimentos da figura 3.4-(b), ter-se-ia o momento igual a $\sum P_{i} \cdot\left(\Delta_{i+1}-\Delta_{i}\right)$. Dividindo-se cada parcela pela respectiva altura $h_{i}$, obtém-se o binário de forças cortantes fictícias, o qual é representado pela expressão 3.1. Subtraindo-se a força cortante $V^{\prime}{ }_{i}$ de $V^{\prime}{ }_{i-1}$, mostrada na figura 3.5-(b), obtém-se a expressão 3.2, anteriormente mostrada, para a carga lateral fictícia $H_{i}^{\prime}$.

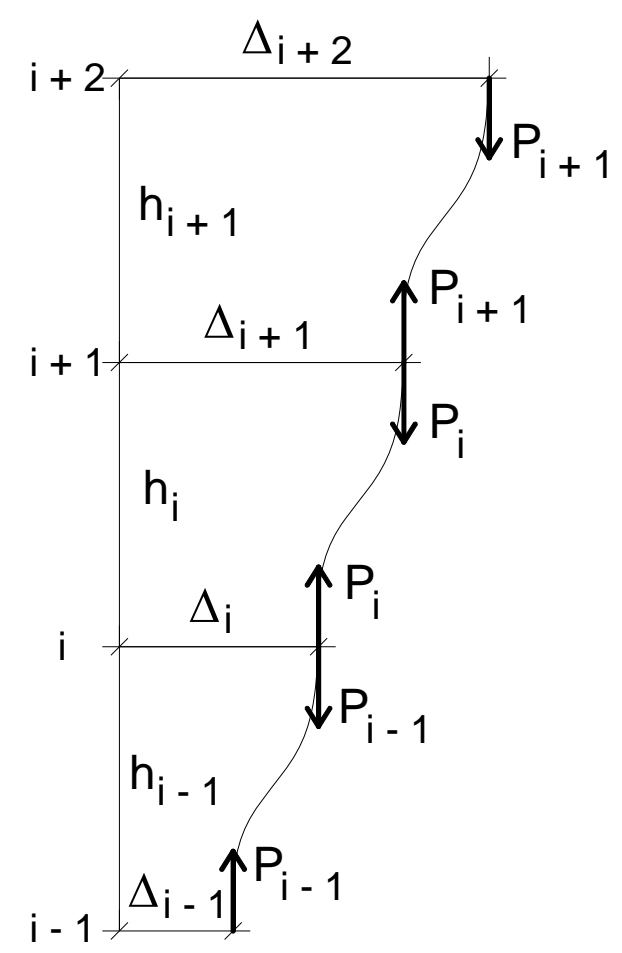

(a)
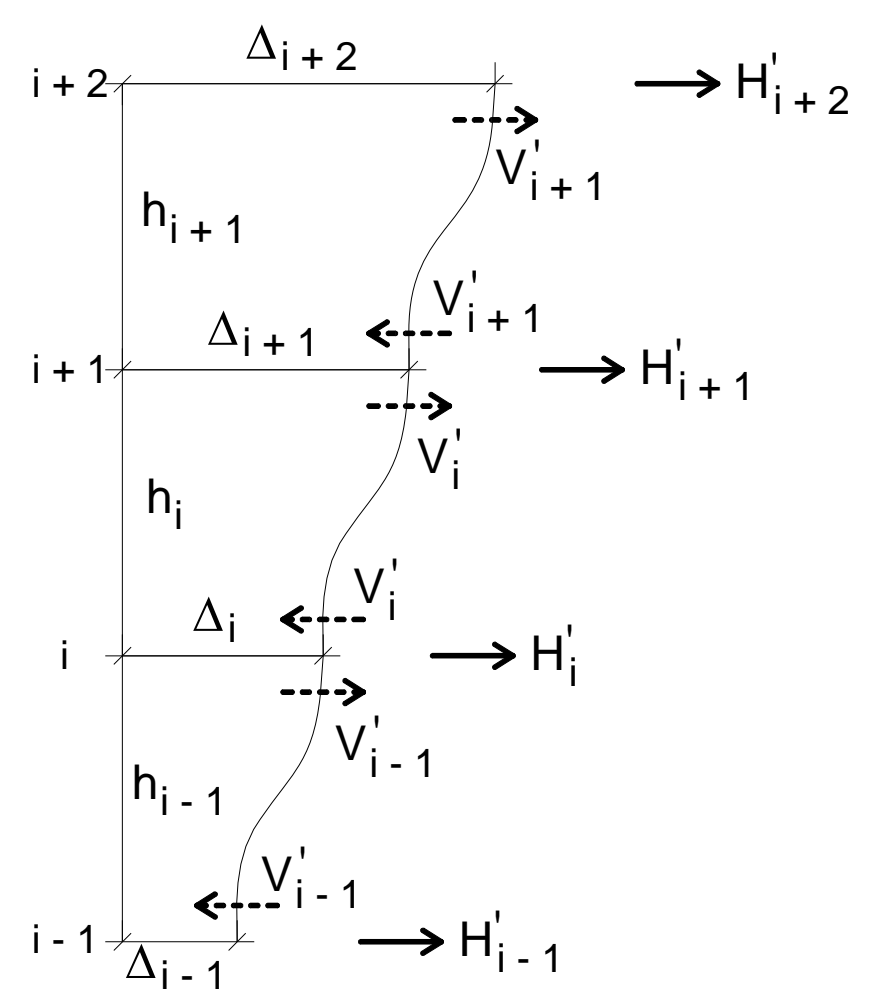

(b)

Figura 3.5. Esquema de forças verticais (a) e horizontais fictícias (b).

Vale ressaltar que na figura 3.5-(b) ainda estão aplicadas as cargas verticais, que não foram indicadas, para permitir melhor visualização das cargas horizontais fictícias.

Para a obtenção do momento final de segunda ordem global, devem-se realizar algumas iterações até que se chegue à posição de equilibro. A maneira como devem ser realizadas as iterações ficará bem clara com o exemplo resolvido passo a passo no próximo item, onde o resultado foi comparado com o relativo ao processo simplificado do coeficiente Gama-z. 


\subsection{EXEMPLO NUMÉRI CO}

Calcular os momentos na base engastada do pilar submetido às ações horizontal e vertical indicadas na figura 3.6, levando em conta os efeitos de segunda ordem pelo processo P-Delta e pelo método simplificado do Gama-z.

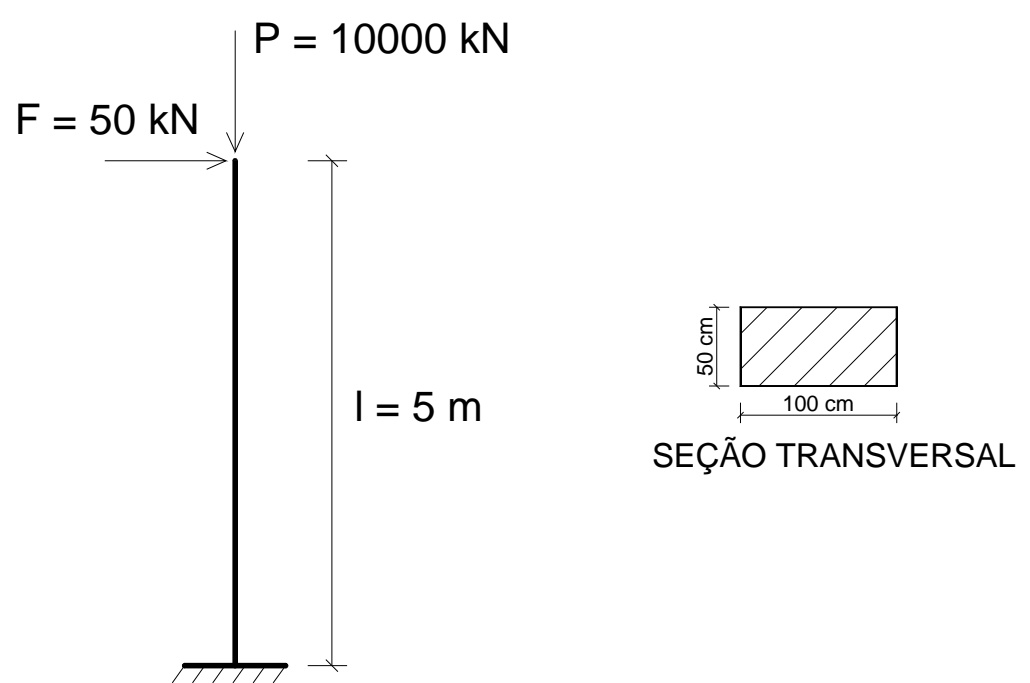

Figura 3.6. Pilar submetido a ações horizontal e vertical.

\subsubsection{ANÁLI SE PELO PROCESSO P-Delta}

As etapas do cálculo pelo processo P-Delta são indicadas a seguir.

a) Módulo de Elasticidade

Considera-se o módulo de elasticidade tangente inicial:

$E_{c i}=5600 \cdot \sqrt{f_{c k}}=5600 \cdot \sqrt{25}=28.000 \mathrm{MPa}$

b) Inércia da seção

$I_{c}=\frac{b \cdot h^{3}}{12}=\frac{0,5 \cdot 1,0^{3}}{12}=0,04166 \mathrm{~m}^{4}$

c) Deslocamento horizontal devido à ação horizontal $(F)$

Como pode ser observado na figura 3.7, o deslocamento horizontal devido à ação horizontal é dado por:

$$
\Delta=\frac{F_{d} \cdot l^{3}}{3 \cdot(E I)_{s e c}}
$$


$F_{d}$ é uma ação de cálculo concentrada na extremidade livre de uma barra vertical engastada na base e livre no topo, $l$ é o comprimento da barra e $(E I)_{s e c}$ é a rigidez secante.

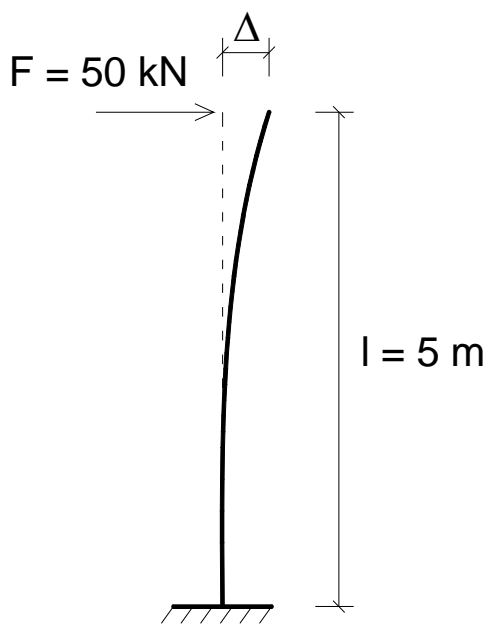

Figura 3.7. Deslocamento horizontal $(\Delta)$.

De acordo com o item 15.7.3 da NBR 6118:2003, será adotado o valor de $(E I)_{s e c}=0,7 E_{c i} I_{c}$ para considerar a não-linearidade física, de forma aproximada.

$$
\begin{aligned}
& \Delta=\frac{F_{d} \cdot l^{3}}{3 \cdot(E I)_{s e c}}=\frac{F_{d} \cdot l^{3}}{3\left(0,7 E_{c i} I_{c, p i l}\right)}=\frac{(50 \cdot 1,4) \cdot 5^{3}}{3 \cdot(0,7 \cdot 28000000 \cdot 0,04166)} \\
& \Delta=3,572 \cdot 10^{-3} \mathrm{~m} \\
& \text { d) Momento na base do pilar } \\
& \text { O cálculo do momento } M_{2} \text { é baseado na figura 3.8: }
\end{aligned}
$$

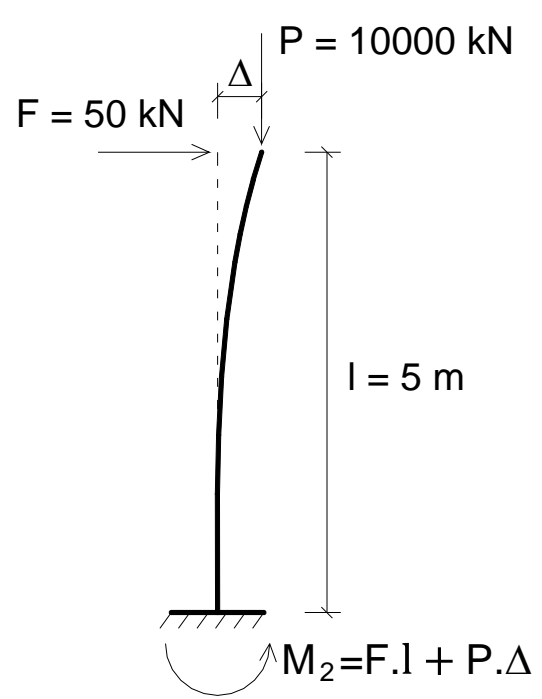

Figura 3.8. Momento na base do pilar $\left(M_{2}\right)$. 


$$
\begin{aligned}
& M_{1}=F_{d} \cdot l=(50 \cdot 1,4) \cdot 5=350 \mathrm{kN} . \mathrm{m} \\
& M_{2}=M_{1}+P_{d} \cdot \Delta \\
& M_{2}=350+(10000 \cdot 1,4) \cdot 3,572 \cdot 10^{-3} \\
& M_{2}=400,008 \mathrm{kN} . \mathrm{m}
\end{aligned}
$$

\section{e) Primeira força horizontal fictícia}

Pergunta-se, então, qual o valor de uma força horizontal fictícia $\left(F_{f}\right)$ que gera o mesmo momento que $P \cdot \Delta$ na base no pilar? Para responder a esta pergunta, basta resolver a equação a seguir.

$$
\begin{aligned}
& F_{f 1, d} \cdot l=P_{d} \cdot \Delta \\
& F_{f 1} \cdot 1,4 \cdot 5=10000 \cdot 1,4 \cdot 3,572 \cdot 10^{-3} \\
& F_{f 1}=\frac{10000 \cdot 1,4 \cdot 3,572 \cdot 10^{-3}}{1,4 \cdot 5} \\
& F_{f 1}=7,144 k N
\end{aligned}
$$

f) Deslocamento horizontal devido à primeira força horizontal fictícia

O cálculo desse deslocamento é baseado na figura 3.9:

$$
\begin{aligned}
& \Delta_{1}=\frac{F_{f 1, d} \cdot l^{3}}{3\left(0,7 E_{c i} I_{c, p i l}\right)}=\frac{(7,144 \cdot 1,4) \cdot 5^{3}}{3 \cdot(0,7 \cdot 28000000 \cdot 0,04166)} \\
& \Delta_{1}=5,104 \cdot 10^{-4} \mathrm{~m}
\end{aligned}
$$

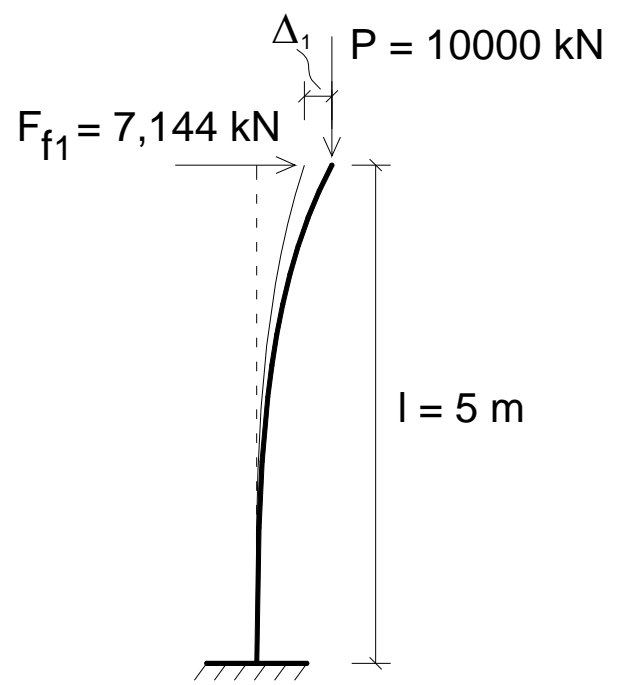

Figura 3.9. Deslocamento horizontal $\left(\Delta_{1}\right)$. 


\section{g) Novo momento na base do pilar}

$$
\begin{aligned}
& M_{3}=M_{2}+P_{d} \cdot \Delta_{1} \\
& M_{3}=400,008+(10000 \cdot 1,4) \cdot 5,104 \cdot 10^{-4} \\
& M_{3}=407,154 \mathrm{kN} . \mathrm{m}
\end{aligned}
$$

Pode-se avaliar a precisão do momento obtido calculando-se o erro a cada iteração. Serão feitas iterações até que o erro seja um valor muito pequeno, que aqui será adotado em torno de $0,01 \%$ do momento da iteração anterior, para assim comparar o momento final obtido com o do processo simplificado do Gama-z.

O erro para esta iteração é calculado a seguir.

$e=M_{3}-M_{2}=407,154-400,008=7,146 k N \cdot m(1,755 \%)$

h) Segunda força horizontal fictícia

$F_{f 2, d} \cdot l=P_{d} \cdot \Delta_{1}$

$F_{f 2} \cdot 1,4 \cdot 5=10000 \cdot 1,4 \cdot 5,104 \cdot 10^{-4}$

$F_{f 2}=\frac{10000 \cdot 1,4 \cdot 5,104 \cdot 10^{-4}}{1,4 \cdot 5}$

$F_{f 2}=1,021 k N$

i) Deslocamento horizontal devido à segunda força horizontal fictícia

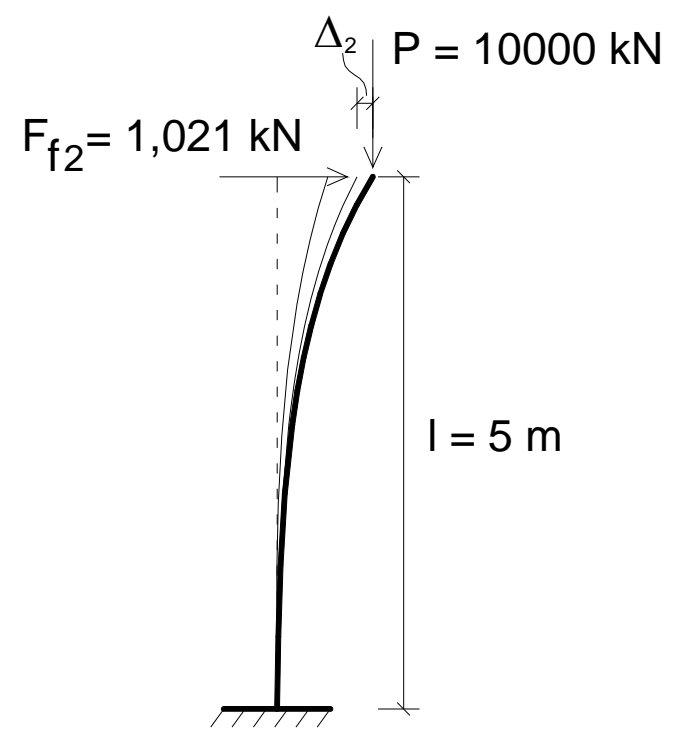

Figura 3.10. Deslocamento horizontal $\left(\Delta_{2}\right)$. 
Cálculo do deslocamento indicado na figura 3.10:

$$
\begin{aligned}
& \Delta_{2}=\frac{F_{f 2, d} \cdot l^{3}}{3\left(0,7 E_{c i} I_{c, p i l}\right)}=\frac{(1,021 \cdot 1,4) \cdot 5^{3}}{3 \cdot(0,7 \cdot 28000000 \cdot 0,04166)} \\
& \Delta_{2}=7,294 \cdot 10^{-5} \mathrm{~m}
\end{aligned}
$$

j) Novo momento na base do pilar

$$
\begin{aligned}
& M_{4}=M_{3}+P_{d} \cdot \Delta_{2} \\
& M_{4}=407,154+(10000 \cdot 1,4) \cdot 7,294 \cdot 10^{-5} \\
& M_{4}=408,175 \mathrm{kN} . \mathrm{m}
\end{aligned}
$$

Erro:

$e=M_{4}-M_{3}=408,175-407,154=1,021 k N . m(0,250 \%)$

\section{k) Terceira força horizontal fictícia}

$F_{f 3, d} \cdot l=P_{d} \cdot \Delta_{2}$

$F_{f 3} \cdot 1,4 \cdot 5=10000 \cdot 1,4 \cdot 7,294 \cdot 10^{-5}$

$F_{f 3}=\frac{10000 \cdot 1,4 \cdot 7,294 \cdot 10^{-5}}{1,4 \cdot 5}$

$F_{f 3}=0,146 k N$

I) Deslocamento horizontal devido à terceira força horizontal fictícia

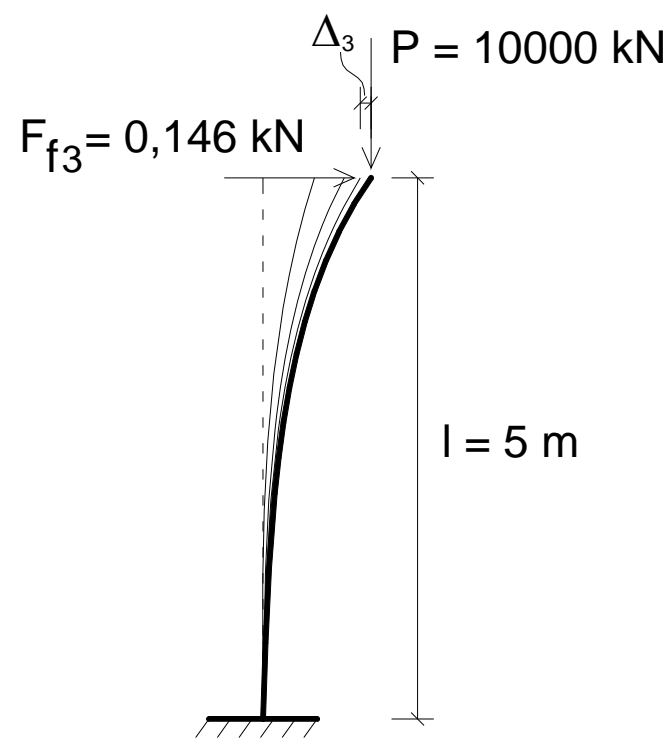

Figura 3.11. Deslocamento horizontal $\left(\Delta_{3}\right)$. 
Cálculo do deslocamento indicado na figura 3.11:

$\Delta_{3}=\frac{F_{f 3, d} \cdot l^{3}}{3\left(0,7 E_{c i} I_{c, p i l}\right)}=\frac{(0,146 \cdot 1,4) \cdot 5^{3}}{3 \cdot(0,7 \cdot 28000000 \cdot 0,04166)}$

$\Delta_{3}=1,043 \cdot 10^{-5} \mathrm{~m}$

m) Novo momento na base do pilar

$M_{5}=M_{4}+P_{d} \cdot \Delta_{3}$

$M_{5}=408,175+(10000 \cdot 1,4) \cdot 1,043 \cdot 10^{-5}$

$M_{5}=408,321 \mathrm{kN} \cdot \mathrm{m}$

Erro:

$e=M_{5}-M_{4}=408,321-408,175=0,146 k N \cdot m(0,0358 \%)$

n) Quarta força horizontal fictícia

$F_{f 4, d} \cdot l=P_{d} \cdot \Delta_{3}$

$F_{f 4} \cdot 1,4 \cdot 5=10000 \cdot 1,4 \cdot 1,043 \cdot 10^{-5}$

$F_{f 4}=\frac{10000 \cdot 1,4 \cdot 1,043 \cdot 10^{-5}}{1,4 \cdot 5}$

$F_{f 4}=0,021 k N$

o) Deslocamento horizontal devido à quarta força horizontal fictícia

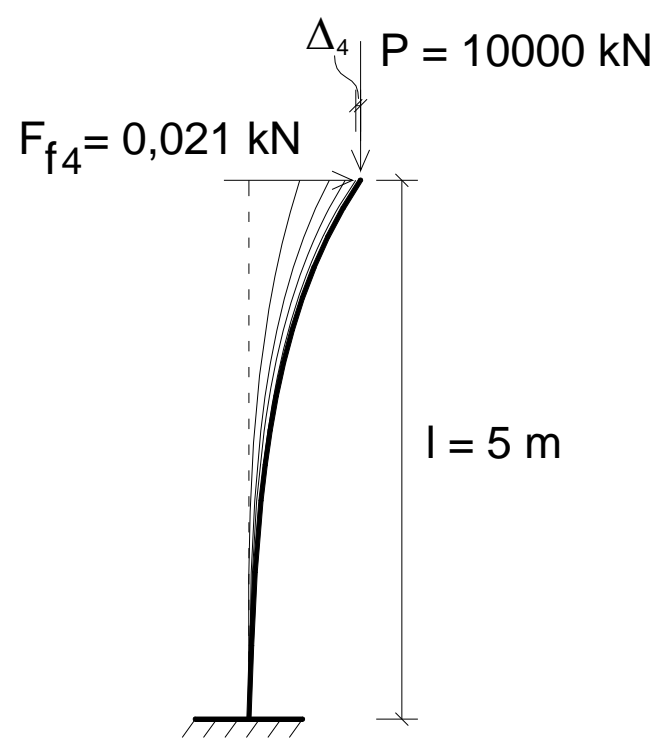

Figura 3.12. Deslocamento horizontal $\left(\Delta_{4}\right)$. 
Cálculo do deslocamento indicado na figura 3.12:

$$
\begin{aligned}
& \Delta_{4}=\frac{F_{f 4, d} \cdot l^{3}}{3\left(0,7 E_{c i} I_{c, p i l}\right)}=\frac{(0,0021 \cdot 1,4) \cdot 5^{3}}{3 \cdot(0,7 \cdot 2800000 \cdot 0,04166)} \\
& \Delta_{4}=1,50 \cdot 10^{-6} \mathrm{~m}
\end{aligned}
$$

p) Novo momento na base do pilar

$$
\begin{aligned}
& M_{6}=M_{5}+P_{d} \cdot \Delta_{4} \\
& M_{6}=408,321+(10000 \cdot 1,4) \cdot 1,50 \cdot 10^{-6} \\
& M_{6}=408,342 \mathrm{kN.m}
\end{aligned}
$$

Erro:

$e=M_{6}-M_{5}=408,342-408,321=0,021 k N \cdot m(0,005 \%)$

Como dito anteriormente, seriam feitas iterações até que o valor do erro fosse em torno de $0,01 \%$ do momento da iteração anterior. Portanto, a última iteração será esta, na qual se tem um erro de apenas 0,005\%. Sendo assim, considera-se $M_{6}=408,342 \mathrm{kN}$. $\mathrm{m}$ o valor final do momento na base do pilar, obtido pelo processo P-Delta.

\subsubsection{ANÁLI SE PELO MÉTODO SI MPLI FI CADO DO Gama-z}

O cálculo será feito com base nos dados indicados na figura 3.6.

a) Deslocamento horizontal devido à ação horizontal $(F)$

$$
\begin{aligned}
& \Delta=\frac{F_{d} \cdot l^{3}}{3 \cdot(E I)_{s e c}}=\frac{F_{d} \cdot l^{3}}{3\left(0,7 E_{c i} I_{c, p i l}\right)}=\frac{(50 \cdot 1,4) \cdot 5^{3}}{3 \cdot(0,7 \cdot 28000000 \cdot 0,04166)} \\
& \Delta=3,572 \cdot 10^{-3} \mathrm{~m}
\end{aligned}
$$

b) Cálculo do Gama-z

$$
\begin{aligned}
& \gamma_{z}=\frac{1}{1-\frac{\Delta M_{t o t, d}}{M_{1, t o t, d}}} \\
& \gamma_{z}=\frac{1}{1-\frac{P_{d} \cdot \Delta}{F_{d} \cdot l}}=\frac{1}{1-\frac{(10000 \cdot 1,4) \cdot 3,572 \cdot 10^{-3}}{(50 \cdot 1,4) \cdot 5}}=\frac{1}{1-0,143} \\
& \gamma_{z}=1,167
\end{aligned}
$$




\section{c) Majoração do esforço horizontal com 0,95 $\gamma_{\underline{z}}$}

Segundo o item 15.7.2 da NBR 6118:2003, uma solução aproximada para a determinação dos esforços finais ( $1^{\mathrm{a}}$ ordem $+2^{\mathrm{a}}$ ordem) consiste em multiplicar os esforços horizontais da combinação de carregamento considerada por $0,95 \cdot \gamma_{z}$, sendo esse processo válido somente para $\gamma_{z} \leq 1,3$. Para este caso, será majorada diretamente a ação $F$, por ser a única ação horizontal.

$$
\begin{aligned}
& F_{m a j}=F \cdot\left(0,95 \cdot \gamma_{z}\right) \\
& F_{m a j}=50 \cdot(0,95 \cdot 1,167) \\
& F_{m a j}=55,43 \mathrm{kN}
\end{aligned}
$$

Após majorar a ação horizontal, calcula-se o momento na base do pilar em sua posição indeformada, ou seja, em sua posição original, sem consideração dos deslocamentos horizontais, como mostrado na figura 3.13. É importante lembrar que esse novo momento na base já considera os efeitos de $2^{a}$ ordem.

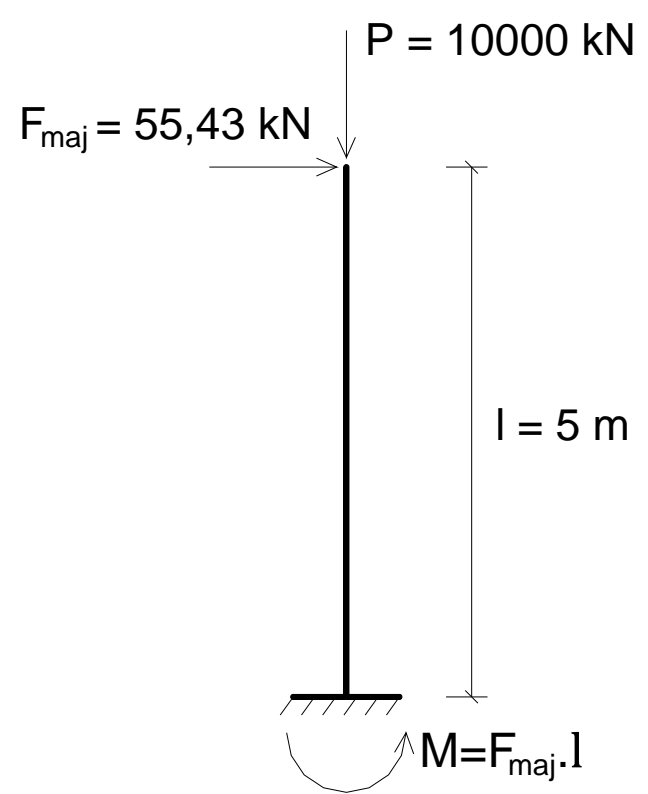

Figura 3.13. Pilar submetido à ação horizontal, majorada por $0,95 \cdot \gamma_{z}$, e à ação vertical.

d) Momento na base do pilar obtido com 0,95 $\gamma_{\underline{z}}$

$$
\begin{aligned}
& M=F_{m a j, d} \cdot l \\
& M=(55,43 \cdot 1,4) \cdot 5 \\
& M=388,01 \mathrm{kN} . \mathrm{m}
\end{aligned}
$$


Se em vez de $0,95 \cdot \gamma_{z}$ fosse utilizado o valor integral $\gamma_{z}$ para majorar a ação horizontal, obter-se-ia:

$$
\begin{aligned}
& F_{m a j}=F \cdot\left(\gamma_{z}\right) \\
& F_{m a j}=50 \cdot(1,167) \\
& F_{m a j}=58,35 \mathrm{kN} \quad(\text { Figura 3.14) }
\end{aligned}
$$

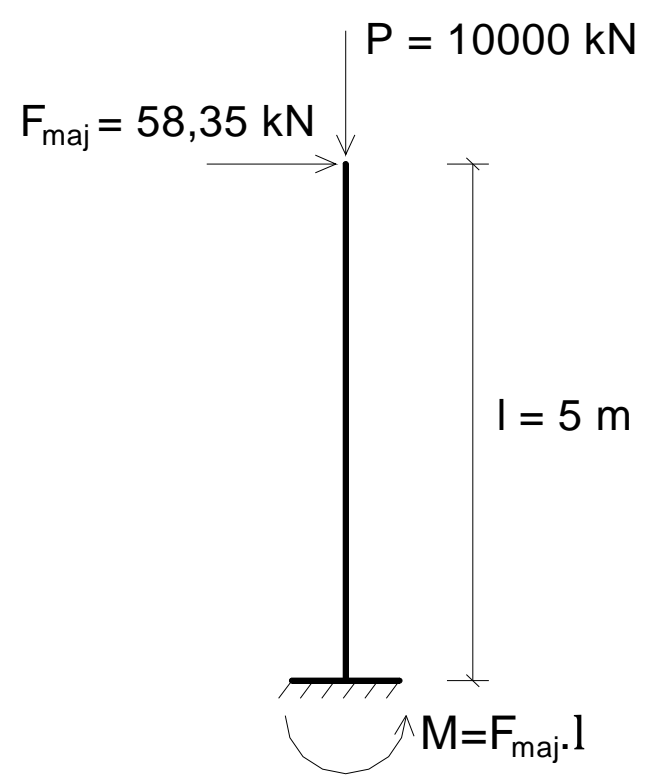

Figura 3.14. Pilar submetido à ação horizontal, majorada por $\gamma_{z}$, e à ação vertical.

e) Momento na base do pilar relativo ao valor integral $\gamma_{\underline{z}}$

$$
\begin{aligned}
& M=F_{m a j, d} \cdot l \\
& M=(58,35 \cdot 1,4) \cdot 5 \\
& M=408,45 \mathrm{kN} . \mathrm{m}
\end{aligned}
$$

\subsubsection{COMPARAÇÃO ENTRE O PROCESSO P-Delta E O Gama-z}

Este exemplo foi utilizado apenas para mostrar os conceitos do processo P-Delta e do Gama-z, de uma forma simples e didática.

Não se pode esquecer que a NBR 6118:2003 prescreve que, para utilização do coeficiente Gama-z em edificações, são necessários no mínimo quatro pavimentos. 
No exemplo, pode-se observar que o momento obtido na base do pilar utilizando-se o P-Delta $(408,34 \mathrm{kN} . \mathrm{m})$ ficou bem próximo do relativo ao valor integral do Gama-z (408,45 kN.m).

O resultado correspondente a $0,95 \gamma_{z}(388,01 \mathrm{kN} . \mathrm{m})$, como permite a Norma, foi aproximadamente $5 \%$ menor que o obtido com o P-Delta.

Lima (2001) também percebeu que, na média, os esforços de segunda ordem obtidos com $0,95 \gamma_{z}$ se afastam dos obtidos com o P-Delta, enquanto que, utilizando-se o valor integral de $\gamma_{z}$, os esforços de segunda ordem praticamente coincidem com os relativos ao processo P-Delta. Carmo (1995) e Pinto (1997) também chegaram à mesma conclusão.

Vale ressaltar, como já foi comentado no capítulo 2, para a dedução do coeficiente Gama-z, que se considera que os acréscimos de momento a cada iteração diminuem segundo uma progressão geométrica de razão $r$.

Com este simples exemplo calculado pelo P-Delta, pode-se perceber que realmente essa hipótese se verifica. A partir da tabela 3.1, verifica-se que os acréscimos de momento constituem uma progressão geométrica de razão $r \cong 0,143$ :

Tabela 3.1. Momentos obtidos pelo processo P-Delta.

\begin{tabular}{|c|c|c|c|c|c|}
\hline \multicolumn{7}{|c|}{ Momentos em kN.m obtidos pelo processo P-Delta } \\
\hline $\mathbf{M}_{\mathbf{1}}$ & $\mathbf{M}_{\mathbf{2}}$ & $\mathbf{M}_{\mathbf{3}}$ & $\mathbf{M}_{\mathbf{4}}$ & $\mathbf{M}_{\mathbf{5}}$ & $\mathbf{M}_{\mathbf{6}}$ \\
\hline 350 & 400,008 & 407,154 & 408,175 & 408,321 & 408,342 \\
\hline
\end{tabular}

$$
\begin{aligned}
& r=\frac{\Delta M_{1}}{M_{1}}=\frac{M_{2}-M_{1}}{M_{1}}=\frac{400,008-350}{350}=\frac{50,008}{350} \cong 0,143 \\
& r=\frac{\Delta M_{2}}{\Delta M_{1}}=\frac{M_{3}-M_{2}}{M_{2}-M_{1}}=\frac{407,154-400,008}{400,008-350}=\frac{7,146}{50,008} \cong 0,143 \\
& r=\frac{\Delta M_{3}}{\Delta M_{2}}=\frac{M_{4}-M_{3}}{M_{3}-M_{2}}=\frac{408,175-407,154}{407,154-400,008}=\frac{1,021}{7,146} \cong 0,143 \\
& r=\frac{\Delta M_{4}}{\Delta M_{3}}=\frac{M_{5}-M_{4}}{M_{4}-M_{3}}=\frac{408,321-408,175}{408,175-407,154}=\frac{0,146}{1,021} \cong 0,143 \\
& r=\frac{\Delta M_{5}}{\Delta M_{4}}=\frac{M_{6}-M_{5}}{M_{5}-M_{4}}=\frac{408,342-408,321}{408,321-408,175}=\frac{0,021}{0,146} \cong 0,143
\end{aligned}
$$




\subsection{CONSI DERAÇÕES SOBRE O PROCESSO P-DELTA NO SOFTWARE TQS}

O processo P-Delta que está inserido no Sistema CAD/TQS surgiu de um trabalho de Medeiros e França (1989), o qual analisa a não-linearidade geométrica em pórticos planos. Na verdade, no Sistema TQS não se trata do tradicional P-Delta descrito no item 3.1, mas sim de um processo numérico mais rigoroso, também iterativo, em que se fazem sucessivas correções na matriz de rigidez. Portanto, mesmo sendo mais refinado, foi mantido o nome de processo P-Delta. Sabe-se também que não existe um único processo com esse nome na literatura técnica, como já foi comentado na introdução deste capítulo.

Foram adotadas algumas hipóteses para o módulo Não Linear Geométrico (NLG) de pórticos tridimensionais do Sistema CAD/TQS. A hipótese cinemática usada para a análise do problema estrutural de flexão composta de barras prismáticas é a de Navier-Bernoulli, na qual se admite que seções planas e normais ao eixo da barra antes da deformação permanecem planas e normais ao eixo após a deformação, e com isso os deslocamentos da barra podem ser obtidos apenas pelos deslocamentos do seu eixo. Admite-se também que o material da barra é elástico linear (domínio de pequenas deformações), e que foi adotada a teoria de rotações moderadas, em que a rotação é da ordem de grandeza da raiz quadrada da deformação específica.

Para as equações de equilíbrio, usa-se o princípio de minimização da energia potencial total e o método dos elementos finitos como ferramenta de discretização (representação do modelo mecânico, protótipo da estrutura real, por pontos, que ligados geram os elementos finitos, que permitem obter nesses pontos os esforços, tensões, deformações e deslocamentos) (MEDEIROS, 1999).

Para uma análise linear, sabe-se que as forças aplicadas $(R)$ se relacionam com os deslocamentos $(r)$ através de uma matriz de rigidez $(K)$ que independe dos deslocamentos, ou seja, o sistema de equações pode ser colocado da seguinte maneira: $[K \cdot r=R]$. Já para a análise não-linear, as forças aplicadas $(R)$ se relacionam com os deslocamentos $(r)$ através de uma matriz de rigidez que depende dos deslocamentos, ou seja: $[K(r) \cdot r=R]$.

O módulo NLG utiliza a matriz $K(r)$ como sendo a matriz de rigidez secante. Portanto o sistema não-linear pode ser representado por: $\left[K_{s}(r) \cdot r=R\right]$. Essa matriz pode corresponder à soma de três parcelas, ou de apenas duas. São elas: 


$$
K_{s}=K_{e}+K_{g}+K_{l} \quad \text { ou } \quad K_{s}=K_{e}+K_{g}
$$

$K_{S}$ é a matriz secante que relaciona as forças aos deslocamentos;

$K_{e}$ é a clássica matriz de rigidez elástica linear;

$K_{g}$ é a matriz de rigidez geométrica, que leva em conta a interação da força axial com o momento fletor na barra;

$K_{l}$ expressa as forças axiais decorrentes dos deslocamentos nodais perpendiculares ao eixo da barra (MEDEIROS, 1999).

A resolução de sistemas não-lineares requer um procedimento iterativo, fundamentalmente baseado em tentativa e correção do erro sobre a estimativa obtida, e há essencialmente duas estratégias diferentes de resolução iterativa: uma dita direta, ou secante, e outra tangente, baseada no Método de Newton. A estratégia incremental-iterativa é também chamada de método de NewtonRaphson. O nome incremental surge quando o carregamento total não é aplicado de uma única vez, sendo dividido em incrementos de carga, ou seja, etapas de carga, até que se chegue ao carregamento total (PROENÇA, 2010).

O método empregado no módulo NLG é o de Newton-Raphson modificado, pois é utilizada a matriz de rigidez elástica como a matriz secante e considera-se o vetor força em apenas um incremento.

Como apresentado anteriormente, a matriz secante pode ser composta por três parcelas ou por apenas duas. A que pode ser desconsiderada é a parcela $K_{l}$, pois existem situações onde a sua contribuição tende a enrijecer fortemente a estrutura. Nesses casos, embora a estrutura possa ser estável, o algoritmo de solução pode mostrar-se ineficiente na determinação da resposta da estrutura (MEDEIROS, 1999).

No Sistema CAD/TQS a consideração dessa parcela $K_{l}$ da matriz de rigidez secante pode ser ativada ou não: fica a cargo do engenheiro projetista. Por default, ela é desativada.

Mais informações sobre o programa podem ser encontradas em Medeiros e França (1989).

No Sistema TQS há dois tipos de análise: o P-Delta convencional e o P-Delta de dois passos. Para que a diferença entre essas análises seja bem compreendida é necessário que se saiba antes qual a influência que os efeitos construtivos podem trazer para a análise estrutural, pois a diferença entre elas está baseada nesse conceito. 
A estrutura é construída por etapas, pavimento por pavimento, até que se chegue à cobertura. A cada pavimento concretado, os pilares se deformam axialmente, ou seja, encurtam em relação à altura, e esse pequeno encurtamento é nivelado horizontalmente para que se dê continuidade à construção. Portanto, esse nivelamento é feito após a concretagem de cada pavimento.

Na modelagem do pórtico tridimensional, não existe esse nivelamento que é feito na obra. O carregamento é aplicado no pórtico por inteiro, de uma só vez, o que causa a deformação axial dos pilares e a alteração do diagrama de momentos fletores, principalmente nos andares superiores, podendo até inverter o sinal nos apoios internos, tornando-se positivos, como pode ser visto na figura 3.15-(a). Na realidade isso não acontece, pois na obra esses encurtamentos são nivelados pavimento por pavimento, e o diagrama final tem a forma indicada na figura 3.15-(b). Agora que já se sabe como é o diagrama real, surge a pergunta: como corrigir o diagrama de momentos fletores da figura 3.15-(a)?

Cob.

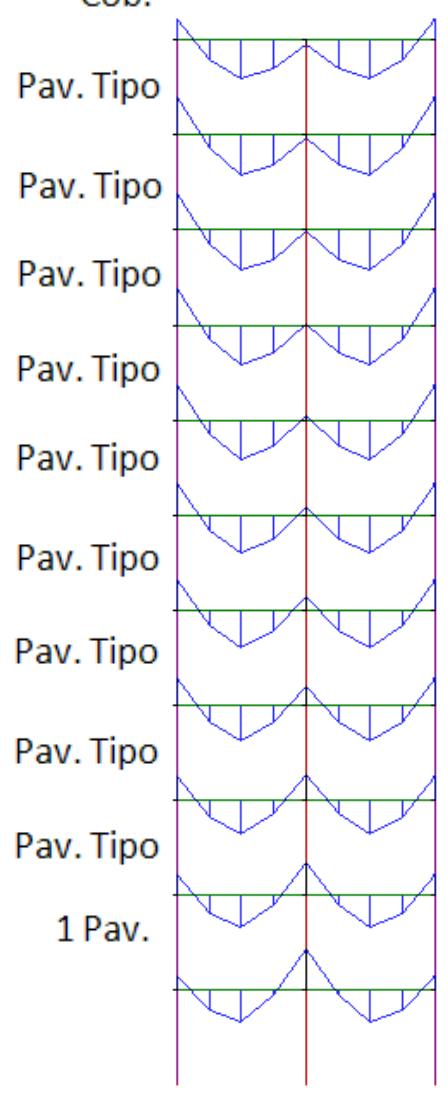

(a)

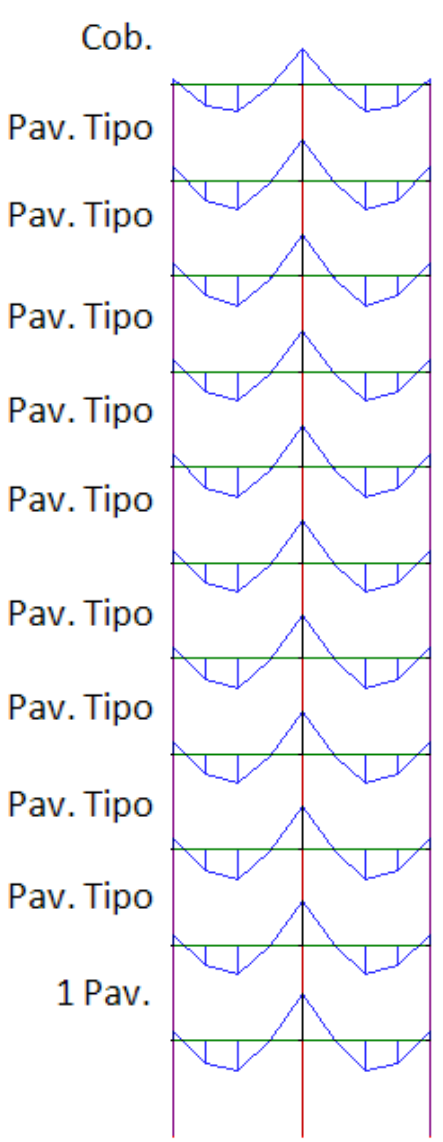

(b)

Figura 3.15. Vista do pórtico plano (a) com rigidez real e (b) com rigidez aumentada. 
Um artifício utilizado pelos sistemas computacionais para levar em conta os efeitos construtivos e consequentemente corrigir esses diagramas de momentos fletores é aumentar a área da seção transversal dos pilares, fazendo com que fiquem com sua rigidez aumentada. Deve-se deixar claro que esse aumento é exclusivo para a análise estrutural, pois a dimensão real dos pilares não será alterada. No Sistema CAD/TQS há um fator chamado MULAXI que é o responsável pelo aumento da área dos pilares. No Apêndice $A$ é mostrado onde fica esse critério e como ativá-lo.

A diferença entre os dois tipos de análise está relacionada à consideração dos efeitos construtivos. Os efeitos de $2^{a}$ ordem obtidos por meio do processo P-Delta são determinados a partir da aplicação das ações verticais e horizontais simultaneamente. Portanto, na análise P-Delta convencional, quando se utiliza o fator MULAXI > 1 para considerar os efeitos construtivos, o deslocamento da estrutura perante as ações horizontais pode ficar comprometido, ou seja, como ao considerar o fator MULAXI a área do pilar é majorada, os deslocamentos horizontais serão menores que os reais, o que afeta diretamente o resultado da análise.

Para solucionar esse problema, o Sistema CAD/TQS disponibilizou uma nova análise chamada P-Delta de dois passos. No primeiro passo, são aplicadas somente as ações verticais, e é realizada uma análise linear da estrutura, sem iterações, com a área dos pilares aumentada para contemplar os efeitos construtivos. Nessa etapa, são armazenados a distribuição de forças normais necessárias para montar a matriz de rigidez geométrica e os esforços nos elementos estruturais vigas e pilares.

No segundo passo são aplicadas somente as ações horizontais e é realizada uma análise não-linear da estrutura, de forma iterativa, sem o aumento da área dos pilares. Na primeira iteração, são consideradas as deformações obtidas no primeiro passo (matriz de rigidez geométrica do primeiro passo). Nas iterações seguintes, são feitas sucessivas correções dessa matriz, com os acréscimos de esforços normais provocados pelas ações horizontais. Esse processo é repetido até a obtenção do equilíbrio final da estrutura.

Os deslocamentos nodais, os esforços nas barras e as reações de apoio ( $1^{a}$ ordem $+2^{a}$ ordem) são a somatória das parcelas obtidas nos dois passos (TQS INFORMÁTICA, 2009). 
Vale ressaltar que na análise aproximada via $\gamma_{z}$, os esforços totais na estrutura ( $1^{a}$ ordem $+2^{a}$ ordem) são calculados a partir de uma combinação linear de casos de carregamentos verticais e horizontais, por isso não se tem o mesmo problema da análise P-Delta convencional.

Como já foi comentado no capítulo $2,0 \gamma_{z}$, além de ser um coeficiente que permite estimar os esforços de segunda ordem, ele avalia a estabilidade do edifício. Já o com processo P-Delta, por ser uma análise não-linear, obtêm-se esforços finais que já consideram os efeitos da não-linearidade geométrica ( $2^{a}$ ordem), e a avaliação da estabilidade global é realizada pós-análise. Para esta avaliação foi então criado um coeficiente $R M 2 M 1$, que representa a intensidade dos esforços de segunda ordem em relação aos de primeira, e que é dado por:

$R M 2 M 1=1+\frac{M_{2}}{M_{1}}$

$M_{1}$ é o momento das forças horizontais em relação à base do edifício;

$M_{2}$ é a somatória das forças verticais multiplicadas pelo deslocamento dos nós da estrutura sob ação das forças horizontais, resultante do cálculo de P-Delta em uma combinação não-linear (TQS INFORMÁTICA, 2009). 



\section{TÓPI COS RELACI ONADOS À ESTABI LI DADE}

Neste capítulo serão comentados alguns tópicos que estão relacionados à estabilidade, como a relação entre os coeficientes $\alpha$ e $\gamma_{z}$, em que, a partir de $\alpha$, se obtém $\gamma_{z}$. Também serão feitos alguns comentários sobre os fatores que tem grande influência na estabilidade de um edifício.

\subsection{RELAÇÕES ENTRE OS COEFICI ENTES $\alpha$ E $\gamma_{z}$}

Carmo (1995), após estudar vários edifícios, obteve uma nuvem de pontos que possibilitaram correlacionar o parâmetro $\alpha$ e o coeficiente $\gamma_{z}$ através de uma equação cúbica.

E qual a vantagem de se correlacionar esses dois coeficientes? Hoje em dia, com a evolução da informática, há softwares de análise estrutural muito eficientes, em que se obtém facilmente os valores para $\gamma_{z}$, além de se ter a possibilidade de fazer análises não-lineares geométricas de uma maneira mais refinada. Com tudo isso, essa correlação pode deixar de ter grande importância, mas no fim do século passado foi uma descoberta que poderia simplificar e agilizar bastante o trabalho dos projetistas, pois muitos deles já possuíam rotinas próprias de cálculo em que o valor do parâmetro $\alpha$ já era obtido, e com essa correlação não seria mais necessário criar uma nova rotina para o cálculo do $\gamma_{z}$, 0 que em parte facilitaria a vida dos projetistas.

O objetivo principal de se achar essa correlação, obtendo-se $\gamma_{z}$ a partir de valores de $\alpha$, é que com o parâmetro $\alpha$ só é possível se fazer uma avaliação da estabilidade do edifício, classificando-o como de nós fixos ou móveis. Com o parâmetro $\gamma_{z}$, além de ser possível a mesma avaliação, pode-se também estimar os esforços de segunda ordem. Lembra-se que o parâmetro $\alpha$ surgiu em 1967, e o $\gamma_{z}$, em 1991. Antes dessa época era muito difícil realizar uma análise de segunda ordem, pois isto era muito trabalhoso e o computador não estava acessível como nos dias atuais.

Aí pergunta-se: como os engenheiros projetavam as estruturas de nós móveis antes do parâmetro $\gamma_{z}$ e do avanço da informática? 
Simplesmente não projetavam. Os engenheiros de antigamente sempre concebiam as estruturas já pensando em uma maneira de torná-las de nós fixos, para que os efeitos de segunda ordem pudessem ser desprezados.

Já era esperada a existência de uma correlação, como por exemplo a indicada na figura 4.1, uma vez que os dois coeficientes foram deduzidos considerando a deformabilidade ao se estabelecer o equilíbrio da estrutura, ou seja, o equilíbrio foi estudado na posição deslocada.

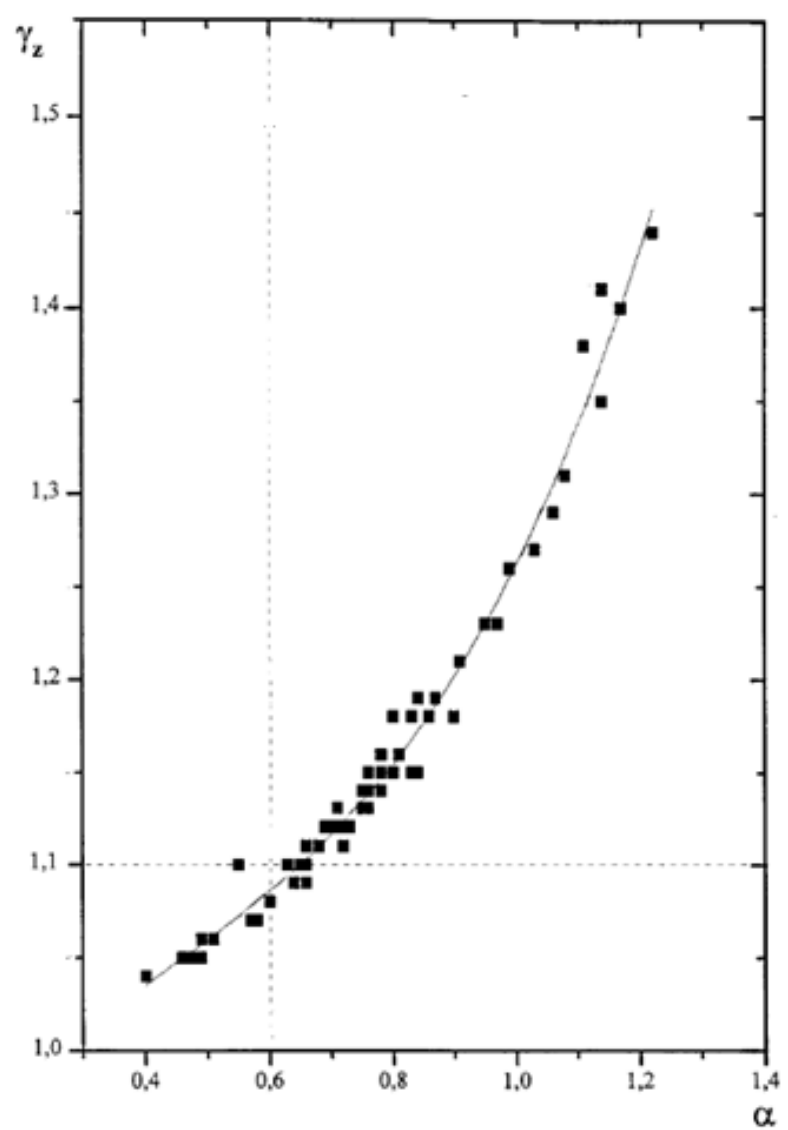

Figura 4.1. Relação entre $\alpha$ e $\gamma_{z}$ para edifícios de concreto armado.

Fonte: CARMO (1995).

Através da nuvem de pontos indicada na figura 1 , foi possível ajustar uma equação cúbica relacionando os dois coeficientes:

$\gamma_{z}=0,90+0,52 \alpha-0,62 \alpha^{2}+0,46 \alpha^{3}$

Porém Corrêa e Ramalho (1995) obtiveram uma equação mais simples, sendo ela quadrática:

$$
\gamma_{z}=1,10-0,33 \alpha+0,50 \alpha^{2}
$$


Essas duas relações entre $\alpha$ e $\gamma_{z}$ foram obtidas para edifícios de concreto armado. Campoó, Corrêa e Ramalho (2005) estenderam o estudo para edifícios de alvenaria estrutural e obtiveram outra nuvem de pontos, relacionando $\alpha$ e $\gamma_{z}$, como mostrado na figura 4.2.

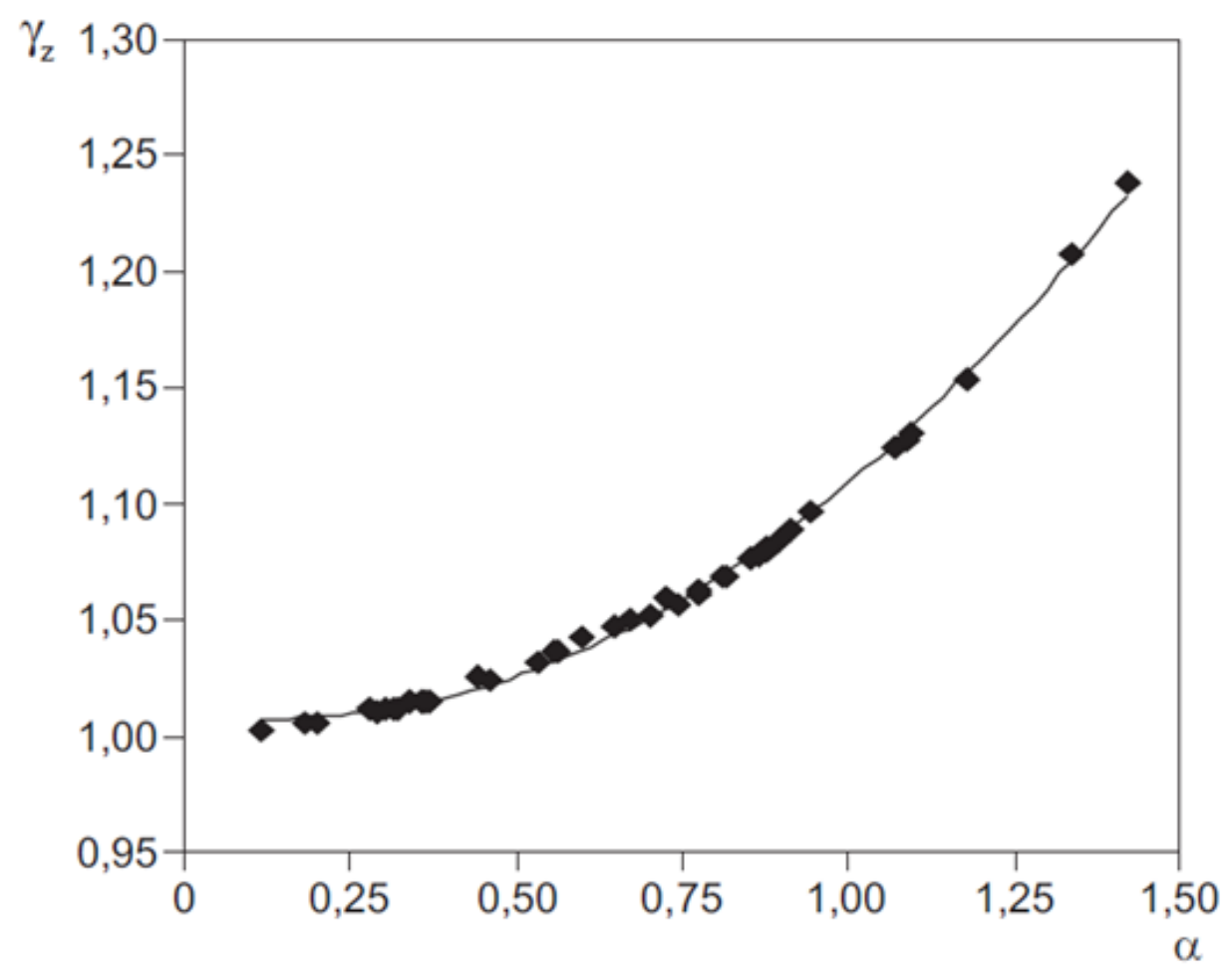

Figura 4.2. Relação entre $\alpha$ e $\gamma_{z}$ para edifícios de alvenaria estrutural. Fonte: CAMPOÓ, CORRÊA e RAMALHO (2005).

A partir dessa nuvem de pontos também foi possível ajustar uma curva relativa a uma equação quadrática:

$$
\gamma_{z}=1,0103-0,0379 \alpha+0,137 \alpha^{2}
$$

Na tabela 4.1, mostra-se uma comparação entre as três correlações obtidas. A análise foi feita no intervalo $0,20 \leq \alpha \leq 1,30$. Na primeira coluna mostram-se os valores para $\alpha$, na segunda, os valores de $\gamma_{z}$ para a correlação de Carmo (1995), na terceira, os valores de $\gamma_{z}$ para a correlação de Corrêa (1995), na quarta, os valores de $\gamma_{z}$ para a correlação de Campoó (2005) e na última, uma diferença percentual entre as correlações de Corrêa e Carmo, por se tratarem de formulações para edifícios de concreto armado, sendo a de Carmo cúbica e a de Corrêa quadrática. 
Tabela 4.1. Tabela comparativa entre as três correlações de $\boldsymbol{\alpha}$ e $\gamma_{\boldsymbol{z}}$.

\begin{tabular}{|c|c|c|c|c|}
\hline \multirow{2}{*}{ Alfa } & \multicolumn{3}{|c|}{ COEFICIENTE GAMA-Z } & \multirow{2}{*}{$\begin{array}{c}\text { Diferença entre Corrêa } \\
\text { e Carmo (\%) }\end{array}$} \\
\hline & Carmo(1995) & Corrêa (1995) & Campoó (2005) & \\
\hline $\mathbf{0 , 2 0}$ & 0,983 & 1,054 & 1,008 & 7,24 \\
\hline 0,25 & 0,998 & 1,049 & 1,009 & 5,04 \\
\hline $\mathbf{0 , 3 0}$ & 1,013 & 1,046 & 1,011 & 3,30 \\
\hline 0,35 & 1,026 & 1,046 & 1,014 & 1,95 \\
\hline $\mathbf{0 , 4 0}$ & 1,038 & 1,048 & 1,017 & 0,94 \\
\hline 0,45 & 1,050 & 1,053 & 1,021 & 0,23 \\
\hline $\mathbf{0 , 5 0}$ & 1,063 & 1,060 & 1,026 & $-0,24$ \\
\hline $\mathbf{0 , 5 5}$ & 1,075 & 1,070 & 1,031 & $-0,49$ \\
\hline $\mathbf{0 , 6 0}$ & 1,088 & 1,082 & 1,037 & $-0,57$ \\
\hline 0,65 & 1,102 & 1,097 & 1,044 & $-0,51$ \\
\hline 0,70 & 1,118 & 1,114 & 1,051 & $-0,36$ \\
\hline 0,75 & 1,135 & 1,134 & 1,059 & $-0,14$ \\
\hline $\mathbf{0 , 8 0}$ & 1,155 & 1,156 & 1,068 & 0,11 \\
\hline $\mathbf{0 , 8 5}$ & 1,177 & 1,181 & 1,077 & 0,36 \\
\hline $\mathbf{0 , 9 0}$ & 1,201 & 1,208 & 1,087 & 0,57 \\
\hline 0,95 & 1,229 & 1,238 & 1,098 & 0,72 \\
\hline 1,00 & 1,260 & 1,270 & 1,109 & 0,79 \\
\hline 1,05 & 1,295 & 1,305 & 1,122 & 0,76 \\
\hline 1,10 & 1,334 & 1,342 & 1,134 & 0,60 \\
\hline 1,15 & 1,378 & 1,382 & 1,148 & 0,30 \\
\hline 1,20 & 1,426 & 1,424 & 1,162 & $-0,15$ \\
\hline 1,25 & 1,480 & 1,469 & 1,177 & $-0,74$ \\
\hline 1,30 & 1,539 & 1,516 & 1,193 & $-1,48$ \\
\hline
\end{tabular}

Comparando-se os resultados de Corrêa (1995) e Carmo (1995), na última coluna percebe-se que para $0,20 \leq \alpha \leq 0,35$ tem-se uma diferença maior que $1 \%$, para $0,40 \leq \alpha \leq 1,25$, menor que $1 \%$, somente voltando a ser maior que $1 \%$ para $\alpha=1,30$. Portanto considera-se que as duas correlações são muito próximas no intervalo $0,40 \leq \alpha \leq 1,25$. Nessa última coluna, os valores positivos representam que os valores de $\gamma_{z}$ para a correlação de Corrêa são maiores que os de Carmo, já os negativos indicam que os de Corrêa são menores que os de Carmo. 
Na tabela 4.1, também se pode observar, na linha destacada em amarelo que, para o valor de $\alpha=0,60$, que é o limite para edifícios usuais a partir de quatro pavimentos, tem-se o valor de $\gamma_{z} \cong 1,1$ para as correlações de Carmo (1995) e Corrêa (1995). Já para correlação obtida por Campoó (2005), para edifícios em alvenaria, percebe-se que só se obtém o valor limite de $\gamma_{z}=1,1$ quando $\alpha \cong 1,0$. Somente a partir desses valores é que as estruturas seriam classificadas como de nós móveis.

\subsection{FATORES QUE I NFLUENCI AM A ESTABI LI DADE}

Há alguns critérios de projeto que, se alterados, podem modificar o grau de instabilidade de uma estrutura, ou seja, podem aumentar ou diminuir o valor dos parâmetros de estabilidade, como os já estudados anteriormente: $\alpha, \gamma_{z}$, e RM2M1.

Alguns fatores relevantes podem influenciar diretamente na estabilidade global das estruturas de edifícios: as ações atuantes, a rigidez dos elementos estruturais, possíveis redistribuições de esforços, interação solo-estrutura e o modelo estrutural adotado (também conhecido como modelo mecânico). Todos esses fatores serão comentados a seguir.

\subsubsection{AÇÕES ATUANTES NA ESTRUTURA}

Têm-se basicamente dois tipos de ações que atuam na estrutura: as ações verticais e as horizontais. Tais ações serão comentadas a seguir, com relação aos efeitos que elas podem causar na estabilidade de um edifício.

\subsubsection{Ações horizontais}

A estabilidade de um edifício independe da intensidade da ação horizontal, por exemplo, o vento. A velocidade pode ser de $30 \mathrm{~m} / \mathrm{s}, 40 \mathrm{~m} / \mathrm{s}$ ou $50 \mathrm{~m} / \mathrm{s}$, o que não altera em nada a estabilidade, ou seja, se resultar um $\gamma_{z}=1,15$ para um edifício analisado com velocidade do vento igual a $30 \mathrm{~m} / \mathrm{s}$, por exemplo, para uma análise com $50 \mathrm{~m} / \mathrm{s}$, o valor de $\gamma_{z}$ deverá ser o mesmo. 
Essa afirmação pode gerar algumas dúvidas, pois intuitivamente considera-se que, com o aumento da velocidade do vento, maiores serão os deslocamentos e, portanto, mais instável será a estrutura analisada, o que é errado!

\subsubsection{Ações verticais}

Ao contrário das ações horizontais, as verticais têm influência direta na estabilidade de um edifício.

Como exemplo dessas ações tem-se o peso próprio, o de revestimentos, o das alvenarias, as ações variáveis etc. Em seguida, será apresentada uma análise com o exemplo mostrado na figura 4.3.

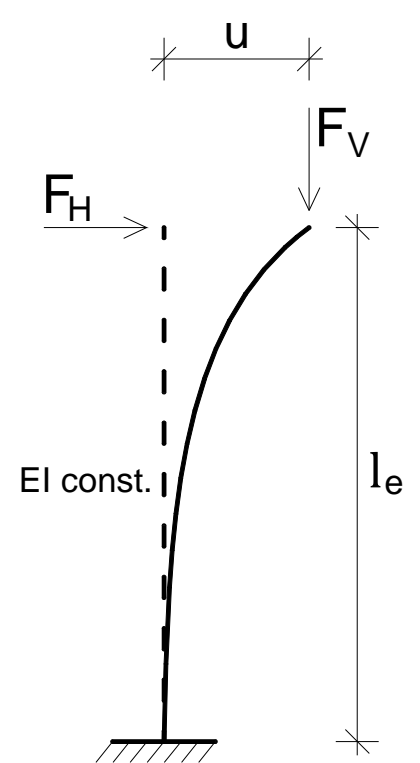

Figura 4.3. Barra vertical engastada na base e livre no topo.

Considerando-se uma ação vertical igual a $5 \cdot F_{V}$, por exemplo, e calculando-se as parcelas do $\gamma_{z}$, obtém-se:

$$
\Delta M_{t o t, d}=5 \cdot F_{V, d} \cdot u \quad e \quad M_{1, t o t, d}=F_{H, d} \cdot l_{e}
$$

Calculando-se $\gamma_{z}$ :

$$
\gamma_{z}=\frac{1}{1-\frac{\Delta M_{t o t, d}}{M_{1, t o t, d}}}=\frac{1}{1-\frac{\mathbf{5} \cdot F_{V, d} \cdot u}{F_{H, d} \cdot l_{e}}}
$$


Pode-se observar que a relação $\frac{\Delta M_{t o t, d}}{M_{1, t o t, d}}$ sempre será alterada, pois ao se considerar outro valor para a ação vertical $F_{V}$, alteram-se apenas os valores dos esforços de segunda ordem $\left(\Delta M_{t o t, d}\right)$. Os de primeira ordem $\left(M_{1, t o t, d}\right)$ não sofrem nenhuma alteração e, portanto, fica comprovado que as ações verticais têm influência direta na estabilidade de um edifício.

\subsubsection{RIGI DEZ}

A alteração da rigidez de uma estrutura tem influência direta na estabilidade global do edifício.

Para edifícios usuais, os elementos de maior importância na avaliação da estabilidade são os pilares e as vigas. As lajes influem muito pouco e, na grande maioria das vezes, sua influência pode até ser desprezada (KIMURA, 2007).

Para a questão das lajes, pode-se notar sua pequena importância na análise da estabilidade até pela recomendação da NBR 6118:2003, que sugere a redução de sua rigidez à flexão para $0,3 \cdot E_{c i} I_{c}$.

Para que se garanta a estabilidade global de uma edificação, é essencial que se formem pórticos pela união de vigas e pilares em direções ortogonais.

Além dos pórticos, outra possibilidade consiste na utilização também de núcleos, ou seja, pilares-parede de grandes dimensões, em geral em formato de "U", junto a escadas e elevadores, pois eles possuem grande rigidez à flexão e contribuem de maneira significativa. Porém, diversas construtoras não são a favor de se utilizarem tais pilares, pois eles são de difícil execução. Algumas até já avisam antecipadamente o projetista que não querem esses núcleos. Mas isso não é muito grave, pois se pode alcançar bons resultados referentes à estabilidade apenas com emprego dos pórticos formados por vigas e pilares.

Para que seja verificada a influência da rigidez na estabilidade global, pode-se utilizar o mesmo exemplo da barra vertical, já utilizado no item anterior, como pode ser visto na figura 4.3.

Como já se sabe, o deslocamento horizontal no topo, devido à ação horizontal $F_{H}$, pode ser obtido pela expressão:

$$
u=\frac{F_{H, d} \cdot l_{e}{ }^{3}}{3 \cdot E \cdot I}
$$


Para esta análise será alterado o valor da rigidez, que será considerada igual $0,5 \cdot E \cdot I$, metade da relativa à seção bruta. Portanto, aplicando-se na expressão (4.3), tem-se:

$$
u=\frac{F_{H, d} \cdot l_{e}{ }^{3}}{3 \cdot(0,5 \cdot E \cdot I)}=\frac{F_{H, d} \cdot l_{e}{ }^{3}}{3 \cdot\left(\frac{E \cdot I}{2}\right)}=2 \cdot \frac{F_{H, d} \cdot l_{e}{ }^{3}}{3 \cdot E \cdot I}
$$

Percebe-se que se obtém o dobro do deslocamento $u$, ou seja, $2 \cdot u$. Calculando-se as parcelas do $\gamma_{z}$ obtém-se:

$$
\Delta M_{t o t, d}=F_{V, d} \cdot 2 \cdot u \quad e \quad M_{1, t o t, d}=F_{H, d} \cdot l_{e}
$$

Calculando-se $\gamma_{z}$ :

$$
\gamma_{z}=\frac{1}{1-\frac{\Delta M_{t o t, d}}{M_{1, t o t, d}}}=\frac{1}{1-\frac{F_{V, d} \cdot 2 \cdot u}{F_{H, d} \cdot l_{e}}}
$$

Para este caso, também se pode observar que a relação $\frac{\Delta M_{t o t, d}}{M_{1, t o t, d}}$ sempre será alterada, pois, ao se modificar o valor da rigidez à flexão, altera-se apenas o valor dos deslocamentos horizontais e, consequentemente, dos esforços de segunda ordem $\left(\Delta M_{t o t, d}\right)$. Os esforços de primeira ordem $\left(M_{1, t o t, d}\right)$, também como no caso anterior, não sofrem nenhuma alteração. Portanto, com este simples exemplo, comprova-se que a alteração da rigidez tem influência direta na estabilidade de um edifício.

\subsubsection{ANÁLI SES COM REDI STRI BUI ÇÃO DE ESFORÇOS}

As análises que consideram redistribuição de esforços têm influência direta na estabilidade de um edifício, e isso será comprovado ao fim deste item.

A NBR 6118:2003, no item 14.5, permite basicamente cinco tipos de análise estrutural: análise linear, análise linear com redistribuição, análise plástica, análise não-linear e análise através de modelos físicos. Porém neste trabalho somente serão considerados dois deles, que se baseiam em redistribuição de esforços: a análise linear com redistribuição e a análise plástica. Esses tipos encontram-se nos itens 14.5 .3 e 14.5.4, respectivamente. 
$\mathrm{Na}$ análise linear com redistribuição, os esforços determinados em uma análise linear são redistribuídos na estrutura, para as combinações de carregamento do ELU. Ao fazer tal redistribuição de esforços, está se aproximando do comportamento real do concreto, pois na análise linear não se considera a fissuração do concreto, e ao se fazer a redistribuição, a fissuração está sendo levada em conta, pois na zona fissurada a rigidez fica reduzida. Consequentemente, absorve menos esforços, o que provoca o remanejamento deles para regiões de maior rigidez.

$\mathrm{Na}$ grande maioria dos casos, a redistribuição é feita como se indica a seguir. Por exemplo, numa ligação viga-pilar, reduz-se o momento negativo na ligação, e ao se realizar a redistribuição, aumenta-se o momento positivo no meio do vão.

Se de acordo com a NBR 6118:2003 é coerente se fazer apenas uma análise linear, por que fazer essa redistribuição? Têm-se dois motivos. Basicamente, o primeiro é que, ao se aproximar o momento negativo da ligação ao momento positivo no meio do vão, resulta em economia de material. O segundo é que, se em uma ligação viga-pilar há momentos de grande intensidade, ao se realizar o dimensionamento pode resultar alta quantidade de armadura, dificultando sua execução, às vezes até a impossibilitando. Aí, para resolver tal problema, costuma-se redistribuir esforços, reduzindo o momento negativo, consequentemente, reduzindo a área de armadura necessária e tornando possível a sua execução.

Mas uma observação muito importante deve ser feita: jamais se deve reduzir tal momento a ponto de anular esse esforço, pois a NBR 6118:2003 no item 14.5.3 é bem clara quando diz que nesta análise as condições de equilíbrio devem ser obrigatoriamente satisfeitas, e para que seja satisfeita tal condição, deve-se redistribuir os esforços de maneira coerente.

A NBR 6118:2003 impõe limites para esse tipo de análise, limites que são diferentes para estruturas de nós fixos e de nós móveis, sendo o limite de redução igual a $10 \%$ para estruturas de nós móveis e $25 \%$ para estruturas de nós fixos. O motivo principal dessa diferença é o que já foi comentado no início deste item, que essa redistribuição de esforços influencia diretamente na estabilidade do edifício, pois, ao se redistribuir esforços, a tendência é deixar a estrutura menos rígida, ou seja, mais deslocável, aumentando os esforços de segunda ordem. 
Por isso o limite de redução é menor para as estruturas de nós móveis, que já são estruturas menos rígidas.

A análise estrutural é denominada plástica, segundo a NBR 6118:2003, quando as não-linearidades puderem ser consideradas admitindo-se materiais de comportamento rígido-plástico perfeito ou elastoplástico perfeito.

Fontes (2005) fez comentários sobre a análise plástica, indicando que a propriedade do material de guardar deformações residuais é chamada de plasticidade, e as principais teorias envolvidas em projetos, que permitem que elementos estruturais sofram certas deformações permanentes, são a teoria das rótulas plásticas (articulações), para elementos lineares, e a teoria das charneiras plásticas (dobradiças), para elementos de superfície que trabalham como placas.

A teoria da plasticidade é pouco estudada na graduação, sendo mais considerada em cursos de pós-graduação.

Na graduação é comum estudar-se a teoria da elasticidade, na qual, ao se aplicar um carregamento em um elemento, ele se deforma de um valor $\delta$, e se o carregamento for retirado, esse elemento volta ao seu estado inicial. Esse comportamento não ocorre na plasticidade, pois quando se retira o carregamento, o elemento não volta ao seu estado inicial, apresentando uma deformação permanente.

De acordo com Fontes (2005), a plastificação em concreto armado se dá pelo escoamento da armadura, elevando a linha neutra (para momentos positivos) e aumentando o braço de alavanca obtido em regime elástico, isso porque, com a elevação da linha neutra, a região comprimida do concreto se reduz, consequentemente, a resultante de tensões no concreto se aproxima da parte superior da seção, assim, aumentando o braço de alavanca.

Segundo a NBR 6118:2003, no item 14.5.4, a análise plástica de estruturas reticuladas (sistemas constituídos por barras ligadas entre si pelas suas extremidades) não pode ser adotada quando se consideram os efeitos de segunda ordem global, ou seja, não pode ser adotada para estruturas de nós móveis, pois para tais estruturas a consideração dos efeitos de segunda ordem é obrigatória. E também quando não houver suficiente dutilidade (propriedade física dos materiais de suportar a deformação plástica, sob a ação de cargas, sem se romper ou fraturar) para que as configurações adotadas sejam atingidas. 
$\mathrm{Na}$ análise plástica, a redistribuição de esforços pode ser feita com maior intensidade que na análise linear com redistribuição, desde que as rótulas plásticas apresentem as devidas capacidades de rotação plástica.

Segundo a NBR 6118:2003, no item 14.6.5, é obrigatória a verificação das rotações nas rótulas plásticas, que não podem superar a capacidade de rotação plástica das seções transversais correspondentes, ou seja, deve ser comprovado que a demanda de rotação plástica seja inferior à capacidade de rotação plástica da seção do elemento estrutural em questão. Portanto, não sendo comprovada tal condição, a estrutura possivelmente entrará em colapso.

Vale ressaltar que quanto maior for a redistribuição de esforços, ou seja, quanto maior for a redução de momentos fletores em ligações localizadas, mais próximo de uma articulação está se chegando nessas ligações.

Portanto, pode-se fazer uma analogia com estruturas de concreto prémoldado, pois, segundo EL Debs (2000), a necessidade de realizar ligações entre os elementos constitui-se em um dos principais problemas a serem enfrentados no emprego da pré-moldagem, e tais ligações se diferenciam quanto ao tipo de vinculação em: ligação articulada, ligação semi-rígida e ligação rígida. Fazendose essa analogia, as ligações articuladas representariam 100\% de redução de momentos, as ligações semi-rígidas representariam algo entre 0 e $100 \%$ de redução de momentos e as ligações rígidas representariam a não redução de momentos, considerando-se a ligação 100\% rígida.

Zumaeta Moncayo (2009) realizou um estudo com pórticos tridimensionais de concreto pré-moldado, avaliando a estabilidade global por meio da análise dos valores de $\alpha$ e $\gamma_{z}$. Para tal análise, variou-se o número de pavimentos e a rigidez das ligações viga-pilar, considerando-as articulada, semi-rígida e rígida. Para a variação das ligações, segundo EL Debs (2000), utilizou um parâmetro chamado de parâmetro de restrição $(\gamma)$, o qual, segundo a NBR 9062:2006 (Projeto e execução de estruturas de concreto pré-moldado), no item 5.1.2.3, é chamado de fator de restrição à rotação $(\alpha)$. Quando $\gamma=0$, está se representando uma ligação articulada, e quando $\gamma=1$, uma ligação rígida. Portanto, $\gamma$ variando entre 0 e 1 representa as ligações semi-rígidas. A forma do pavimento do pórtico analisado está mostrada na figura 4.4. 


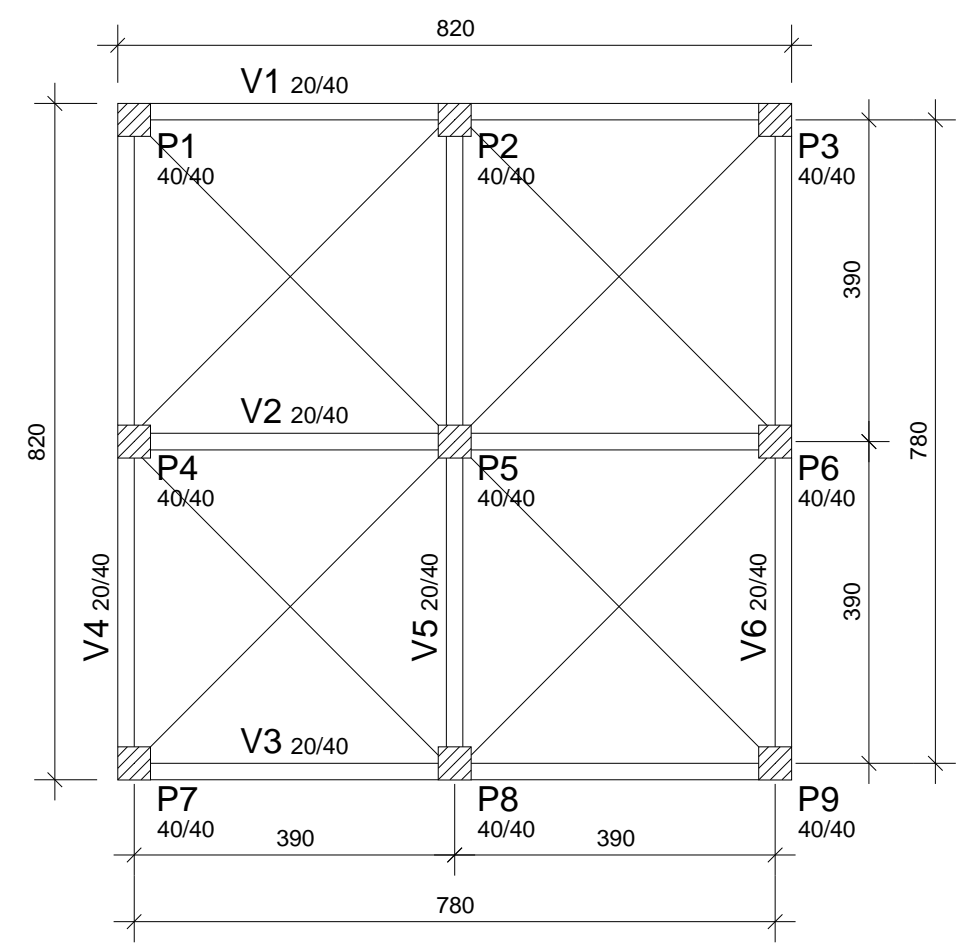

Figura 4.4. Forma do pavimento do pórtico analisado (dimensões em $\mathrm{cm}$ ).

Para analisar a variação do número de pavimentos, foram admitidos dois pavimentos (figura 4.5-a), três, quatro, cinco e seis (figura 4.5-b).

Foram consideradas ações verticais e horizontais arbitrárias, sendo as horizontais as ações de vento.

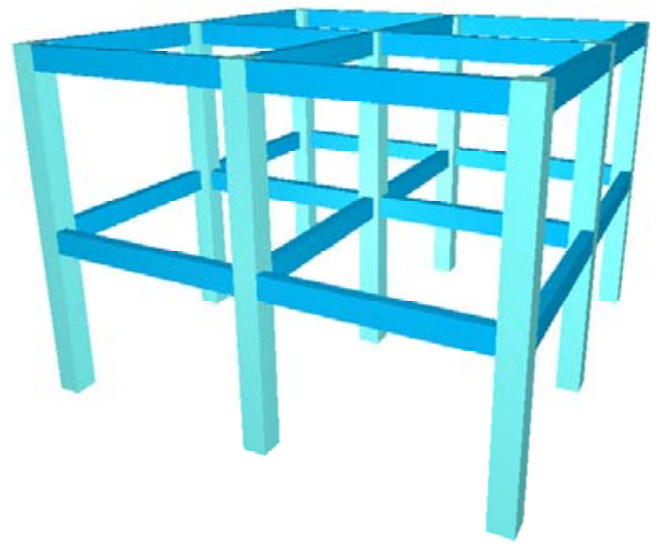

(a)

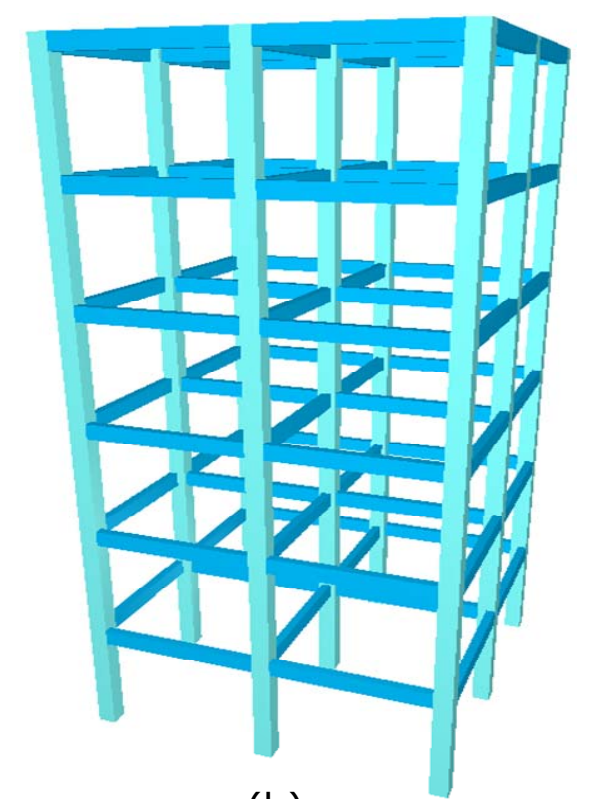

(b)

Figura 4.5. Número de pavimentos do pórtico analisado. 
Os resultados obtidos são mostrados nas figuras 4.6 e 4.7.

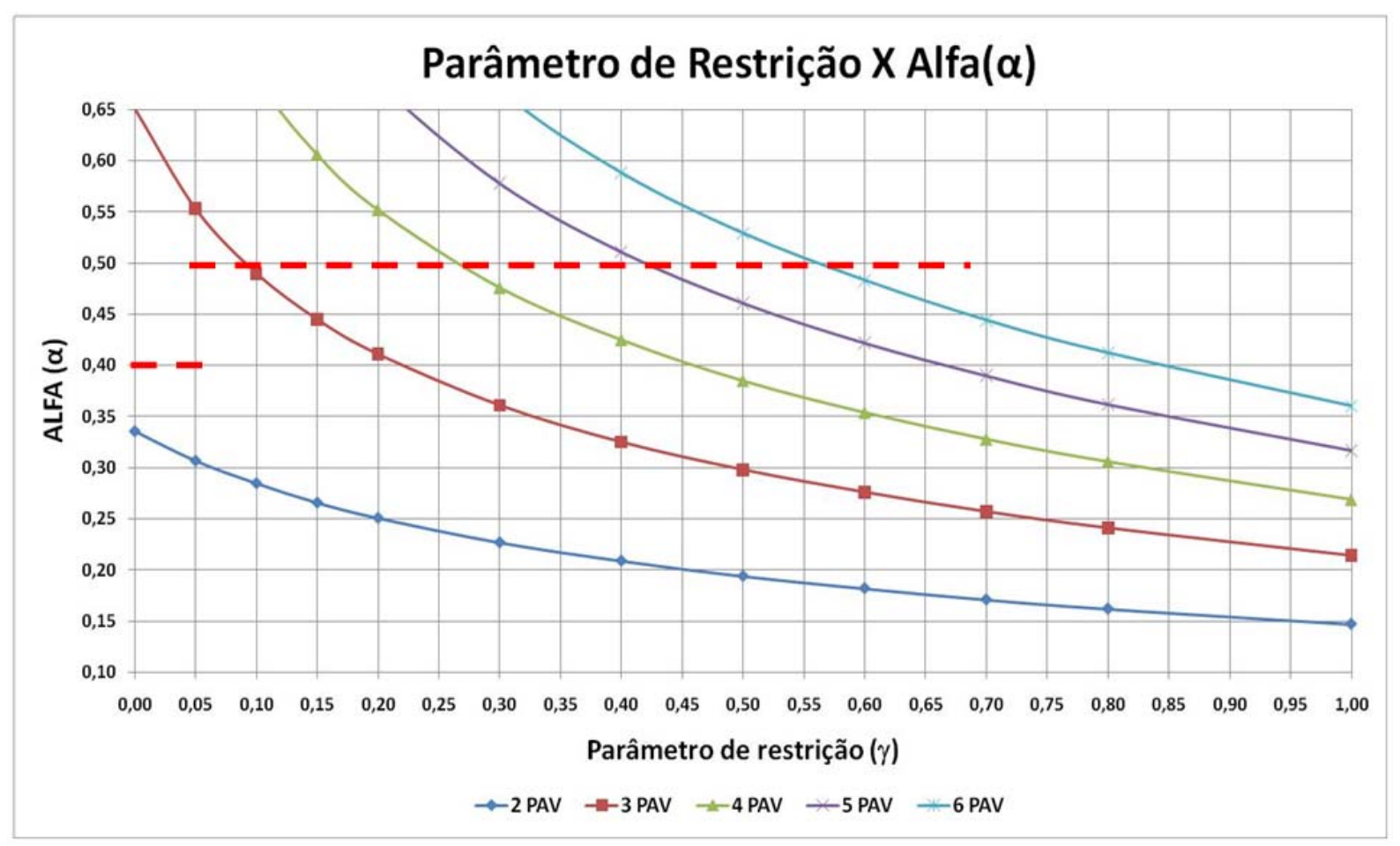

Figura 4.6. Valores de alfa obtidos para a variação das ligações.

$\mathrm{Na}$ figura 4.6, pode-se observar retas tracejadas em vermelho para valores de $\alpha$ iguais a 0,40 e 0,50, que são os limites para considerar de nós fixos as estruturas reticuladas de dois pavimentos e para a partir de três pavimentos, respectivamente. Segundo a NBR 6118:2003, no item 15.5.2. o limite de $\alpha$ para estruturas reticuladas a partir de quatro pavimentos é igual a 0,60 , porém neste mesmo item está escrito que este limite deve ser reduzido para 0,50 quando a estrutura de contraventamento for constituída exclusivamente de pórticos, como é o caso em questão.

Observa-se também que quando $\gamma=1$, ou seja, de acordo com a analogia, este seria o caso em que não há redução de momentos, obteve-se valores de $\alpha$ abaixo de 0,40 para todos os pórticos analisados. $E$ à medida que se consideram valores para $\gamma$ abaixo de 1,0, ou seja, casos em que há redução de momento, caminha-se no sentido do limite de $100 \%$ de redução, ou seja, uma articulação quando $\gamma=0$. O valor de $\alpha$ aumentou de uma maneira não-linear para todos os pórticos analisados, sendo que o único que continuou abaixo do limite foi o pórtico de dois pavimentos; todos os outros ficaram bem acima do limite. 


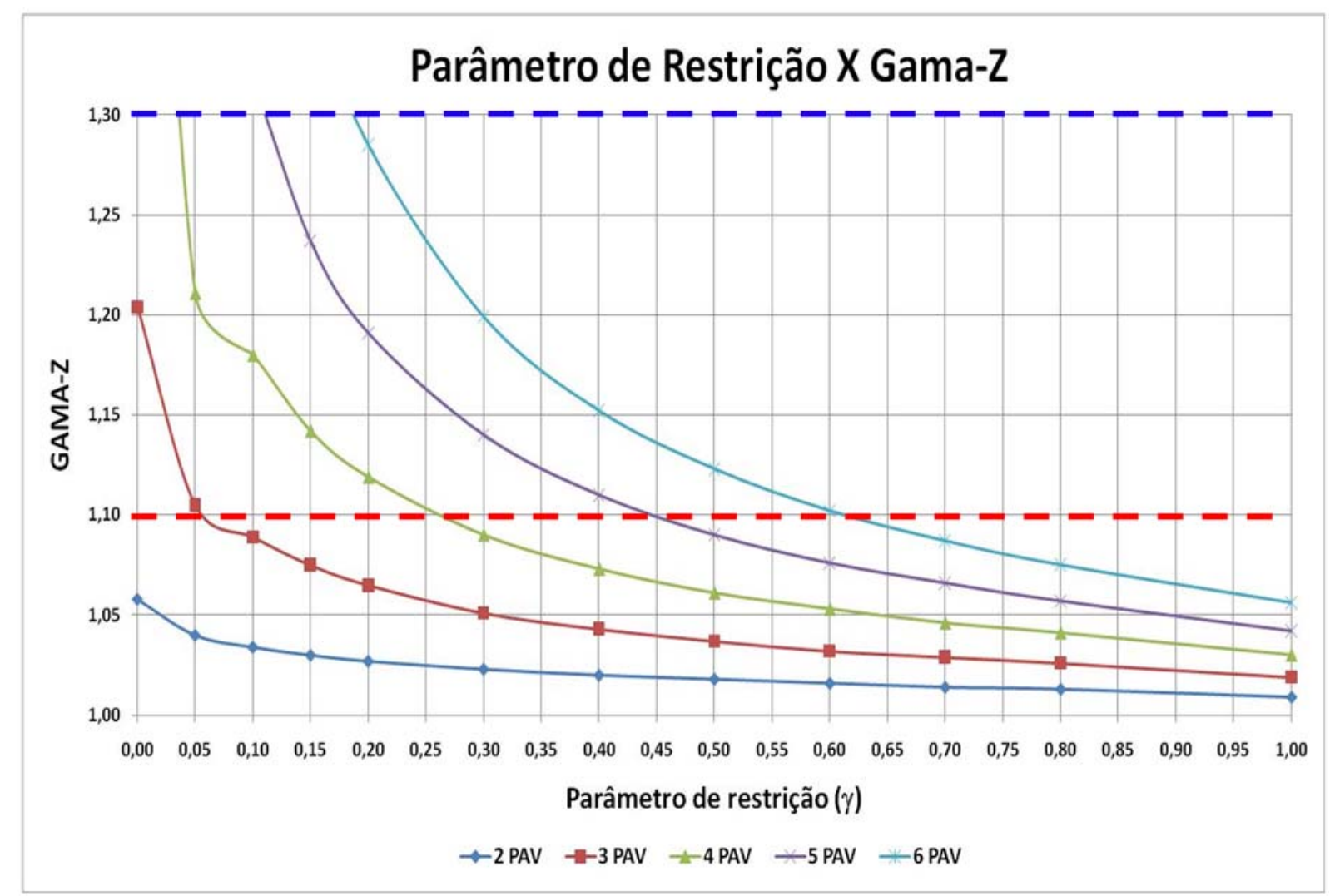

Figura 4.7. Valores de Gama-z obtidos para a variação das ligações.

Para a figura 4.7, foi obtida uma conclusão parecida. Apenas no pórtico de dois pavimentos o valor permaneceu abaixo do limite de 1,10 . No de três pavimentos obteve-se um valor de aproximadamente 1,20 , sendo considerado como de nós móveis, e em todos os outros foram obtidos valores bem acima do valor aceitável de 1,30. Vale ressaltar que o $\gamma_{z}$ de acordo com a NBR 6118:2003 não pode ser utilizado para estruturas abaixo de quatro pavimentos, porém este foi apenas um exemplo com o objetivo de avaliar como as estruturas se comportam com a variação do tipo das ligações viga-pilar.

A partir da analogia com as estruturas de concreto pré-moldado, pode-se concluir com o exemplo que à medida que se reduzem os momentos negativos, com o objetivo da redistribuição de esforços, aproxima-se de uma articulação, e dessa maneira os valores de $\alpha$ e $\gamma_{z}$ aumentam desproporcionalmente, ou seja, de uma maneira não-linear. Portanto, comprova-se que a redistribuição de esforços influencia diretamente na estabilidade de um edifício. 


\subsubsection{NTERAÇÃO SOLO-ESTRUTURA}

Quando a análise global da superestrutura (edifício) e a infraestrutura (fundação) são realizadas em conjunto, ou seja, considerando-se um corpo único e levando-se em consideração o solo em que a edificação está apoiada, tal análise é chamada de interação solo-estrutura.

$\mathrm{Na}$ atualidade ainda é comum considerar a análise da superestrutura separadamente da infraestrutura. Admitindo-se o edifício engastado no solo como se o este fosse um corpo extremamente rígido e que não sofra deformação, obtêm-se as reações nesses engastes e tais reações são repassadas para o engenheiro de fundações, para que ele tenha condições de realizar o projeto da infraestrutura. Porém, na realidade, o solo não se comporta dessa maneira. Ele não é um corpo indeformável, o que torna de grande importância a consideração da interação solo-estrutura, e assim levar em conta a deformabilidade da fundação. Mas esta análise não será considerada neste trabalho.

A interação solo-estrutura é uma análise complexa, sendo que Winkler, em 1867, foi o primeiro a representar o solo como um sistema de molas com resposta linear, representando de forma aproximada a citada interação.

Delalibera et al. (2005) fizeram um estudo da estabilidade global de edifícios considerando a deformabilidade da fundação e concluíram que essa deformabilidade afeta diretamente a estabilidade global. Isso ficou comprovado, pois os deslocamentos horizontais nos edifícios foram maiores e, em consequência, aumentaram os esforços de segunda ordem.

Um exemplo simples pode ser mostrado para comprovar como a consideração aproximada da deformabilidade do solo por meio de molas influencia na estabilidade global. Seja uma barra vertical apoiada sobre uma base indeformável e livre no topo, como mostrado na figura 4.8-(a), e uma barra vertical considerando-se a deformabilidade do solo por meio de uma mola, como mostrado na figura 4.8-(b). Serão admitidas as duas barras com seção retangular de $20 \mathrm{~cm} \times 40 \mathrm{~cm}$, sendo o lado de $40 \mathrm{~cm}$ na mesma direção da ação horizontal atuante, $E=25 \mathrm{GPa}$ e a constante da mola $K=10 \mathrm{MN} . \mathrm{m} / \mathrm{rad}$. 


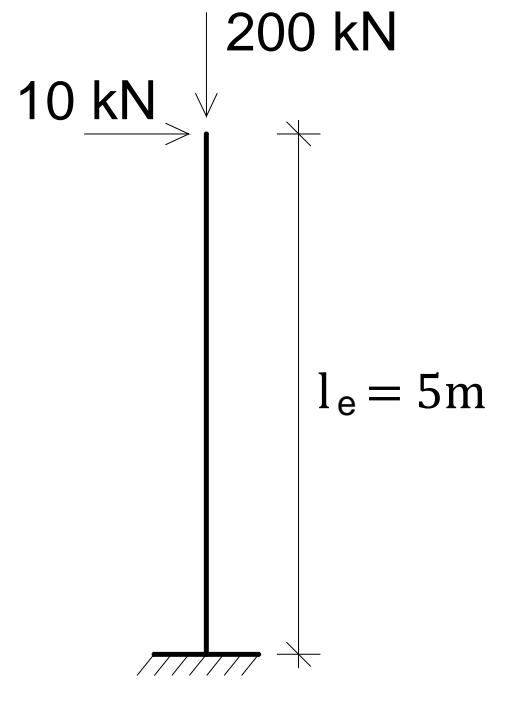

(a)

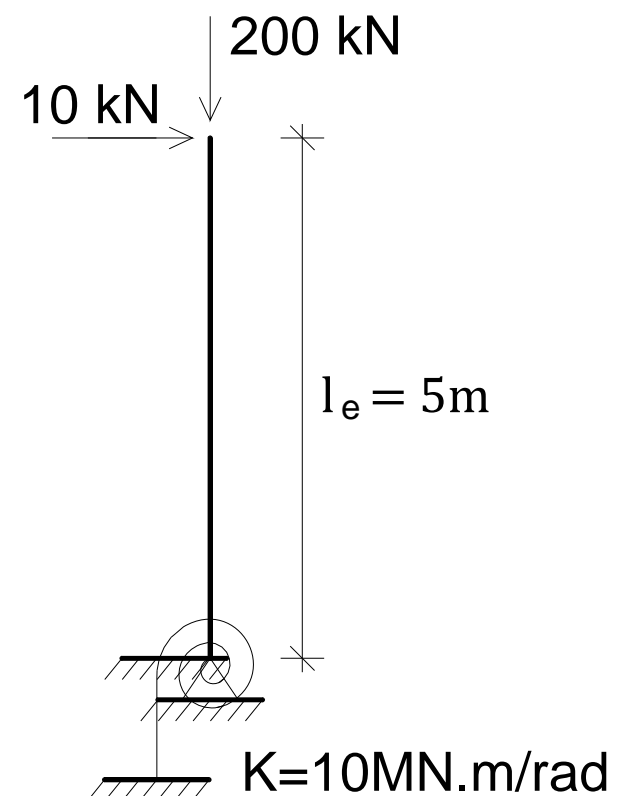

(b)

Figura 4.8. Barra vertical apoiada em base rígida e em base deformável.

O cálculo do deslocamento horizontal devido à ação horizontal (figura 4.9) na barra vertical apoiada em base rígida pode ser calculado pela mesma expressão já vista nos exemplos anteriores:

$$
\begin{aligned}
& u_{h, h}=\frac{F_{H, d} \cdot l_{e}^{3}}{3 \cdot E \cdot I} \\
& u_{h, h}=\frac{10 \cdot 1,4 \cdot 5^{3}}{3 \cdot 25 \cdot 10^{6} \cdot \frac{0,20 \cdot 0,40^{3}}{12}} \cong 0,0219 \\
& u_{h, h} \cong 0,022 \mathrm{~m}
\end{aligned}
$$

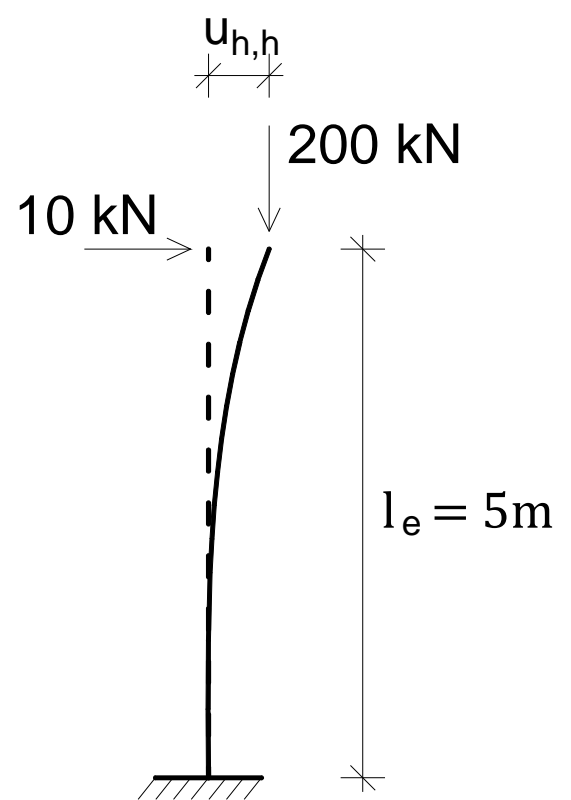

Figura 4.9. Deslocamento horizontal da barra apoiada em base rígida. 
Portanto o $\gamma_{z}$ dessa estrutura será:

$$
\begin{aligned}
& \gamma_{z}=\frac{1}{1-\frac{\Delta M_{t o t, d}}{M_{1, t o t, d}}} \\
& \gamma_{z}=\frac{1}{1-\frac{P_{d} \cdot u_{h, h}}{F_{H, d} \cdot l}} \\
& \gamma_{z}=\frac{1}{1-\frac{(200 \cdot 1,4) \cdot 0,022}{(10 \cdot 1,4) \cdot 5}}=\frac{1}{1-\frac{6,16}{70}} \\
& \gamma_{z} \cong 1,096
\end{aligned}
$$

O deslocamento horizontal devido à ação horizontal na barra apoiada em base deformável será o mesmo calculado para a barra apoiada em base rígida, somado a um deslocamento horizontal $\left(u_{h, \theta}\right)$ gerado pela deformabilidade da base, pois essa base sofre uma certa rotação $\theta$, como mostrado na figura 4.10.

Portando o deslocamento horizontal total $\left(\boldsymbol{u}_{\boldsymbol{h}, t}\right)$, mostrado na figura 4.11, pode ser calculado como indicado a seguir:

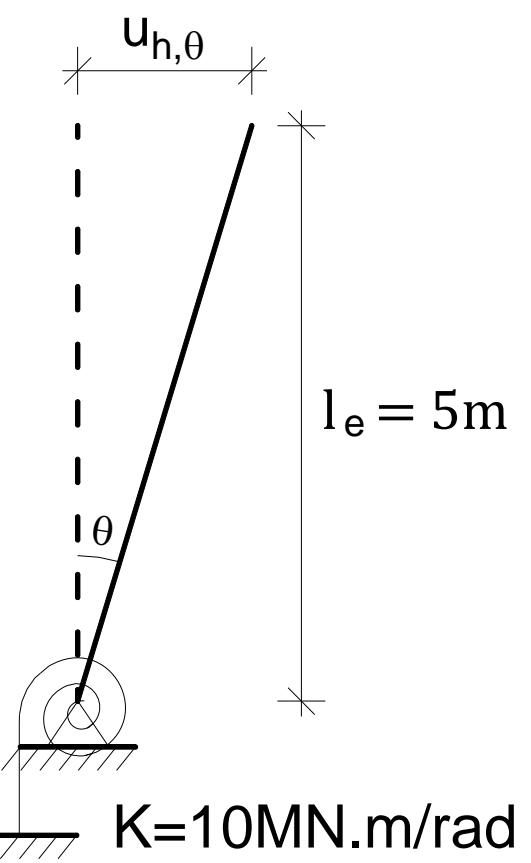

Figura 4.10. Deslocamento horizontal devido à rotação da base deformável. 


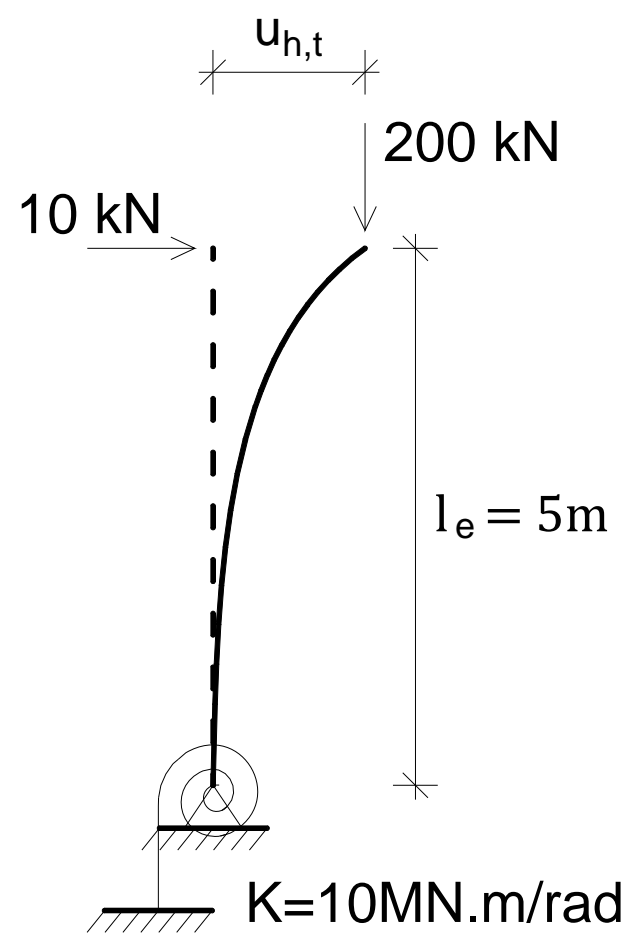

Figura 4.11. Deslocamento horizontal total

$$
\begin{aligned}
& u_{h, t}=u_{h, h}+u_{h, \theta} \\
& u_{h, t}=\frac{F_{H, d} \cdot l_{e}^{3}}{3 \cdot E \cdot I}+l_{e} \cdot \operatorname{tg} \theta \\
& \theta=\frac{\mathrm{M}}{\mathrm{K}}=\frac{F_{H, d} \cdot l_{e}}{\mathrm{~K}}=\frac{10 \cdot 1,4 \cdot 5}{10000}=\frac{70}{10000}=0,007
\end{aligned}
$$

Portanto:

$$
\begin{aligned}
& u_{h, t}=0,022+5 \cdot \operatorname{tg} 0,007 \\
& u_{h, t}=0,057 m
\end{aligned}
$$

O $\gamma_{z}$ dessa estrutura será:

$$
\gamma_{z}=\frac{1}{1-\frac{\Delta M_{t o t, d}}{M_{1, t o t, d}}}
$$$$
\gamma_{z}=\frac{1}{1-\frac{P_{d} \cdot u_{h, \mathrm{t}}}{F_{H, d} \cdot l}}
$$

$$
\gamma_{z}=\frac{1}{1-\frac{(200 \cdot 1,4) \cdot 0,057}{(10 \cdot 1,4) \cdot 5}}=\frac{1}{1-\frac{15,96}{70}}
$$

$\gamma_{z} \cong 1,295$ 
Para a barra apoiada sobre base rígida obteve-se $\gamma_{z} \cong 1,096$, e para a apoiada sobre base deformável, $\gamma_{z} \cong 1,295$. Portanto percebe-se a influência da interação solo-estrutura na estabilidade global.

\subsubsection{MODELO ESTRUTURAL ADOTADO}

O modelo estrutural também influencia na estabilidade global do edifício. Antes de mostrar um exemplo, será feito um resumo dos principais modelos estruturais existentes na atualidade, para o cálculo de um pavimento no sistema laje/viga/pilar, mostrando as principais diferenças entre eles quanto à montagem e aos resultados obtidos. São eles: lajes isoladas e vigas contínuas, lajes isoladas e grelha, lajes e vigas como grelha equivalente, lajes e vigas pelo MEF.

Também será comentado sobre o modelo de pórtico tridimensional, utilizado para o cálculo da estrutura como um todo.

\subsubsection{Lajes isoladas e vigas contínuas}

Neste modelo cada viga é tratada de maneira independente das demais. Uma viga pode se apoiar sobre pilar ou sobre outra viga, sendo que a mais rígida serve de apoio para a menos rígida.

No cálculo das reações de apoio das lajes, essas reações são calculadas separadamente, considerando o processo das áreas baseado na teoria das charneiras plásticas, com valor aproximado da inclinação das charneiras em relação aos apoios adjacentes a cada canto. Tais reações são admitidas uniformemente distribuídas sobre as vigas que servem de apoio. Este é um modelo simplificado e deve ser evitado sempre que possível, devido às imprecisões que pode produzir.

Por exemplo, uma dessas imprecisões é relativa ao cálculo dos esforços nas lajes, pois se considera que seus apoios são suficientemente rígidos quanto ao deslocamento vertical, o que não é verdade para o caso das vigas, por exemplo, pois elas também se deformam, assim como as lajes. A distribuição de esforços entre os apoios também não condiz com a realidade. Por exemplo, em uma laje retangular apoiada em vigas com diferentes rigidezes, a distribuição de esforços nesses elementos não fica correta. 


\subsubsection{Lajes isoladas e grelha}

Neste modelo cada viga não é mais tratada de maneira independente das demais. Elas são consideradas como uma grelha, ou seja, como um conjunto. Para as reações de apoio das lajes valem todas as observações relativas ao modelo anterior.

\subsubsection{Lajes e vigas consideradas como grelha equivalente}

Neste modelo todas as vigas e lajes do pavimento são tratadas como um conjunto. As vigas são representadas por barras e as lajes por um conjunto de barras. A ligação entre essas barras é chamada de nó, e ao conjunto de nós e barras denomina-se malha. Para que a grelha se comporte de maneira semelhante a uma laje, é necessário dispor a malha de uma maneira apropriada, bem como conferir a cada barra propriedades adequadas.

As forças atuantes nas lajes são lançadas como cargas pontuais nas vigas, e se tem um comportamento mais realista, pois aqui a distribuição de esforços para o exemplo da laje retangular é feito de maneira mais condizente com a realidade.

Os deslocamentos obtidos, de um modo geral, são menores que os relativos aos modelos anteriores, pois aqui se conta com a rigidez da laje, e também a laje pode se apoiar em vigas ou diretamente nos pilares, passando parte do carregamento direto para esses pilares, diferentemente dos outros modelos, onde as lajes transferiam carregamento apenas para as vigas.

\subsubsection{Lajes e vigas pelo MEF}

Neste modelo todas as vigas e lajes do pavimento são tratadas também como um conjunto, porém as vigas são representadas por barras e as lajes por placas. Cada laje é subdividida em diversas placas, e cada placa pode ter um formato qualquer, usualmente triangular ou quadrangular.

As forças atuantes nas lajes são lançadas como cargas distribuídas nas vigas. Este modelo gera resultados parecidos com os do modelo de grelha equivalente, pois aqui também as lajes fazem parte do conjunto e podem se apoiar em vigas ou diretamente nos pilares. 
As cargas recebidas pelas lajes são transferidas preferencialmente para as regiões mais rígidas, tornando assim a distribuição de esforços mais condizentes com a realidade.

\subsubsection{Pórtico tridimensional}

Há também os modelos globais do edifício, ou seja, modelos estruturais para a consideração do pórtico tridimensional que é formado por vigas e pilares.

As lajes são consideradas como diafragma rígido, ou seja, um elemento extremamente rígido no seu plano, compatibilizando os deslocamentos em todos os nós do pavimento. Esse efeito, no modelo IV do Sistema TQS, é simulado de forma aproximada aumentando-se a rigidez lateral das vigas.

Para tornar a análise mais próxima do real, pode-se utilizar a flexibilização das ligações viga-pilar, ou seja, fazer a análise da ligação viga-pilar por meio de uma mola. Por isso o modelo IV, presente no Sistema CAD/TQS, é chamado de Modelo Integrado e Flexibilizado de Pórtico Espacial.

Na próxima versão do Sistema, a versão 16, haverá um novo modelo disponível para a estrutura do edifício, o modelo VI, chamado de Modelo Flexibilizado com Lajes como Subestruturas. Diferentemente do modelo IV, no modelo VI as lajes farão parte do modelo de pórtico tridimensional.

De acordo com a TQS Informática (2010-a), atualmente no modelo IV, da versão 15.5 , são criados modelos independentes de cada um dos pavimentos do edifício, que são utilizados para o dimensionamento das lajes.

Os esforços nas barras das lajes que chegam às vigas são transferidos para o modelo de pórtico espacial, onde o efeito de diafragma rígido é levado em conta de forma aproximada, como já foi apresentado.

Através desse modelo são feitas as análises globais do edifício e o dimensionamento de vigas e pilares. Vale ressaltar que a rigidez das lajes à flexão é totalmente desprezada, sendo restrita sua participação ao efeito de diafragma rígido.

No modelo VI, da versão 16, existirá um modelo único, onde as lajes serão discretizadas e farão parte do pórtico tridimensional, calculadas com seis graus de liberdade, ou seja, toda a estrutura será calculada por um único pórtico tridimensional. 
Esse modelo será o mais indicado para avaliar edificações com lajes sem vigas, pois essas lajes passarão a participar na análise da estabilidade global com o coeficiente de não-linearidade física representada de forma aproximada pelo valor 0,3, de acordo com a NBR 6118:2003.

Há muitas outras vantagens com a utilização desse novo modelo, presente na versão 16, que podem ser encontradas em TQS Informática (2010-a) e TQS Informática (2010-b).

Uma observação relacionada à análise estrutural não pode deixar de ser comentada: quanto mais rígido é o elemento estrutural, mais carga ele absorve. Um exemplo simples para comprovar isso pode ser observado no item seguinte.

\subsubsection{Exemplos}

Suponha-se uma viga 01 biengastada, com seção transversal constante de $20 \mathrm{~cm}$ por $50 \mathrm{~cm}$, submetida a uma ação uniformemente distribuída de $40 \mathrm{kN} / \mathrm{m}$, para a qual resulta o diagrama de momentos fletores mostrado na figura 4.12. Ressalta-se que o conceito a ser visto neste exemplo é válido para as estruturas hiperestáticas. A viga biapoiada, por exemplo, constitui uma exceção.

\section{Viga 01}

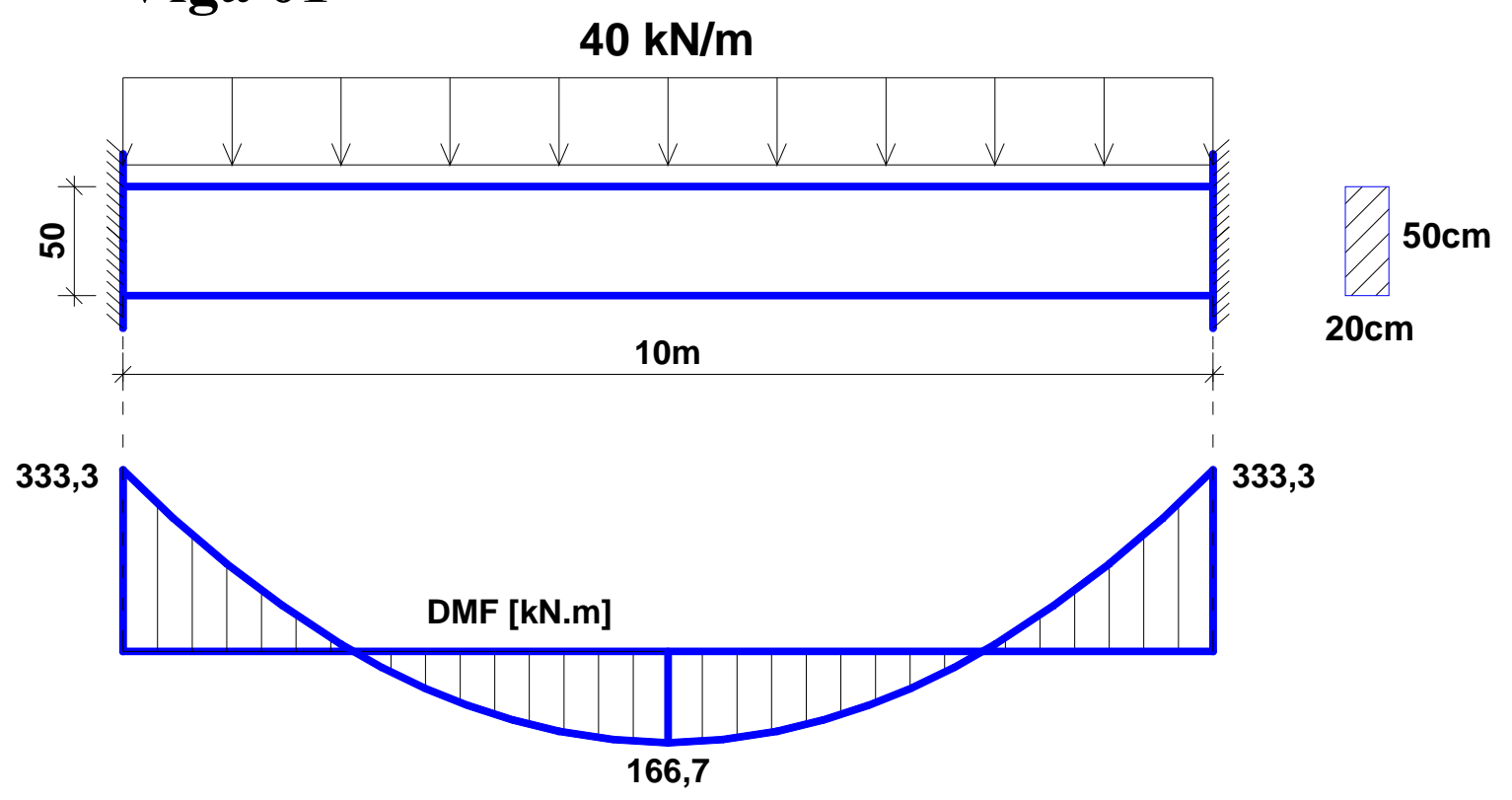

Figura 4.12. Viga com seção transversal constante. 
Se a seção transversal for gradualmente reduzida do centro para as extremidades, até $20 \mathrm{~cm}$ por $20 \mathrm{~cm}$, a rigidez diminuirá no sentido das extremidades, ou seja, a região central irá se tornar a maior seção transversal ao longo da viga, possuindo maior rigidez.

Portanto a região central irá absorver mais esforços, com o momento fletor aumentando de $166,7 \mathrm{kN} . \mathrm{m}$ para $276,8 \mathrm{kN} . \mathrm{m}$, e o momento nas extremidades diminuindo de $333,3 \mathrm{kN}$.m para $223,2 \mathrm{kN} . \mathrm{m}$. O novo diagrama de momentos fletores pode ser visto na figura 4.13.

Agora fazendo o inverso, ou seja, reduzindo a seção transversal das extremidades para o centro, as regiões de maior rigidez serão as extremidades.

Então o momento o fletor na região central irá diminuir, passando de 166,7 kN.m para 75,7 kN.m, e o momento nas extremidades irá aumentar, passando de $333,3 \mathrm{kN} . \mathrm{m}$ para $424,3 \mathrm{kN} . \mathrm{m}$. O novo diagrama pode ser visualizado na figura 4.14.

Portanto, este exemplo mostra de forma clara e simples, que elementos estruturais que possuem maior rigidez absorvem mais esforços.

\section{Viga 02}

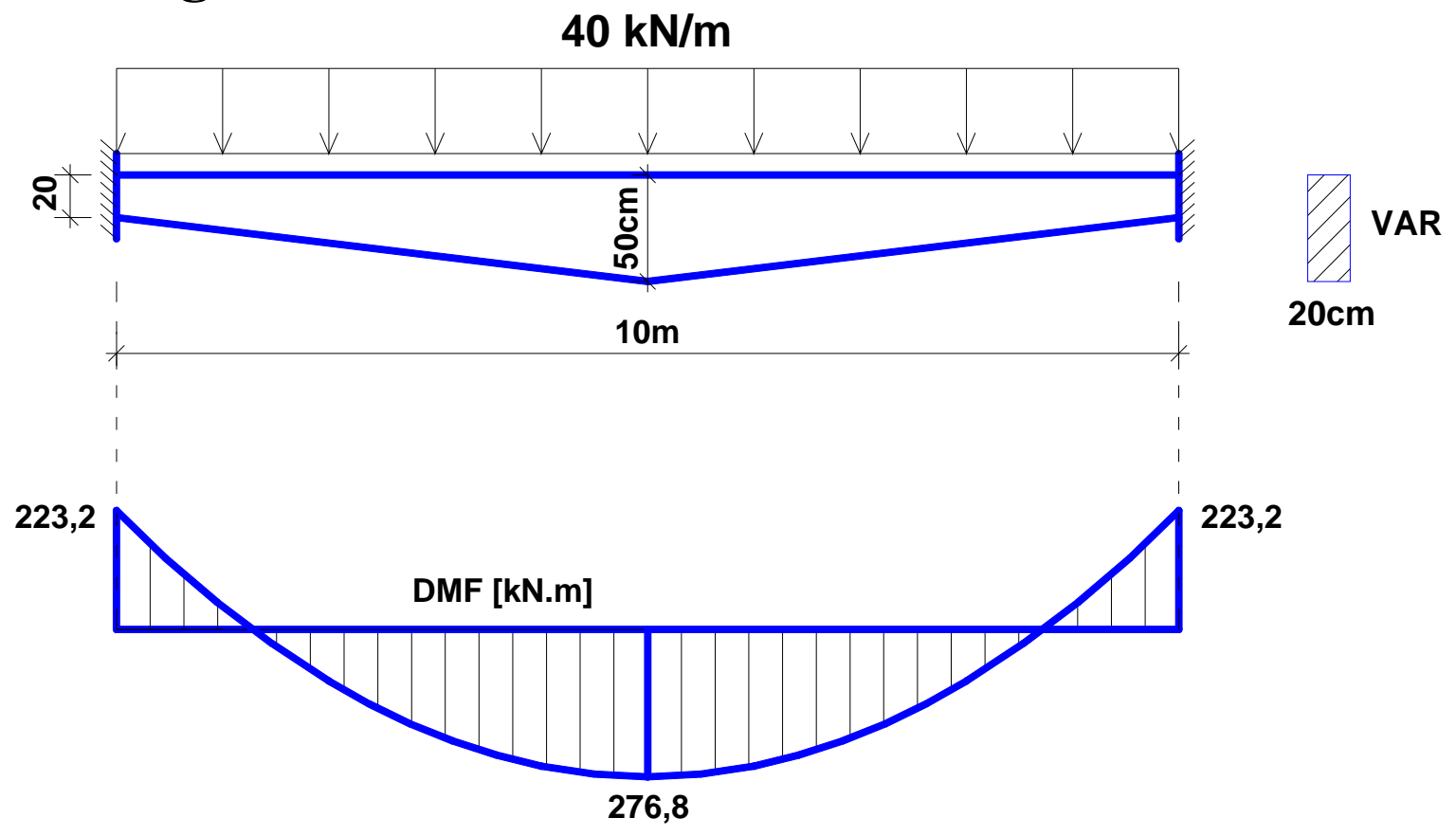

Figura 4.13. Viga com altura diminuindo do centro para as extremidades. 


\section{Viga 03}

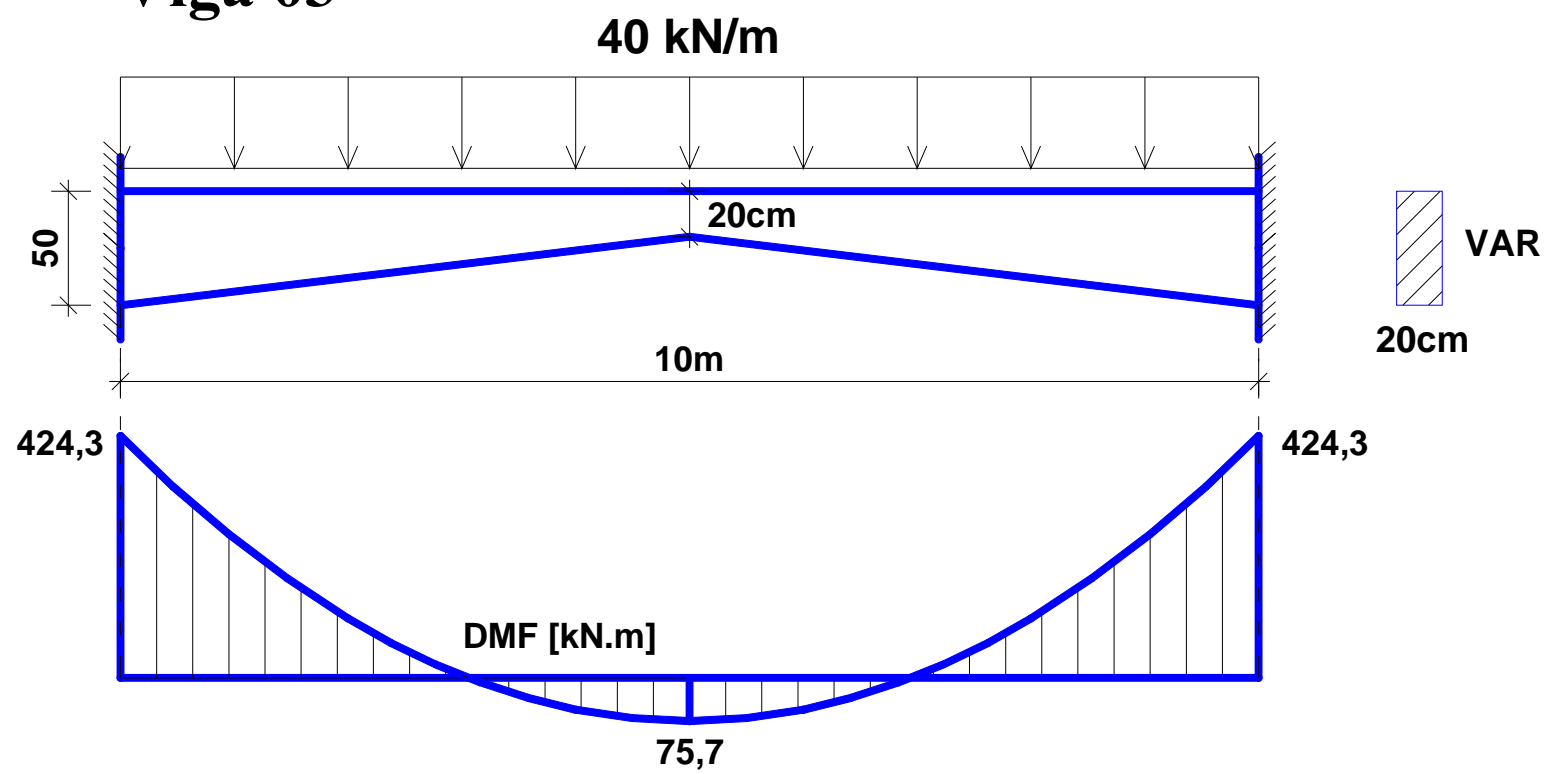

Figura 4.14. Viga com altura aumentando do centro para as extremidades.

Apresenta-se a seguir outro exemplo em que se verifica que a mudança no modelo estrutural influencia diretamente na estabilidade global do edifício.

A TQS Informática (2002) analisa a estabilidade global de um edifício hipotético considerando 10 e 15 pavimentos, variando a rigidez das ligações viga-pilar, considerando-as rígidas e semi-rígidas ou flexibilizadas (representadas por molas). A forma do pavimento do edifício analisado é mostrada nas figuras 4.15 e 4.16, onde se tem os pavimentos com nós rígidos e nós flexibilizados, respectivamente.

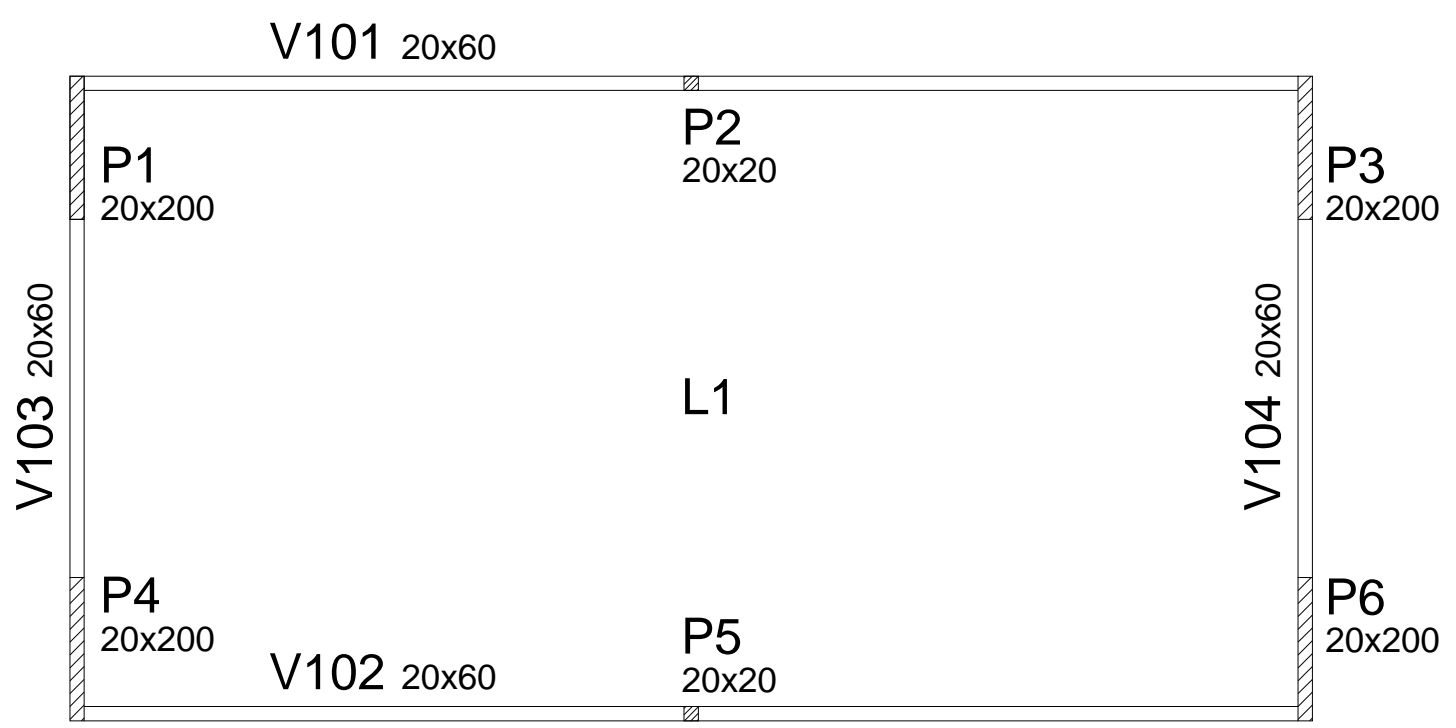

Figura 4.15. Forma do pavimento tipo com nós rígidos. Adaptada de TQS Informática (2002). 


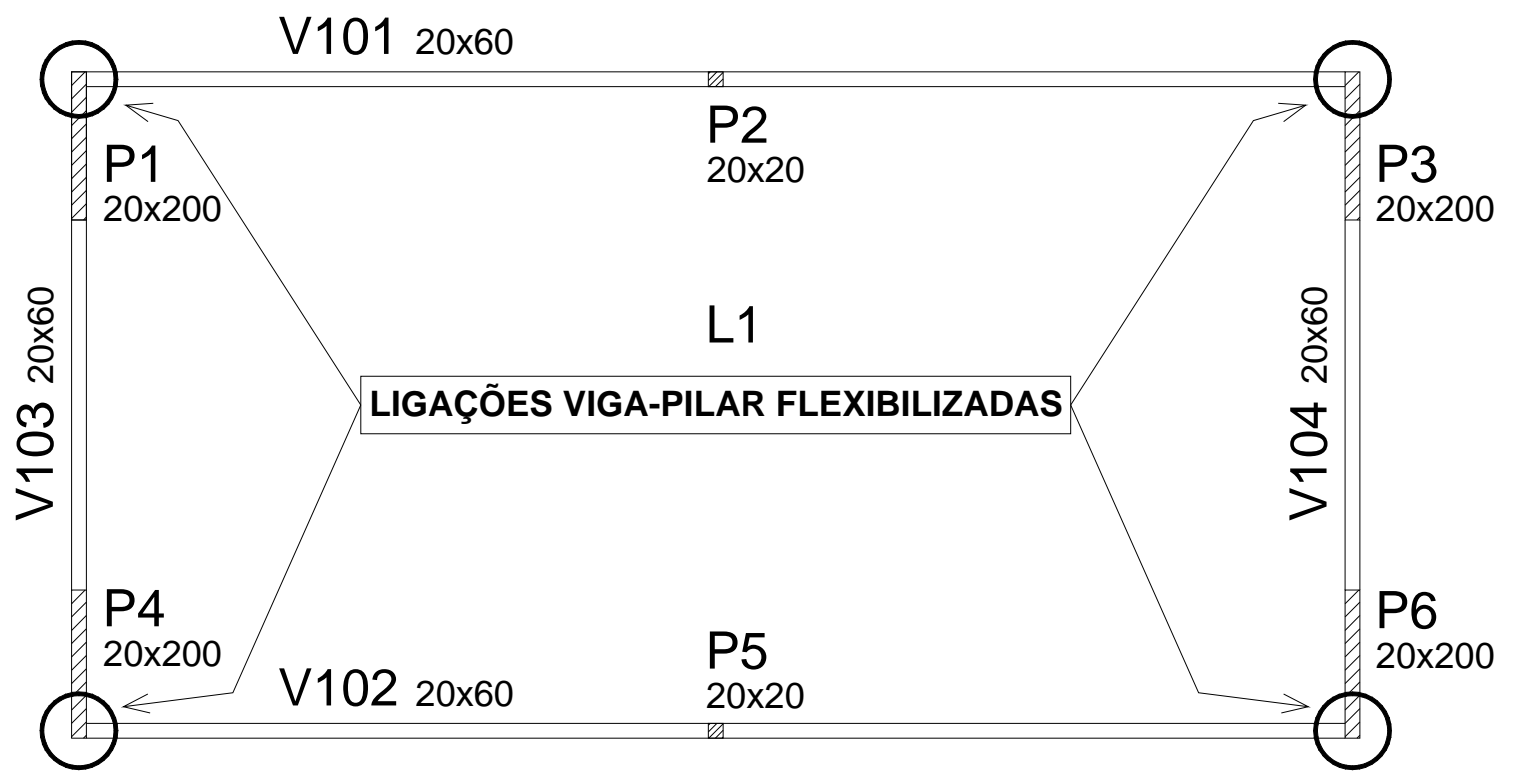

Figura 4.16. Forma do pavimento tipo com nós flexibilizados. Adaptada de TQS Informática (2002).

Considerando-se as ligações viga-pilar flexibilizadas, por meio de molas, no pórtico tridimensional, sabe-se que o comportamento da estrutura está sendo representado de uma maneira mais realista, e, portanto, é comum que cresçam os deslocamentos horizontais gerados pelas ações horizontais, aumentando, consequentemente, o valor de $\gamma_{z}$ nas direções de $0^{\circ}$ e $180^{\circ}$. Os resultados obtidos para a análise realizada estão mostrados na tabela 4.2.

Tabela 4.2. Comparação entre o pórtico com nós rígidos e com nós flexibilizados.

\begin{tabular}{|c|c|c|c|c|}
\hline \multirow{2}{*}{ N. de Pavimentos } & \multicolumn{2}{|c|}{ Nós Rígidos } & \multicolumn{2}{c|}{ Nós Flexibilizados } \\
\cline { 2 - 5 } & Gama-Z & Classificação & Gama-Z & Classificação \\
\hline 10 & 1,071 & Nós fixos & 1,150 & Nós móveis \\
\hline 15 & 1,115 & Nós móveis & 1,266 & Nós móveis \\
\hline
\end{tabular}

De acordo com essa tabela, analisando-se o edifício com 10 pavimentos e as ligações viga-pilar rígidas, obteve-se $\gamma_{z}=1,071 \mathrm{e}$, portanto, o edifício é classificado como de nós fixos. 
Para o mesmo edifício de 10 pavimentos, considerando-se as ligações flexibilizadas, obteve-se $\gamma_{z}=1,150$, sendo ele classificado como de nós móveis e, portanto, necessária a consideração dos efeitos de segunda ordem.

Já para o edifício com 15 pavimentos e ligações rígidas, obteve-se $\gamma_{z}=1,115$, e para ligações flexibilizadas, $\gamma_{z}=1,266$. Neste caso os dois valores de $\gamma_{z}$ classificam a estrutura como de nós móveis, e a com nós flexibilizadas irá gerar maiores esforços de segunda ordem.

Os valores dos coeficientes elásticos considerados para as molas fazem a ligação viga-pilar ser representada com mais exatidão.

É fácil perceber intuitivamente que a seção (rigidez) dos pilares de canto, no exemplo mostrado, que efetivamente colaboram para impedir a rotação das vigas V101 e V102, é muito menor que a sua largura plena, ou seja, é muito menor que os $200 \mathrm{~cm}$, pois as vigas se apoiam no canto desses pilares.

Para ficar mais claro, pode-se segurar uma folha de papel A4 na posição vertical, com o lado maior apoiado no plano horizontal e o lado menor no plano vertical. Em seguida, aperta-se com o dedo no canto superior da folha, como mostrado com a seta na figura 4.17. Pergunta-se: todo o comprimento horizontal de $297 \mathrm{~mm}$ da folha se curva? A resposta é não.

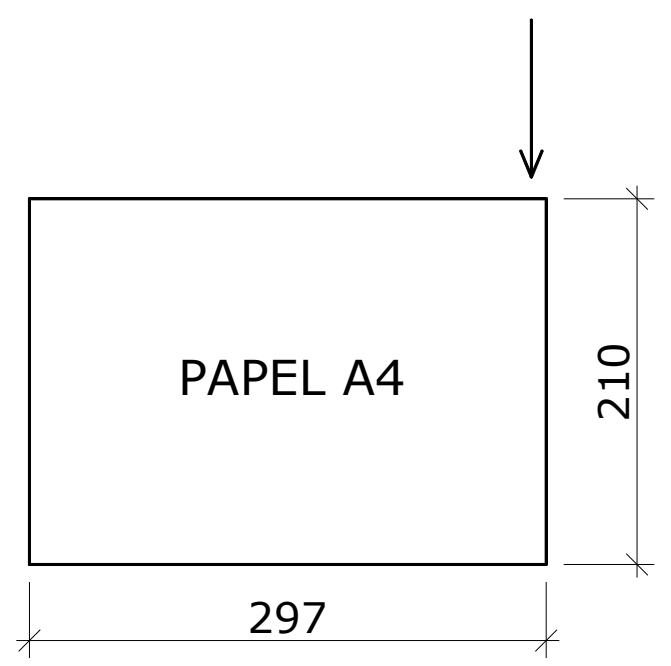

Figura 4.17. Papel A4 (dimensões em mm)

Portanto, com este exemplo, pode-se verificar que a consideração da flexibilização das ligações viga-pilar torna bem mais realista a análise do modelo de pórtico tridimensional. 


\section{AÇÕES ATUANTES NA ESTRUTURA}

As ações atuantes na estrutura se resumem basicamente a dois tipos: horizontais e verticais.

Neste capitulo serão estudadas as ações horizontais oriundas do desaprumo global e as ações de vento.

Também serão estudadas as ações verticais relativas ao peso próprio, as demais ações permanentes e os valores mínimos das ações variáveis, que são recomendados pela NBR 6120:1980 - Cargas para o cálculo de estruturas de edificações.

\subsection{AÇÕES DEVI DAS ÀS I MPERFEI ÇÕES GEOMÉTRI CAS GLOBAI S}

Todo edifício com estrutura de concreto armado está sujeito a imperfeições: na posição e na forma dos eixos dos elementos estruturais, na forma e nas dimensões da seção transversal, na distribuição da armadura, entre outras.

Muitas dessas imperfeições estão cobertas pelos coeficientes de segurança, mas a do eixo das peças, não.

Por isso, ela deve ser obrigatoriamente considerada pelo engenheiro de estruturas nos seus projetos, pois tem efeitos significativos sobre a estabilidade da edificação (IBRACON, 2007).

A análise dessas imperfeições é algo bastante complexo, pois não há como saber a magnitude dessas "falhas" que vão ocorrer durante a construção. Vale ressaltar que tais imperfeições têm influência em toda a estrutura, porém nos pilares essa influência é muito mais significativa. Por isso os pilares devem ser dimensionados adequadamente para resistir aos esforços adicionais gerados por essas imperfeições (KIMURA, 2010). 
No item 11.3.3.4 "Imperfeições geométricas" da NBR 6118:2003, está escrito o seguinte: "Na verificação do estado limite último das estruturas reticuladas, devem ser consideradas as imperfeições geométricas do eixo dos elementos estruturais da estrutura descarregada. Essas imperfeições podem ser divididas em dois grupos: imperfeições globais e imperfeições locais".

Aqui será feita somente uma análise das imperfeições globais, pois as locais estão relacionadas ao cálculo de um lance isolado do pilar, e as globais, ao edifício como um todo, e é este o foco deste trabalho.

No item 11.3.3.4.1 "Imperfeições globais" da citada Norma, tem-se que na análise global das estruturas reticuladas, sejam elas contraventadas ou não, deve ser considerado um desaprumo dos elementos verticais, ou seja, deve ser considerada para os elementos verticais uma inclinação com um ângulo $\theta_{a}$ em radianos, como mostra a figura 5.1 .

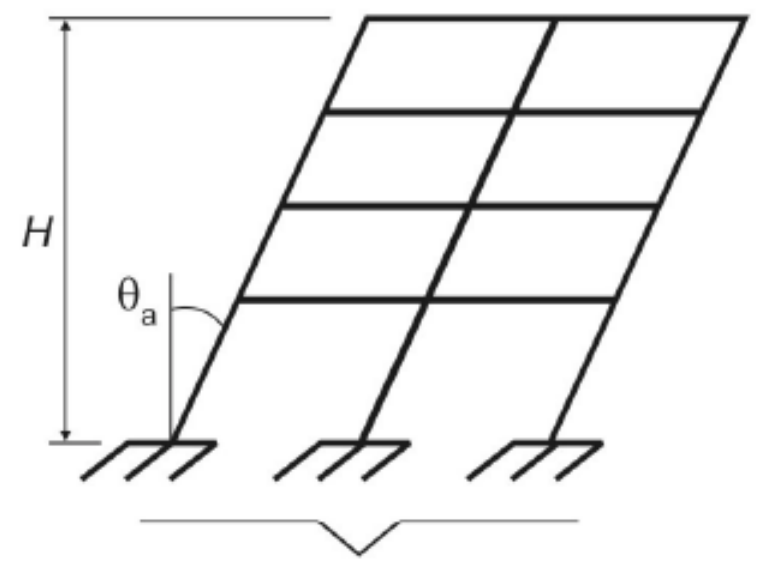

$$
\begin{aligned}
\theta_{1} & =\frac{1}{100 \sqrt{H}} \\
\theta_{a} & =\theta_{1} \sqrt{\frac{1+1 / n}{2}}
\end{aligned}
$$

\section{$n$ prumadas de pilares}

$\theta_{1 \min }=1 / 400$ para estruturas de nós fixos;

$\theta_{1 \min }=1 / 300$ para estruturas de nós móveis e imperfeições locais;

$\theta_{1 \text { máx }}=1 / 200 ;$

$H$ é a altura total da edificação, em metros.

Figura 5.1. Imperfeições geométricas globais. Fonte: NBR 6118:2003.

Segundo a NBR 6118:2003, o desaprumo não deve ser superposto ao carregamento de vento. Entre as ações devidas ao desaprumo e ao vento, deve ser considerada apenas a mais desfavorável, que pode ser definida como a que provoca o maior momento da base da construção. 
Pode-se dizer, de uma maneira geral, que o desaprumo global somente será mais desfavorável que o vento em edificações baixas submetidas a cargas verticais elevadas. Em edifícios altos, normalmente o vento se torna o caso mais desfavorável (KIMURA, 2010).

Segundo o IBRACON (2007), a imperfeição geométrica global pode ser substituída por conjuntos de ações externas autoequilibradas equivalentes, como mostra a figura 5.2 .

\section{Comentários Técnicos NB-1}

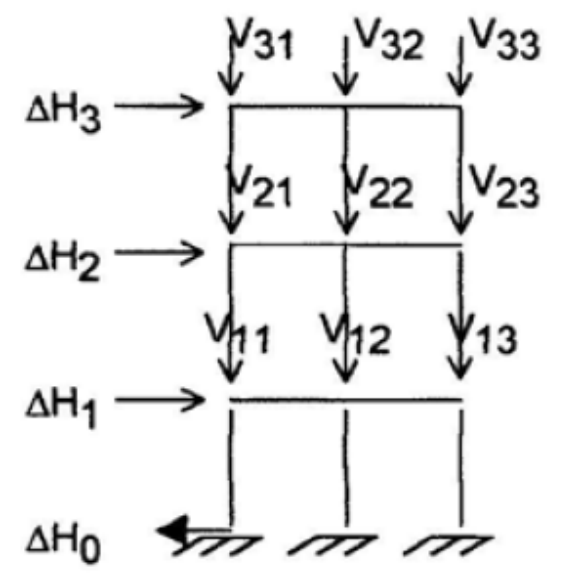

$$
\begin{aligned}
\Delta H_{i} & =\sum_{j=1}^{n} V_{i j} \theta_{a} \\
\Delta H_{0} & =\sum_{i=1}^{m} \Delta H_{i} \\
V_{i j}= & \text { carga vertical aplicada pelo andar } i \text { ao pilar } j \\
& \text { ou pela fundação }(i=0)
\end{aligned}
$$

Figura 5.2. Desaprumo global. Fonte: IBRACON (2007).

Para que isso fique mais claro, veja no exemplo da figura 5.3 como achar essa expressão para a ação horizontal equivalente $\Delta \mathrm{H}_{\mathrm{i}}$, mostrada na figura 5.2.

Para simular uma edificação submetida a um carregamento vertical, na figura 5.3-(a) tem-se uma barra vertical engastada na base e livre no topo, submetida a um carregamento vertical V. Ao considerar o ângulo $\theta_{a}$ para levar em conta as imperfeições geométricas globais, a barra vertical fica inclinada, como mostra a figura 5.3-(b).

Após a consideração do ângulo $\theta_{a}$, o ponto de aplicação da carga $V$ fica deslocado horizontalmente de um valor "u", como também mostra a figura 5.3-(b). Considerando-se um triangulo retângulo, esse valor "u" pode ser obtido da seguinte maneira:

$$
\begin{aligned}
& \operatorname{tg} \theta_{a}=\frac{u}{L} \\
& u=\operatorname{tg} \theta_{a} \cdot L
\end{aligned}
$$




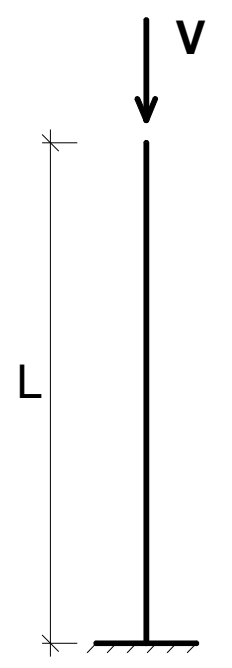

(a)

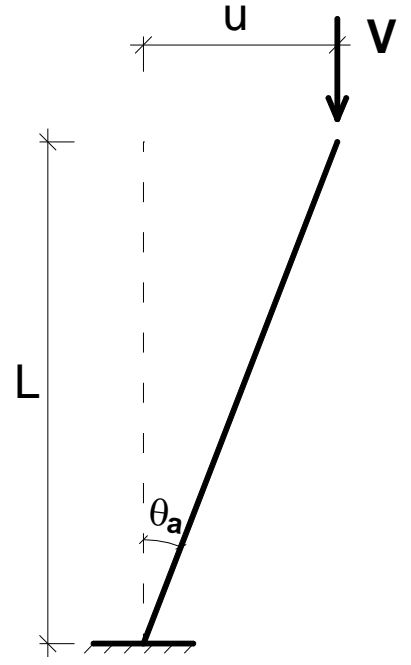

(b)

Figura 5.3. Exemplo sobre desaprumo global.

Para ângulos pequenos, que é o caso, a tangente do ângulo em radianos é aproximadamente igual ao próprio ângulo, portanto:

$$
\begin{aligned}
& \operatorname{tg} \theta_{a} \cong \theta_{a} \\
& u=\theta_{a} \cdot L
\end{aligned}
$$

Sabe-se que com o deslocamento na horizontal do ponto de aplicação da ação vertical, tal ação gera um momento na base igual a $M=V \cdot u$. Então pergunta-se: qual o valor da ação horizontal $H$, mostrada na figura 5.4, que gera o mesmo momento na base que foi gerado por $V$ ?

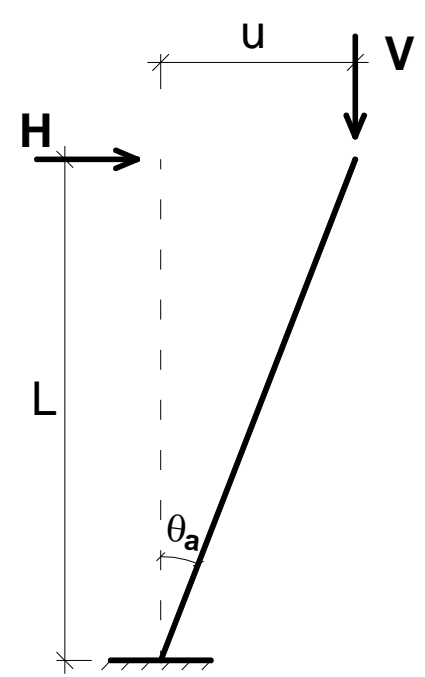

Figura 5.4. Ação horizontal equivalente ao efeito do desaprumo. 
Para responder à pergunta anterior, basta resolver a seguinte equação:

$$
\begin{aligned}
& H \cdot L=V \cdot u \\
& H \cdot L=V \cdot \theta_{a} \cdot L \\
& H \cdot t=V \cdot \theta_{a} \cdot t \\
& H=V \cdot \theta_{a}
\end{aligned}
$$

Portanto, comprova-se que a ação horizontal equivalente é igual à ação vertical multiplicada pelo ângulo $\theta_{a}$ em radianos, como mostra a equação na figura 5.2 .

\subsection{AÇÃO DO VENTO NAS EDI FICAÇÕES}

A ação do vento em edificações depende de dois aspectos: meteorológicos e aerodinâmicos. Os aspectos meteorológicos serão responsáveis pela velocidade do vento a considerar no projeto da estrutura de uma dada edificação. Ela é avaliada a partir de considerações como: local da edificação, tipo de terreno, altura da edificação, rugosidade do terreno e tipo de ocupação.

Os aspectos aerodinâmicos estão relacionados com a análise do vento levando em conta a forma da edificação, pois sabe-se que o vento, ao incidir sobre uma edificação, terá um comportamento diferente em função da sua forma (GONÇALVES, 2007).

\subsubsection{DETERMI NAÇÃO DA VELOCI DADE DO VENTO}

Primeiramente, não se pode esquecer que a velocidade do vento é diferente para cada região do planeta. A NBR 6123:1988 define uma velocidade básica do vento, $V_{0}$, que varia de acordo com a região do Brasil que está sendo considerada. A velocidade básica do vento é a velocidade de uma rajada de três segundos, probabilidade de $63 \%$ de ser excedida pelo menos uma vez em 50 anos, à altura de $10 \mathrm{~m}$ acima do terreno, em campo aberto e sem obstruções.

A partir da velocidade básica do vento, é possível determinar a velocidade com que ele incidirá numa determinada edificação, chamada de velocidade característica $V_{k}$. 
Essa velocidade característica deverá considerar os aspectos particulares, entre os quais: topografia do local, rugosidade do terreno, altura da edificação, suas dimensões, tipo de ocupação e risco de vida.

Assim, a velocidade característica pode ser obtida pela seguinte equação:

$V_{k}=V_{0} \cdot S_{1} \cdot S_{2} \cdot S_{3}$

$V_{0}$ é a velocidade básica do vento;

$S_{1}$ é um fator topográfico;

$S_{2}$ é um fator relativo à rugosidade do terreno e às dimensões da edificação;

$S_{3}$ é um fator estatístico.

A seguir será mostrado como podem ser obtidos os fatores $S_{1}, S_{2}$ e $S_{3}$.

\subsubsection{Fator topográfico $-S_{1}$}

O fator topográfico considera a variação do relevo do terreno onde será construída a edificação.

A Norma Brasileira NBR 6123:1988 considera basicamente as três situações indicadas a seguir.

$>$ Terreno plano ou pouco ondulado: $S_{1}=1,0$.

> Para talude e morros, o valor de $S_{1}$ é obtido a partir do ângulo de inclinação $\theta$, como mostrado na figura 5.5.

No ponto $\mathrm{B}$, valem as seguintes equações para determinação de $S_{1}$ :

$\theta \leq 3^{\circ} \quad \rightarrow \quad S_{1}(z)=1,0$

$6^{\circ} \leq \theta \leq 17^{\circ} \rightarrow S_{1}(z)=1,0+\left(2,5-\frac{z}{d}\right) \cdot \operatorname{tg}\left(\theta-3^{\circ}\right) \geq 1$

$\theta \geq 45^{\circ} \quad \rightarrow \quad S_{1}(z)=1,0+\left(2,5-\frac{z}{d}\right) \cdot 0,31 \geq 1$

Vales profundos protegidos de ventos de qualquer direção: $S_{1}=0,9$. 


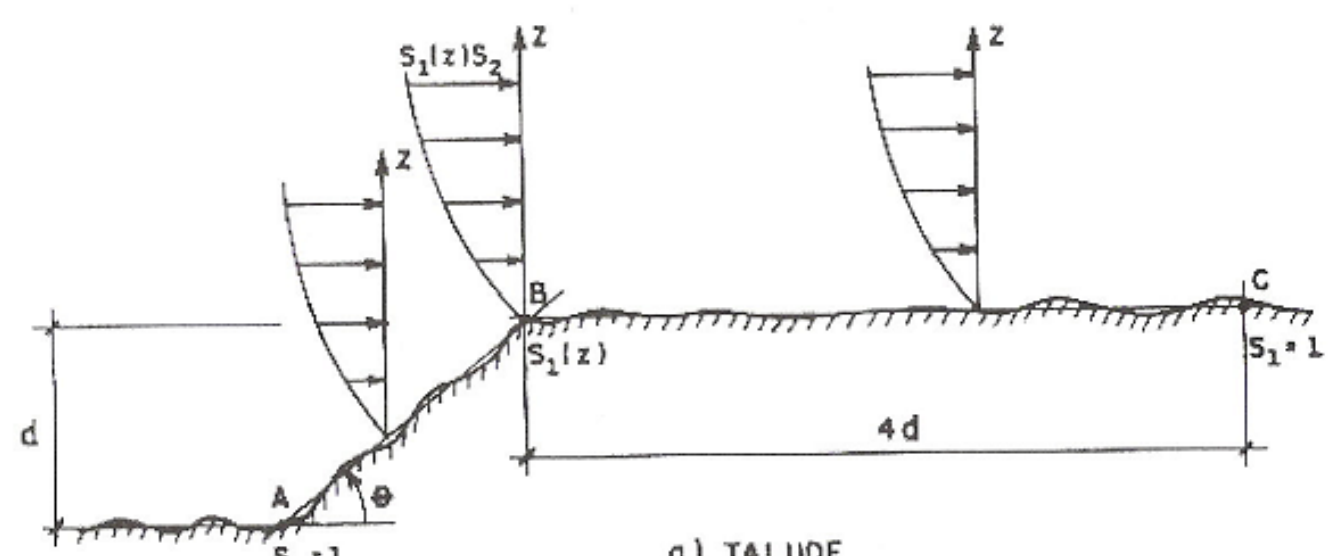

a) TALUDE

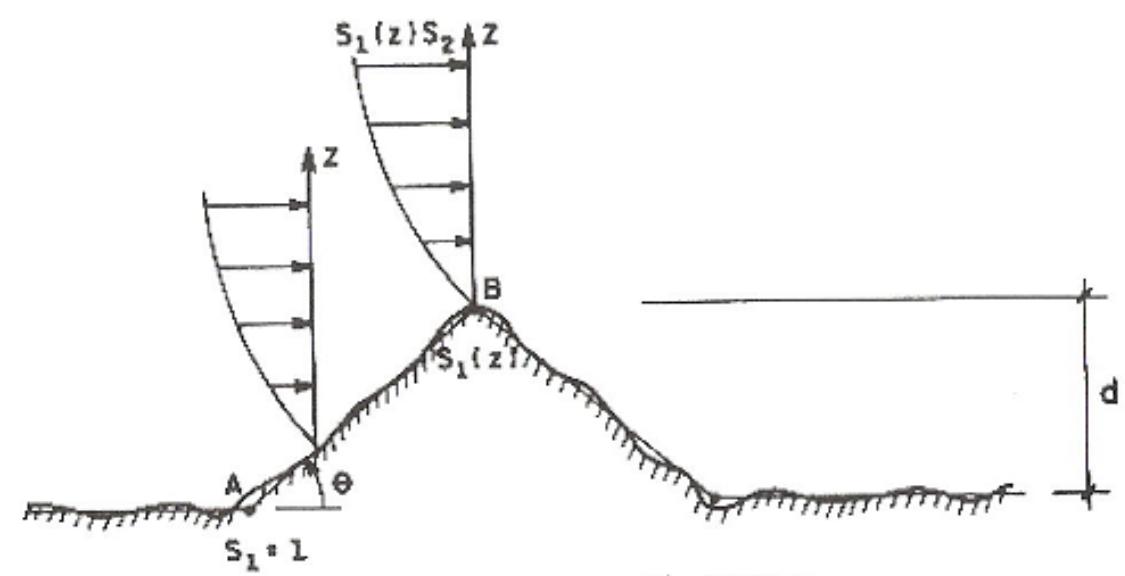

b) MORRO

Figura 5.5. Fator topográfico $S_{1}$. Fonte: GONÇALVES (2007).

\subsubsection{Fator $S_{2}$}

O fator $S_{2}$ considera o efeito combinado da rugosidade do terreno, da variação da velocidade com a altura do terreno e das dimensões da edificação. $A$ rugosidade do terreno está diretamente associada à velocidade do vento quando há presença de obstáculos naturais ou artificiais.

A NBR 6123:1988 estabelece cinco categorias de terreno, em função de sua rugosidade:

CATEGORI A I: Superfícies lisas de grandes dimensões, com mais de 5 km de extensão, medida na direção e sentido do vento incidente. Exemplos: mar calmo, lagos, rios e pântanos sem vegetação. 
> CATEGORIA II: Terrenos abertos em nível ou aproximadamente em nível, com poucos obstáculos isolados, tais como árvores e edificações baixas. A cota média do topo dos obstáculos é considerada igual ou inferior a um metro. Exemplos: zonas costeiras planas, pântanos com vegetação rala, campos de aviação, pradarias, charnecas e fazendas sem sebes ou muros.

CATEGORIA III: Terrenos planos ou ondulados com obstáculos, tais como sebes e muros, poucos quebra-ventos de árvores, edificações baixas e esparsas. A cota média do topo dos obstáculos é considerada igual a três metros. Exemplos: granjas e casas de campo, com exceção das partes com matos, fazenda com sebes e/ou muros, subúrbios a considerável distância do centro, com casas baixas e esparsas.

CATEGORIA IV: Terrenos cobertos por obstáculos numerosos, pouco espaçados e situados em zonas florestais, industriais ou urbanizadas. A cota média do topo dos obstáculos é considerada igual a dez metros e também inclui zonas com obstáculos maiores e que ainda não possam ser considerados na categoria V. Exemplos: zonas de parques e bosques com muitas árvores, cidades pequenas e seus arredores, subúrbios densamente construídos de grandes cidades, áreas industriais plena ou parcialmente desenvolvidas.

> CATEGORIA V: Terrenos cobertos por obstáculos numerosos, grandes, altos e pouco espaçados. A cota média do topo dos obstáculos é considerada igual ou superior a 25 metros. Exemplos: florestas com árvores altas, de copas isoladas, centros de grandes cidades, complexos industriais bem desenvolvidos.

Sobre as dimensões da edificação, a NBR 6123:1988 define três classes de edificações e seus elementos, considerando os intervalos de tempo para cálculo da velocidade média de 3, 5 e 10 segundos, respectivamente:

CLASSE A: Todas as unidades de vedação, seus elementos de fixação e peças individuais de estruturas sem vedação. Toda edificação ou parte da edificação na qual a maior dimensão horizontal ou vertical da superfície frontal (superfície de incidência do vento) não exceda 20 metros; 
CLASSE B: Toda edificação ou parte da edificação para a qual a maior dimensão horizontal ou vertical da superfície frontal (superfície de incidência do vento) esteja entre 20 e 50 metros;

CLASSE C: Toda edificação ou parte da edificação para a qual a maior dimensão horizontal ou vertical da superfície frontal (superfície de incidência do vento) exceda 50 metros.

Portanto, calcula-se o valor de $S_{2}$ com a seguinte expressão:

$S_{2}=b \cdot F_{r} \cdot\left(\frac{z}{10}\right)^{p}$

$z$ é a altura acima do terreno;

$F_{r}$ é o fator de rajada correspondente à categoria II;

$b$ é o parâmetro de correção da classe da edificação;

$p$ é o parâmetro meteorológico.

A expressão para o cálculo de $S_{2}$ é aplicável até a altura $z$ limite, a qual define o contorno superior da camada atmosférica para cada categoria, mostrada na segunda coluna da tabela 5.1. Os parâmetros $F_{r}$, b e $p$ adotados pela Norma Brasileira NBR 6123:1988 estão apresentados também na tabela 5.1.

Tabela 5.1. Parâmetros Meteorológicos para o Fator $S_{2}$.

Adaptada: NBR 6123:1988.

\begin{tabular}{|c|c|c|c|c|c|}
\hline \multicolumn{6}{|c|}{ Parâmetros Meteorológicos para o Fator $S_{2}$} \\
\hline \multirow{2}{*}{ Categoria } & \multirow{2}{*}{$\mathrm{z}(\mathrm{m})$} & \multirow{2}{*}{ Parâmetro } & \multicolumn{3}{|c|}{ Classe } \\
\hline & & & $\mathbf{A}$ & B & C \\
\hline \multirow{2}{*}{ I } & \multirow{2}{*}{250} & $\mathrm{~b}$ & 1,10 & 1,11 & 1,12 \\
\hline & & $\mathrm{p}$ & 0,06 & 0,065 & 0,07 \\
\hline \multirow{3}{*}{ II } & \multirow{3}{*}{300} & $\mathrm{~b}$ & 1,00 & 1,00 & 1,00 \\
\hline & & $\mathrm{F}_{\mathrm{r}}$ & 1,00 & 0,98 & 0,95 \\
\hline & & $\mathrm{p}$ & 0,085 & 0,09 & 0,10 \\
\hline \multirow{2}{*}{ III } & \multirow{2}{*}{350} & b & 0,94 & 0,94 & 0,93 \\
\hline & & $\mathrm{p}$ & 0,10 & 0,105 & 0,115 \\
\hline \multirow{2}{*}{ IV } & \multirow{2}{*}{420} & b & 0,86 & 0,85 & 0,84 \\
\hline & & $\mathrm{p}$ & 0,12 & 0,125 & 0,135 \\
\hline \multirow{2}{*}{$\mathrm{V}$} & \multirow{2}{*}{500} & $\mathrm{~b}$ & 0,74 & 0,73 & 0,71 \\
\hline & & $\mathrm{p}$ & 0,15 & 0,16 & 0,175 \\
\hline
\end{tabular}


Em vez de se utilizar a expressão para o cálculo de $S_{2}$, pode-se também utilizar os valores de $S_{2}$ para as diversas categorias de rugosidade do terreno e classes de dimensões das edificações, mostrados na tabela 5.2.

Tabela 5.2. Fator $S_{2}$. Adaptada: NBR 6123:1988.

\begin{tabular}{|c|c|c|c|c|c|c|c|c|c|c|c|c|c|c|c|}
\hline \multicolumn{16}{|c|}{ Fator $S_{2}$} \\
\hline \multirow{4}{*}{$\mathrm{z}(\mathrm{m})$} & \multicolumn{15}{|c|}{ Categoria } \\
\hline & \multicolumn{3}{|c|}{ I } & \multicolumn{3}{|c|}{ II } & \multicolumn{3}{|c|}{ III } & \multicolumn{3}{|c|}{ IV } & \multicolumn{3}{|c|}{$\mathbf{V}$} \\
\hline & \multicolumn{3}{|c|}{ Classe } & \multicolumn{3}{|c|}{ Classe } & \multicolumn{3}{|c|}{ Classe } & \multicolumn{3}{|c|}{ Classe } & \multicolumn{3}{|c|}{ Classe } \\
\hline & $\mathbf{A}$ & B & $\mathrm{C}$ & A & B & $\mathrm{C}$ & $\mathbf{A}$ & B & $\mathrm{C}$ & $\mathbf{A}$ & B & C & $\mathbf{A}$ & B & $\mathrm{C}$ \\
\hline 5 & 1,06 & 1,04 & 1,01 & 0,94 & 0,92 & 0,89 & 0,88 & 0,86 & 0,82 & 0,79 & 0,76 & 0,73 & 0,74 & 0,72 & 0,67 \\
\hline 10 & 1,10 & 1,09 & 1,06 & 1,00 & 0,98 & 0,95 & 0,94 & 0,92 & 0,88 & 0,86 & 0,83 & 0,80 & 0,74 & 0,72 & 0,67 \\
\hline 15 & 1,13 & 1,12 & 1,09 & 1,04 & 1,02 & \begin{tabular}{|l|l}
0,99 \\
\end{tabular} & 0,98 & 0,96 & 0,93 & \begin{tabular}{|l|l}
0,90 \\
\end{tabular} & \begin{tabular}{|l|l}
0,88 \\
\end{tabular} & 0,84 & 0,79 & \begin{tabular}{|l|l}
0,76 \\
\end{tabular} & \begin{tabular}{|l|l|}
0,72 \\
\end{tabular} \\
\hline 20 & 1,15 & 1,14 & 1,12 & 1,06 & 1,04 & 1,02 & 1,01 & 0,99 & 0,96 & 0,93 & 0,91 & 0,88 & 0,82 & 0,80 & $0,7 €$ \\
\hline 30 & 1,17 & 1,17 & 1,15 & 1,10 & 1,08 & 1,06 & 1,05 & 1,03 & 1,00 & 0,98 & 0,96 & 0,93 & 0,87 & 0,85 & \begin{tabular}{|l|l|}
0,82 \\
\end{tabular} \\
\hline 40 & 1,20 & 1,19 & 1,17 & 1,13 & 1,11 & 1,09 & 1,08 & 1,07 & 1,04 & 1,02 & \begin{tabular}{|l|l|}
0,99 \\
\end{tabular} & 0,96 & 0,91 & 0,89 & $\mid 0,86$ \\
\hline 50 & 1,21 & 1,21 & 1,19 & 1,15 & 1,13 & 1,12 & 1,10 & 1,09 & 1,06 & 1,04 & 1,02 & 0,99 & 0,94 & 0,93 & 0,89 \\
\hline 60 & 1,22 & 1,22 & 1,21 & 1,16 & 1,15 & 1,14 & 1,12 & 1,11 & 1,09 & 1,07 & 1,04 & 1,02 & 0,97 & 0,95 & $\mid 0,92$ \\
\hline 80 & 1,25 & 1,25 & 1,23 & 1,19 & 1,18 & 1,17 & 1,16 & 1,15 & 1,12 & 1,10 & 1,08 & 1,06 & 1,01 & 1,00 & \begin{tabular}{|l|l}
0,97 \\
\end{tabular} \\
\hline 100 & 1,26 & 1,26 & 1,25 & 1,22 & 1,21 & 1,20 & 1,18 & 1,17 & 1,15 & 1,13 & 1,11 & 1,09 & 1,05 & 1,03 & 1,01 \\
\hline 120 & 1,28 & 1,28 & 1,27 & 1,24 & 1,23 & 1,22 & 1,21 & 1,20 & 1,18 & 1,16 & 1,14 & 1,12 & $\begin{array}{ll}1,07 \\
\end{array}$ & 1,06 & 1,04 \\
\hline 140 & 1,29 & 1,29 & 1,28 & 1,25 & 1,24 & 1,24 & 1,22 & 1,22 & 1,20 & 1,18 & 1,16 & 1,14 & 1,10 & 1,09 & 1,07 \\
\hline 160 & 1,30 & 1,30 & 1,29 & 1,27 & 1,26 & 1,25 & 1,24 & 1,23 & 1,22 & 1,20 & 1,18 & 1,16 & 1,12 & 1,11 & 1,10 \\
\hline 180 & 1,31 & 1,31 & 1,31 & 1,28 & 1,27 & 1,27 & 1,26 & 1,25 & 1,23 & 1,22 & 1,20 & 1,18 & 1,14 & 1,14 & 1,12 \\
\hline 200 & 1,32 & 1,32 & 1,32 & 1,29 & 1,28 & 1,28 & 1,27 & 1,26 & 1,25 & 1,23 & 1,21 & 1,20 & 1,16 & 1,16 & 1,14 \\
\hline 250 & 1,33 & 1,34 & 1,33 & 1,31 & 1,31 & 1,31 & $\mid 1,30$ & 1,29 & 1,28 & \begin{tabular}{|l}
1,27 \\
\end{tabular} & 1,25 & 1,23 & 1,20 & 1,20 & \begin{tabular}{|l}
1,18 \\
\end{tabular} \\
\hline 300 & - & - & - & 1,34 & 1,33 & 1,33 & 1,32 & 1,32 & 1,31 & 1,29 & 1,27 & 1,26 & 1,23 & 1,23 & 1,22 \\
\hline 350 & - & - & - & - & - & - & 1,34 & 1,34 & 1,33 & \begin{tabular}{|l}
1,32 \\
\end{tabular} & 1,30 & 1,29 & 1,26 & 1,26 & 1,26 \\
\hline 400 & - & - & - & - & - & - & - & - & - & 1,34 & 1,32 & 1,32 & 1,29 & 1,29 & 1,29 \\
\hline 420 & - & - & - & - & - & - & - & - & - & 1,35 & 1,35 & 1,33 & 1,30 & 1,30 & \begin{tabular}{|l}
1,30 \\
\end{tabular} \\
\hline 450 & - & - & - & - & - & - & - & - & - & - & - & - & 1,32 & $\mid 1,32$ & 1,32 \\
\hline 500 & - & - & - & - & - & - & - & - & - & - & - & - & 1,34 & \begin{tabular}{|l|l}
1,34 \\
\end{tabular} & 1,34 \\
\hline
\end{tabular}

\subsubsection{Fator estatístico $-S_{3}$}

O fator estatístico $S_{3}$, considerando conceitos probabilísticos e o tipo de ocupação, está relacionado com a segurança da edificação.

A Norma Brasileira NBR 6123:1988 estabelece como vida útil da edificação o período de 50 anos e uma probabilidade de $63 \%$ de a velocidade básica ser excedida pelo menos uma vez nesse período. Apresentam-se na tabela 5.3 os valores mínimos do fator $S_{3}$. 
Tabela 5.3. Valores mínimos do fator $S_{3}$. Adaptada: NBR 6123:1988.

\begin{tabular}{|c|c|c|}
\hline \multicolumn{4}{|c|}{ Valores mínimos do fator estatístico $\mathbf{S}_{\mathbf{3}}$} \\
\hline Grupo & Descrição do tipo de ocupação & Valor de $\mathbf{S}_{\mathbf{3}}$ \\
\hline 1 & $\begin{array}{c}\text { Edificação cuja rúna total ou parcial pode afetar a segurança ou } \\
\text { possibilidade de socorro a pessoas após uma tempestade } \\
\text { destrutiva (hospitais, quartéis de bombeiros e de forças de } \\
\text { segurança, centrais de comunicação, etc). }\end{array}$ & $\mathbf{1 , 1 0}$ \\
\hline 2 & $\begin{array}{r}\text { Edificações para hotéis e residências. Edificações para comércio } \\
\text { e indústria com alto fator de ocupação. }\end{array}$ & $\mathbf{1 , 0 0}$ \\
\hline 3 & $\begin{array}{r}\text { Edificações e instalações industriais com baixo fator de ocupação } \\
\text { (depósitos, silos, construções rurais, etc). }\end{array}$ & $\mathbf{0 , 9 5}$ \\
\hline 4 & Vedações (telhas, vidros, painéis de vedação, etc). & $\mathbf{0 , 8 8}$ \\
\hline 5 & Edificações temporárias. Estruturas dos grupos de 1 a 3 durante a & $\mathbf{0 , 8 3}$ \\
\hline
\end{tabular}

\subsubsection{FORÇA DE ARRASTO E COEFI CI ENTE DE ARRASTO}

A consideração de vento em edificações altas recebe um tratamento, dentro de uma análise global, em que a superposição de efeitos externos (forma) com efeitos internos (aberturas) é obtida por meio de um comportamento global da edificação, e representada por um único coeficiente, $C_{a}$, denominado coeficiente de arrasto (GONÇALVES, 2007).

A força de arrasto $F_{a}$ é a componente da força global do vento sobre uma edificação, e tal força global pode ser obtida pela soma vetorial das forças de arrasto que atuam na edificação.

Essa força de arrasto pode ser obtida pela seguinte expressão:

$F_{a}=C_{a} \cdot q \cdot A_{e}$

$C_{a}$ é o coeficiente de arrasto;

$q$ é a pressão dinâmica ou pressão de obstrução;

$A_{e}$ é a área efetiva, que é a área da projeção ortogonal da edificação, sobre um plano perpendicular à direção do vento ("área da sombra"). 
Pressão de obstrução $q$ é aquela obtida num dado ponto onde só existe pressão estática, sendo, por este motivo, de interesse para a Engenharia Civil (GONÇALVES, 2007).

Segundo a NBR 6123:1988, item 4.2.c, a pressão dinâmica pode ser obtida pela seguinte expressão:

$$
q=0,613 \cdot V_{k}^{2}, \text { sendo } q \text { em } N / m^{2} \text { e } V_{k} \text { em } m / s
$$

\subsubsection{Edificações de planta retangular}

Segundo a NBR 6123:1988, para se determinar o coeficiente de arrasto $\left(C_{a}\right)$ em edificações de múltiplos andares com planta retangular, devem-se considerar, principalmente, as condições de vento de baixa ou alta turbulência.

O vento de baixa turbulência, caracterizado pela ausência de obstruções como, por exemplo, em campo aberto e plano, foi o utilizado para a determinação do $C_{a}$ nos ensaios de túnel de vento. No gráfico da figura 5.6 podem-se observar os valores do $C_{a}$ (curvas em marrom variando de 0,7 a 2,2) em função da largura, comprimento e altura. Para se retirar o valor do $C_{a}$ do gráfico dividem-se os comprimentos da edificação em planta L1 por L2, valores esses que dependem do ângulo de incidência do vento, ou seja, da direção em que se está realizando a análise, como indicado na figura 5.6.

A razão desses dois comprimentos está representada no eixo das abscissas (horizontal). O eixo das ordenadas (vertical) é representado pela divisão da altura da edificação $H$ pelo comprimento L1.

No caso de vento de alta turbulência, os valores de $C_{a}$ devem levar em conta este efeito e variam de 0,7 a 1,6 , como mostrado na figura 5.7. Para se obter o valor do $C_{a}$, o processo é análogo ao de vento de baixa turbulência, descrito anteriormente.

Segundo a NBR 6123:1988, uma edificação é considerada em zona de alta turbulência quando a sua altura não excede o dobro da altura média das edificações vizinhas, ou seja, se a altura da edificação for maior que o dobro da altura média das edificações vizinhas, ela estará em zona de baixa turbulência, caso contrário, estará em zona de alta turbulência. 


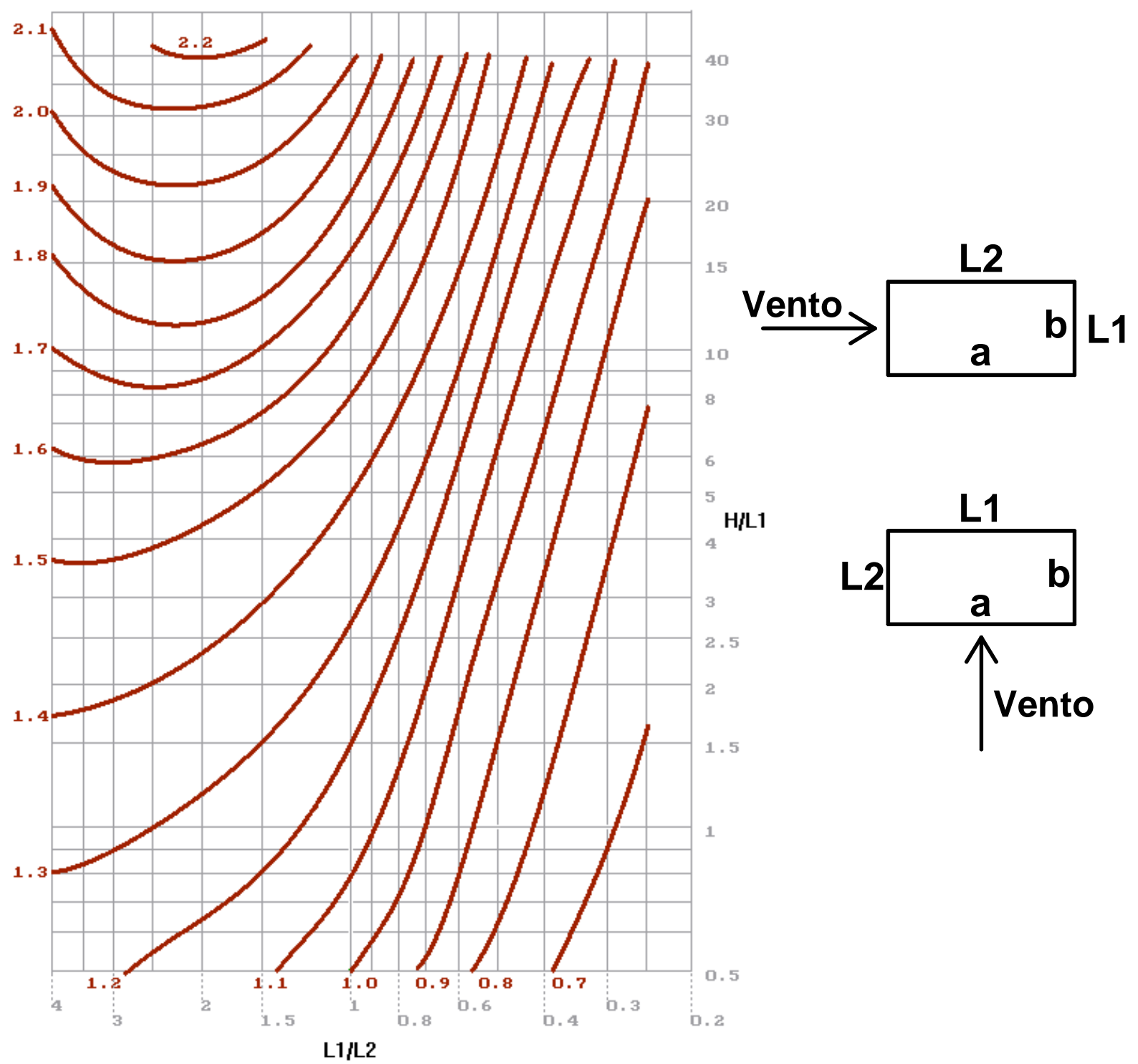

Figura 5.6. Coeficiente de Arrasto $\left(C_{a}\right)$ para edificações com Planta Retangular em vento de baixa turbulência. Fonte: SISTEMA TQS (Versão 15.5).

A altura média das edificações vizinhas deve ser obtida com a altura de todas as edificações até certa distância na direção do vento incidente.

Essa distância depende da altura da edificação em análise, como mostrado a seguir:

> 500 metros, para uma edificação de até 40 metros de altura;

> 1000 metros, para uma edificação de até 55 metros de altura;

$>2000$ metros, para uma edificação de até 70 metros de altura;

> 3000 metros, para uma edificação de até 80 metros de altura. 
Vale ressaltar que a força global do vento que se obtém em zona de baixa turbulência é maior que a que se obtém em zona de alta turbulência, embora o nome baixa e alta possa induzir ao pensamento contrário. Para entender bem isto, basta pensar que em zona de baixa turbulência, como o nome já diz, a turbulência é baixa, pois não há obstáculos, dessa maneira o vento segue livremente em direção à edificação, e no caso de alta turbulência, como o nome também já diz, a turbulência é alta, pois há diversos obstáculos no caminho, fazendo com que o vento não atinja a edificação com força máxima.

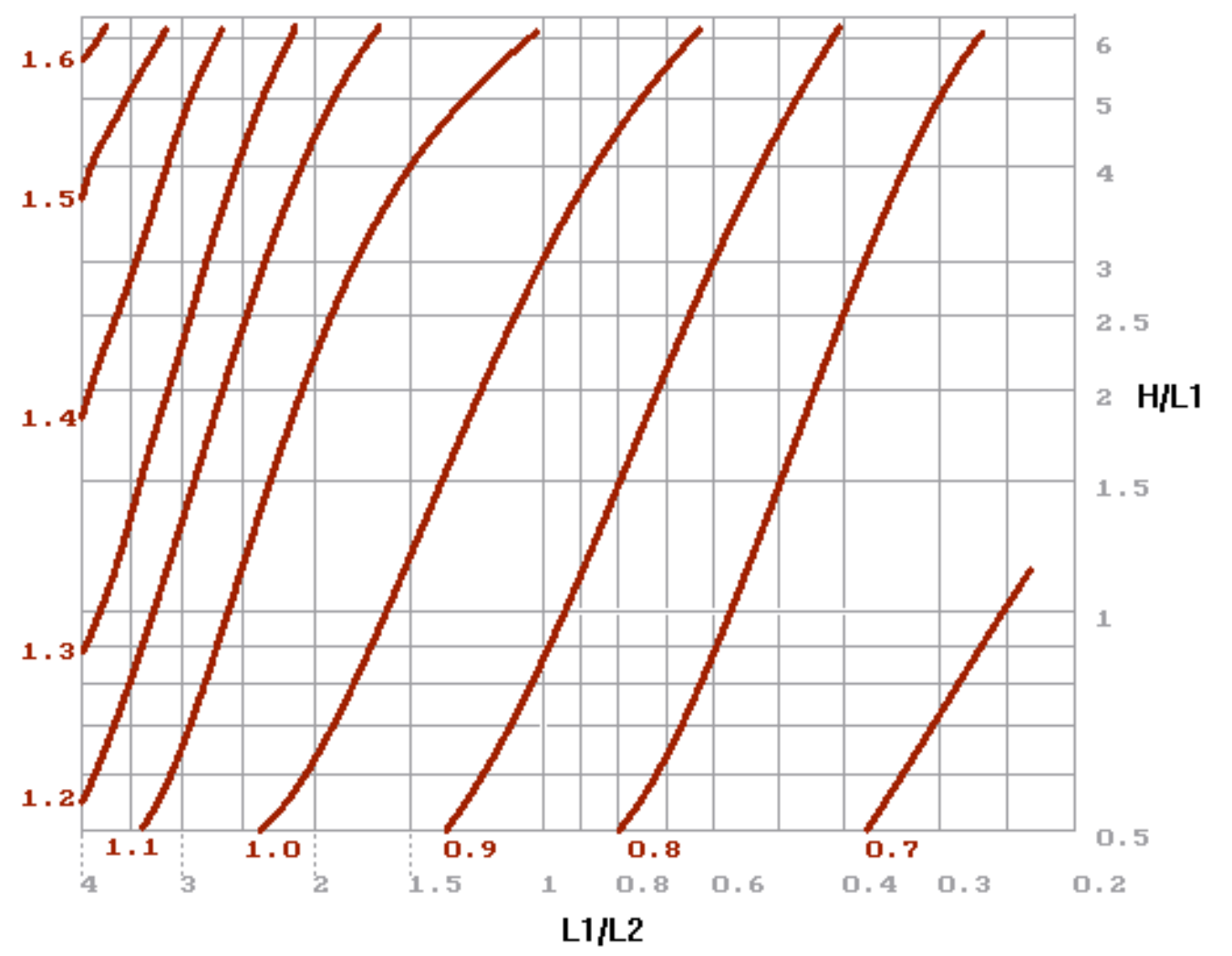

L2

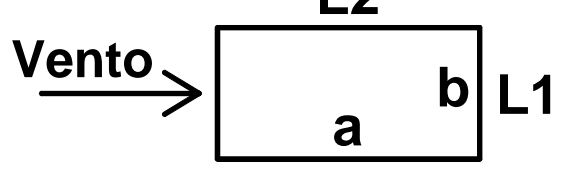

L1

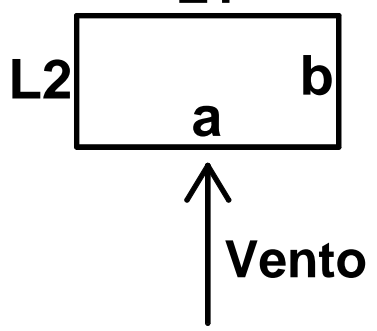

Figura 5.7. Coeficiente de Arrasto $\left(C_{a}\right)$ para edificações com Planta Retangular em vento de alta turbulência. Fonte: SISTEMA TQS (Versão 15.5). 


\subsubsection{ANÁLI SE DE VENTO NO SI STEMA COMPUTACI ONAL CAD/ TQS}

Neste trabalho a análise de vento será feita automaticamente pelo Sistema CAD/TQS. Ela é realizada da seguinte maneira:

a) Para cada piso da edificação acima do Térreo, determina-se sua cota;

b) Nessa cota, define-se a geometria e escolhe-se uma reta " $r$ " arbitrária, ortogonal à direção do vento. Sobre essa reta, projetam-se os extremos do edifício e os centros de gravidade dos pilares, conforme a figura 5.8;

c) A projeção dos extremos sobre a reta " $r$ " define a largura do edifício em que atuará o vento. Tal largura também está indicada na figura 5.8;

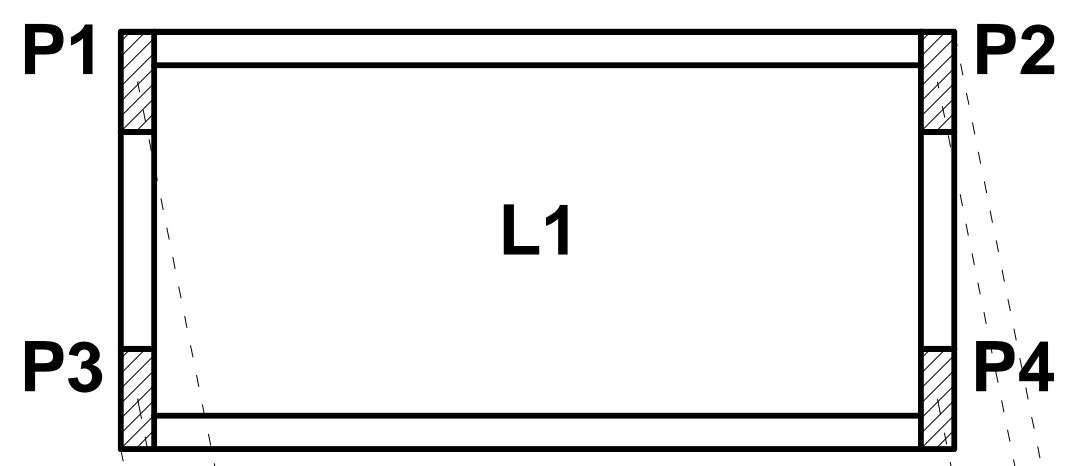

Trecho

P4 P2

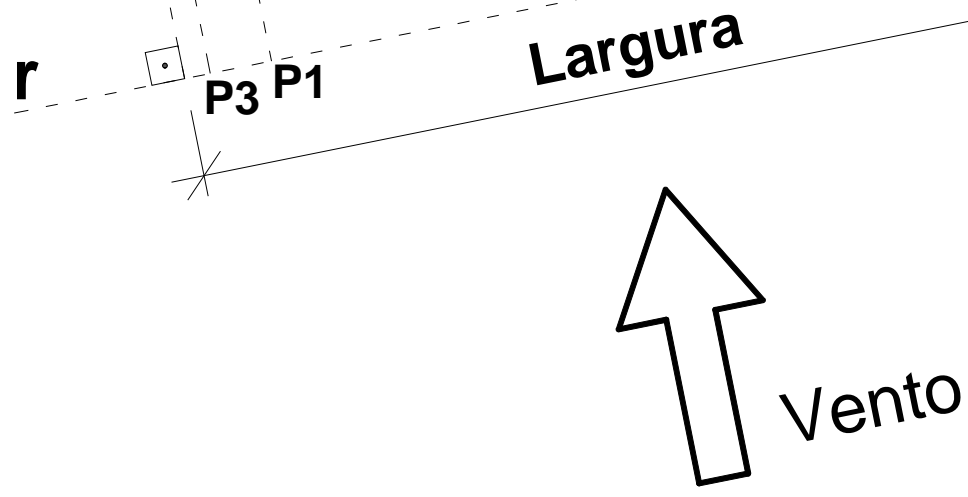

Figura 5.8. Esquema em planta da análise de vento existente no Sistema CAD/TQS. Adaptado: TQS INFORMÁTICA (2009-b).

d) A projeção dos centros dos pilares sobre a reta " $r$ " divide-a em trechos relativos a esses centros;

e) Com a largura do edifício, definida no item c, e o pé-direito do piso, calcula-se a área que receberá o vento nessa direção; 
f) Calcula-se a força total de vento no piso $f_{i}$, mostrada na figura 5.9-(a), de acordo com a NBR 6123:1988, ou seja, de acordo com o item 5.2.2 deste capítulo;

g) Essa força total é distribuída entre os nós dos pilares no piso, proporcionalmente à área de influência de cada pilar. Cada um deles terá influência da metade do trecho anterior (esquerda) até a metade do trecho posterior (direita), isto olhando para o edifício na vertical, de frente para face exposta ao vento;

h) Essa força calculada para cada pilar é distribuída metade para o nó superior e metade para o inferior do lance, exceto no primeiro piso acima do térreo, onde a força vai toda para o nó superior, como pode ser observado na figura 5.9-(b) (TQS INFORMÁTICA, 2009-b).

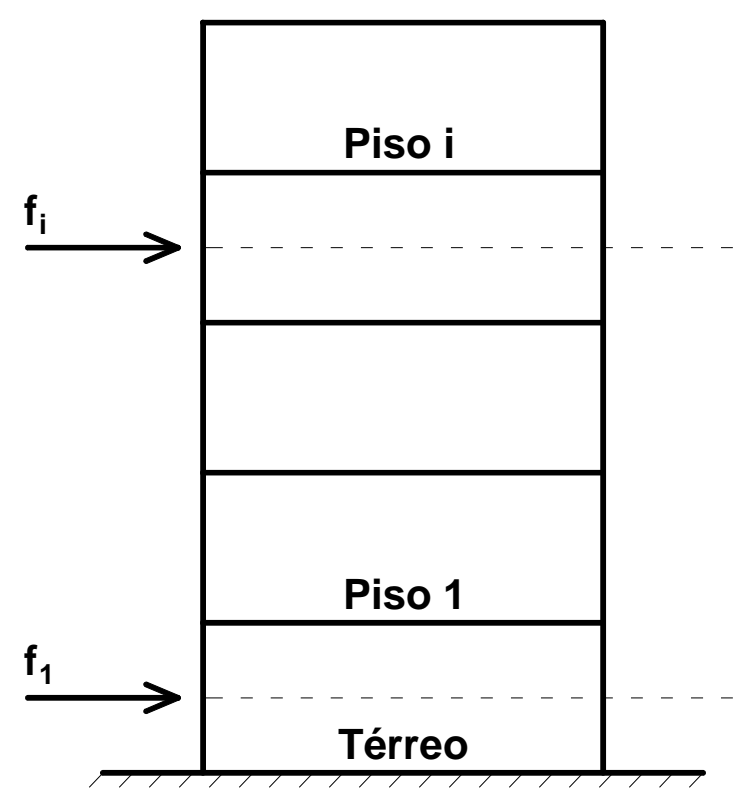

(a)

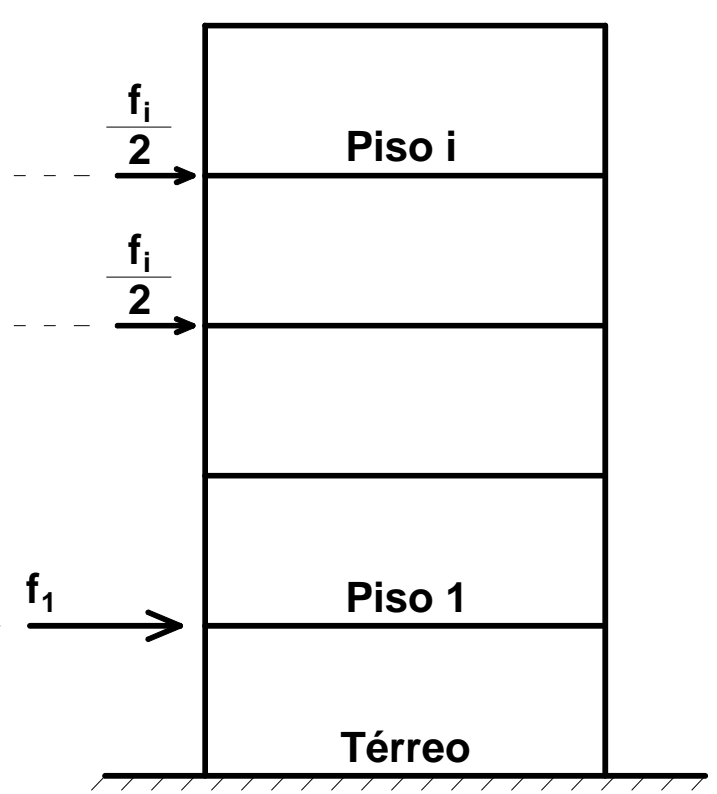

(b)

Figura 5.9. Esquema para análise de vento conforme o Sistema CAD/TQS. Adaptado: TQS INFORMÁTICA (2009-b).

\subsection{AÇÕES VERTI CAIS}

Segundo a NBR 6120:1980, as ações verticais são classificadas em: carga permanente e carga acidental. 


\subsubsection{CARGA PERMANENTE}

Para as cargas permanentes, é considerado o peso próprio de todos os elementos da estrutura, como, por exemplo, lajes, vigas e pilares. E, também, o peso do contrapiso, dos revestimentos e das alvenarias. Há outros tipos de ações permanentes. Porém, são consideradas apenas essas aqui indicadas.

No item 2.1.2 da NBR 6120:1980, há uma consideração especial para paredes divisórias, cujas posições não estejam definidas no projeto. O cálculo dos pisos com suficiente capacidade de distribuição da carga, quando não for feito por processo exato, pode ser feito admitindo, além dos demais carregamentos já mencionados, uma carga uniformemente distribuída por metro quadrado de piso, não menor que um terço do peso por metro linear de parede pronta, observando o valor mínimo de $1 \mathrm{kN} / \mathrm{m}^{2}$.

\subsubsection{CARGA ACI DENTAL}

Segundo a NBR 6120:1980, as cargas verticais que se consideram atuando nos pisos de edificações, além das que se aplicam em caráter especial, referemse a pessoas, móveis, utensílios e veículos, ou seja, referem-se à carga acidental, e são supostas uniformemente distribuídas, com os valores mínimos indicados nas tabelas 5.4 e 5.5 as quais são adaptadas da Norma, reunindo apenas os carregamentos para edificações, sejam residenciais ou de escritórios.

Tabela 5.4. Valores mínimos das cargas verticais acidentais para edifícios residenciais.

\begin{tabular}{|l|c|}
\hline \multicolumn{2}{|c|}{ Cargas verticais acidentais em edifícios residenciais } \\
\hline Local & Carga $\left(\mathbf{k N} / \mathbf{m}^{\mathbf{2}}\right)$ \\
\hline Dormitórios, salas, cozinhas e banheiros & 1,5 \\
\hline Despensas, áreas de serviço e lavanderias & 2,0 \\
\hline Forros sem acesso a pessoas & 0,5 \\
\hline Escadas sem acesso ao público & 2,5 \\
\hline Corredores sem acesso ao público & 2,0 \\
\hline Garagens & 3,0 \\
\hline Terraços sem acesso ao público & 2,0 \\
\hline
\end{tabular}


Tabela 5.5. Valores mínimos das cargas verticais acidentais para edifícios de escritórios.

\begin{tabular}{|l|c|}
\hline \multicolumn{2}{|c|}{ Cargas verticais acidentais em edicifíos de escritórios } \\
\hline Local & Carga $\left(\mathbf{k N} / \mathbf{m}^{\mathbf{2}}\right)$ \\
\hline Salas de uso geral e banheiros & 2,0 \\
\hline Escadas com acesso ao público & 3,0 \\
\hline Corredores com acesso ao público & 3,0 \\
\hline Terraços com acesso ao público & 3,0 \\
\hline Garagens & 3,0 \\
\hline Restaurantes & 3,0 \\
\hline
\end{tabular}




\section{ANÁLI SE DE DOIS EDI FÍ CI OS}

Neste trabalho serão analisados sete edifícios, sendo dois deles neste capítulo e os outros cinco no próximo. Para todos, serão consideradas quatro combinações últimas normais:

$$
N_{d}=\gamma_{\mathrm{g}} \cdot F_{\mathrm{gk}}+\gamma_{\mathrm{q}} \cdot\left(F_{\mathrm{q} 1 \mathrm{k}}+\sum \Psi_{0 \mathrm{j}} \cdot F_{\mathrm{qjk}}\right)
$$

$F_{\text {gk }}$ : ações permanentes diretas

$F_{\mathrm{q} 1 \mathrm{k}}$ : ação variável principal

$F_{\mathrm{qjk}}$ : ação variável secundária, se existir

$\gamma_{\mathrm{g}}$ : coeficiente de ponderação das ações permanentes no ELU

$\gamma_{\mathrm{q}}$ : coeficiente de ponderação das ações variáveis no ELU

$\Psi_{0 \mathrm{j}}$ : coeficiente redutor das ações variáveis secundárias no ELU

As ações permanentes diretas serão divididas em duas, peso próprio e demais cargas permanentes, ambas com coeficiente de ponderação $\gamma_{\mathrm{g}}=1,4$. A ação variável principal será a carga acidental, por ela ter maior influência sobre a estabilidade da edificação, e a secundária, o vento, as duas com coeficiente de ponderação $\gamma_{\mathrm{q}}=1,4$, sendo esta última multiplicada pelo coeficiente $\Psi_{0 \mathrm{j}}=0,6$. Os coeficientes de ponderação e os coeficientes redutores podem ser obtidos no item 11.7.1 da NBR 6118:2003, nas tabelas 11.1 e 11.2, respectivamente. O coeficiente $\gamma_{f 3}$, que considera as aproximações de projeto, foi adotado igual a 1,1. E o $f_{c k}$ utilizado foi de $25 \mathrm{MPa}$.

As quatro combinações utilizadas para comparação dos resultados serão abreviadas por COMB. Elas são mostradas a seguir.

COMB. 1: Peso próprio + carga perm. + carga acid. + 0,6 vento $0^{\circ}$

COMB. 2: Peso próprio + carga perm. + carga acid. + 0,6 vento $90^{\circ}$

COMB. 3: Peso próprio + carga perm. + carga acid. + 0,6 vento $180^{\circ}$

COMB. 4: Peso próprio + carga perm. + carga acid. + 0,6 vento $270^{\circ}$

Para melhor compreensão dos resultados obtidos, nas combinações o sentido do vento variou de acordo com o círculo trigonométrico, ou seja, no sentido anti-horário, e para melhor exemplificar segue a legenda na figura 6.1. 


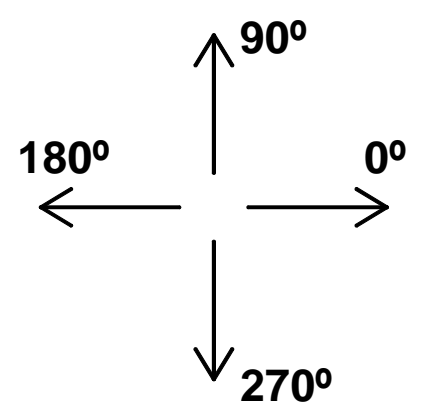

Figura 6.1. Sentidos da ação do vento.

\subsection{EXEMPLO 1}

Este exemplo, com pavimento tipo mostrado na figura 6.2, é totalmente simétrico e possui 14 pavimentos. Seu único propósito é mostrar como os esforços de segunda ordem globais são considerados nos pilares. Ressalta-se que seria impossível dimensionar esse edifício para as seções utilizadas, pois elas foram reduzidas propositadamente para que resultasse um valor elevado de Gama-z. Uma vista do edifício, em perspectiva, é indicada na figura 6.3.

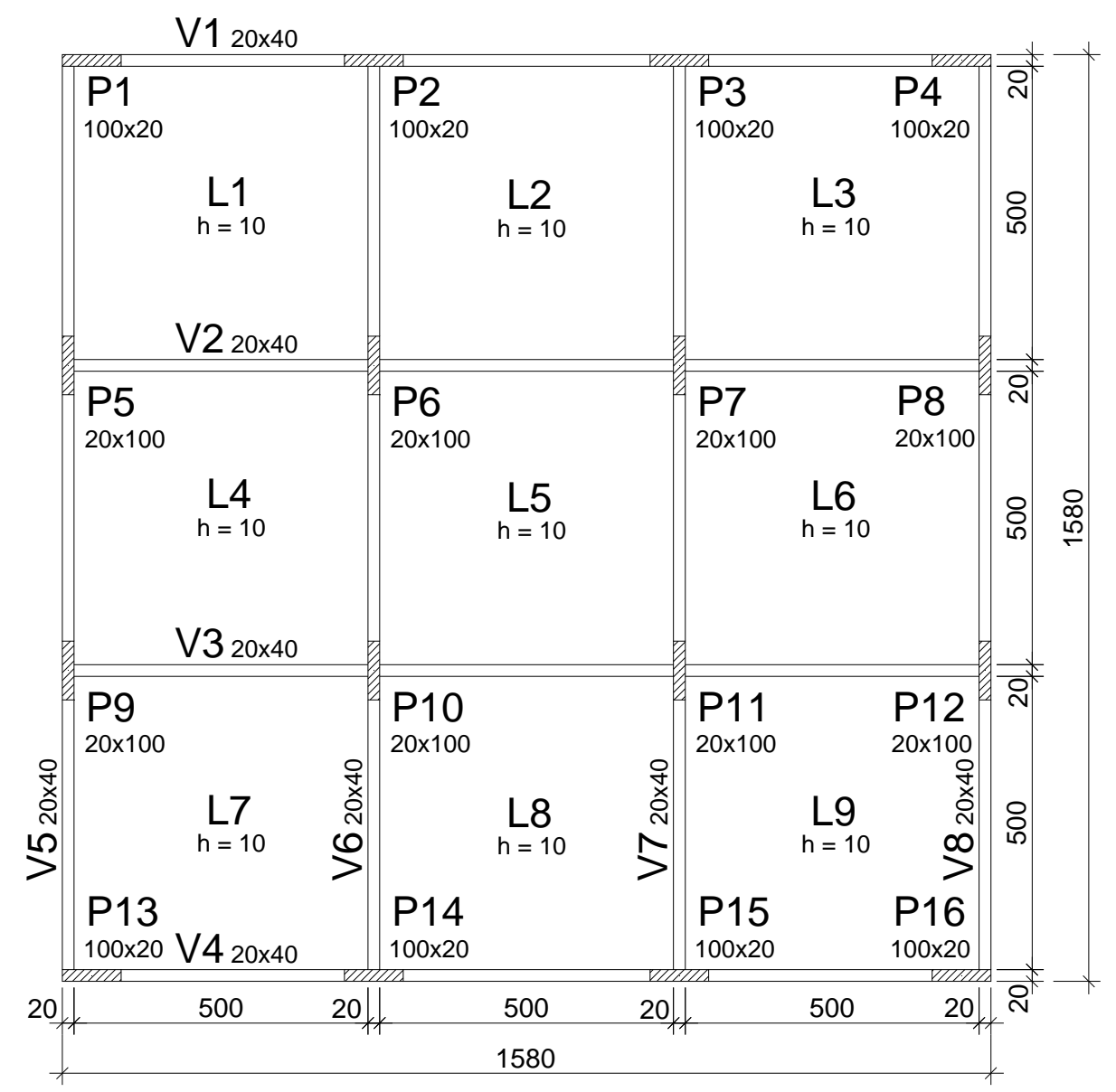

Figura 6.2. Planta de forma do pavimento tipo (dimensões em cm). 
Os carregamentos horizontais e verticais também foram aleatórios, com o intuito de se obter valores elevados dos parâmetros de estabilidade. A nãolinearidade física foi considerada de forma aproximada, por meio da redução da rigidez dos pilares e vigas, sendo considerada 0,8 EI para os pilares e 0,4 EI para as vigas. Para as lajes, a rigidez à flexão foi desprezada. Há uma alternativa para essa consideração aproximada, que será vista mais adiante.

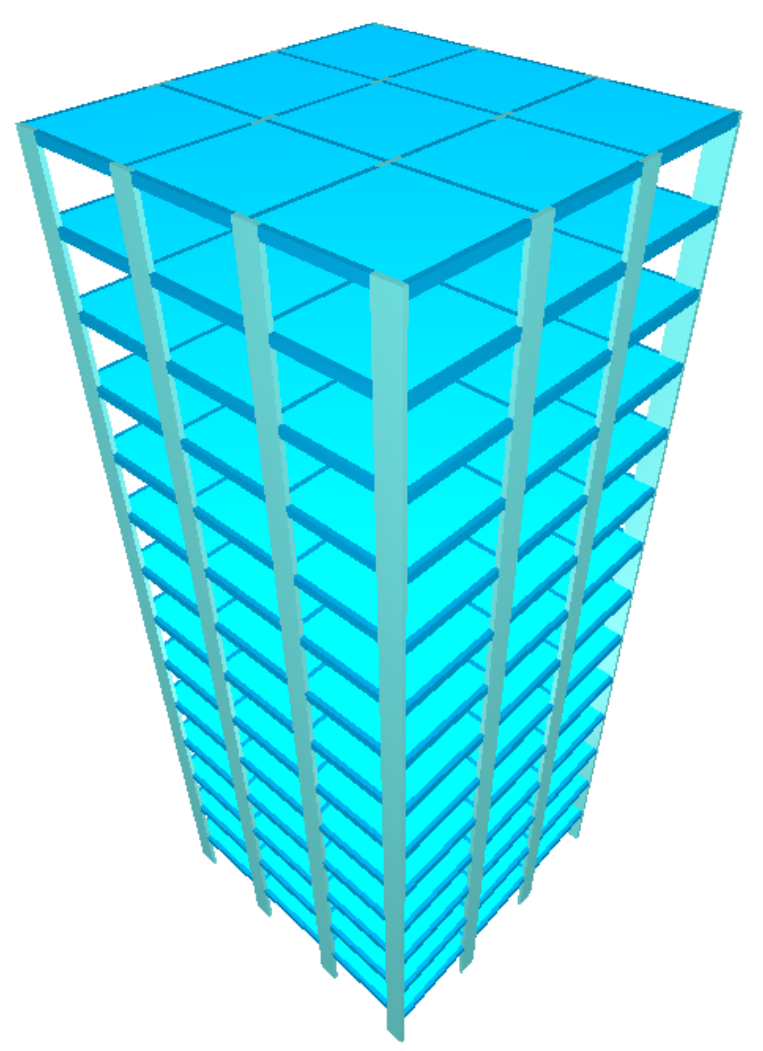

Figura 6.3. Vista em perspectiva do edifício analisado.

\subsubsection{PARÂMETROS DE ESTABI LI DADE}

Estão indicados, na tabela 6.1 , os valores de $\alpha, \gamma_{z}, F A V t$ e $R M 2 M 1$, que podem ser considerados como parâmetros de estabilidade. Os três últimos referem-se à rigidez 0,8 EI nos pilares e 0,4 EI nas vigas. Ressalta-se que, para se obter o valor correto de $\alpha$ no processamento dentro do Sistema TQS, não se deve considerar a redução da rigidez que leva em conta, de forma aproximada, os efeitos da não-linearidade física, ou seja, deve-se considerar o valor igual a 1,0 no lugar dos coeficientes 0,8 para pilares 0,4 para vigas. 
Isso se deve ao fato do valor calculado de $\alpha$ ser comparado com um valor limite, indicado no item 15.5.2 da NBR 6118:2003, onde esse valor limite já leva em consideração uma redução de $30 \%$ da rigidez integral, ou seja, já é considerado o valor de 0,7, tanto para pilares quanto para vigas. Se os coeficientes 0,8 e 0,4 não forem desativados dentro do sistema, a redução será considerada duas vezes, obtendo-se resultados errados.

Tabela 6.1. Parâmetros de estabilidade.

\begin{tabular}{|c|c|c|c|c|}
\hline \multicolumn{5}{|c|}{ PARÂMETRO DE ESTABILIDADE } \\
\hline Ang. & $\boldsymbol{\alpha}$ & GAMA-Z & FAVt & RM2M1 \\
\hline $0^{\circ}$ & 0,753 & 1,263 & 1,263 & 1,272 \\
\hline $90^{\circ}$ & 0,729 & 1,237 & 1,237 & 1,244 \\
\hline $180^{\circ}$ & 0,753 & 1,263 & 1,263 & 1,272 \\
\hline $270^{\circ}$ & 0,729 & 1,237 & 1,237 & 1,244 \\
\hline
\end{tabular}

Antes de comentar os valores da tabela 6.1, vale lembrar que todos eles, exceto o parâmetro $\alpha$, possuem o mesmo principio do coeficiente $\gamma_{z}$, ou seja, representam a relação entre os esforços de segunda ordem e os de primeira. Isto já foi comentado nos capítulos 2 e 3 deste trabalho.

Os valores de $\alpha$ devem ser comparados ao valor limite 0,5 , pois, segundo o item 15.5.2 da NBR 6118:2003, o valor limite deve ser reduzido de 0,6 para 0,5 quando o contraventamento for formado somente por pórticos, o que é o caso deste exemplo. Portanto, em todas as direções, obtiveram-se valores maiores que 0,5 , sendo então a edificação considerada de nós móveis.

Para este caso, de um edifício totalmente simétrico, os valores de $\gamma_{z} \mathrm{e}$ FAVt são idênticos. Assim, os esforços finais obtidos por qualquer um desses dois parâmetros serão os mesmos. Como todos os valores estão no intervalo $1,1<\gamma_{z} \leq 1,3$, o edifício também é considerado como de nós móveis, segundo esses parâmetros.

Os valores de $\gamma_{z}$ e $F A V t$ resultaram bem próximos dos relativos à RM2M1, o qual é gerado pelo processo P-Delta, como já foi comentado no capítulo 3. 


\subsubsection{ANÁLI SE DE SEGUNDA ORDEM GLOBAL}

De posse dos valores dos parâmetros de estabilidade, como se pode considerar os esforços de segunda ordem nos elementos estruturais do edifício considerado?

Antes de responder a essa pergunta, devem-se fazer algumas observações.

Dos quatro parâmetros encontrados, somente o $\gamma_{z}$ e FAVt permitem estimar os esforços de segunda ordem global.

O $\alpha$ só avalia a edificação quanto à estabilidade, e o RM2M1 é um parâmetro calculado posteriormente à obtenção dos esforços de segunda ordem, diferente dos outros dois, pois, para o cálculo de $\gamma_{z}$ e $F A V t$, não é necessário conhecer esses esforços. Na realidade, são eles que permitem estimar tais esforços de segunda ordem.

Neste trabalho, serão focados os esforços de segunda ordem global nos pilares, por eles serem os mais importantes para a estabilidade de um edifício.

De acordo com o item 15.7.2 da NBR 6118:2003, para se obter de forma aproximada os esforços finais ( $1^{a}+2^{a}$ ordem), deve-se majorar os esforços horizontais, da combinação de carregamento considerada, por $0,95 \gamma_{\mathrm{z}}$, ou seja, majorar os esforços horizontais das combinações 1, 2, 3 e 4, sendo esse procedimento válido somente para $\gamma_{\mathrm{z}} \leq 1,3$. E a obtenção dos esforços finais de forma refinada será pelo processo P-Delta de dois passos, descrito em detalhes no item 3.3, na página 65 deste trabalho.

Portanto, como nas combinações consideradas o esforço horizontal é o referente ao vento, então essa parcela será multiplicada por $0,95 \gamma_{z}$, lembrando que o valor de $\gamma_{\mathrm{z}}$ deverá ser o correspondente à direção do vento considerado.

As parcelas do peso próprio, demais cargas permanentes, carga acidental e vento, das combinações consideradas, foram obtidas no visualizador do pórtico espacial do sistema TQS.

Serão mostrados na tabela 6.2 os esforços normais de cálculo de primeira ordem, e na tabela 6.3 , os esforços finais $\left(1^{a}+2^{a}\right.$ ordem) na base de todos os pilares do pórtico tridimensional.

Primeiramente será mostrado como é realizado o cálculo dos esforços na base do pilar P1, para as quatro combinações. 
COMB. 1: Peso próprio + carga perm. + carga acid. + 0,6 vento $0^{\circ}$ $N_{d}=\gamma_{\mathrm{g}} \cdot(P P+C P)+\gamma_{\mathrm{q}} \cdot\left(C A+0,95 \gamma_{\mathrm{z}} \cdot \Psi_{0 \mathrm{j}} \cdot\right.$ Vento $\left.0^{0}\right)$

$N_{d}=1,4 \cdot(499,97+752,63)+1,4 \cdot(200,92+0,95 \cdot 1,263 \cdot 0,6 \cdot-649,82)$

$N_{d}=1,4 \cdot(1252,6)+1,4 \cdot(-266,89)$

$N_{d}=1379,99 \mathrm{kN}$

COMB. 2: Peso próprio + carga perm. + carga acid. + 0,6 vento $90^{\circ}$

$N_{d}=\gamma_{\mathrm{g}} \cdot(P P+C P)+\gamma_{\mathrm{q}} \cdot\left(C A+0,95 \gamma_{\mathrm{z}} \cdot \Psi_{0 \mathrm{j}} \cdot\right.$ Vento $\left.90^{\circ}\right)$

$N_{d}=1,4 \cdot(499,97+752,63)+1,4 \cdot(200,92+0,95 \cdot 1,237 \cdot 0,6 \cdot 273,41)$

$N_{d}=1,4 \cdot(1252,6)+1,4 \cdot(393,70)$

$N_{d}=2304,82 \mathrm{kN}$

COMB. 3: Peso próprio + carga perm. + carga acid. + 0,6 vento $180^{\circ}$

$N_{d}=\gamma_{\mathrm{g}} \cdot(P P+C P)+\gamma_{\mathrm{q}} \cdot\left(C A+0,95 \gamma_{\mathrm{z}} \cdot \Psi_{0 \mathrm{j}} \cdot\right.$ Vento $\left.180^{\circ}\right)$

$N_{d}=1,4 \cdot(499,97+752,63)+1,4 \cdot(200,92+0,95 \cdot 1,263 \cdot 0,6 \cdot 649,82)$

$N_{d}=1,4 \cdot(1252,6)+1,4 \cdot(668,73)$

$N_{d}=2689,86 k N$

COMB. 4: Peso próprio + carga perm. + carga acid. + 0,6 vento $270^{\circ}$

$N_{d}=\gamma_{\mathrm{g}} \cdot(P P+C P)+\gamma_{\mathrm{q}} \cdot\left(C A+0,95 \gamma_{\mathrm{z}} \cdot \Psi_{0 \mathrm{j}} \cdot\right.$ Vento $\left.270^{\circ}\right)$

$N_{d}=1,4 \cdot(499,97+752,63)+1,4 \cdot(200,92+0,95 \cdot 1,237 \cdot 0,6 \cdot-273,41)$

$N_{d}=1,4 \cdot(1252,6)+1,4 \cdot(8,14)$

$N_{d}=1765,04 k N$

Na tabela 6.3, na segunda linha, tem-se as combinações utilizadas, na terceira linha, os métodos para a obtenção dos esforços de segunda ordem, e na primeira coluna, a relação de todos os pilares. Para cada combinação, os esforços majorados por $\gamma_{\mathrm{z}}$ e $F A V t$ estão na primeira e segunda coluna respectivamente, e os esforços obtidos pelo processo P-Delta, na terceira coluna.

Comparando-se os esforços obtidos por $\gamma_{\mathrm{z}}$ e FAVt, idênticos neste caso, com os obtidos pelo processo P-Delta, pode-se perceber que $50 \%$ do total de esforços, para todos os pilares, estão acima do valor obtido pelo P-Delta, e 50\% estão abaixo, ou seja, 32 esforços estão acima e 32 abaixo, isso porque se tem, para cada combinação, 16 esforços, portanto $16 \times 4=64$ esforços. 
Tabela 6.2. Força normal de cálculo de $1^{\mathrm{a}}$ ordem.

\begin{tabular}{|c|c|c|c|c|}
\hline \multicolumn{5}{|c|}{ ESFORÇOS NORMAIS DE CÁLCULO DE 1a ORDEM (kN) } \\
\hline PILARES & COMB.1 & COMB.2 & COMB.3 & COMB.4 \\
\hline P1 & 1489,08 & 2264,59 & 2580,78 & 1805,27 \\
\hline P2 & 3474,51 & 3651,39 & 3324,40 & 3147,52 \\
\hline P3 & 3324,40 & 3651,39 & 3474,51 & 3147,52 \\
\hline P4 & 2580,78 & 2264,59 & 1489,08 & 1805,27 \\
\hline P5 & 3758,16 & 4103,92 & 4044,62 & 3698,87 \\
\hline P6 & 8121,48 & 8326,77 & 8048,51 & 7843,23 \\
\hline P7 & 8048,51 & 8326,77 & 8121,48 & 7843,23 \\
\hline P8 & 4044,62 & 4103,92 & 3758,16 & 3698,87 \\
\hline P9 & 3758,16 & 3698,87 & 4044,62 & 4103,92 \\
\hline P10 & 8121,48 & 7843,23 & 8048,51 & 8326,77 \\
\hline P11 & 8048,51 & 7843,23 & 8121,48 & 8326,77 \\
\hline P12 & 4044,62 & 3698,87 & 3758,16 & 4103,91 \\
\hline P13 & 1489,08 & 1805,27 & 2580,78 & 2264,59 \\
\hline P14 & 3474,51 & 3147,52 & 3324,40 & 3651,39 \\
\hline P15 & 3324,40 & 3147,52 & 3474,51 & 3651,39 \\
\hline P16 & 2580,78 & 1805,27 & 1489,08 & 2264,59 \\
\hline
\end{tabular}

Tabela 6.3. Força normal de cálculo com efeitos de $2^{a}$ ordem global $\left(0,95 \gamma_{z}\right)$.

\begin{tabular}{|c|c|c|c|c|c|c|c|c|c|c|c|c|}
\hline \multicolumn{13}{|c|}{ FORÇA NORMAL DE CÁLCULO NA BASE DO PILAR COM EFEITOS DE 2a ORDEM GLOBAL (kN) } \\
\hline \multirow{2}{*}{ PILARES } & \multicolumn{3}{|c|}{ СОМв. 1} & \multicolumn{3}{|c|}{ СОМв. 2} & \multicolumn{3}{|c|}{ СОМв. 3} & \multicolumn{3}{|c|}{ СОМв. 4} \\
\hline & GAMA-Z & FAVt & P-DELTA & GAMA-Z & FAVt & P-DELTA & GAMA-Z & FAVt & P-DELTA & GAMA-Z & FAVt & P-DELTA \\
\hline P1 & 1379,98 & 1379,98 & 1332,24 & 2304,82 & 2304,82 & 2322,88 & 2689,86 & 2689,86 & 2737,56 & 1765,04 & 1765,04 & 1747,06 \\
\hline $\mathbf{P 2}$ & 3489,50 & 3489,50 & 3497,20 & 3695,44 & 3695,44 & 3715,32 & 3309,46 & 3309,46 & 3301,76 & 3103,38 & 3103,38 & 3083,64 \\
\hline P3 & 3309,04 & 309,46 & 3301,76 & 3695,44 & 3695,44 & 3715,32 & 3489,50 & 3489,50 & 3497,20 & 3103,38 & 3103,38 & 3083,64 \\
\hline P4 & 2689,96 & 2689,96 & 2737,56 & 2304,82 & 2304,82 & 2322,88 & 1379,84 & 1379,84 & 1332,24 & 1765,12 & 1765,12 & 1747,06 \\
\hline P5 & 3729,46 & 3729,46 & 3717,98 & 4139,38 & 4139,38 & 4155,90 & 4073,30 & 4073,30 & 4084,78 & 3663,38 & 3663,38 & 3646,72 \\
\hline P6 & 8128,82 & 8128,82 & 8132,32 & 8369,06 & 8369,06 & 8389,22 & 8041,18 & 8041,18 & 8037,68 & 7800,94 & 7800,94 & 7780,78 \\
\hline P7 & 8041,18 & 8041,18 & 8037,68 & 8369,06 & 8369,06 & 8389,22 & 8128,82 & 8128,82 & 8132,32 & 7800,94 & 7800,94 & 7780,78 \\
\hline P8 & 4073,30 & 4073,30 & 4084,78 & 4139,38 & 4139,38 & 4155,90 & 3729,46 & 3729,46 & 3717,98 & 3663,38 & 3663,38 & 3646,72 \\
\hline P9 & 3729,46 & 3729,46 & 3717,98 & 3663,38 & 3663,38 & 3646,72 & 4073,30 & 4073,30 & 4084,78 & 4139,38 & 4139,38 & 4155,90 \\
\hline P10 & 8128,82 & 8128,82 & 8132,32 & 7800,94 & 7800,94 & 7780,78 & 8041,18 & 8041,18 & 8037,68 & 8369,06 & 8369,06 & 8389,22 \\
\hline P11 & 8041,18 & 8041,18 & 8037,68 & 7800,94 & 7800,94 & 7780,78 & 8128,82 & 8128,82 & 8132,32 & 8369,06 & 8369,06 & 8389,22 \\
\hline P12 & 4073,30 & 4073,30 & 4084,78 & 3663,38 & 3663,38 & 3646,72 & 3729,46 & 3729,46 & 3717,98 & 4139,38 & 4139,38 & 4155,90 \\
\hline P13 & 1379,84 & 1379,84 & 1332,24 & 1765,12 & 1765,12 & 1747,06 & 2689,96 & 2689,96 & 2737,56 & 2304,82 & 2304,82 & 2322,88 \\
\hline P14 & 3489,50 & 3489,50 & 3497,20 & 3103,38 & 3103,38 & 3083,64 & 3309,46 & 3309,46 & 3301,76 & 3695,44 & 3695,44 & 3715,32 \\
\hline P15 & 3309,46 & 3309,46 & 3301,20 & 3103,38 & 3103,38 & 3083,64 & 3489,78 & 3489,50 & 3497,20 & 3695,44 & 3695,44 & 3715,32 \\
\hline P16 & 2689,96 & 2689,96 & 2737,56 & 1765,12 & 1765,12 & 1747,06 & 1379,84 & 1379,84 & 1332,24 & 2304,82 & 2304,82 & 2322,88 \\
\hline
\end{tabular}


Em relação aos valores obtidos pelo P-Delta, dos que ficaram abaixo, eles estão em média 0,53\% menores, e dos que ficaram acima, 0,82\% maiores. Com isso pode-se concluir que os esforços aproximados não estão muito distantes dos obtidos pelo processo P-Delta, mais refinado.

Agora, em vez de $0,95 \gamma_{\mathrm{z}}$, se fosse considerado o valor integral de $\gamma_{\mathrm{z}}$ para majoração dos esforços horizontais, obter-se-iam os resultados mostrados na tabela 6.4, lembrando que essa consideração também vale para o FAVt.

Tabela 6.4. Força normal de cálculo com efeitos de $2^{\mathrm{a}}$ ordem global $\left(\gamma_{\mathrm{z}}\right)$.

\begin{tabular}{|c|c|c|c|c|c|c|c|c|c|c|c|c|}
\hline \multicolumn{13}{|c|}{ FORÇA NORMAL DE CÁLCULO NA BASE DO PILAR COM EFEITOS DE 2a ORDEM GLOBAL (kN) } \\
\hline \multirow{2}{*}{ LARES } & \multicolumn{3}{|c|}{ СОМв. 1} & \multicolumn{3}{|c|}{ СОМB. 2} & \multicolumn{3}{|c|}{ СОМв. 3} & \multicolumn{3}{|c|}{ СОМв. 4} \\
\hline & GAMA-Z & FAVt & P-DELTA & GAMA-Z & FAVt & P-DELTA & GAMA-Z & FAVt & P-DELTA & GAMA-Z & FAVt & P-DELTA \\
\hline P1 & 1345,54 & 1345,54 & 1332,24 & 2318,96 & 2315,60 & 2322,88 & 2724,40 & 2724,40 & 2737,56 & 1750,84 & 1750,84 & 1747,06 \\
\hline P2 & 94,26 & 3494,26 & 97,20 & 711,12 & 3711,12 & 3715,32 & 3304,70 & 3304,70 & 3301,76 & 3087,84 & 3087,84 & 3083,64 \\
\hline P3 & 04,70 & 3304,70 & 3301,76 & 3711,12 & 3711,12 & 3715,32 & 3494,26 & 3494,26 & 3497,20 & 3087,84 & 3087,84 & 3083,64 \\
\hline P4 & 24,40 & 2724,40 & 2737,56 & 2318,96 & 2318,96 & 2322,88 & 1345,54 & 1345,54 & 1332,24 & 1750,84 & 1750,84 & 1747,06 \\
\hline P5 & 3720,50 & 3720,50 & 3717,98 & 4151,98 & 4151,98 & 4155,90 & 4082,26 & 4082,26 & 4084,78 & 3650,92 & 3650,92 & 3646,72 \\
\hline P6 & 31,06 & 8131,06 & 8132,32 & 8384,04 & 8384,04 & 8389,22 & 8038,94 & 8038,94 & 8037,68 & 7785,96 & 7785,96 & 7780,78 \\
\hline P7 & 8038,94 & 8038,94 & 8037,68 & 8384,04 & 8384,04 & 8389,22 & 8131,06 & 8131,06 & 8132,32 & 7785,96 & 7785,96 & 7780,78 \\
\hline P8 & 4082,26 & 4082,26 & 4084,78 & 4151,98 & 4151,98 & 4155,90 & 3720,50 & 3720,50 & 3717,98 & 3650,92 & 3650,92 & 3646,72 \\
\hline P9 & 3720,50 & 3720,50 & 3717,98 & 3650,92 & 3650,92 & 3646,72 & 4082,26 & 4082,26 & 4084,78 & 4151,98 & 4151,98 & 4155,90 \\
\hline P10 & 8131,06 & 8131,06 & 8132,32 & 7785,96 & 7785,96 & 7780,78 & 8038,94 & 8038,94 & 8037,68 & 8384,04 & 8384,04 & 8389,22 \\
\hline P11 & 8038,94 & 8038,94 & 8037,68 & & 7785,96 & 7780,78 & 8131,06 & 8131,06 & 8132,32 & 8384,04 & 8384,04 & 8389,22 \\
\hline P12 & 4082,26 & 4082,26 & 4084,78 & 3650,92 & 3650,92 & 3646,72 & 3720,50 & 3720,50 & 3717,98 & 4151,98 & 4151,98 & 4155,90 \\
\hline P13 & 1345,54 & 1345,54 & 1332,24 & 1750,84 & 1750,84 & 1747,06 & 2724,40 & 2724,40 & 2737,56 & 2318,96 & 2318,96 & 2322,88 \\
\hline P14 & 3494,26 & 3494,26 & 3497,20 & 3087,84 & 3087,84 & 3083,64 & 3304,70 & 3304,70 & 3301,76 & 3711,12 & 3711,12 & 3715,32 \\
\hline P15 & 3304,70 & 3304,70 & 3301,20 & 3087,84 & 3087,84 & 3083,64 & 3494,26 & 3494,26 & 3497,20 & 3711,12 & 3711,12 & 3715,32 \\
\hline P16 & 2724,40 & 2724,40 & & & & & & & & & & 2322,88 \\
\hline
\end{tabular}

A leitura da tabela 6.4 se faz da mesma maneira que a da tabela 6.3. Em comparação análoga à anterior, pode-se perceber que também $50 \%$ do total de esforços nos pilares estão acima e 50\% estão abaixo dos obtidos pelo P-Delta.

Em relação a esses valores referentes ao P-Delta, os que ficaram abaixo são em média $0,14 \%$ menores, e os que ficaram acima, 0,21\% maiores. Com isso pode-se afirmar que os esforços de segunda ordem global obtidos com $\gamma_{\mathrm{z}}$ para este exemplo, são bem melhores que os relativos a $0,95 \gamma_{\mathrm{z}}$, pois os valores acima e abaixo são mais próximos dos obtidos com o P-Delta. 
Isso pode ser explicado pelo fato de, em algumas combinações, como já foi comentado, o esforço de vento ser somado, e em outras, subtraído. Com os valores integrais de $\gamma_{\mathrm{z}}$ eFAVt, os esforços que eram calculados pela combinação em que o vento era somado tornaram-se maiores, e aquelas em que o vento era subtraído tornaram-se menores, aproximando-os dos obtidos pelo P-Delta.

Serão considerados, agora, os momentos fletores na base do pilares. São mostrados na tabela 6.5 os momentos fletores de cálculo de $1^{\mathrm{a}}$ ordem, e na tabela 6.6, os valores, em módulo, dos momentos finais na base para todos os pilares, sendo eles relativos à direção mais rígida de cada pilar. Os cálculos dos esforços finais serão realizados, em detalhes, somente para o pilar P1.

COMB. 1: Peso próprio + carga perm. + carga acid. + 0,6 vento 00

$$
\begin{aligned}
& M_{d}=\gamma_{\mathrm{g}} \cdot(P P+C P)+\gamma_{\mathrm{q}} \cdot\left(C A+0,95 \gamma_{\mathrm{z}} \cdot \Psi_{0 \mathrm{j}} \cdot \text { Vento } 0^{0}\right) \\
& M_{d}=1,4 \cdot(-2,35-5,79)+1,4 \cdot(-2,15+0,95 \cdot 1,263 \cdot 0,6 \cdot 655,92) \\
& M_{d}=1,4 \cdot(-8,14)+1,4 \cdot(470,05) \\
& M_{d}=646,67 \mathrm{kN} . \mathrm{m}
\end{aligned}
$$

COMB. 2: Peso próprio + carga perm. + carga acid. + 0,6 vento $90^{\circ}$ $M_{d}=\gamma_{\mathrm{g}} \cdot(P P+C P)+\gamma_{\mathrm{q}} \cdot\left(C A+0,95 \gamma_{\mathrm{z}} \cdot \Psi_{0 \mathrm{j}} \cdot\right.$ Vento $\left.90^{0}\right)$

$M_{d}=1,4 \cdot(-2,35-5,79)+1,4 \cdot(-2,15+0,95 \cdot 1,237 \cdot 0,6 \cdot 0,91)$

$M_{d}=1,4 \cdot(-8,14)+1,4 \cdot(-1,508)$

$M_{d}=-13,51 \mathrm{kN} \cdot \mathrm{m}$

COMB. 3: Peso próprio + carga perm. + carga acid.I + 0,6 vento $180^{\circ}$ $M_{d}=\gamma_{\mathrm{g}} \cdot(P P+C P)+\gamma_{\mathrm{q}} \cdot\left(C A+\Psi_{0 \mathrm{j}} \cdot 0,95 \gamma_{\mathrm{z}} \cdot\right.$ Vento $\left.180^{\circ}\right)$

$M_{d}=1,4 \cdot(-2,35-5,79)+1,4 \cdot(-2,15+0,95 \cdot 1,263 \cdot 0,6 \cdot-655,92)$

$M_{d}=1,4 \cdot(-8,14)+1,4 \cdot(-474,35)$

$M_{d}=-675,49 \mathrm{kN} \cdot \mathrm{m}$

COMB. 4: Peso próprio + carga perm. + carga acid. + 0,6 vento $270^{\circ}$

$$
\begin{aligned}
& M_{d}=\gamma_{\mathrm{g}} \cdot(P P+C P)+\gamma_{\mathrm{q}} \cdot\left(C A+\Psi_{0 \mathrm{j}} \cdot 0,95 \gamma_{\mathrm{z}} \cdot \text { Vento } 270^{0}\right) \\
& M_{d}=1,4 \cdot(-2,35-5,79)+1,4 \cdot(-2,15+0,95 \cdot 1,237 \cdot 0,6 \cdot-0,91) \\
& M_{d}=1,4 \cdot(-8,14)+1,4 \cdot(-2,79) \\
& M_{d}=-15,30 \mathrm{kN} \cdot \mathrm{m}
\end{aligned}
$$


Tabela 6.5. Momento fletor de cálculo de $1^{\mathrm{a}}$ ordem.

\begin{tabular}{|c|c|c|c|c|}
\hline \multicolumn{5}{|c|}{ MOMENTOS FLETORES DE CÁLCULO DE 1a ORDEM (kN.m) } \\
\hline PILARES & COMB.1 & COMB.2 & COMB.3 & COMB.4 \\
\hline P1 & 536,57 & 13,65 & 565,38 & 15,17 \\
\hline P2 & 562,76 & 2,04 & 566,63 & 1,83 \\
\hline P3 & 566,63 & 2,04 & 562,72 & 1,83 \\
\hline P4 & 565,38 & 13,65 & 536,56 & 15,17 \\
\hline P5 & 5,34 & 527,55 & 6,23 & 539,11 \\
\hline P6 & 13,25 & 523,27 & 13,11 & 549,63 \\
\hline P7 & 13,11 & 523,27 & 13,25 & 549,63 \\
\hline P8 & 6,22 & 527,56 & 5,33 & 539,11 \\
\hline P9 & 5,33 & 539,11 & 6,23 & 527,55 \\
\hline P10 & 13,25 & 549,63 & 13,11 & 523,27 \\
\hline P11 & 13,11 & 549,63 & 13,25 & 523,27 \\
\hline P12 & 6,22 & 539,11 & 5,33 & 527,56 \\
\hline P13 & 536,56 & 15,17 & 565,38 & 13,65 \\
\hline P14 & 562,76 & 1,83 & 566,63 & 2,04 \\
\hline P15 & 566,63 & 1,83 & 562,76 & 2,04 \\
\hline P16 & 565,39 & 15,17 & 536,57 & 13,65 \\
\hline
\end{tabular}

Tabela 6.6. Momento fletor de cálculo com efeitos de $2^{a}$ ordem global $\left(0,95 \gamma_{\mathrm{z}}\right)$.

\begin{tabular}{|c|c|c|c|c|c|c|c|c|c|c|c|c|}
\hline \multicolumn{13}{|c|}{ MOMENTO FLETOR DE CÁLCULO COM EFEITOS DE 2a ORDEM GLOBAL (kN.m) } \\
\hline \multirow{2}{*}{ PILARES } & \multicolumn{3}{|c|}{ СОМВ. 1} & \multicolumn{3}{|c|}{ СОМB. 2} & \multicolumn{3}{|c|}{ СОМВ. 3} & \multicolumn{3}{|c|}{ COMB. 4} \\
\hline & GAMA-Z & FAVt & P-DELTA & GAMA-Z & FAVt & P-DELTA & GAMA-Z & FAVt & P-DELTA & GAMA-Z & FAVt & P-DELTA \\
\hline P1 & 646,67 & 646,67 & 661,86 & 13,51 & 13,51 & 13,16 & 675,49 & 675,49 & 689,22 & 15,30 & 15,30 & 15,65 \\
\hline $\mathbf{P 2}$ & 675,70 & 675,70 & 689,70 & 2,06 & 2,06 & 1,92 & 679,57 & 679,57 & 693,38 & 1,82 & 1,82 & 1,95 \\
\hline $\mathbf{P 3}$ & 679,57 & 679,57 & 693,39 & 2,06 & 2,06 & 1,92 & 675,71 & 675,71 & 689,70 & 1,81 & 1,81 & 1,95 \\
\hline P4 & 675,58 & 675,58 & 689,22 & 13,51 & 13,51 & 13,16 & 646,76 & 646,76 & 661,86 & 15,30 & 15,30 & 15,65 \\
\hline P5 & 5,25 & 5,25 & 4,72 & 620,89 & 620,89 & 633,12 & 6,31 & 6,31 & 6,83 & 632,45 & 632,45 & 645,22 \\
\hline P6 & 13,26 & 13,26 & 13,10 & 617,15 & 617,15 & 627,93 & 13,09 & 13,09 & 13,24 & 643,51 & 643,51 & 654,86 \\
\hline P7 & 13,09 & 13,09 & 13,24 & 617,15 & 617,15 & 627,93 & 13,26 & 13,26 & 13,10 & 643,51 & 643,51 & 654,86 \\
\hline P8 & 6,31 & 6,31 & 6,83 & 620,89 & 620,89 & 633,12 & 5,24 & 5,24 & 4,72 & 632,44 & 632,44 & 645,22 \\
\hline P9 & 5,25 & 5,25 & 4,72 & 632,44 & 632,44 & 645,22 & 6,31 & 6,31 & 6,83 & 620,89 & 620,89 & 633,12 \\
\hline P10 & 13,26 & 13,26 & 13,10 & 643,51 & 643,51 & 654,86 & 13,09 & 13,09 & 13,26 & 617,15 & 617,15 & 627,93 \\
\hline P11 & 13,09 & 13,09 & 13,24 & 643,51 & 643,51 & 654,86 & 13,26 & 13,26 & 13,10 & 617,15 & 617,15 & 627,93 \\
\hline P12 & 6,31 & 6,31 & 6,83 & 632,45 & 632,45 & 645,22 & 5,24 & 5,24 & 4,72 & 620,89 & 620,89 & 633,12 \\
\hline P13 & 646,76 & 646,76 & 661,86 & 15,30 & 15,30 & 15,65 & 675,58 & 675,58 & 689,22 & 13,51 & 13,51 & 13,16 \\
\hline P14 & 675,70 & 675,70 & 689,70 & 1,82 & 1,82 & 1,95 & 675,71 & 675,71 & 693,38 & 1,81 & 1,81 & 1,92 \\
\hline P15 & 679,57 & 679,57 & 693,38 & 1,81 & 1,81 & 1,95 & 675,70 & 675,70 & 689,70 & 2,06 & 2,06 & 1,92 \\
\hline P16 & 675,58 & 675,58 & 689,22 & 15,30 & 15,30 & 15,65 & 646,76 & 646,76 & 661,86 & 13,51 & 13,51 & 13,16 \\
\hline
\end{tabular}


Comparando-se os esforços obtidos por $\gamma_{\mathrm{z}}$ e FAVt, idênticos neste caso, com os relativos ao P-Delta, pode-se perceber que apenas $25 \%$ do total de esforços, para todos os pilares, estão acima dos obtidos pelo P-Delta, e 75\%, abaixo, ou seja, 16 esforços estão acima e 48 abaixo. Em relação aos valores obtidos pelo P-Delta, dos que ficaram abaixo, eles são em média 2,86\% menores, e dos que ficaram acima, 5,37\% maiores.

Se em vez de $0,95 \gamma_{\mathrm{z}}$ fosse considerado o valor integral de $\gamma_{\mathrm{z}}$ para majoração dos esforços horizontais, obter-se-iam os resultados mostrados na tabela 6.7 , consideração que também vale para o FAVt.

Comparando-se os esforços obtidos por $\gamma_{\mathrm{z}}$ e FAVt, idênticos neste caso, com os relativos ao P-Delta, pode-se perceber que 75\% dos esforços estão acima dos referentes ao P-Delta, e 25\% estão abaixo, ou seja, 48 dos esforços estão acima e 16 abaixo. Em relação aos obtidos pelo P-Delta, dos que ficaram abaixo, eles são em média 4,36\% menores, e dos que ficaram acima, 3,94\% maiores.

Tabela 6.7. Momento fletor de cálculo com efeitos de $2^{a}$ ordem global $\left(\gamma_{z}\right)$.

\begin{tabular}{|c|c|c|c|c|c|c|c|c|c|c|c|c|}
\hline \multicolumn{9}{|c}{ MOMENTO FLETOR DE CÁLCULO COM EFEITOS DE 2a ORDEM GLOBAL (kN.m) } \\
\hline \multirow{2}{*}{ PILARES } & \multicolumn{3}{|c|}{ COMB. 1 } & \multicolumn{3}{c|}{ COMB. 2 } & \multicolumn{3}{c|}{ COMB. 3 } & \multicolumn{3}{c|}{ COMB. 4 } \\
\cline { 2 - 15 } & GAMA-Z & FAVt & P-DELTA & GAMA-Z & FAVt & P-DELTA & GAMA-Z & FAVt & P-DELTA & GAMA-Z & FAVt & P-DELTA \\
\hline P1 & 681,48 & 681,48 & 661,86 & 13,47 & 13,47 & 13,16 & 710,29 & 710,29 & 689,22 & 15,36 & 15,36 & 15,65 \\
\hline P2 & 711,28 & 711,28 & 689,70 & 2,06 & 2,06 & 1,92 & 715,15 & 715,15 & 693,38 & 1,81 & 1,81 & 1,95 \\
\hline P3 & 715,15 & 715,15 & 693,39 & 2,06 & 2,06 & 1,92 & 711,28 & 711,28 & 689,70 & 1,81 & 1,81 & 1,95 \\
\hline P4 & 710,29 & 710,29 & 689,22 & 13,47 & 13,47 & 13,16 & 681,46 & 681,46 & 661,86 & 15,36 & 15,36 & 15,65 \\
\hline P5 & 5,22 & 5,22 & 4,72 & 653,95 & 653,95 & 633,12 & 6,34 & 6,34 & 6,83 & 665,50 & 665,50 & 645,22 \\
\hline P6 & 13,27 & 13,27 & 13,10 & 650,41 & 650,41 & 627,93 & 13,09 & 13,09 & 13,24 & 676,76 & 676,76 & 654,86 \\
\hline P7 & 13,09 & 13,09 & 13,24 & 650,41 & 650,41 & 627,93 & 13,27 & 13,27 & 13,10 & 676,76 & 676,76 & 654,86 \\
\hline P8 & 6,34 & 6,34 & 6,83 & 653,95 & 653,95 & 633,12 & 5,21 & 5,21 & 4,72 & 665,50 & 665,50 & 645,22 \\
\hline P9 & 5,22 & 5,22 & 4,72 & 665,50 & 665,50 & 645,22 & 6,34 & 6,34 & 6,83 & 653,95 & 653,95 & 633,12 \\
\hline P10 & 13,27 & 13,27 & 13,10 & 676,76 & 676,76 & 654,86 & 13,09 & 13,09 & 13,26 & 650,41 & 650,41 & 627,93 \\
\hline P11 & 13,09 & 13,09 & 13,24 & 676,76 & 676,76 & 654,86 & 13,27 & 13,27 & 13,10 & 650,41 & 650,41 & 627,93 \\
\hline P12 & 6,34 & 6,34 & 6,83 & 665,50 & 665,50 & 645,22 & 5,21 & 5,21 & 4,72 & 653,95 & 653,95 & 633,12 \\
\hline P13 & 681,46 & 681,46 & 661,86 & 15,36 & 15,36 & 15,65 & 710,29 & 710,29 & 689,22 & 13,47 & 13,47 & 13,16 \\
\hline P14 & 711,27 & 711,27 & 689,70 & 1,81 & 1,81 & 1,95 & 715,15 & 715,15 & 693,38 & 2,06 & 2,06 & 1,92 \\
\hline P15 & 715,15 & 715,15 & 693,38 & 1,81 & 1,81 & 1,95 & 711,27 & 711,27 & 689,70 & 2,07 & 2,07 & 1,92 \\
\hline P16 & 710,29 & 710,29 & 689,22 & 15,34 & 15,34 & 15,65 & 681,48 & 681,48 & 661,86 & 13,47 & 13,47 & 13,16 \\
\hline
\end{tabular}

Neste caso nota-se que os esforços abaixo dos obtidos com o P-Delta se distanciaram um pouco mais do que no caso anterior, porém a quantidade desses que ficaram abaixo foi reduzida de $75 \%$ para $25 \%$ do total de esforços. 
Pode-se assim concluir que para os momentos fletores também se obtém melhores resultados com a majoração dos esforços horizontais por $\gamma_{\mathrm{z}}$ apenas.

\subsubsection{ALTERNATI VA PARA CONSI DERAR A NÃO-LI NEARI DADE FÍ SI CA}

Segundo o item 15.7.3 da NBR 6118:2003, pode-se considerar um valor único igual a 0,7 EI para pilares e vigas, somente quando a estrutura de contraventamento for composta exclusivamente por vigas e pilares e $\gamma_{\mathrm{z}} \leq 1,3$.

Como essas exigências são atendidas pelo exemplo em questão, esta alternativa pode ser considerada. Os respectivos resultados são mostrados na tabela 6.8 .

Tabela 6.8. Parâmetros de estabilidade para rigidez 0,7 EI em pilares e vigas.

\begin{tabular}{|c|c|c|c|c|}
\hline \multicolumn{5}{|c|}{ PARÂMETRO DE ESTABILIDADE } \\
\hline Ang. & $\boldsymbol{\alpha}$ & GAMA-Z & FAVt & RM2M1 \\
\hline $0^{\circ}$ & 0,753 & 1,174 & 1,174 & 1,178 \\
\hline $90^{\circ}$ & 0,729 & 1,161 & 1,161 & 1,164 \\
\hline $180^{\circ}$ & 0,753 & 1,174 & 1,174 & 1,178 \\
\hline $270^{\circ}$ & 0,729 & 1,161 & 1,161 & 1,164 \\
\hline
\end{tabular}

Comparando-se esses resultados com os indicados na tabela 6.1 , percebese que os valores do parâmetros de estabilidade são menores quando a redução da rigidez é considerada por um valor único para pilares e vigas. Isso pode ser justificado pelo fato do pórtico ficar mais rígido, gerando menores deslocamentos horizontais e, consequentemente, também menores esforços de segunda ordem. Vale ressaltar que os valores de $\alpha$ não se alteraram, pois eles não são calculados considerando a redução da rigidez do pórtico. Como já foi explicado, deve-se considerar a rigidez integral, pois a consideração da não-linearidade física já está embutida no valor de $\alpha$ limite, ao qual o valor calculado de $\alpha$ será comparado. 


\subsection{EXEMPLO 2}

Este segundo exemplo, com pavimento tipo mostrado na figura 6.4 (e vista em 3D na figura 6.5), possui 14 pavimentos, e é um edifício excêntrico, pois possui balanço somente de um lado. Como o exemplo anterior, também tem o único propósito de mostrar como os esforços de segunda ordem globais são considerados nos pilares.

Vale ressaltar que, para este exemplo, também seria impossível dimensionar as seções utilizadas, pois elas foram reduzidas propositadamente para que resultasse um valor elevado de $\gamma_{\mathrm{z}}$.

Os carregamentos horizontais e verticais também foram aleatórios, com intuito de se obter valores elevados dos parâmetros de estabilidade. A nãolinearidade física foi considerada de forma aproximada, por meio da redução da rigidez dos pilares e vigas, sendo considerada 0,8 EI para os pilares e 0,4 EI para as vigas.

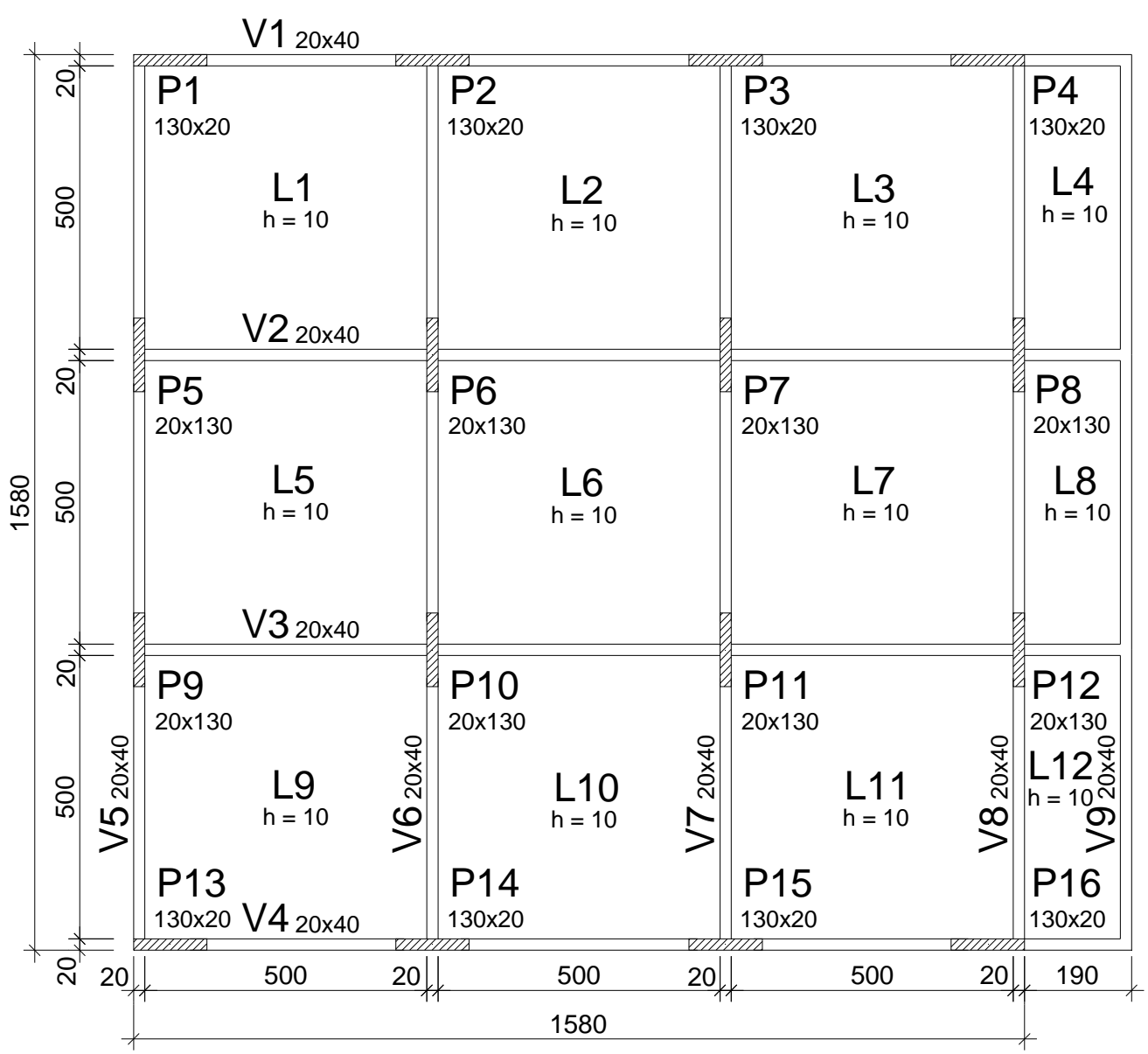

Figura 6.4. Planta de forma do pavimento tipo (dimensões em cm). 


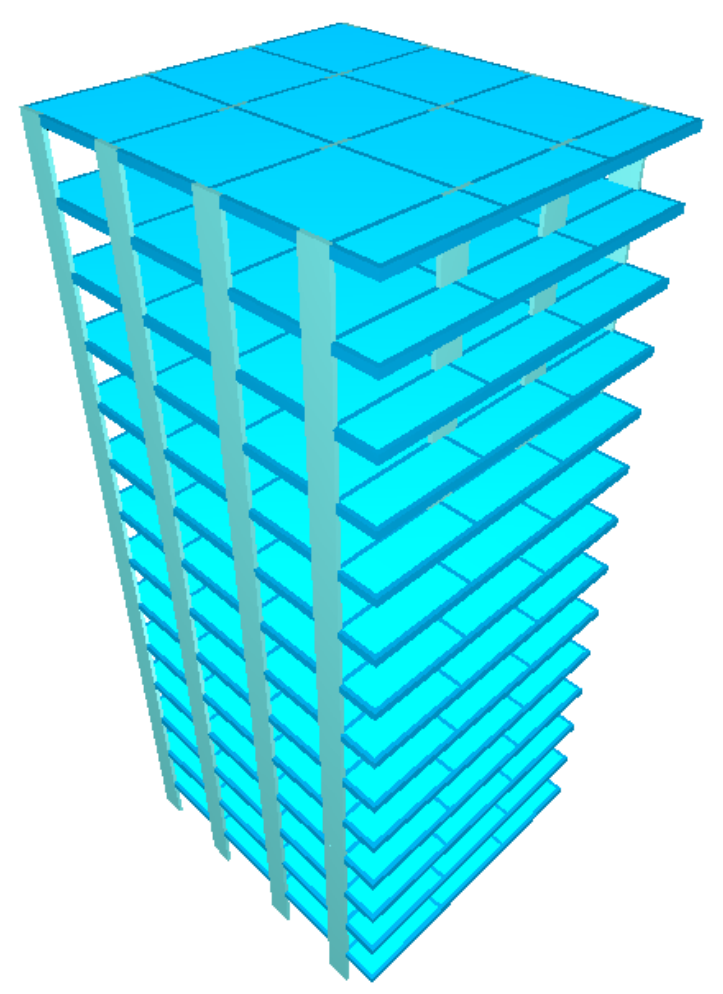

Figura 6.5. Vista em perspectiva do edifício analisado.

\subsubsection{PARÂMETROS DE ESTABI LI DADE}

A tabela 6.9 indica os resultados de $\alpha, \gamma_{z}, F A V t$ e RM2M1, que podem ser considerados parâmetros de estabilidade. Os três últimos referem-se à rigidez 0,8 EI nos pilares e 0,4 EI nas vigas

Como já foi explicado no item 6.1.1, para se obter o valor correto de $\alpha$ pelo Sistema TQS, não se deve considerar a redução da rigidez.

Tabela 6.9. Parâmetros de estabilidade.

\begin{tabular}{|c|c|c|c|c|}
\hline \multicolumn{5}{|c|}{ PARÂMETRO DE ESTABILIDADE } \\
\hline Ang. & $\boldsymbol{\alpha}$ & GAMA-Z & FAVt & RM2M1 \\
\hline $0^{\circ}$ & 0,689 & 1,206 & 1,260 & 1,260 \\
\hline $90^{\circ}$ & 0,675 & 1,191 & 1,191 & 1,195 \\
\hline $180^{\circ}$ & 0,689 & 1,206 & 1,206 & 1,162 \\
\hline $270^{\circ}$ & 0,675 & 1,191 & 1,191 & 1,195 \\
\hline
\end{tabular}


Neste exemplo, verifica-se que os valores de $\gamma_{z}$ e $F A V t$ não são sempre iguais, pois a estrutura não é totalmente simétrica. São iguais na direção $90^{\circ} \mathrm{e}$ $270^{\circ}$, em que a estrutura é simétrica. Deveriam ser diferentes na direção $0^{\circ} \mathrm{e}$ $180^{\circ}$, pois há um balanço do lado direito do edifício, e os deslocamentos gerados por essa excentricidade só afetariam essa direção ( $0^{\circ}$ e $\left.180^{\circ}\right)$.

Como pode ser visto na tabela 6.9 , no sentido $0^{\circ}$, o valor de $\gamma_{z}$ é menor que o do $F A V t$, pois o vento a $0^{\circ}$ é da esquerda para a direita, provocando deslocamentos para a direita. Os deslocamentos gerados pela excentricidade também são para a direita, aumentando o deslocamento horizontal e o valor do coeficiente FAVt para 1,260.

No sentido $180^{\circ}$, o valor de $\gamma_{z}$ é igual ao do $F A V t$, sendo que deveria ser maior, pois o vento a $180^{\circ}$ é da direita para a esquerda, deslocando a estrutura para a esquerda. Porém, o balanço à direita faz com que os deslocamentos gerados pela excentricidade sejam para a direita. Assim, um alivia o outro e, portanto, o deslocamento resultante seria menor, diminuindo o valor do coeficiente FAVt. Nesta situação, o Sistema TQS, a favor da segurança, adota o valor de $F A V t$ igual ao de $\gamma_{z}$.

Convém destacar que o valor real do FAVt deveria estar em torno do obtido pelo processo P-Delta, ou seja, em torno do valor de $R M 2 M 1=1,162$.

Outra observação é que todos os parâmetros mostrados na tabela 6.9 indicam que a estrutura é de nós móveis.

\subsubsection{ANÁLI SE DE SEGUNDA ORDEM GLOBAL}

De posse dos valores dos parâmetros de estabilidade, podem-se fazer as análises de segunda ordem global. Porém, neste exemplo, os valores de $\gamma_{z}$ e $F A V t$ não são idênticos, e para o cálculo do $F A V t$ foi considerada uma redução dos deslocamentos gerados pelas cargas verticais, sendo essa redução de $50 \%$ para cargas de peso próprio e $25 \%$ para as demais cargas permanentes, pelos motivos já mencionados no capítulo 2.

A análise é similar à anterior, mas vale lembrar que as parcelas de peso próprio, demais cargas permanentes, carga acidental e vento, das combinações consideradas, foram obtidas no visualizador do pórtico espacial do Sistema TQS. 
Será mostrado como é realizado o cálculo dos esforços na base do pilar P1, para as quatro combinações, considerando 0,95 $\gamma_{z}$ e 0,95 FAVt. Na tabela 6.10, são indicados os esforços normais de cálculo de primeira ordem, e na tabela 6.11 , os esforços finais na base de todos os pilares do pórtico tridimensional.

Destaca-se que o Sistema TQS sempre utiliza o FAVt como majorador de esforços. Aqui os esforços serão majorados pelos dois coeficientes, para se fazer a comparação. Caso o usuário queira utilizar o $\gamma_{z}$, deve desativar a opção "considerar deslocamentos horizontais de carga vertical". No apêndice A deste trabalho, é mostrado como fazer essa alteração. Para a primeira combinação têm-se dois esforços distintos, pois há valores diferentes de $\gamma_{z}$ e FAVt.

COMB. $1\left(0,95 \gamma_{\mathrm{z}}\right)$ : Peso próprio + carga perm. + carga acid. + 0,6 vento 00 $N_{d}=\gamma_{\mathrm{g}} \cdot(P P+C P)+\gamma_{\mathrm{q}} \cdot\left(C A+0,95 \gamma_{\mathrm{z}} \cdot \Psi_{0 \mathrm{j}} \cdot\right.$ Vento $\left.0^{0}\right)$

$N_{d}=1,4 \cdot(522,35+623,19)+1,4 \cdot(188,80+0,95 \cdot 1,206 \cdot 0,6 \cdot-662,23)$

$N_{d}=1,4 \cdot(1145,54)+1,4 \cdot(-266,43)$

$N_{d}=1230,75 \mathrm{kN}$

COMB. $1(0,95 F A V t)$ : Peso próprio + carga perm. + carga acid. + 0,6 vento 00 $N_{d}=\gamma_{\mathrm{g}} \cdot(P P+C P)+\gamma_{\mathrm{q}} \cdot\left(C A+0,95 F A V t \cdot \Psi_{0 \mathrm{j}} \cdot\right.$ Vento $\left.0^{0}\right)$

$N_{d}=1,4 \cdot(522,35+623,19)+1,4 \cdot(188,80+0,95 \cdot 1,260 \cdot 0,6 \cdot-662,23)$

$N_{d}=1,4 \cdot(1145,54)+1,4 \cdot(-286,81)$

$N_{d}=1202,22 \mathrm{kN}$

COMB. $2\left(0,95 \gamma_{\mathrm{z}}\right)$ : Peso próprio + carga perm. + carga acid. + 0,6 vento $90^{\circ}$ $N_{d}=\gamma_{\mathrm{g}} \cdot(P P+C P)+\gamma_{\mathrm{q}} \cdot\left(C A+0,95 \gamma_{\mathrm{z}} \cdot \Psi_{0 \mathrm{j}} \cdot\right.$ Vento $\left.90^{\circ}\right)$

$N_{d}=1,4 \cdot(522,35+623,19)+1,4 \cdot(188,80+0,95 \cdot 1,191 \cdot 0,6 \cdot 282,59)$

$N_{d}=1,4 \cdot(1145,54)+1,4 \cdot(380,64)$

$N_{d}=2136,65 \mathrm{kN}$

COMB. $3\left(0,95 \gamma_{\mathrm{z}}\right)$ : Peso próprio + carga perm. + carga acid. + 0,6 vento $180^{\circ}$ $N_{d}=\gamma_{\mathrm{g}} \cdot(P P+C P)+\gamma_{\mathrm{q}} \cdot\left(C A+0,95 \gamma_{\mathrm{z}} \cdot \Psi_{0 \mathrm{j}} \cdot\right.$ Vento $\left.180^{\circ}\right)$

$N_{d}=1,4 \cdot(522,35+623,19)+1,4 \cdot(188,80+0,95 \cdot 1,206 \cdot 0,6 \cdot 662,23)$

$N_{d}=1,4 \cdot(1145,54)+1,4 \cdot(644,03)$

$N_{d}=2505,40 \mathrm{kN}$ 
COMB. $4\left(0,95 \gamma_{\mathrm{z}}\right)$ : Peso próprio + carga perm. + carga acid. + 0,6 vento $270^{\circ}$

$$
\begin{aligned}
& N_{d}=\gamma_{\mathrm{g}} \cdot(P P+C P)+\gamma_{\mathrm{q}} \cdot\left(C A+0,95 \gamma_{\mathrm{z}} \cdot \Psi_{0 \mathrm{j}} \cdot \text { Vento } 270^{0}\right) \\
& N_{d}=1,4 \cdot(522,35+623,19)+1,4 \cdot(188,80+0,95 \cdot 1,191 \cdot 0,6 \cdot-282,59) \\
& N_{d}=1,4 \cdot(1145,54)+1,4 \cdot(-3,04) \\
& N_{d}=1599,50 \mathrm{kN}
\end{aligned}
$$

Comparando-se os esforços obtidos com $0,95 \gamma_{z}$ e $0,95 F A V t$, diferentes neste caso, com os obtidos pelo processo P-Delta, pode-se perceber que, em relação a $0,95 \gamma_{\mathrm{z}}, 50 \%$ do total de esforços estão acima dos relativos ao P-Delta, e 50\% estão abaixo, ou seja, 32 esforços estão acima e 32 abaixo. Em relação ao P-Delta, dos que ficaram abaixo, eles estão em média 0,45\% menores, e dos que ficaram acima, 0,65\% maiores.

Em relação a 0,95FAVt, 50\% do total de esforços também estão acima do valor obtido pelo P-Delta e 50\% estão abaixo, ou seja, 32 esforços estão acima e 32 abaixo. Em relação ao valor obtido por P-Delta, dos que ficaram abaixo, eles estão em média 0,39\% menores, e dos que ficaram acima, 0,48\% maiores. Portanto, percebe-se que, para este caso, usar $0,95 F A V t$ é melhor que $0,95 \gamma_{z}$.

Em vez de $0,95 \gamma_{\mathrm{z}}$ e $0,95 \mathrm{FAVt}$, se fossem considerados os valores integrais de $\gamma_{z}$ e FAVt para majoração dos esforços horizontais, obter-se-iam os resultados mostrados na tabela 6.12 .

Comparando-se os esforços obtidos por $\gamma_{\mathrm{z}}$ com os relativos ao P-Delta, pode-se perceber que $53 \%$ do total de esforços, para todos os pilares, estão acima dos obtidos com o P-Delta, e 47\% estão abaixo, ou seja, 34 esforços estão acima e 30 abaixo. Em relação aos valores obtidos por P-Delta, dos que ficaram abaixo, eles estão em média 0,11\% menores, e dos que ficaram acima, 0,16\% maiores. Nota-se que os esforços abaixo dos referentes ao P-Delta se distanciaram bem menos que no caso anterior, sendo também um pouco menor a quantidade de esforços que ficaram abaixo.

Em relação ao $F A V t, 53 \%$ do total de esforços, para todos os pilares, também estão acima dos obtidos com o P-Delta, e $47 \%$ estão abaixo, ou seja, também 34 esforços estão acima e 30 abaixo. Em relação aos valores obtidos por P-Delta, dos que ficaram abaixo, eles estão em média 0,21\% menores, e dos que ficaram acima, $0,13 \%$ maiores. 
Tabela 6.10. Força normal de cálculo de $1^{\mathrm{a}}$ ordem.

\begin{tabular}{|c|c|c|c|c|}
\hline \multicolumn{5}{|c|}{ ESFORÇOS NORMAIS DE CÁLCULO DE 1a ORDEM (kN) } \\
\hline PILARES & COMB.1 & COMB.2 & COMB.3 & COMB.4 \\
\hline P1 & 1311,79 & 2105,45 & 2424,35 & 1630,69 \\
\hline P2 & 3516,20 & 3641,13 & 3299,83 & 3174,9 \\
\hline P3 & 3159,96 & 3497,75 & 3329,71 & 2991,92 \\
\hline P4 & 4211,26 & 3930,27 & 3174,7 & 3455,69 \\
\hline P5 & 3789,21 & 4139,63 & 4032,38 & 3681,96 \\
\hline P6 & 8280,06 & 8526,47 & 8219,7 & 7973,29 \\
\hline P7 & 7478,79 & 7799,62 & 7540,38 & 7219,54 \\
\hline P8 & 7970,37 & 8116,86 & 7696,62 & 7550,14 \\
\hline P9 & 3789,21 & 3681,96 & 4032,38 & 4139,64 \\
\hline P10 & 8280,06 & 7973,29 & 8219,7 & 8526,47 \\
\hline P11 & 7478,78 & 7219,54 & 7540,37 & 7799,62 \\
\hline P12 & 7970,37 & 7550,13 & 7696,62 & 8116,85 \\
\hline P13 & 1311,79 & 1630,69 & 2424,34 & 2105,44 \\
\hline P14 & 3516,20 & 3174,9 & 3299,83 & 3641,13 \\
\hline P15 & 3159,96 & 2991,91 & 3329,7 & 3497,75 \\
\hline P16 & 4211,27 & 3455,7 & 3174,71 & 3930,28 \\
\hline
\end{tabular}

Tabela 6.11. Força normal de cálculo com efeitos de $2^{a}$ ordem global $\left(0,95 \gamma_{z}\right)$.

\begin{tabular}{|c|c|c|c|c|c|c|c|c|c|c|c|c|}
\hline \multicolumn{13}{|c|}{ FORÇA NORMAL DE CÁLCULO NA BASE DO PILAR COM EFEITOS DE 2a ORDEM GLOBAL (kN) } \\
\hline \multirow{2}{*}{ PILARES } & \multicolumn{3}{|c|}{ СОМв. 1} & \multicolumn{3}{|c|}{ СОМв. 2} & \multicolumn{3}{|c|}{ СОМв. 3} & \multicolumn{3}{|c|}{ СОМв. 4} \\
\hline & GAMA-Z & FAVt & P-DELTA & GAMA-Z & FAVt & P-DELTA & GAMA-Z & FAVt & P-DELTA & GAMA-Z & FAVt & P-DELTA \\
\hline P1 & 30, & 202,22 & 86,22 & 136,65 & 2136,65 & 94 & 2505,40 & 2505,40 & 2549 & 1599, & 1599 & 577,80 \\
\hline $\mathbf{P 2}$ & 532,06 & 537,52 & 3541,16 & 3671,64 & 3671,64 & 3686,62 & 3283,98 & 3283,98 & 3274,74 & 3144,40 & 3144,40 & 3129,42 \\
\hline $\mathbf{P 3}$ & 3147,62 & 3143,28 & 3140,20 & 3530,94 & 3530,94 & 3551,80 & 3342,08 & 3342,08 & 3349,36 & 2958,76 & 2958,76 & 2938,04 \\
\hline P4 & 4286,94 & 4313,40 & 4328,24 & 3961,30 & 3961,30 & 3975,16 & 3099,04 & 3099,04 & 3057,74 & 3424,54 & 3424,54 & 3410,40 \\
\hline P5 & 3771,46 & 3765,30 & 3762,22 & 4169,62 & 4169,62 & 4184,88 & 4050,06 & 4050,06 & 4059,44 & 3652,04 & 3652,04 & 3636,78 \\
\hline P6 & 8284,50 & 8286,04 & 8287,02 & 8562,68 & 8562,68 & 8582,56 & 8215,34 & 8215,34 & 8212,82 & 7937,02 & 7937,02 & 7917,00 \\
\hline P7 & 7474,32 & 7472,78 & 7471,80 & 7837,62 & 7837,62 & 7861,14 & 7544,88 & 7544,88 & 7547,40 & 7181,58 & 7181,58 & 7157,92 \\
\hline P8 & 7990,36 & 7997,36 & 8000,72 & 8154,02 & 8154,02 & 8177,96 & 7676,62 & 7676,62 & 7666,26 & 7512,96 & 7512,96 & 7488,88 \\
\hline P9 & 3771,46 & 3765,30 & 3762,22 & 3652,04 & 3652,04 & 3636,78 & 4050,06 & 4050,06 & 4059,44 & 4169,62 & 4169,62 & 4184,88 \\
\hline P10 & 8284,50 & 8286,04 & 8287,02 & 7937,02 & 7937,02 & 7917,00 & 8215,34 & 8215,34 & 8212,82 & 8562,68 & 8562,68 & 8582,56 \\
\hline P11 & 7474,32 & 7472,78 & 7471,80 & 7181,58 & 7181,58 & 7157,92 & 7544,88 & 7544,88 & 7547,40 & 7837,62 & 7837,62 & 7861,14 \\
\hline P12 & 7990,36 & 7997,36 & 8000,72 & 7512,96 & 7512,96 & 7488,88 & 7676,62 & 7676,62 & 7666,26 & 8154,02 & 8154,02 & 8177,96 \\
\hline P13 & 1230,60 & 1202,18 & 1186,22 & 1599,64 & 1599,64 & 1577,80 & 2505,58 & 2505,58 & 2549,82 & 2136,54 & 2136,54 & 2158,94 \\
\hline P14 & 3532,06 & 3537,52 & 3541,16 & 3144,40 & 3144,40 & 3129,42 & 3283,98 & 3283,98 & 3274,74 & 3671,64 & 3671,64 & 3686,62 \\
\hline P15 & 3147,62 & 3143,28 & 3140,20 & 2958,76 & 2958,76 & 2938,04 & 3342,08 & 3342,08 & 3349,36 & 3530,94 & 3530,94 & 3551,80 \\
\hline P16 & 4286,94 & 4313,40 & 4328,24 & 3424,54 & 3424,54 & 3410,40 & 3099,04 & 3099,04 & 3057,74 & 3961,30 & 3961,30 & 3975,16 \\
\hline
\end{tabular}


Tabela 6.12. Força normal de cálculo com efeitos de $2^{a}$ ordem global $\left(\gamma_{z}\right)$.

\begin{tabular}{|c|c|c|c|c|c|c|c|c|c|c|c|c|}
\hline \multicolumn{13}{|c|}{ FORÇA NORMAL DE CÁLCULO NA BASE DO PILAR COM EFEITOS DE 2a ORDEM GLOBAL (kN) } \\
\hline \multirow{2}{*}{ PILARES } & \multicolumn{3}{|c|}{ СОМв. 1} & \multicolumn{3}{|c|}{ СОМв. 2} & \multicolumn{3}{|c|}{ СОМв. 3} & \multicolumn{3}{|c|}{ СОМв. 4} \\
\hline & GAMA-Z & FAVt & P-DELTA & GAMA-Z & FAVt & P-DELTA & GAMA-Z & FAVt & P-DELTA & GAMA-Z & FAVt & P-DELTA \\
\hline P1 & 1197,14 & 1167,18 & 1186,22 & 2158,94 & 2549,82 & 1577,80 & 2538,90 & 2538,90 & 2549,82 & 1585,36 & 1585,36 & 1577,80 \\
\hline $\mathbf{P 2}$ & 3538,50 & 3544,38 & 3541,16 & 3686,62 & 3274,74 & 3129,42 & 3277,54 & 3277,54 & 3274,74 & 3130,40 & 3130,40 & 3129,42 \\
\hline $\mathbf{P 3}$ & 3142,44 & 3137,82 & 3140,20 & 3551,80 & 3349,36 & 2938,04 & 3347,26 & 3347,26 & 3349,36 & 2943,64 & 2943,64 & 2938,04 \\
\hline P4 & 4318,02 & 4346,02 & 4328,24 & 3975,16 & 3057,74 & 3410,40 & 3067,96 & 3067,96 & 3057,74 & 3410,40 & 3410,40 & 3410,40 \\
\hline P5 & 3764,18 & 3757,60 & 3762,22 & 4184,88 & 4059,44 & 3636,78 & 4057,48 & 4057,48 & 4059,44 & 3638,32 & 3638,32 & 3636,78 \\
\hline P6 & 8286,32 & 8287,86 & 8287,02 & 8582,56 & 8212,82 & 7917,00 & 8213,52 & 8213,52 & 8212,82 & 7920,50 & 7920,50 & 7917,00 \\
\hline P7 & 7472,50 & 7470,82 & 7471,80 & 7861,14 & 7547,40 & 7157,92 & 7546,70 & 7546,70 & 7547,40 & 7164,08 & 7164,08 & 7157,92 \\
\hline P8 & 7998,62 & 8005,90 & 8000,72 & 8177,96 & 7666,26 & 7488,88 & 7668,50 & 7668,50 & 7666,26 & 7496,02 & 7496,02 & 7488,88 \\
\hline P9 & 3764,18 & 3757,60 & 3762,22 & 3636,78 & 4059,44 & 4184,88 & 4057,48 & 4057,48 & 4059,44 & 4183,34 & 4183,34 & 4184,88 \\
\hline P10 & 8286,32 & 8287,86 & 8287,02 & 7917,00 & 8212,82 & 8582,56 & 8213,52 & 8216,32 & 8212,82 & 8579,34 & 8579,34 & 8582,56 \\
\hline P11 & 7472,50 & 7470,82 & 7471,80 & 7157,92 & 7547,40 & 7861,14 & 7546,70 & 7546,70 & 7547,40 & 7854,98 & 7854,98 & 7861,14 \\
\hline P12 & 7998,62 & 8005,90 & 8000,72 & 7488,88 & 7666,26 & 8177,96 & 7668,36 & 7668,36 & 7666,26 & 8170,96 & 8170,96 & 8177,96 \\
\hline P13 & 1197,14 & 1167,18 & 1186,22 & 1577,80 & 2549,82 & 2158,94 & 2538,90 & 2538,90 & 2549,82 & 2150,82 & 2150,82 & 2158,94 \\
\hline P14 & 3538,50 & 3544,38 & 3541,16 & 3129,42 & 3274,74 & 3686,62 & 3277,54 & 3277,54 & 3274,74 & 3685,64 & 3685,64 & 3686,62 \\
\hline P15 & 3142,44 & 3137,82 & 3140,20 & 2938,04 & 3349,36 & 3551,80 & 3347,26 & 3347,26 & 3349,36 & 3546,06 & 3546,06 & 3551,80 \\
\hline P16 & 4318,02 & 4346,02 & 4328,24 & 3410,40 & 3057,74 & 3975,16 & 3067,96 & 3067,96 & 3057,74 & 3975,58 & 3975,58 & 3975,16 \\
\hline
\end{tabular}

Para este caso, em relação aos esforços obtidos por $\gamma_{\mathrm{z}}$ e $F A V t$, eles foram bem próximos. Porém, os resultados obtidos por $\gamma_{\mathrm{z}}$ ficaram pouca coisa a favor da segurança. Mas em relação à majoração dos esforços horizontais por $0,95 \gamma_{\mathrm{z}} \mathrm{e}$ $0,95 F A V t$ ou por $\gamma_{\mathrm{z}}$ e FAVt, estes últimos apresentaram melhores resultados, também para este exemplo.

Para os momentos fletores na base do pilares, o cálculo é mostrado em detalhes somente para o pilar P1. Na tabela 6.13 encontram-se os valores, em módulo, dos momentos de cálculo de primeira ordem na base para todos os pilares, sendo esses momentos relativos à direção mais rígida de cada pilar. $\mathrm{Na}$ tabela 6.14 encontram-se os momentos finais ( $1^{\mathrm{a}}$ ordem $+2^{\mathrm{a}}$ ordem).

COMB. $1\left(0,95 \gamma_{z}\right)$ : Peso próprio + carga perm. + carga acid. + 0,6 vento 00

$$
\begin{aligned}
& M_{d}=\gamma_{\mathrm{g}} \cdot(P P+C P)+\gamma_{\mathrm{q}} \cdot\left(C A+0,95 \gamma_{\mathrm{z}} \cdot \Psi_{0 \mathrm{j}} \cdot \text { Vento } 0^{0}\right) \\
& M_{d}=1,4 \cdot(17,23+55,38)+1,4 \cdot(7,30+0,95 \cdot 1,206 \cdot 0,6 \cdot 841,12) \\
& M_{d}=1,4 \cdot(72,61)+1,4 \cdot(585,50) \\
& M_{d}=921,35 \mathrm{kN} . \mathrm{m}
\end{aligned}
$$


COMB. $1(0,95 F A V t)$ : Peso próprio + carga perm. + carga acid. + 0,6 vento 00 $M_{d}=\gamma_{\mathrm{g}} \cdot(P P+C P)+\gamma_{\mathrm{q}} \cdot\left(C A+0,95 F A V t \cdot \Psi_{0 \mathrm{j}} \cdot\right.$ Vento $\left.0^{0}\right)$

$M_{d}=1,4 \cdot(17,23+55,38)+1,4 \cdot(7,30+0,95 \cdot 1,260 \cdot 0,6 \cdot 841,12)$

$M_{d}=1,4 \cdot(72,61)+1,4 \cdot(611,39)$

$M_{d}=957,60 \mathrm{kN} \cdot \mathrm{m}$

COMB. $2\left(0,95 \gamma_{z}\right)$ : Peso próprio + carga perm. + carga acid. + 0,6 vento $90^{\circ}$ $M_{d}=\gamma_{\mathrm{g}} \cdot(P P+C P)+\gamma_{\mathrm{q}} \cdot\left(C A+0,95 \gamma_{\mathrm{z}} \cdot \Psi_{0 \mathrm{j}} \cdot\right.$ Vento $\left.90^{0}\right)$

$M_{d}=1,4 \cdot(17,23+55,38)+1,4 \cdot(7,30+0,95 \cdot 1,191 \cdot 0,6 \cdot-50,80)$

$M_{d}=1,4 \cdot(72,61)+1,4 \cdot(-27,19)$

$M_{d}=63,59 \mathrm{kN} . \mathrm{m}$

COMB. $3\left(0,95 \gamma_{\mathrm{z}}\right)$ : Peso próprio + carga perm. + carga acid. + 0,6 vento $180^{\circ}$ $M_{d}=\gamma_{\mathrm{g}} \cdot(P P+C P)+\gamma_{\mathrm{q}} \cdot\left(C A+\Psi_{0 \mathrm{j}} \cdot 0,95 \gamma_{\mathrm{z}} \cdot\right.$ Vento $\left.180^{\circ}\right)$

$M_{d}=1,4 \cdot(17,23+55,38)+1,4 \cdot(7,30+0,95 \cdot 1,206 \cdot 0,6 \cdot-841,12)$

$M_{d}=1,4 \cdot(72,61)+1,4 \cdot(-570,90)$

$M_{d}=-697,61 \mathrm{kN} \cdot \mathrm{m}$

COMB. $4\left(0,95 \gamma_{\mathrm{z}}\right)$ : Peso próprio + carga perm. + carga acid. + 0,6 vento $270^{\circ}$ $M_{d}=\gamma_{\mathrm{g}} \cdot(P P+C P)+\gamma_{\mathrm{q}} \cdot\left(C A+\Psi_{0 \mathrm{j}} \cdot 0,95 \gamma_{\mathrm{z}} \cdot\right.$ Vento $\left.270^{\circ}\right)$

$M_{d}=1,4 \cdot(17,23+55,38)+1,4 \cdot(7,30+0,95 \cdot 1,191 \cdot 0,6 \cdot 50,80)$

$M_{d}=1,4 \cdot(72,61)+1,4 \cdot(41,79)$

$M_{d}=160,16 \mathrm{kN} \cdot \mathrm{m}$

Comparando-se os esforços obtidos por $0,95 \gamma_{\mathrm{z}}$ com os referentes ao processo P-Delta, pode-se perceber que apenas $25 \%$ do total de esforços, para todos os pilares, estão acima dos relativos ao P-Delta, e 75\%, abaixo, ou seja, 16 esforços estão acima e 48 abaixo.

Em relação ao P-Delta, dos que ficaram abaixo, eles estão em média 2,99\% menores, dos que ficaram acima, 9,81\% maiores. 
Tabela 6.13. Momentos fletores de cálculo de $1^{\text {a }}$ ordem.

\begin{tabular}{|c|c|c|c|c|}
\hline \multicolumn{5}{|c|}{ MOMENTOS FLETORES DE CÁLCULO DE 1a ORDEM (kN.m) } \\
\hline PILARES & COMB.1 & COMB.2 & COMB.3 & COMB.4 \\
\hline P1 & 818,42 & 69,21 & 594,66 & 154,55 \\
\hline P2 & 837,09 & 77,75 & 593,75 & 165,59 \\
\hline P3 & 837,97 & 79,26 & 591,66 & 167,06 \\
\hline P4 & 808,67 & 58,34 & 603,15 & 147,19 \\
\hline P5 & 5,01 & 712,15 & 5,32 & 722,48 \\
\hline P6 & 11,11 & 737,39 & 10,91 & 759,42 \\
\hline P7 & 11,07 & 766,91 & 11,08 & 789,07 \\
\hline P8 & 9,50 & 798,53 & 8,76 & 816,78 \\
\hline P9 & 5,00 & 722,47 & 5,31 & 712,16 \\
\hline P10 & 11,11 & 759,42 & 10,91 & 737,40 \\
\hline P11 & 11,08 & 789,07 & 11,09 & 766,91 \\
\hline P12 & 9,51 & 816,79 & 8,77 & 798,52 \\
\hline P13 & 818,42 & 154,55 & 594,66 & 69,21 \\
\hline P14 & 837,10 & 165,59 & 593,75 & 77,75 \\
\hline P15 & 837,97 & 167,06 & 591,65 & 79,26 \\
\hline P16 & 808,69 & 147,20 & 603,14 & 58,36 \\
\hline
\end{tabular}

Tabela 6.14. Momento fletor de cálculo com efeitos de $2^{a}$ ordem global $\left(0,95 \gamma_{\mathrm{z}}\right)$

\begin{tabular}{|c|c|c|c|c|c|c|c|c|c|c|c|c|}
\hline \multicolumn{7}{|c}{ MOMENTO FLETOR DE CÁLCULO COM EFEITOS DE 2a ORDEM GLOBAL (kN.m) } \\
\hline \multirow{2}{*}{ PILARES } & \multicolumn{3}{|c|}{ COMB. 1 } & \multicolumn{3}{c|}{ COMB. 2 } & \multicolumn{3}{c|}{ COMB. 3 } & \multicolumn{3}{c|}{ COMB. 4 } \\
\cline { 2 - 14 } & GAMA-Z & FAVt & P-DELTA & GAMA-Z & FAVt & P-DELTA & GAMA-Z & FAVt & P-DELTA & GAMA-Z & FAVt & P-DELTA \\
\hline P1 & 921,35 & 957,60 & 943,66 & 63,59 & 63,59 & 55,64 & 697,61 & 697,61 & 719,12 & 160,16 & 160,16 & 167,38 \\
\hline P2 & 941,54 & 978,03 & 962,71 & 72,00 & 72,00 & 63,81 & 698,21 & 698,21 & 719,12 & 171,35 & 171,35 & 178,79 \\
\hline P3 & 942,33 & 978,78 & 962,49 & 73,50 & 73,50 & 65,16 & 696,02 & 696,02 & 716,41 & 172,80 & 172,80 & 180,40 \\
\hline P4 & 911,74 & 947,74 & 930,62 & 52,53 & 52,53 & 44,11 & 706,20 & 706,20 & 725,83 & 153,01 & 153,01 & 160,68 \\
\hline P5 & 4,98 & 4,97 & 4,44 & 806,12 & 806,12 & 818,87 & 5,35 & 5,35 & 5,88 & 816,45 & 816,45 & 829,58 \\
\hline P6 & 11,13 & 11,13 & 10,93 & 835,44 & 835,44 & 853,57 & 10,91 & 10,91 & 11,10 & 857,46 & 857,46 & 875,97 \\
\hline P7 & 11,07 & 11,07 & 11,16 & 868,83 & 868,83 & 891,94 & 11,09 & 11,09 & 10,99 & 890,99 & 890,99 & 914,44 \\
\hline P8 & 9,55 & 9,58 & 9,94 & 904,33 & 904,33 & 932,67 & 8,71 & 8,71 & 8,32 & 922,59 & 922,59 & 951,24 \\
\hline P9 & 4,97 & 4,97 & 4,44 & 816,44 & 816,44 & 829,57 & 5,33 & 5,33 & 5,88 & 806,13 & 806,13 & 818,89 \\
\hline P10 & 11,13 & 11,13 & 10,92 & 857,46 & 857,46 & 875,95 & 10,89 & 10,89 & 11,10 & 835,44 & 835,44 & 853,58 \\
\hline P11 & 11,07 & 11,07 & 11,17 & 890,99 & 890,99 & 914,45 & 11,09 & 11,09 & 11,00 & 868,83 & 868,83 & 891,94 \\
\hline P12 & 9,56 & 9,58 & 9,94 & 922,60 & 922,60 & 951,24 & 8,71 & 8,71 & 8,33 & 904,32 & 904,32 & 932,65 \\
\hline P13 & 921,58 & 957,60 & 943,66 & 160,13 & 160,13 & 167,38 & 697,82 & 697,82 & 719,11 & 63,62 & 63,62 & 55,64 \\
\hline P14 & 941,54 & 978,04 & 962,71 & 171,35 & 171,35 & 178,79 & 698,19 & 698,19 & 719,11 & 72,00 & 72,00 & 63,81 \\
\hline P15 & 942,33 & 978,78 & 962,49 & 172,80 & 172,80 & 180,40 & 696,01 & 696,01 & 716,41 & 73,50 & 73,50 & 65,16 \\
\hline P16 & 911,75 & 947,76 & 930,64 & 153,02 & 153,02 & 160,68 & 706,20 & 706,20 & 725,82 & 52,54 & 52,54 & 44,13 \\
\hline
\end{tabular}


Em relação ao $0,95 F A V t, 37,50 \%$ do total de esforços, para todos os pilares, estão acima dos obtidos pelo P-Delta, e 62,50\%, abaixo, ou seja, 24 esforços estão acima e 40 abaixo.

Tendo como base o P-Delta, dos que ficaram abaixo, eles estão em média $3,00 \%$ menores, dos que ficaram acima, 8,91\% maiores.

Para este caso, em relação aos esforços obtidos por 0,95 $\gamma_{\mathrm{z}}$ e 0,95FAVt, eles ficaram próximos. Porém, com $0,95 F A V t$, os resultados foram um pouco melhores, pois há uma quantidade maior de esforços com valor superior ao obtido pelo P-Delta.

Em vez de $0,95 \gamma_{\mathrm{z}}$ e $0,95 F A V t$, se fossem considerados os valores integrais de $\gamma_{\mathrm{z}}$ e FAVt para majoração dos esforços horizontais, obter-se-iam os resultados mostrados na tabela 6.15 .

Tabela 6.15. Momento fletor de cálculo com efeitos de $2^{a}$ ordem global $\left(\gamma_{z}\right)$.

\begin{tabular}{|c|c|c|c|c|c|c|c|c|c|c|c|c|}
\hline \multicolumn{9}{|c}{ MOMENTO FLETOR DE CÁLCULO COM EFEITOS DE 2a ORDEM GLOBAL (kN.m) } \\
\hline \multirow{2}{*}{ PILARES } & \multicolumn{3}{|c|}{ COMB. 1 } & \multicolumn{3}{c|}{ COMB. 2} & \multicolumn{3}{c|}{ COMB. 3 } & \multicolumn{3}{c|}{ COMB. 4 } \\
\cline { 2 - 15 } & GAMA-Z & FAVt & P-DELTA & GAMA-Z & FAVt & P-DELTA & GAMA-Z & FAVt & P-DELTA & GAMA-Z & FAVt & P-DELTA \\
\hline P1 & 963,97 & 1002,12 & 943,66 & 61,05 & 61,05 & 55,64 & 740,21 & 740,21 & 719,12 & 162,69 & 162,69 & 167,38 \\
\hline P2 & 984,47 & 1023,11 & 962,71 & 69,36 & 69,36 & 63,81 & 741,13 & 741,13 & 719,12 & 173,98 & 173,98 & 178,79 \\
\hline P3 & 985,22 & 1023,82 & 962,49 & 70,87 & 70,87 & 65,16 & 738,91 & 738,91 & 716,41 & 175,43 & 175,43 & 180,40 \\
\hline P4 & 954,09 & 992,21 & 930,62 & 49,85 & 49,85 & 44,11 & 748,57 & 748,57 & 725,83 & 155,67 & 155,67 & 160,68 \\
\hline P5 & 4,97 & 4,97 & 4,44 & 849,16 & 849,16 & 818,87 & 5,35 & 5,35 & 5,88 & 859,49 & 859,49 & 829,58 \\
\hline P6 & 11,13 & 11,14 & 10,93 & 880,33 & 880,33 & 853,57 & 10,89 & 10,89 & 11,10 & 902,37 & 902,37 & 875,97 \\
\hline P7 & 11,07 & 11,07 & 11,16 & 915,52 & 915,52 & 891,94 & 11,09 & 11,09 & 10,99 & 937,66 & 937,66 & 914,44 \\
\hline P8 & 9,58 & 9,59 & 9,94 & 952,78 & 952,78 & 932,67 & 8,68 & 8,68 & 8,32 & 971,05 & 971,05 & 951,24 \\
\hline P9 & 4,96 & 4,96 & 4,44 & 859,47 & 859,47 & 829,57 & 5,35 & 5,35 & 5,88 & 849,17 & 849,17 & 818,89 \\
\hline P10 & 11,13 & 11,13 & 10,92 & 902,37 & 902,37 & 875,95 & 10,89 & 10,89 & 11,10 & 880,35 & 880,35 & 853,58 \\
\hline P11 & 11,07 & 11,07 & 11,17 & 937,66 & 937,66 & 914,45 & 11,09 & 11,09 & 11,00 & 915,50 & 915,50 & 891,94 \\
\hline P12 & 9,58 & 9,60 & 9,94 & 971,05 & 971,05 & 951,24 & 8,69 & 8,69 & 8,33 & 952,78 & 952,78 & 932,65 \\
\hline P13 & 963,97 & 1002,12 & 943,66 & 162,69 & 162,69 & 167,38 & 740,21 & 740,21 & 719,11 & 61,07 & 61,07 & 55,64 \\
\hline P14 & 984,47 & 1023,11 & 962,71 & 173,98 & 173,98 & 178,79 & 741,12 & 741,12 & 719,11 & 69,37 & 69,37 & 63,81 \\
\hline P15 & 985,22 & 1023,82 & 962,49 & 175,45 & 175,45 & 180,40 & 738,91 & 738,91 & 716,41 & 70,87 & 70,87 & 65,16 \\
\hline P16 & 954,11 & 992,24 & 930,64 & 155,68 & 155,68 & 160,68 & 748,55 & 748,55 & 725,82 & 49,87 & 49,87 & 44,13 \\
\hline
\end{tabular}


Comparando-se os esforços obtidos por $\gamma_{\mathrm{z}}$ com os relativos ao P-Delta, pode-se perceber que $75 \%$ do total de esforços, para todos os pilares, estão acima dos referentes ao P-Delta, e 25\%, abaixo, ou seja, 48 esforços estão acima e 16 abaixo. Em relação ao P-Delta, dos que ficaram abaixo, eles estão em média 3,35\% menores, e dos que ficaram acima, 4,31\% maiores.

Para o FAVt, 75\% do total de esforços, para todos os pilares, também estão acima dos relativos ao P-Delta, e 25\%, abaixo, ou seja, também 48 esforços estão acima e 16 abaixo.

Em relação ao P-Delta, dos que ficaram abaixo, eles estão em média $3,32 \%$ menores, e dos que ficaram acima, 4,99\% maiores.

Para este caso, em relação aos esforços obtidos por $\gamma_{\mathrm{z}}$ e $F A V t$, foram obtidos resultados próximos. Porém, os resultados referentes ao FAVt ficaram pouca coisa a favor da segurança.

Mas em relação à majoração dos esforços horizontais por $0,95 \gamma_{\mathrm{z}}$ e $0,95 F A V t$ ou por $\gamma_{\mathrm{z}}$ e FAVt, os resultados referentes a estes valores integrais também foram melhores, para este exemplo.

\subsubsection{ALTERNATI VA PARA CONSI DERAR A NÃO-LI NEARI DADE Fí SI CA}

Como visto no item anterior, pode-se considerar um valor único, igual a 0,7 EI, para pilares e vigas, somente quando a estrutura de contraventamento for composta exclusivamente por vigas e pilares e $\gamma_{\mathrm{z}} \leq 1,3$, condições que também são atendidas por este exemplo. Os resultados obtidos com esta alternativa são mostrados na tabela 6.16.

Tabela 6.16. Parâmetros de estabilidade para rigidez 0,7 EI em pilares e vigas.

\begin{tabular}{|c|c|c|c|c|}
\hline \multicolumn{5}{|c|}{ PARÂMETRO DE ESTABILIDADE } \\
\hline Ang. & $\boldsymbol{\alpha}$ & GAMA-Z & FAVt & RM2M1 \\
\hline $0^{\circ}$ & 0,689 & 1,139 & 1,168 & 1,171 \\
\hline $90^{\circ}$ & 0,675 & 1,132 & 1,132 & 1,134 \\
\hline $180^{\circ}$ & 0,689 & 1,139 & 1,139 & 1,111 \\
\hline $270^{\circ}$ & 0,675 & 1,132 & 1,132 & 1,134 \\
\hline
\end{tabular}


Comparando-se com a tabela 6.9, percebe-se que os valores do parâmetros de estabilidade também são menores, como no exemplo anterior. Chega-se à mesma conclusão, que quando a não-linearidade física é considerada com a redução da rigidez por um valor único para pilares e vigas, a estrutura tende a ficar mais rígida.

Neste caso também vale ressaltar que os valores de $\alpha$ não se alteraram, pois eles não são calculados considerando a redução da rigidez do pórtico. Como já foi visto, deve-se considerar a rigidez integral, pois a consideração da nãolinearidade física já está embutida no de $\alpha$ limite, ao qual o calculado de $\alpha$ será comparado. 


\section{ANÁLI SE DE CI NCO EDI FÍ CI OS}

Como foi visto, no capítulo anterior analisaram-se dois edifícios. Neste, serão considerados mais cinco, para os quais foram respeitados todos os ELU e ELS. Aqui também o coeficiente $\gamma_{f 3}$, que considera as aproximações de projeto, foi adotado igual a 1,1 .

O terceiro e o quarto edifícios são compostos por lajes nervuradas, o quinto, o sexto e o sétimo, por lajes maciças.

A estrutura de contraventamento do terceiro é formada por pórticos de pilares e vigas, a do quarto, por pórticos e núcleos de grande rigidez, junto à escada e ao elevador. As estruturas de contraventamento do quinto e do sexto são, respectivamente, as mesmas do terceiro e do quarto edifício. A estrutura de contraventamento do sétimo também é formada por pórticos de pilares e vigas, sendo que este é de 22 pavimentos, sendo os quatro anteriores de apenas 10.

O carregamento vertical utilizado nos pavimentos tipo dos quatro edifícios foi $280 \mathrm{~kg} / \mathrm{m}^{2}$ de carga permanente, considerando contrapiso, revestimentos, alvenarias e carga especial para parede divisória, como mencionado no capitulo 5, item 5.3.1, e $150 \mathrm{~kg} / \mathrm{m}^{2}$ como carga acidental. Para a cobertura foi utilizado $150 \mathrm{~kg} / \mathrm{m}^{2}$ de carga permanente e $100 \mathrm{~kg} / \mathrm{m}^{2}$ de carga acidental.

A ação horizontal considerada foi a do vento, com as características:

> Velocidade básica $40 \mathrm{~m} / \mathrm{s}$;

$>$ Fator do terreno igual a $1,0\left(\mathrm{~S}_{1}\right)$;

> Categoria de Rugosidade IV $\left(\mathrm{S}_{2}\right)$;

Classe da edificação B $\left(\mathrm{S}_{2}\right)$;

Fator estatístico igual a $1,0\left(\mathrm{~S}_{3}\right)$;

> O coeficiente de arrasto foi calculado automaticamente pelo Sistema TQS, considerando-se vento de baixa turbulência. 


\subsection{EXEMPLO 3}

Na figura 7.1 pode-se observar o pavimento tipo do terceiro edifício analisado, e nas figuras 7.2 e 7.3, vistas em perspectiva, uma mostrando o edifício como um todo e a outra indicando que o edifício é composto por lajes nervuradas. O edifício possui 10 pavimentos.

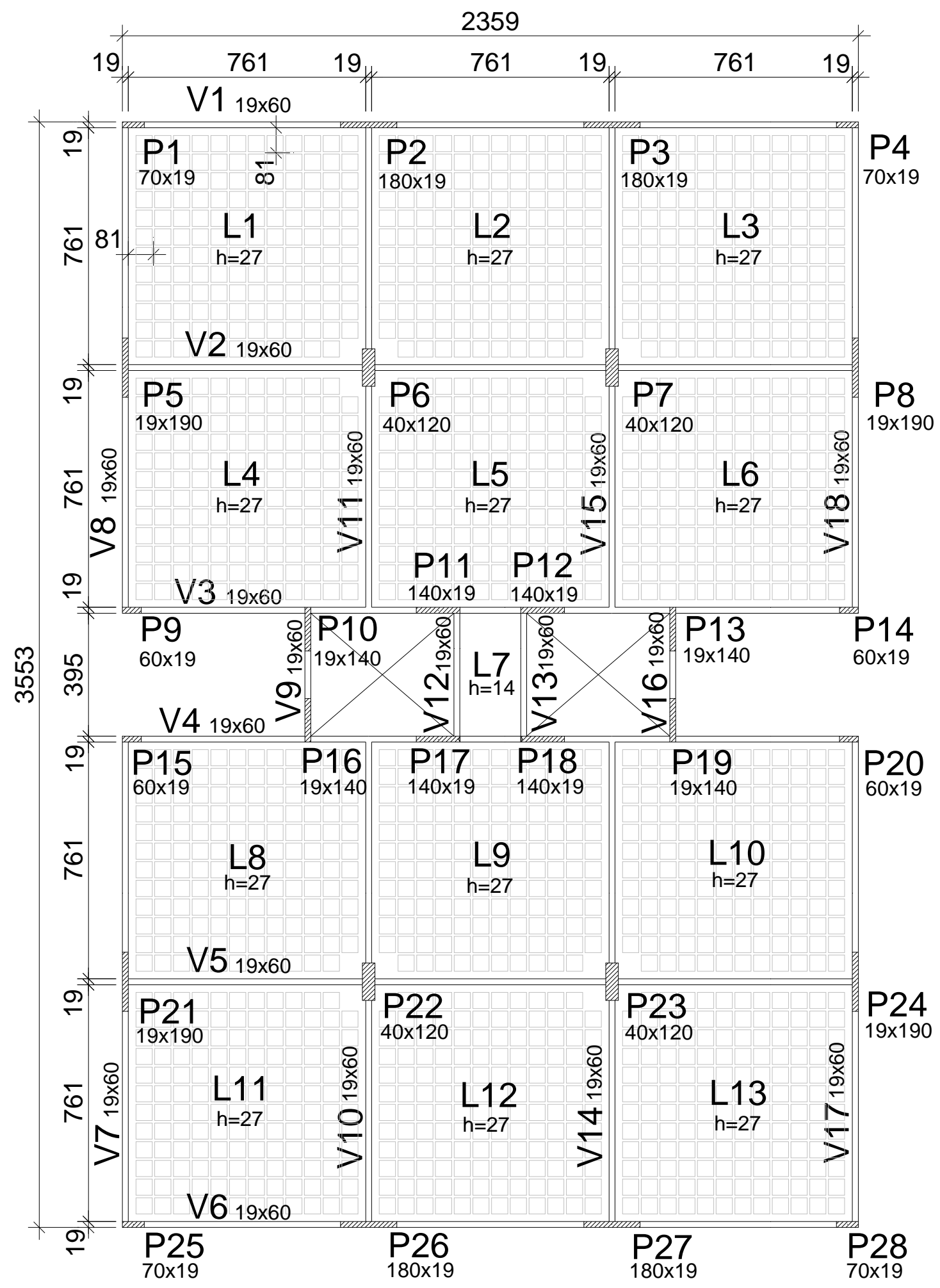

Figura 7.1. Planta de forma do pavimento tipo (dimensões em cm). 


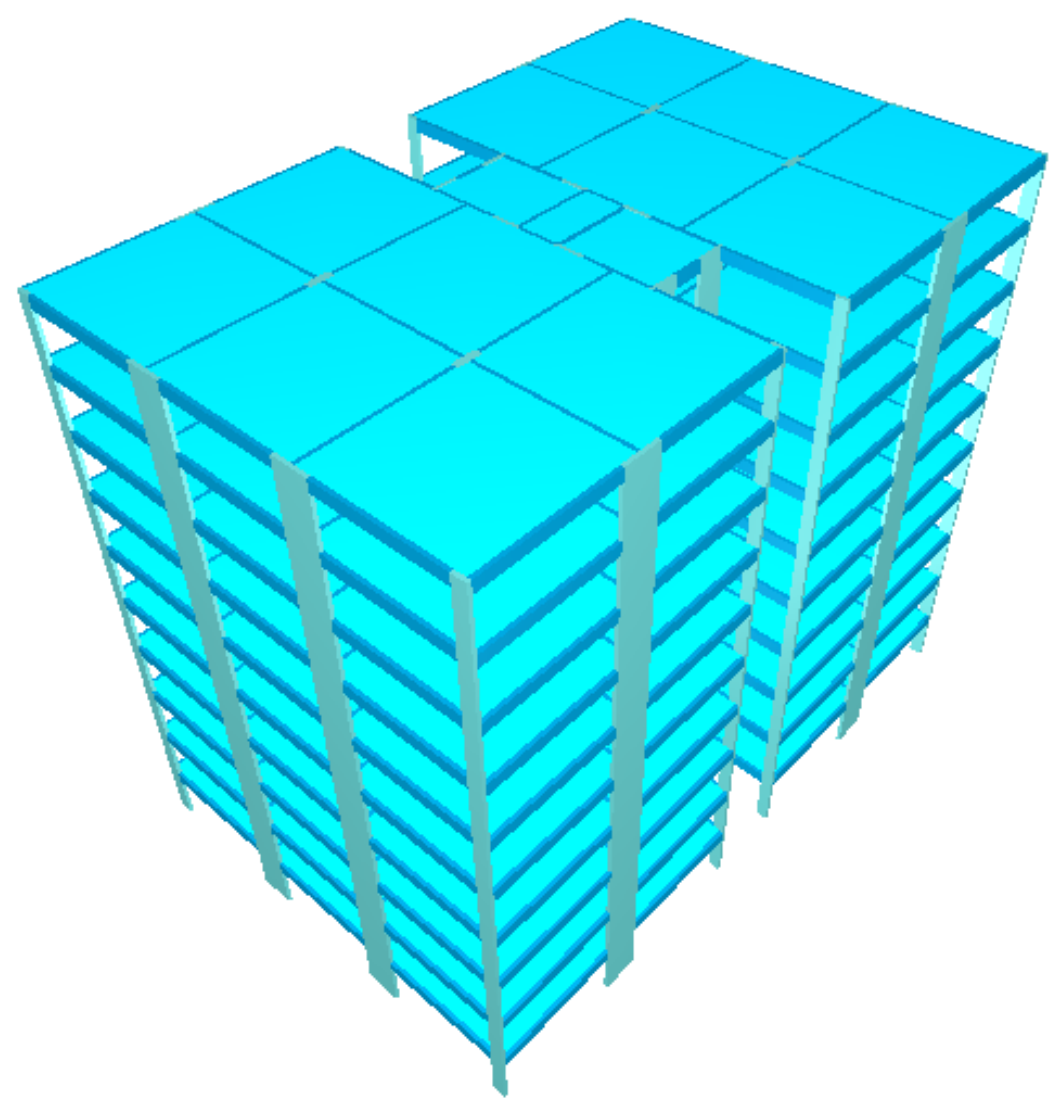

Figura 7.2. Vista em perspectiva do edifício analisado.

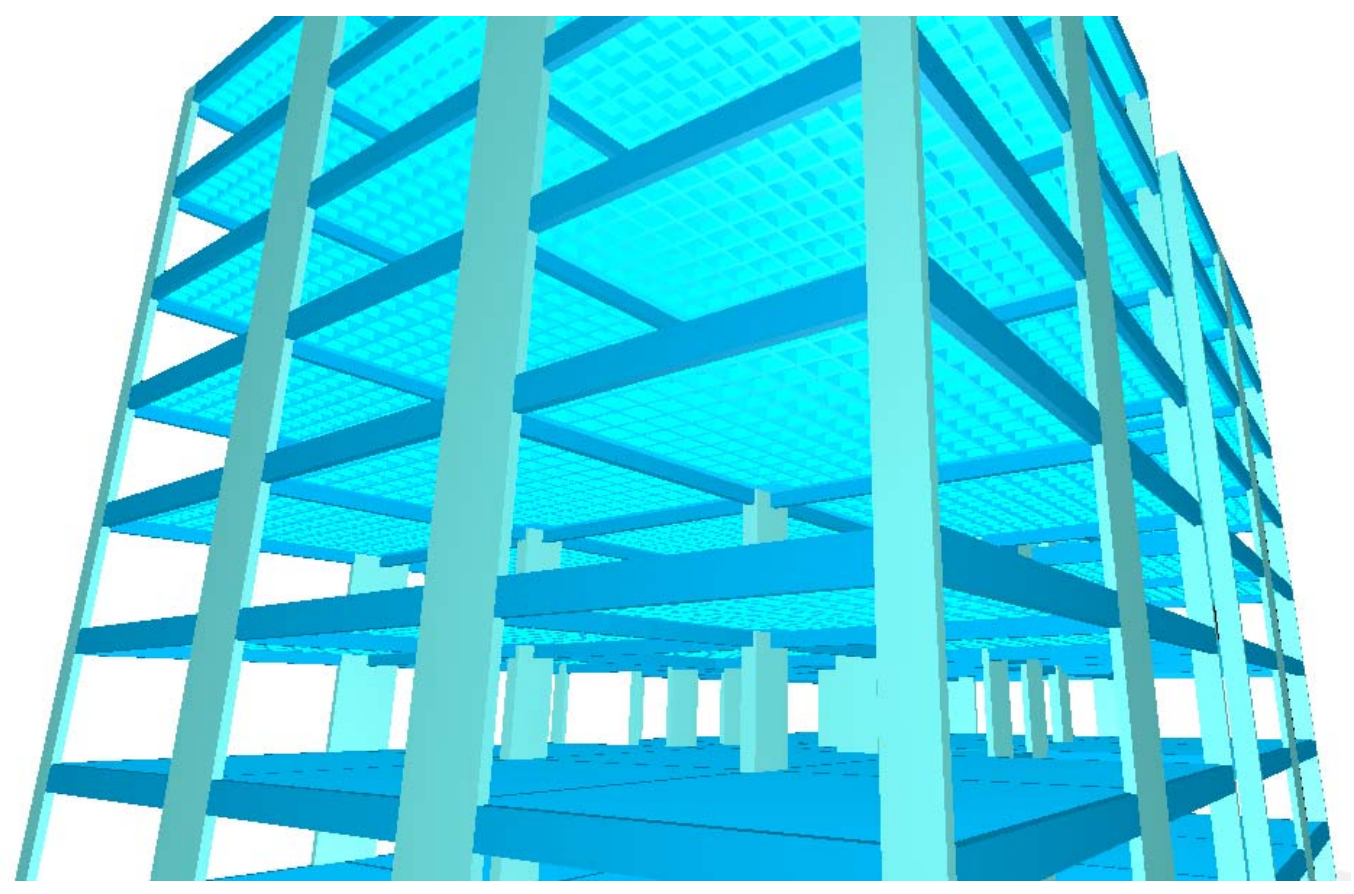

Figura 7.3. Vista em perspectiva do edifício, mostrando as lajes nervuradas. 


\subsubsection{PARÂMETROS DE ESTABI LI DADE}

Estão indicados, na tabela 7.1, os valores de $\alpha, \gamma_{z}, F A V t$ e $R M 2 M 1$, que podem ser considerados como parâmetros de estabilidade. Os três últimos referem-se à rigidez 0,8 EI nos pilares e 0,4 EI nas vigas. Lembra-se que, para se obter o valor correto de $\alpha$ no processamento dentro do Sistema TQS, não se deve considerar a redução da rigidez. Isso se deve ao fato do valor calculado de $\alpha$ ser comparado com um valor limite, indicado no item 15.5.2 da NBR 6118:2003, que já leva em conta uma redução de 30\% da rigidez integral, ou seja, já é considerado o valor 0,7 EI.

Tabela 7.1. Parâmetros de estabilidade.

\begin{tabular}{|c|c|c|c|c|}
\hline \multicolumn{5}{|c|}{ PARÂMETRO DE ESTABILIDADE } \\
\hline Ang. & $\boldsymbol{\alpha}$ & GAMA-Z & FAVt & RM2M1 \\
\hline $0^{\circ}$ & 0,472 & 1,080 & 1,080 & 1,081 \\
\hline $90^{\circ}$ & 0,567 & 1,106 & 1,106 & 1,107 \\
\hline $180^{\circ}$ & 0,472 & 1,080 & 1,080 & 1,081 \\
\hline $270^{\circ}$ & 0,567 & 1,106 & 1,106 & 1,107 \\
\hline
\end{tabular}

Os valores de $\alpha$ devem ser comparados ao limite 0,5, pois, segundo o item 15.5.2 da NBR 6118:2003, o valor limite deve ser reduzido de 0,6 para 0,5 quando o contraventamento for formado somente por pórticos, o que é o caso deste exemplo. Portanto, somente para $90^{\circ}$ e $270^{\circ}$ resultaram valores maiores que 0,5 , sendo, então, nessas direções, a edificação considerada de nós móveis, e, para $0^{\circ}$ e $180^{\circ}$, ela é admitida de nós fixos.

Para este caso, de um edifício totalmente simétrico, os valores de $\gamma_{z} \mathrm{e}$ FAVt são idênticos. Assim, os esforços finais, obtidos por qualquer um desses dois parâmetros, serão os mesmos. Somente a $90^{\circ}$ e $270^{\circ}$ os valores estão no intervalo $1,1<\gamma_{z} \leq 1,3$. Portanto, somente nessas direções a edificação é considerada como de nós móveis, e nas direções de $0^{\circ}$ e $180^{\circ}$ ela é admitida de nós fixos, exatamente como resultou na análise com o parâmetro alfa. 
Os valores de $\gamma_{z}$ e FAVt resultaram quase idênticos aos de RM2M1, os quais são gerados pelo processo P-Delta, como já foi comentado no capítulo 3.

\subsubsection{ANÁLI SE DE SEGUNDA ORDEM GLOBAL}

Observações em relação à análise já foram feitas no capitulo anterior, portanto não será necessário repeti-las.

As análises de segunda ordem só serão realizadas nas direções em que a edificação foi classificada como de nós móveis, de acordo com o item anterior. Portanto a análise só será realizada nas direções de $90^{\circ}$ e $270^{\circ}$, para as combinações 2 e 4, respectivamente.

Vale lembrar que as parcelas do peso próprio, demais cargas permanentes, carga acidental e do vento, das combinações consideradas, foram obtidas no visualizador do pórtico espacial do Sistema TQS.

São mostrados na tabela 7.2 os esforços normais de cálculo de primeira ordem, e na tabela 7.3, os esforços finais $\left(1^{a}+2^{a}\right.$ ordem) na base de apenas metade dos pilares do pórtico tridimensional, pois a edificação é simétrica nas duas direções. Nessa tabela 7.3, foi considerado o valor reduzido $0,95 \gamma_{\mathrm{z}}$, de acordo com a NBR 6118:2003.

Primeiramente será mostrado como é realizado o cálculo dos esforços na base do pilar P1, para as combinações 2 e 4 .

COMB. 2: Peso próprio + carga perm. + carga acid. + 0,6 vento $90^{\circ}$

$$
\begin{aligned}
& N_{d}=\gamma_{\mathrm{g}} \cdot(P P+C P)+\gamma_{\mathrm{q}} \cdot\left(C A+0,95 \gamma_{\mathrm{z}} \cdot \Psi_{0 \mathrm{j}} \cdot \text { Vento } 90^{0}\right) \\
& N_{d}=1,4 \cdot(584,25+675,06)+1,4 \cdot(141,75+0,95 \cdot 1,106 \cdot 0,6 \cdot 27,82) \\
& N_{d}=1,4 \cdot(1259,31)+1,4 \cdot(159,288) \\
& N_{d}=1986,04 \mathrm{kN}
\end{aligned}
$$

COMB. 4 : Peso próprio + carga perm. + carga acid. + 0,6 vento $270^{\circ}$

$$
\begin{aligned}
& N_{d}=\gamma_{\mathrm{g}} \cdot(P P+C P)+\gamma_{\mathrm{q}} \cdot\left(C A+0,95 \gamma_{\mathrm{z}} \cdot \Psi_{0 \mathrm{j}} \cdot \text { Vento } 270^{0}\right) \\
& N_{d}=1,4 \cdot(584,25+675,06)+1,4 \cdot(141,75+0,95 \cdot 1,106 \cdot 0,6 \cdot-27,82) \\
& N_{d}=1,4 \cdot(1259,31)+1,4 \cdot(124,212) \\
& N_{d}=1936,93 \mathrm{kN}
\end{aligned}
$$


Tabela 7.2. Força normal de cálculo de $1^{\mathrm{a}}$ ordem.

\begin{tabular}{|c|c|c|c|c|}
\hline \multicolumn{5}{|c|}{ ESFORÇOS NORMAIS DE CÁLCULO DE 1a ORDEM (kN) } \\
\hline PILARES & COMB.1 & COMB.2 & COMB.3 & COMB.4 \\
\hline P1 & 1884,54 & 1984,92 & 2038,54 & 1938,16 \\
\hline P2 & 3759,84 & 3810,94 & 3812,34 & 3761,38 \\
\hline P3 & 3812,34 & 3810,94 & 3759,84 & 3761,38 \\
\hline P4 & 2038,54 & 1984,92 & 1884,54 & 1938,16 \\
\hline P5 & 4619,02 & 4639,04 & 4658,64 & 4638,48 \\
\hline P6 & 9205,70 & 9218,44 & 9244,90 & 9232,16 \\
\hline P8 & 9245,04 & 9218,44 & 9205,70 & 9232,30 \\
\hline P9 & 4658,64 & 4639,18 & 4619,02 & 4638,62 \\
\hline P10 & 27694,70 & 1716,68 & 1733,76 & 1711,78 \\
\hline P11 & 2421,44 & 3174,36 & 2970,24 & 2557,24 \\
\hline P12 & 3190,32 & 2864,54 & 2421,58 & 2747,36 \\
\hline P13 & 2970,24 & 3174,36 & 2761,36 & 2557,24 \\
\hline P14 & 1733,90 & 1716,68 & 1694,70 & 1711,78 \\
\hline
\end{tabular}

Tabela 7.3. Força normal de cálculo com efeitos de $2^{a}$ ordem global $\left(0,95 \gamma_{z}\right)$.

\begin{tabular}{|c|c|c|c|c|c|c|c|c|c|c|c|c|}
\hline \multicolumn{2}{|c|}{ FORÇA NORMAL DE CÁLCULO NA BASE DO PILAR COM EFEITOS DE 2a ORDEM GLOBAL (kN) } \\
\hline \multirow{2}{*}{ PILARES } & \multicolumn{3}{|c|}{ COMB. 1 } & \multicolumn{3}{|c|}{ COMB. 2} & \multicolumn{3}{|c|}{ COMB. 3 } & \multicolumn{3}{c|}{ COMB. 4 } \\
\cline { 2 - 8 } & GAVt & P-DELTA & GAMA-Z & FAVt & P-DELTA & GAMA-Z & FAVt & P-DELTA & GAMA-Z & FAVt & P-DELTA \\
\hline P1 & 1884,54 & 1884,54 & 1877,82 & 1986,04 & 1986,04 & 1987,72 & 2038,54 & 2038,54 & 2045,12 & 1936,93 & 1936,93 & 1935,36 \\
\hline P2 & 3759,84 & 3759,84 & 3757,60 & 3812,20 & 3812,20 & 3813,88 & 3812,34 & 3812,34 & 3814,58 & 3760,12 & 3760,12 & 3758,44 \\
\hline P3 & 3812,34 & 3812,34 & 3814,58 & 3812,20 & 3812,20 & 3813,88 & 3759,84 & 3759,84 & 3757,60 & 3760,12 & 3760,12 & 3758,44 \\
\hline P4 & 2038,54 & 2038,54 & 2045,26 & 1986,04 & 1986,04 & 1987,72 & 1884,54 & 1884,54 & 1877,82 & 1936,90 & 1936,90 & 1935,36 \\
\hline P5 & 4619,02 & 4619,02 & 4617,34 & 4639,18 & 4639,18 & 4639,18 & 4658,64 & 4658,64 & 4660,32 & 4638,48 & 4638,48 & 4638,48 \\
\hline P6 & 9205,70 & 9205,70 & 9204,02 & 9218,02 & 9218,02 & 9217,60 & 9244,90 & 9244,90 & 9246,58 & 9232,58 & 9232,58 & 9233,00 \\
\hline P7 & 9245,04 & 9245,04 & 9246,72 & 9218,16 & 9218,16 & 9217,60 & 9205,70 & 9205,70 & 9204,02 & 9232,58 & 9232,58 & 9233,14 \\
\hline P8 & 4658,64 & 4658,64 & 4660,32 & 4639,18 & 4639,18 & 4639,18 & 4619,02 & 4619,02 & 4617,34 & 4638,48 & 4638,48 & 4638,48 \\
\hline P9 & 1694,70 & 1694,70 & 1692,88 & 1716,82 & 1716,82 & 1717,10 & 1733,76 & 1733,76 & 1735,58 & 1711,64 & 1711,64 & 1711,50 \\
\hline P10 & 2761,36 & 2761,36 & 2752,40 & 3190,04 & 3190,04 & 3210,90 & 2970,24 & 2970,24 & 2979,20 & 2541,56 & 2541,56 & 2520,70 \\
\hline P11 & 2421,44 & 2421,44 & 2387,56 & 2867,48 & 2867,48 & 2871,40 & 3190,32 & 3190,32 & 3224,20 & 2744,28 & 2744,28 & 2740,22 \\
\hline P12 & 3190,32 & 3190,32 & 3224,20 & 2867,48 & 2867,48 & 2871,54 & 2421,58 & 2421,58 & 2387,56 & 2744,28 & 2744,28 & 2740,36 \\
\hline P13 & 2970,24 & 2970,24 & 2979,34 & 3190,04 & 3190,04 & 3210,90 & 2761,36 & 2761,36 & 2752,40 & 2541,56 & 2541,56 & 2520,70 \\
\hline P14 & 1733,90 & 1733,90 & 1735,58 & 1716,82 & 1716,82 & 1717,10 & 1694,70 & 1694,70 & 1692,88 & 1711,64 & 1711,64 & 1711,50 \\
\hline
\end{tabular}


Os resultados das combinações 1 e 3 mostrados na tabela 7.3 são os próprios esforços de primeira ordem, pois a análise de segunda ordem não foi realizada e os resultados são diferentes dos obtidos por P-Delta, pois este é um processo de análise não-linear que sempre considera esforços de segunda ordem, caso existam, mesmo eles sendo pequenos, ou seja, menores que $10 \%$ dos esforços de primeira ordem.

Comparando-se os esforços obtidos por $\gamma_{\mathrm{z}}$ e FAVt para as combinações 2 e 4 , idênticos neste caso, com os do processo P-Delta, pode-se perceber que 57\% do total de esforços, para todos os pilares, estão acima dos obtidos pelo P-Delta, e $43 \%$ estão abaixo, ou seja, 16 esforços estão acima e 12 abaixo, isso porque se tem, para cada combinação, 14 pilares, ou seja, 14 esforços para cada combinação, com um total de 28 esforços.

Em relação aos valores obtidos pelo P-Delta, dos que ficaram abaixo, eles estão em média 0,10\% menores, e dos que ficaram acima, 0,11\% maiores. Com isso pode-se concluir que os esforços aproximados estão muito próximos dos obtidos pelo processo P-Delta, mais refinado.

Realizando-se novamente a análise, agora com o valor integral do $\gamma_{\mathrm{z}}$ obtém-se os resultados mostrados na tabela 7.4.

Tabela 7.4. Força normal de cálculo com efeitos de $2^{a}$ ordem global $\left(\gamma_{z}\right)$.

\begin{tabular}{|c|c|c|c|c|c|c|c|c|c|c|c|c|}
\hline \multicolumn{3}{|c|}{ FORÇA NORMAL DE CÁLCULO NA BASE DO PILAR COM EFEITOS DE 2a ORDEM GLOBAL (kN) } \\
\hline \multirow{2}{*}{ PILARES } & \multicolumn{3}{|c|}{ COMB. 1 } & \multicolumn{3}{c|}{ COMB. 2} & \multicolumn{3}{c|}{ COMB. 3 } & \multicolumn{3}{c|}{ COMB. 4 } \\
\cline { 2 - 14 } & GAMA-Z & FAVt & P-DELTA & GAMA-Z & FAVt & P-DELTA & GAMA-Z & FAVt & P-DELTA & GAMA-Z & FAVt & P-DELTA \\
\hline P1 & 1884,54 & 1884,54 & 1877,82 & 1987,44 & 1987,44 & 1987,72 & 2038,54 & 2038,54 & 2045,12 & 1935,64 & 1935,64 & 1935,36 \\
\hline P2 & 3758,72 & 3758,72 & 3757,60 & 3813,46 & 3813,46 & 3813,88 & 3812,34 & 3812,34 & 3814,58 & 3758,72 & 3758,72 & 3758,44 \\
\hline P3 & 3812,34 & 3812,34 & 3814,58 & 3813,46 & 3813,46 & 3813,88 & 3759,84 & 3759,84 & 3757,60 & 3758,72 & 3758,72 & 3758,44 \\
\hline P4 & 2038,54 & 2038,54 & 2045,26 & 1987,44 & 1987,44 & 1987,72 & 1884,54 & 1884,54 & 1877,82 & 1935,64 & 1935,64 & 1935,36 \\
\hline P5 & 4619,02 & 4619,02 & 4617,34 & 4639,18 & 4639,18 & 4639,18 & 4658,64 & 4658,64 & 4660,32 & 4638,48 & 4638,48 & 4638,48 \\
\hline P6 & 9205,70 & 9205,70 & 9204,02 & 9217,60 & 9217,60 & 9217,60 & 9244,90 & 9244,90 & 9246,58 & 9233,00 & 9233,00 & 9233,00 \\
\hline P7 & 9245,04 & 9245,04 & 9246,72 & 9217,74 & 9217,74 & 9217,60 & 9205,70 & 9205,70 & 9204,02 & 9233,00 & 9233,00 & 9233,14 \\
\hline P8 & 4658,64 & 4658,64 & 4660,32 & 4639,18 & 4639,18 & 4639,18 & 4619,02 & 4619,02 & 4617,34 & 4638,48 & 4638,48 & 4638,48 \\
\hline P9 & 1694,70 & 1694,70 & 1692,88 & 1716,96 & 1716,96 & 1717,10 & 1733,76 & 1733,76 & 1735,58 & 1711,50 & 1711,50 & 1711,50 \\
\hline P10 & 2761,36 & 2761,36 & 2752,40 & 3206,98 & 3206,98 & 3210,90 & 2970,24 & 2970,24 & 2979,20 & 2524,48 & 2524,48 & 2520,70 \\
\hline P11 & 2421,44 & 2421,44 & 2387,56 & 2870,70 & 2870,70 & 2871,40 & 3190,32 & 3190,32 & 3224,20 & 2741,06 & 2741,06 & 2740,22 \\
\hline P12 & 3190,32 & 3190,32 & 3224,20 & 2870,70 & 2870,70 & 2871,54 & 2421,58 & 2421,58 & 2387,56 & 2741,06 & 2741,06 & 2740,36 \\
\hline P13 & 2970,24 & 2970,24 & 2979,34 & 3207,12 & 3207,12 & 3210,90 & 2761,36 & 2761,36 & 2752,40 & 2524,62 & 2524,62 & 2520,70 \\
\hline P14 & 1733,90 & 1733,90 & 1735,58 & 1716,96 & 1716,96 & 1717,10 & 1694,70 & 1694,70 & 1692,88 & 1711,50 & 1711,50 & 1711,50 \\
\hline
\end{tabular}


Em comparação análoga à anterior, pode-se perceber que $61 \%$ do total de esforços nos pilares estão acima e 39\%, abaixo dos obtidos pelo P-Delta, ou seja, agora tem-se 17 esforços acima e 11 abaixo. Em relação aos valores referentes ao P-Delta, os que ficaram abaixo são 0,02\% menores, e os que ficaram acima, 0,03\% maiores. Com isso pode-se afirmar que os esforços de segunda ordem global obtidos com $\gamma_{\mathrm{z}}$, para este exemplo, também são bem melhores que os relativos a $0,95 \gamma_{\mathrm{z}}$, pois os valores acima e abaixo são mais próximos dos obtidos com o P-Delta.

São considerados, agora, os momentos fletores na base do pilares. São mostrados na tabela 7.5 os momentos fletores de cálculo de $1^{\mathrm{a}}$ ordem, e na tabela 7.6, os valores, em módulo, dos momentos finais na base para apenas 14 pilares, por conta da simetria já mencionada, sendo esses momentos relativos à direção mais rígida de cada pilar. Os cálculos dos esforços finais serão realizados, em detalhes, somente para o pilar P1 e para as combinações 2 e 4.

COMB. 2: Peso próprio + carga perm. + carga acid. + 0,6 vento $90^{\circ}$

$$
\begin{aligned}
& M_{d}=\gamma_{\mathrm{g}} \cdot(P P+C P)+\gamma_{\mathrm{q}} \cdot\left(C A+0,95 \gamma_{\mathrm{z}} \cdot \Psi_{0 \mathrm{j}} \cdot \text { Vento } 90^{0}\right) \\
& M_{d}=1,4 \cdot(-6,27-8,96)+1,4 \cdot(-2,11+0,95 \cdot 1,106 \cdot 0,6 \cdot-0,04) \\
& M_{d}=1,4 \cdot(-15,23)+1,4 \cdot(-2,135) \\
& M_{d}=-24,31 \mathrm{kN} \cdot \mathrm{m}
\end{aligned}
$$

COMB. 4: Peso próprio + carga perm. + carga acid. + 0,6 vento 2700

$$
\begin{aligned}
& M_{d}=\gamma_{\mathrm{g}} \cdot(P P+C P)+\gamma_{\mathrm{q}} \cdot\left(C A+\Psi_{0 \mathrm{j}} \cdot 0,95 \gamma_{\mathrm{z}} \cdot \text { Vento } 270^{0}\right) \\
& M_{d}=1,4 \cdot(-6,27-8,96)+1,4 \cdot(-2,11+0,95 \cdot 1,106 \cdot 0,6 \cdot 0,04) \\
& M_{d}=1,4 \cdot(-15,23)+1,4 \cdot(-2,085) \\
& M_{d}=-24,24 \mathrm{kN} . \mathrm{m}
\end{aligned}
$$

Comparando-se os esforços relativos a $0,95 \gamma_{\mathrm{z}}$ com os referentes ao processo P-Delta, pode-se perceber que apenas 29\% do total de esforços, para os 14 pilares, estão acima dos relativos ao P-Delta, e 71\%, abaixo, ou seja, 8 esforços estão acima e 20 abaixo.

Em relação ao P-Delta, dos que ficaram abaixo, eles estão em média $2,18 \%$ menores, e dos que ficaram acima, $0,42 \%$ maiores. 
Tabela 7.5. Momentos fletores de cálculo de $1^{\mathrm{a}}$ ordem.

\begin{tabular}{|c|c|c|c|c|}
\hline \multicolumn{5}{|c|}{ MOMENTOS FLETORES DE CÁLCULO DE 1a ORDEM (kN.m) } \\
\hline PILARES & COMB.1 & COMB.2 & COMB.3 & COMB.4 \\
\hline P1 & 11,63 & 24,32 & 60,20 & 24,25 \\
\hline P2 & 533,18 & 5,18 & 521,46 & 6,54 \\
\hline P3 & 521,50 & 5,14 & 533,15 & 6,51 \\
\hline P4 & 60,20 & 24,32 & 11,62 & 24,25 \\
\hline P5 & 10,95 & 342,23 & 16,76 & 336,42 \\
\hline P6 & 0,41 & 185,93 & 6,38 & 179,14 \\
\hline P7 & 6,40 & 185,93 & 0,41 & 179,14 \\
\hline P8 & 16,77 & 342,24 & 10,95 & 336,42 \\
\hline P9 & 9,10 & 14,31 & 36,46 & 13,03 \\
\hline P10 & 27,83 & 126,10 & 27,10 & 181,02 \\
\hline P11 & 306,18 & 20,50 & 267,13 & 18,55 \\
\hline P12 & 267,15 & 20,48 & 306,17 & 18,54 \\
\hline P13 & 27,10 & 126,10 & 27,83 & 181,02 \\
\hline P14 & 36,44 & 14,31 & 9,10 & 13,03 \\
\hline
\end{tabular}

Tabela 7.6. Momento fletor de cálculo com efeitos de $2^{a}$ ordem global $\left(0,95 \gamma_{z}\right)$.

\begin{tabular}{|c|c|c|c|c|c|c|c|c|c|c|c|c|}
\hline \multicolumn{9}{|c|}{ MOMENTO FLETOR DE CÁLCULO COM EFEITOS DE 2a ORDEM GLOBAL (kN.m) } \\
\hline \multirow{2}{*}{ PILARES } & \multicolumn{3}{|c|}{ COMB. 1 } & \multicolumn{3}{c|}{ COMB. 2 } & \multicolumn{3}{c|}{ COMB. 3 } & \multicolumn{3}{c|}{ COMB. 4 } \\
\cline { 2 - 13 } & GAMA-Z & FAVt & P-DELTA & GAMA-Z & FAVt & P-DELTA & GAMA-Z & FAVt & P-DELTA & GAMA-Z & FAVt & P-DELTA \\
\hline P1 & 11,63 & 11,63 & 13,69 & 24,31 & 24,31 & 24,30 & 60,20 & 60,20 & 62,23 & 24,24 & 24,24 & 24,26 \\
\hline P2 & 533,18 & 533,18 & 568,71 & 5,14 & 5,14 & 5,25 & 521,46 & 521,46 & 556,93 & 6,57 & 6,57 & 6,45 \\
\hline P3 & 521,50 & 521,50 & 556,98 & 5,10 & 5,10 & 5,21 & 533,15 & 533,15 & 568,67 & 6,55 & 6,55 & 6,44 \\
\hline P4 & 60,20 & 60,20 & 62,23 & 24,32 & 24,32 & 24,30 & 11,62 & 11,62 & 13,69 & 24,25 & 24,25 & 24,28 \\
\hline P5 & 10,95 & 10,95 & 10,85 & 359,53 & 359,53 & 371,74 & 16,76 & 16,76 & 16,65 & 353,72 & 353,72 & 365,96 \\
\hline P6 & 0,41 & 0,41 & 0,39 & 195,24 & 195,24 & 200,83 & 6,38 & 6,38 & 6,41 & 188,45 & 188,45 & 194,04 \\
\hline P7 & 6,40 & 6,40 & 6,41 & 195,24 & 195,24 & 200,83 & 0,41 & 0,41 & 0,38 & 188,45 & 188,45 & 194,05 \\
\hline P8 & 16,77 & 16,77 & 16,66 & 359,55 & 359,55 & 371,77 & 10,95 & 10,95 & 10,85 & 353,72 & 353,72 & 365,97 \\
\hline P9 & 9,10 & 9,10 & 10,25 & 14,35 & 14,35 & 14,39 & 36,46 & 36,46 & 37,58 & 13,01 & 13,01 & 12,96 \\
\hline P10 & 27,83 & 27,83 & 27,79 & 133,92 & 133,92 & 139,10 & 27,10 & 27,10 & 27,15 & 188,86 & 188,86 & 194,12 \\
\hline P11 & 306,18 & 306,18 & 325,15 & 20,54 & 20,54 & 20,61 & 267,13 & 267,13 & 285,92 & 18,49 & 18,49 & 18,44 \\
\hline P12 & 267,15 & 267,15 & 285,95 & 20,52 & 20,52 & 20,59 & 306,17 & 306,17 & 325,14 & 18,48 & 18,48 & 18,42 \\
\hline P13 & 27,10 & 27,10 & 27,15 & 133,92 & 133,92 & 139,10 & 27,83 & 27,83 & 27,79 & 188,86 & 188,86 & 194,12 \\
\hline P14 & 36,44 & 36,44 & 37,58 & 14,34 & 14,34 & 14,39 & 9,10 & 9,10 & 10,25 & 13,01 & 13,01 & 12,96 \\
\hline
\end{tabular}


Em vez de $0,95 \gamma_{\mathrm{z}}$, se fosse considerado o valor integral de $\gamma_{\mathrm{z}}$ para majoração dos esforços horizontais, obter-se-iam os resultados mostrados na tabela 7.7 .

Tabela 7.7. Momento fletor de cálculo com efeitos de $2^{a}$ ordem global $\left(\gamma_{z}\right)$.

\begin{tabular}{|c|c|c|c|c|c|c|c|c|c|c|c|c|}
\hline \multicolumn{9}{|c|}{ MOMENTO FLETOR DE CÁLCULO COM EFEITOS DE 2a ORDEM GLOBAL (kN.m) } \\
\hline \multirow{2}{*}{ PILARES } & \multicolumn{3}{|c|}{ COMB. 1 } & \multicolumn{3}{c|}{ COMB. 2 } & \multicolumn{3}{c|}{ COMB. 3 } & \multicolumn{3}{c|}{ COMB. 4 } \\
\hline & GAMA-Z & FAVt & P-DELTA & GAMA-Z & FAVt & P-DELTA & GAMA-Z & FAVt & P-DELTA & GAMA-Z & FAVt & P-DELTA \\
\hline P1 & 11,63 & 11,63 & 13,69 & 24,32 & 24,32 & 24,30 & 60,20 & 60,20 & 62,23 & 24,25 & 24,25 & 24,26 \\
\hline P2 & 533,18 & 533,18 & 568,71 & 5,10 & 5,10 & 5,25 & 521,46 & 521,46 & 556,93 & 6,61 & 6,61 & 6,45 \\
\hline P3 & 521,50 & 521,50 & 556,98 & 5,07 & 5,07 & 5,21 & 533,15 & 533,15 & 568,67 & 6,58 & 6,58 & 6,44 \\
\hline P4 & 60,20 & 60,20 & 62,23 & 24,33 & 24,33 & 24,30 & 11,62 & 11,62 & 13,69 & 24,25 & 24,25 & 24,28 \\
\hline P5 & 10,95 & 10,95 & 10,85 & 378,20 & 378,20 & 371,74 & 16,76 & 16,76 & 16,65 & 372,39 & 372,39 & 365,96 \\
\hline P6 & 0,41 & 0,41 & 0,39 & 205,28 & 205,28 & 200,83 & 6,38 & 6,38 & 6,41 & 198,49 & 198,49 & 194,04 \\
\hline P7 & 6,40 & 6,40 & 6,41 & 205,28 & 205,28 & 200,83 & 0,41 & 0,41 & 0,38 & 198,49 & 198,49 & 194,05 \\
\hline P8 & 16,77 & 16,77 & 16,66 & 378,21 & 378,21 & 371,77 & 10,95 & 10,95 & 10,85 & 372,39 & 372,39 & 365,97 \\
\hline P9 & 9,10 & 9,10 & 10,25 & 14,38 & 14,38 & 14,39 & 36,46 & 36,46 & 37,58 & 12,98 & 12,98 & 12,96 \\
\hline P10 & 27,83 & 27,83 & 27,79 & 142,37 & 142,37 & 139,10 & 27,10 & 27,10 & 27,15 & 197,30 & 197,30 & 194,12 \\
\hline P11 & 306,18 & 306,18 & 325,15 & 20,59 & 20,59 & 20,61 & 267,13 & 267,13 & 285,92 & 18,45 & 18,45 & 18,44 \\
\hline P12 & 267,15 & 267,15 & 285,95 & 20,58 & 20,58 & 20,59 & 306,17 & 306,17 & 325,14 & 18,42 & 18,42 & 18,42 \\
\hline P13 & 27,10 & 27,10 & 27,15 & 142,37 & 142,37 & 139,10 & 27,83 & 27,83 & 27,79 & 197,30 & 197,30 & 194,12 \\
\hline P14 & 36,44 & 36,44 & 37,58 & 14,38 & 14,38 & 14,39 & 9,10 & 9,10 & 10,25 & 12,96 & 12,96 & 12,96 \\
\hline
\end{tabular}

Comparando-se os esforços obtidos por $\gamma_{\mathrm{z}}$ com os relativos ao P-Delta, pode-se perceber que geraram resultados mais a favor da segurança, pois, para os 14 pilares, $71 \%$ do total de esforços estão acima e 29\%, abaixo, ou seja, 20 esforços estão acima e 8 abaixo. Em relação ao P-Delta, dos que ficaram abaixo, eles estão em média 0,54\% menores, e dos que ficaram acima, 1,60\% maiores.

Pode-se concluir que, também para este caso, os esforços relativos ao valor integral de $\gamma_{\mathrm{z}}$ foram melhores, pois resultaram mais esforços acima dos obtidos por P-Delta, e os que ficaram abaixo se distanciaram menos.

\subsubsection{ALTERNATI VA PARA CONSI DERAR A NÃO-LI NEARI DADE FÍ SI CA}

Como já se sabe, pode-se considerar um valor único para a rigidez em pilares e vigas, igual a 0,7 EI, somente quando a estrutura de contraventamento for composta exclusivamente por vigas e pilares e $\gamma_{\mathrm{z}} \leq 1,3$. 
Como essas exigências são atendidas pelo exemplo em questão, esta alternativa pode ser considerada. Os respectivos resultados são mostrados na tabela 7.8.

Tabela 7.8. Parâmetros de estabilidade para rigidez 0,7 EI em pilares e vigas.

\begin{tabular}{|c|c|c|c|c|}
\hline \multicolumn{5}{|c|}{ PARÂMETRO DE ESTABILIDADE } \\
\hline Ang. & $\boldsymbol{\alpha}$ & GAMA-Z & FAVt & RM2M1 \\
\hline $0^{\circ}$ & 0,472 & 1,059 & 1,059 & 1,060 \\
\hline $90^{\circ}$ & 0,567 & 1,081 & 1,081 & 1,082 \\
\hline $180^{\circ}$ & 0,472 & 1,059 & 1,059 & 1,060 \\
\hline $270^{\circ}$ & 0,567 & 1,081 & 1,081 & 1,082 \\
\hline
\end{tabular}

Utilizando-se esta alternativa, a edificação seria considerada de nós fixos em todas as direções, pois o valor de $\gamma_{\mathrm{z}}$ é menor que 1,1 em todas elas.

Os valores de $\gamma_{\mathrm{z}}$ e FAVt geraram resultados quase idênticos aos obtidos por P-Delta.

Os valores de $\alpha$ são os mesmos da tabela 7.1 e indicam que a edificação é de nós móveis nas direções de $90^{\circ}$ e $270^{\circ}$, pois nas duas resultou o mesmo valor de $\alpha(0,567)$, maior que 0,5 .

Porém, atualmente, muitos escritórios de projeto consideram prioritárias as análises feitas pelo processo $\gamma_{\mathrm{z}}$, pelo fato de considerar a não-linearidade geométrica, mesmo que de forma aproximada, e pela credibilidade já adquirida por ele. Neste caso, o processo $\gamma_{\mathrm{z}}$ indica estrutura de nós fixos em todas as direções.

\subsection{EXEMPLO 4}

$\mathrm{Na}$ figura 7.4 pode-se observar o pavimento tipo do quarto edifício analisado, e na figura 7.5, uma vista em perspectiva.

Este edifício possui núcleos rígidos junto à escada e ao elevador e possui 10 pavimentos. 


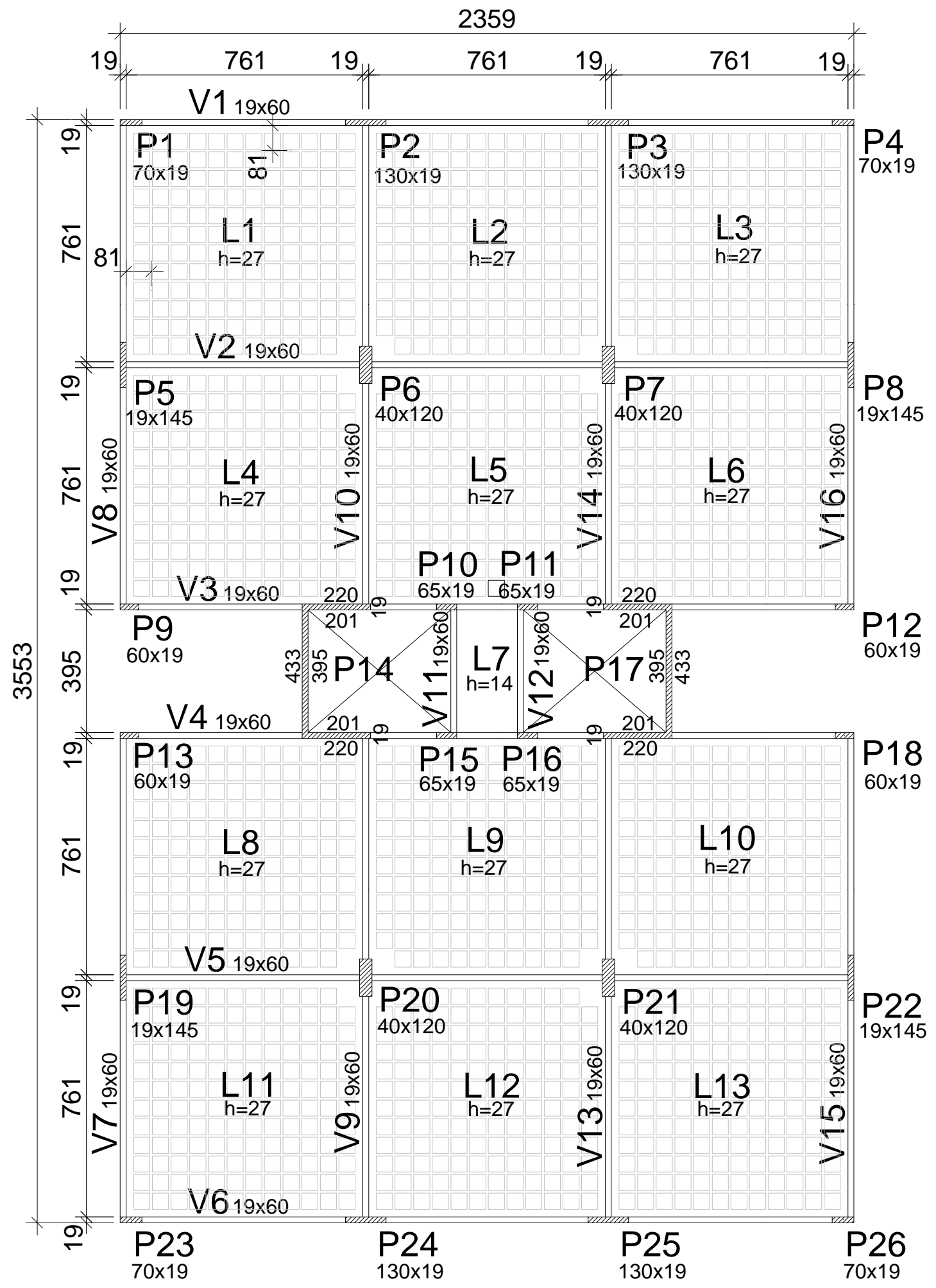

Figura 7.4. Planta de forma do pavimento tipo (dimensões em $\mathrm{cm}$ ). 


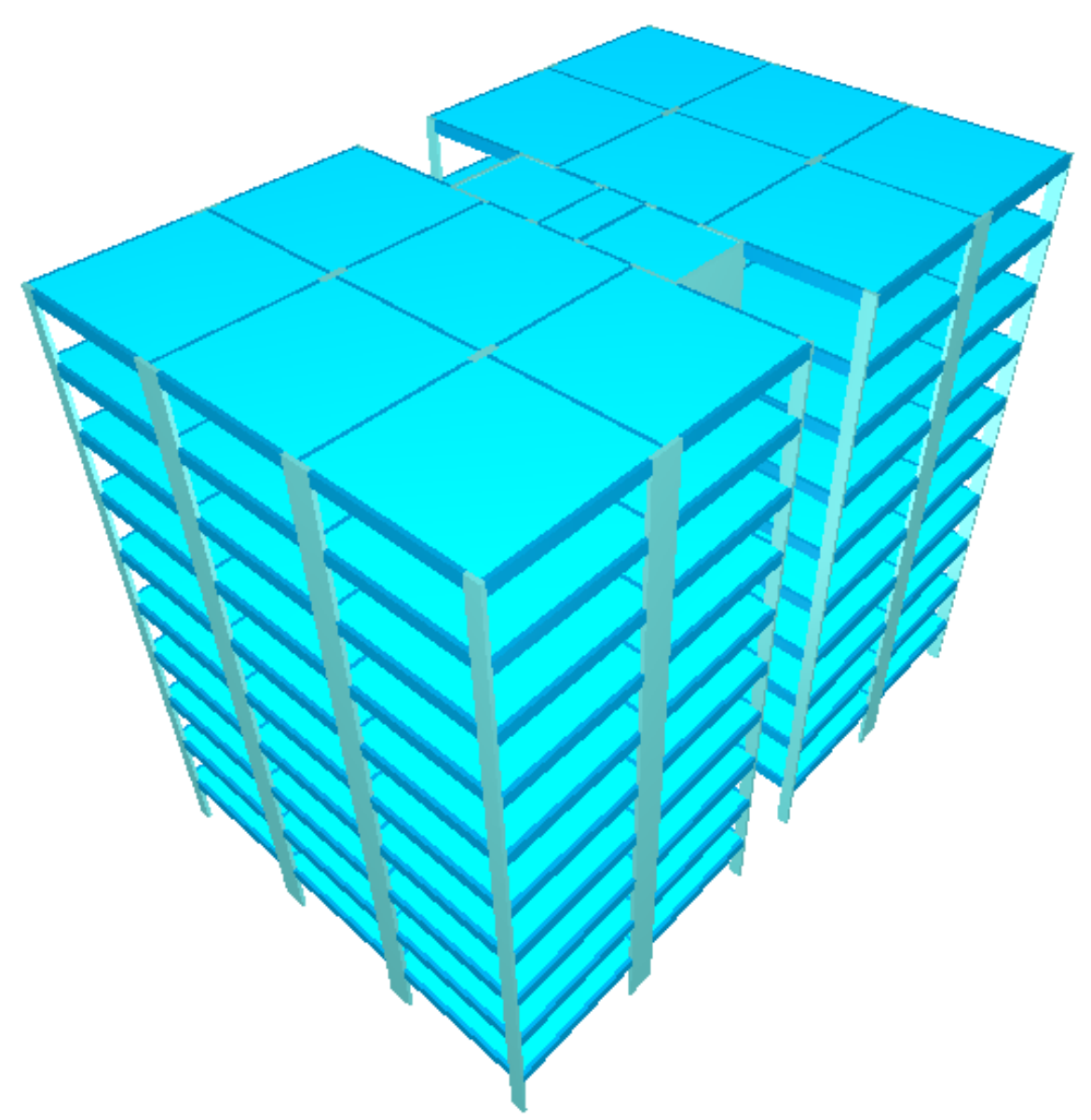

Figura 7.5. Vista em perspectiva do edifício analisado.

\subsubsection{PARÂMETROS DE ESTABI LI DADE}

Estão indicados, na tabela 7.9, os valores de $\alpha, \gamma_{z}, F A V t$ e $R M 2 M 1$, sendo que os três últimos referem-se à rigidez 0,8 EI nos pilares e 0,4 EI nas vigas.

Tabela 7.9. Parâmetros de estabilidade.

\begin{tabular}{|c|c|c|c|c|}
\hline \multicolumn{5}{|c|}{ PARÂMETRO DE ESTABILIDADE } \\
\hline Ang. & $\boldsymbol{\alpha}$ & GAMA-Z & FAVt & RM2M1 \\
\hline $0^{\circ}$ & 0,381 & 1,045 & 1,045 & 1,045 \\
\hline $90^{\circ}$ & 0,397 & 1,035 & 1,035 & 1,035 \\
\hline $180^{\circ}$ & 0,381 & 1,045 & 1,045 & 1,045 \\
\hline $270^{\circ}$ & 0,397 & 1,035 & 1,035 & 1,035 \\
\hline
\end{tabular}


Para este exemplo a edificação é considerada de nós fixos em todas as direções, tanto para a análise com o parâmetro $\alpha$ quanto com o parâmetro $\gamma_{Z}$.

Neste caso $\alpha$ deve ser comparado com o valor limite 0,6 , que é aplicável às estruturas usuais de edifícios.

Os valores de $\gamma_{z}$ resultaram idênticos aos obtidos com o P-Delta, o que indica ótima precisão.

\subsubsection{ANÁLI SE DE SEGUNDA ORDEM GLOBAL}

Para este exemplo, como os valores de Gama-z são menores que 1,10, ou seja, os efeitos de segunda ordem não superaram em $10 \%$ os de primeira, não é necessário realizar a análise de segunda ordem.

\subsubsection{ALTERNATI VA PARA CONSI DERAR A NÃO-LI NEARI DADE FÍ SI CA}

Como neste exemplo a estrutura de contraventamento não é composta exclusivamente por vigas e pilares, a alternativa de um valor único igual a 0,7 EI para a rigidez de pilares e vigas não pode ser utilizada.

\subsection{EXEMPLO 5}

Na figura 7.6 pode-se observar o pavimento tipo do quinto edifício analisado.

Nas figuras 7.7 e 7.8 encontram-se vistas em 3D, uma mostrando o edifício como um todo e a outra mostrando que o edifício é composto por lajes maciças.

Este edifício também possui 10 pavimentos. 


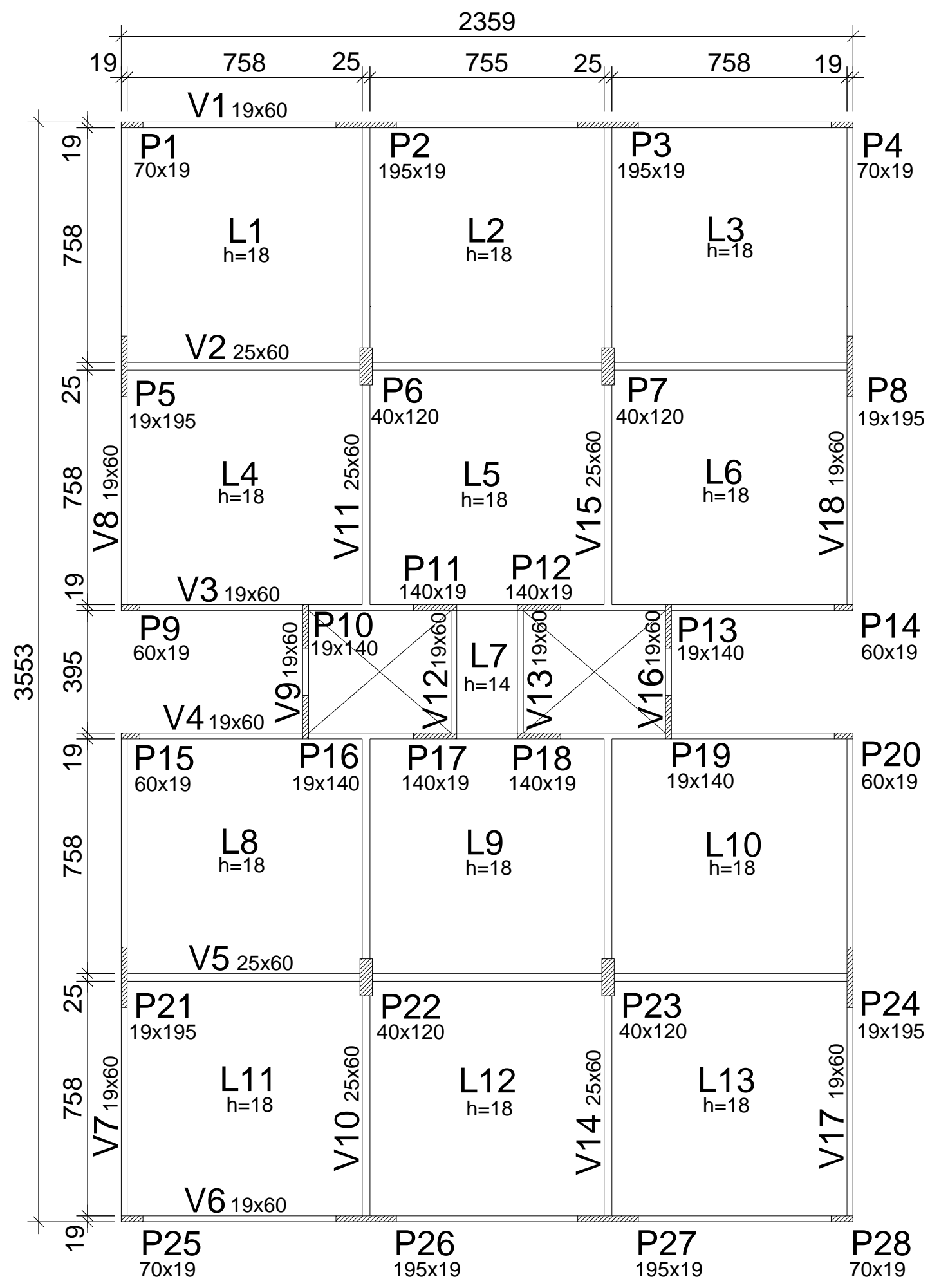

Figura 7.6. Planta de forma do pavimento tipo (dimensões em cm). 


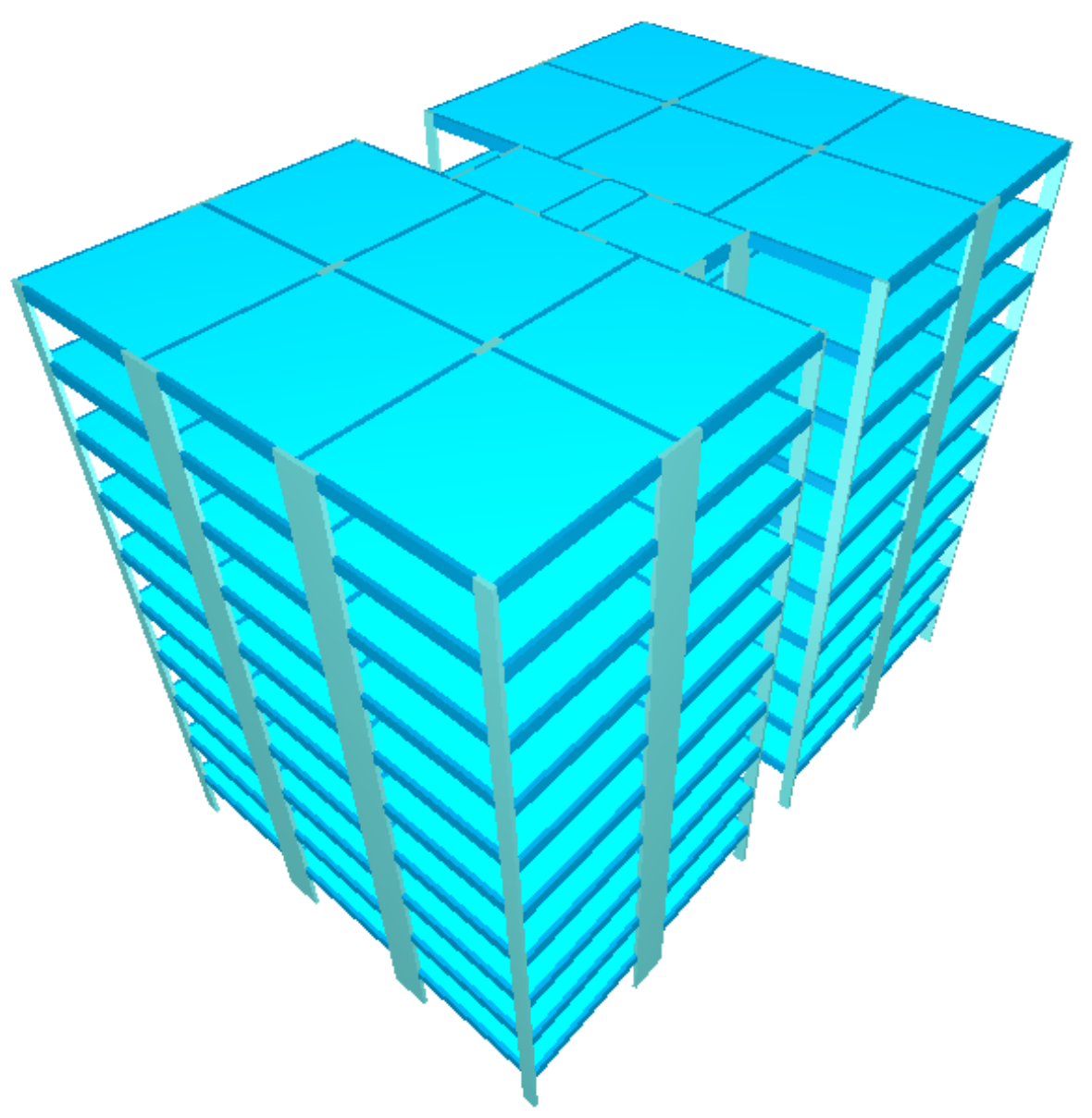

Figura 7.7. Vista em perspectiva do edifício analisado.

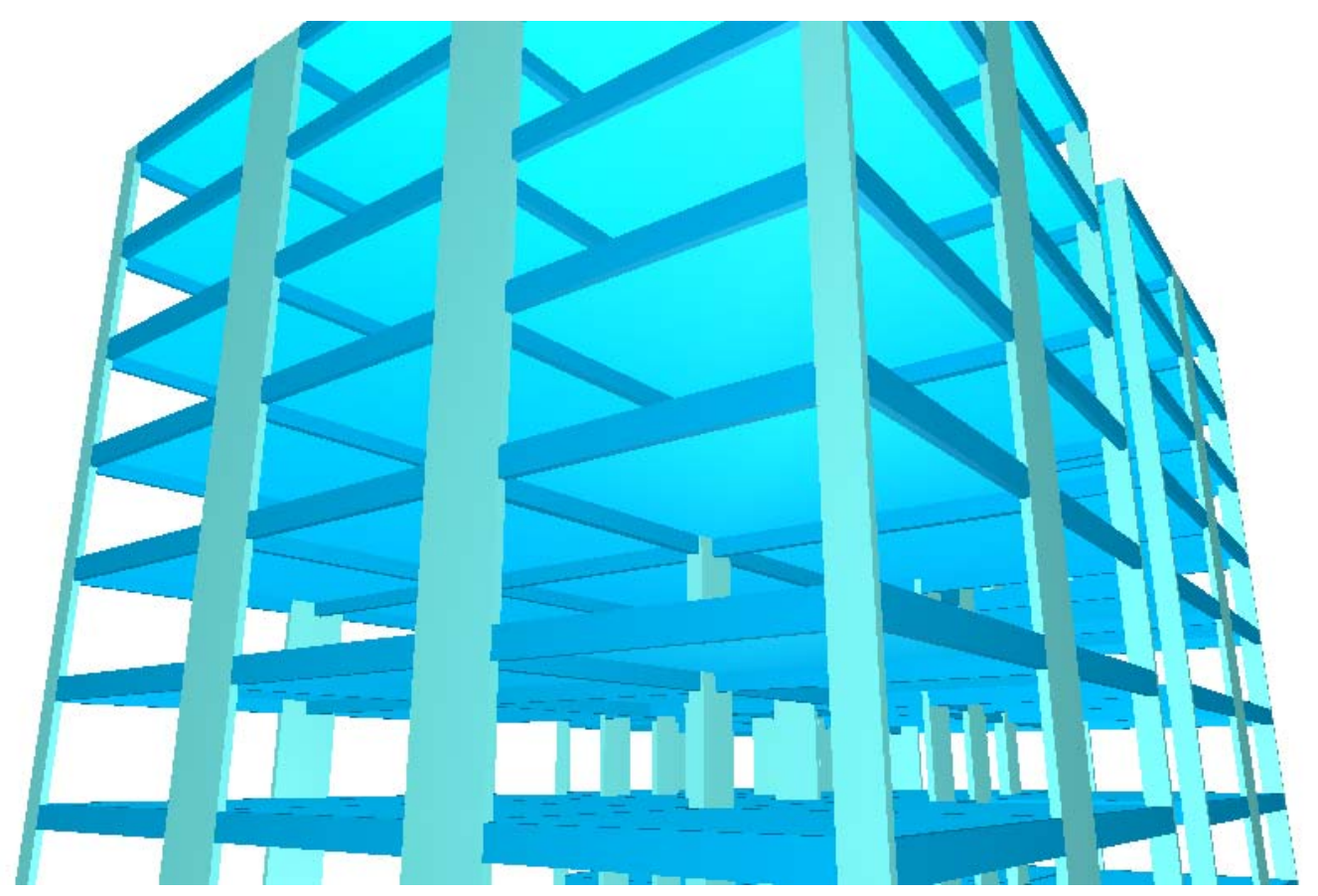

Figura 7.8. Vista em perspectiva do edifício, mostrando as lajes maciças. 


\subsubsection{PARÂMETROS DE ESTABI LI DADE}

Estão indicados, na tabela 7.10, os valores de $\alpha, \gamma_{z}, F A V t$ e $R M 2 M 1$, sendo que os três últimos referem-se à rigidez 0,8 EI nos pilares e 0,4 EI nas vigas.

Tabela 7.10. Parâmetros de estabilidade.

\begin{tabular}{|c|c|c|c|c|}
\hline \multicolumn{5}{|c|}{ PARÂMETRO DE ESTABILIDADE } \\
\hline Ang. & $\boldsymbol{\alpha}$ & GAMA-Z & FAVt & RM2M1 \\
\hline $0^{\circ}$ & 0,457 & 1,076 & 1,076 & 1,076 \\
\hline $90^{\circ}$ & 0,529 & 1,095 & 1,095 & 1,096 \\
\hline $180^{\circ}$ & 0,457 & 1,076 & 1,076 & 1,076 \\
\hline $270^{\circ}$ & 0,529 & 1,095 & 1,095 & 1,096 \\
\hline
\end{tabular}

Para este exemplo, os valores de $\gamma_{Z}$ indicam que a edificação é de nós fixos em todas as direções, e são quase iguais aos obtidos com o P-Delta.

Os resultados do parâmetro $\alpha$ indicam que a estrutura é de nós móveis nas direções de $90^{\circ}$ e $270^{\circ}$.

Porém, como já foi dito, atualmente os valores de $\gamma_{\mathrm{z}}$ são considerados prioritários, e neste caso eles indicam estrutura de nós fixos em todas as direções.

\subsubsection{ANÁLI SE DE SEGUNDA ORDEM GLOBAL}

Para este exemplo, como os valores de Gama-z são menores que 1,10 , ou seja, os efeitos de segunda ordem não superaram em $10 \%$ os de primeira, não é necessário realizar a análise de segunda ordem.

\subsubsection{ALTERNATI VA PARA CONSI DERAR A NÃO-LI NEARI DADE Fí SI CA}

Considerando-se o valor único 0,7 EI para a rigidez de pilares e vigas, os respectivos resultados são indicados na tabela 7.11 . 
Tabela 7.11. Parâmetros de estabilidade para rigidez 0,7 EI de pilares e vigas.

\begin{tabular}{|c|c|c|c|c|}
\hline \multicolumn{5}{|c|}{ PARÂMETRO DE ESTABILIDADE } \\
\hline Ang. & $\boldsymbol{\alpha}$ & GAMA-Z & FAVt & RM2M1 \\
\hline $0^{\circ}$ & 0,457 & 1,056 & 1,056 & 1,057 \\
\hline $90^{\circ}$ & 0,529 & 1,072 & 1,072 & 1,072 \\
\hline $180^{\circ}$ & 0,457 & 1,056 & 1,056 & 1,057 \\
\hline $270^{\circ}$ & 0,529 & 1,072 & 1,072 & 1,072 \\
\hline
\end{tabular}

Utilizando-se esta alternativa, a edificação continua sendo considerada de nós fixos em todas as direções, pois o valor de $\gamma_{z}$ é menor que 1,1 em todas elas.

Os valores de $\gamma_{\mathrm{z}}$ e FAVt também são quase iguais aos obtidos por P-Delta. Os de $\alpha$ são os mesmos da tabela 7.10 e indicam que a edificação é de nós móveis nas direções de $90^{\circ}$ e $270^{\circ}$, pois nas duas resultou o mesmo valor de $\alpha$ $(0,529)$, maior que 0,5 .

Porém, como já foi dito, atualmente considera-se que as análises feitas pelo processo aproximado $\gamma_{\mathrm{z}}$ geram resultados melhores, que neste caso indicam estrutura de nós fixos em todas as direções.

\subsection{EXEMPLO 6}

Na figura 7.9 pode-se observar o pavimento tipo do sexto edifício analisado, e na figura 7.10, uma vista em 3D. Este edifício possui núcleos rígidos junto à escada e ao elevador e possui 10 pavimentos. 


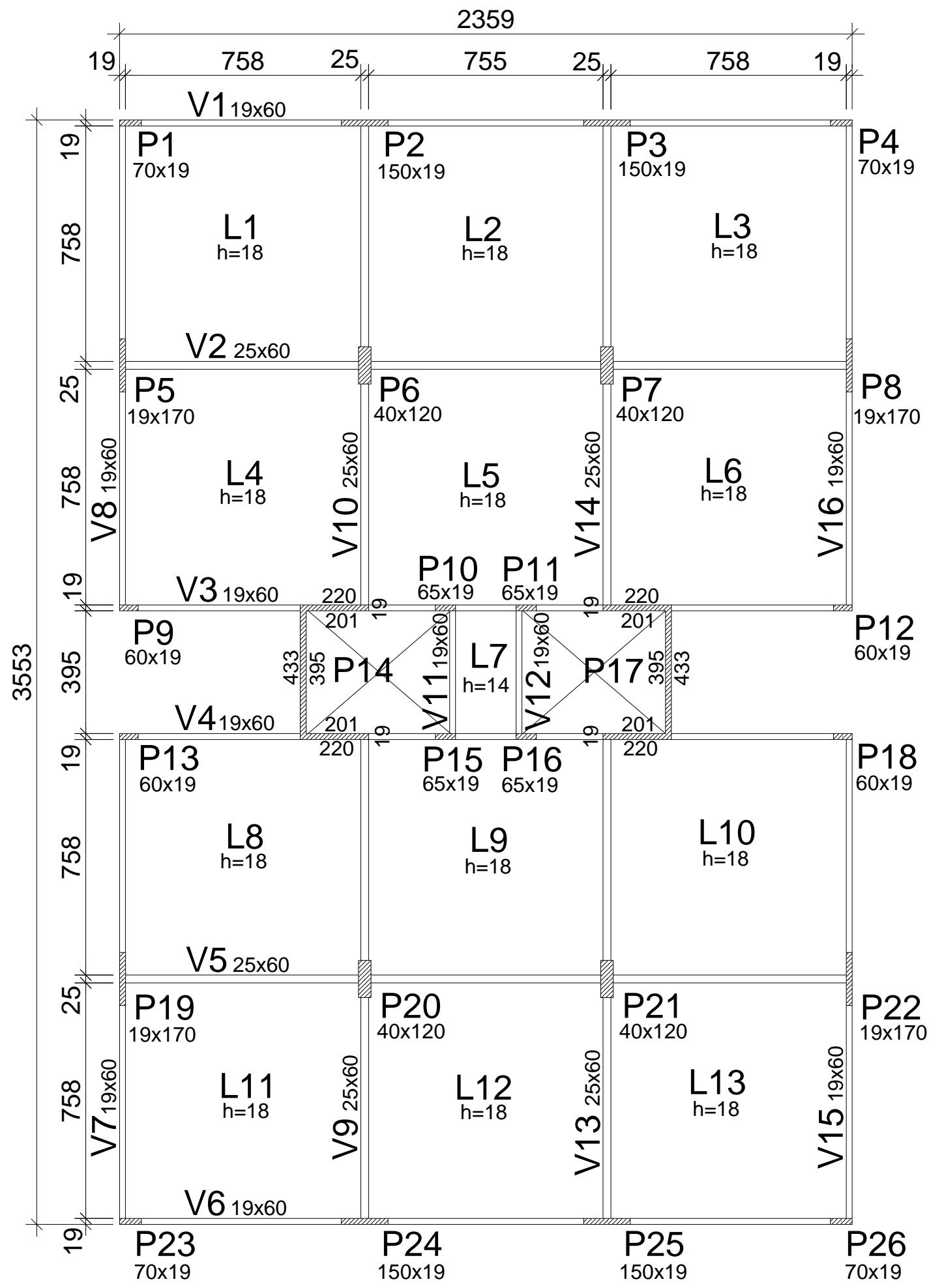

Figura 7.9. Planta de forma do pavimento tipo (dimensões em $\mathrm{cm}$ ). 


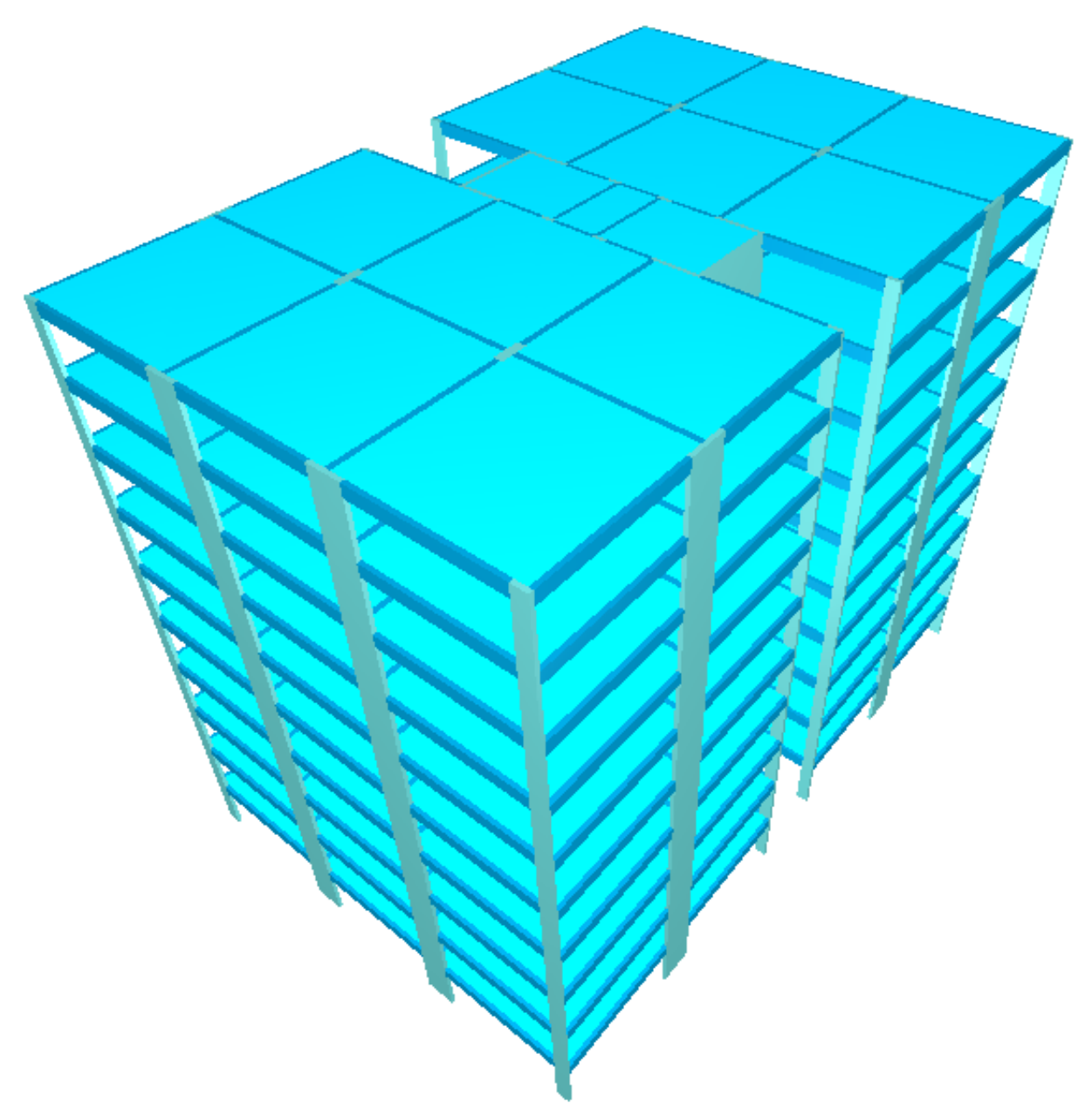

Figura 7.10. Vista em perspectiva do edifício analisado.

\subsubsection{PARÂMETROS DE ESTABI LI DADE}

Estão indicados, na tabela 7.12, os valores de $\alpha, \gamma_{z}, F A V t$ e $R M 2 M 1$, sendo que os três últimos referem-se à rigidez 0,8 EI nos pilares e 0,4 EI nas vigas.

Tabela 7.12. Parâmetros de estabilidade.

\begin{tabular}{|c|c|c|c|c|}
\hline \multicolumn{5}{|c|}{ PARÂMETRO DE ESTABILIDADE } \\
\hline Ang. & $\boldsymbol{\alpha}$ & GAMA-Z & FAVt & RM2M1 \\
\hline $0^{\circ}$ & 0,379 & 1,045 & 1,045 & 1,045 \\
\hline $90^{\circ}$ & 0,386 & 1,035 & 1,035 & 1,035 \\
\hline $180^{\circ}$ & 0,379 & 1,045 & 1,045 & 1,045 \\
\hline $270^{\circ}$ & 0,386 & 1,035 & 1,035 & 1,035 \\
\hline
\end{tabular}


Para este exemplo a edificação também é considerada de nós fixos em todas as direções, tanto na análise com o parâmetro $\alpha$ quanto na relativa ao parâmetro $\gamma_{z}$. Neste caso, o $\alpha$ deve ser comparado a 0,6 , que é aplicável às estruturas usuais de edifícios. Os valores de $\gamma_{z}$ resultaram idênticos aos obtidos por P-Delta, o que indica ótima precisão.

\subsubsection{ANÁLI SE DE SEGUNDA ORDEM GLOBAL}

Para este exemplo, como o valor de Gama-z é menor que 1,10, ou seja, os efeitos de segunda ordem não superaram em $10 \%$ os de primeira, não é necessário realizar a análise de segunda ordem.

\subsubsection{ALTERNATI VA PARA CONSI DERAR A NÃO-LI NEARI DADE FÍ SI CA}

Como neste exemplo a estrutura de contraventamento também não é composta exclusivamente por vigas e pilares, como no exemplo 4, a alternativa de um valor único igual a 0,7 EI para a rigidez de pilares e vigas não pode ser utilizada.

\subsection{EXEMPLO 7}

Na figura 7.11 pode-se observar o pavimento tipo do sétimo edifício analisado, e na figura 7.12, vista em perspectiva. O edifício possui 22 pavimentos. 


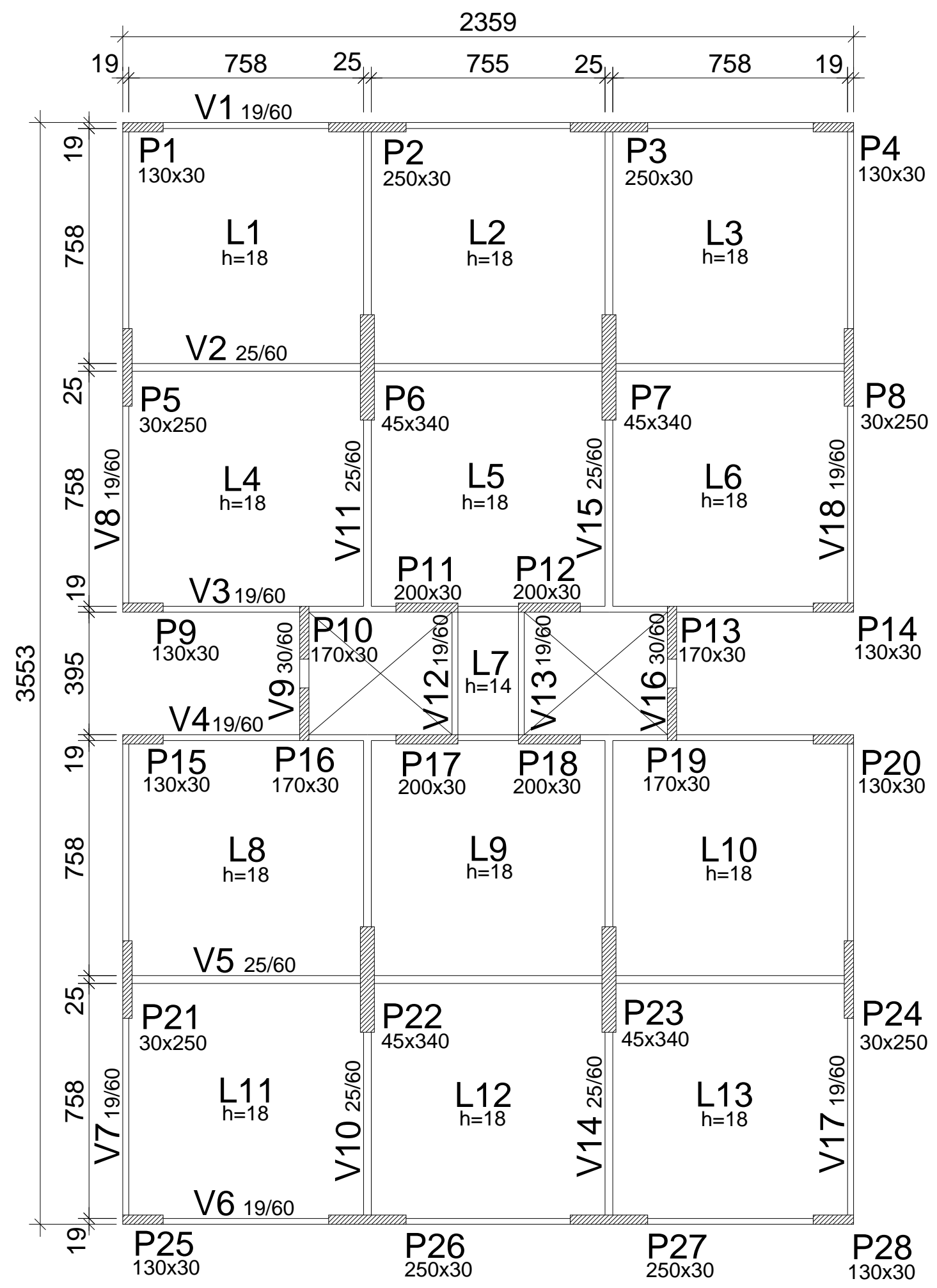

Figura 7.11. Planta de forma do pavimento tipo (dimensões em $\mathrm{cm}$ ). 


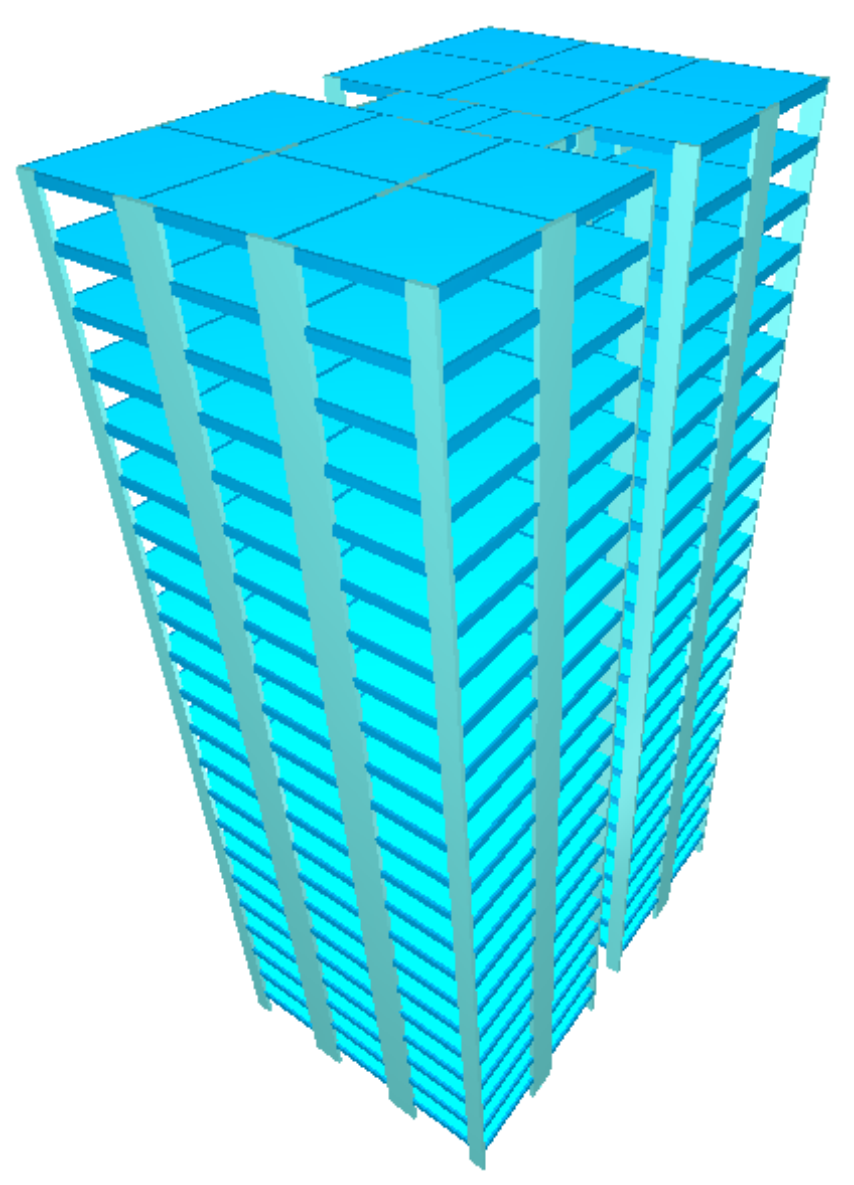

Figura 7.12. Vista em perspectiva do edifício analisado.

\subsubsection{PARÂMETROS DE ESTABI LI DADE}

Estão indicados, na tabela 7.13, os valores de $\alpha, \gamma_{z}, F A V t$ e $R M 2 M 1$, sendo que os três últimos referem-se à rigidez 0,8 EI nos pilares e 0,4 EI nas vigas.

Tabela 7.13. Parâmetros de estabilidade.

\begin{tabular}{|c|c|c|c|c|}
\hline \multicolumn{5}{|c|}{ PARÂMETRO DE ESTABILIDADE } \\
\hline Ang. & $\boldsymbol{\alpha}$ & GAMA-Z & FAVt & RM2M1 \\
\hline $0^{\circ}$ & 0,601 & 1,137 & 1,137 & 1,139 \\
\hline $90^{\circ}$ & 0,660 & 1,142 & 1,142 & 1,144 \\
\hline $180^{\circ}$ & 0,601 & 1,137 & 1,137 & 1,139 \\
\hline $270^{\circ}$ & 0,660 & 1,142 & 1,142 & 1,144 \\
\hline
\end{tabular}


Para este exemplo, os valores de $\gamma_{z}$ indicam que a edificação é de nós móveis em todas as direções, sendo necessária a consideração dos efeitos de segunda ordem.

Os resultados do parâmetro $\alpha$ também indicam que a estrutura é de nós móveis em todas as direções.

Neste exemplo também se percebe que os resultados obtidos pelos métodos aproximados ficaram bem próximos aos obtidos por P-Delta.

\subsubsection{ANÁLI SE DE SEGUNDA ORDEM GLOBAL}

Observações em relação à análise já foram feitas no capitulo anterior, portanto não será necessário repeti-las.

Como a edificação foi considerada de nós móveis no item anterior, as análises de segunda ordem serão realizadas em todas as direções.

Vale lembrar que as parcelas do peso próprio, demais cargas permanentes, carga acidental e do vento, das combinações consideradas, foram obtidas no visualizador do pórtico espacial do Sistema TQS.

São mostrados na tabela 7.14 os valores de cálculo dos esforços normais de primeira ordem, e na tabela 7.15 , os esforços finais $\left(1^{a}+2^{a}\right.$ ordem) na base de apenas metade dos pilares do pórtico tridimensional, pois a edificação é simétrica nas duas direções. Nessa tabela 7.15, foi considerado o valor reduzido $0,95 \gamma_{\mathrm{z}}$, de acordo com a NBR 6118:2003.

Primeiramente será mostrado como é realizado o cálculo dos esforços na base do pilar P1, para todas as combinações.

COMB. 1: Peso próprio + carga perm. + carga acid. + 0,6 vento 00

$$
\begin{aligned}
& N_{d}=\gamma_{\mathrm{g}} \cdot(P P+C P)+\gamma_{\mathrm{q}} \cdot\left(C A+0,95 \gamma_{\mathrm{z}} \cdot \Psi_{0 \mathrm{j}} \cdot \text { Vento } 0^{0}\right) \\
& N_{d}=1,4 \cdot(2047,70+1511,00)+1,4 \cdot(331,3+0,95 \cdot 1,137 \cdot 0,6 \cdot-685,40) \\
& N_{d}=1,4 \cdot(3558,70)+1,4 \cdot(-112,90) \\
& N_{d}=4824,12 k N
\end{aligned}
$$


COMB. 2: Peso próprio + carga perm. + carga acid. + 0,6 vento $90^{\circ}$

$N_{d}=\gamma_{\mathrm{g}} \cdot(P P+C P)+\gamma_{\mathrm{q}} \cdot\left(C A+0,95 \gamma_{\mathrm{z}} \cdot \Psi_{0 \mathrm{j}} \cdot\right.$ Vento $\left.90^{0}\right)$

$N_{d}=1,4 \cdot(2047,70+1511,00)+1,4 \cdot(331,3+0,95 \cdot 1,142 \cdot 0,6 \cdot 200,80)$

$N_{d}=1,4 \cdot(3558,70)+1,4 \cdot(462,01)$

$N_{d}=5628,99 \mathrm{kN}$

COMB. 3: Peso próprio + carga perm. + carga acid. + 0,6 vento $180^{\circ}$

$N_{d}=\gamma_{\mathrm{g}} \cdot(P P+C P)+\gamma_{\mathrm{q}} \cdot\left(C A+0,95 \gamma_{\mathrm{z}} \cdot \Psi_{0 \mathrm{j}} \cdot\right.$ Vento $\left.180^{\circ}\right)$

$N_{d}=1,4 \cdot(2047,70+1511,00)+1,4 \cdot(331,3+0,95 \cdot 1,137 \cdot 0,6 \cdot 685,40)$

$N_{d}=1,4 \cdot(3558,70)+1,4 \cdot(775,50)$

$N_{d}=6067,88 \mathrm{kN}$

COMB. 4: Peso próprio + carga perm. + carga acid. + 0,6 vento $270^{\circ}$

$N_{d}=\gamma_{\mathrm{g}} \cdot(P P+C P)+\gamma_{\mathrm{q}} \cdot\left(C A+0,95 \gamma_{\mathrm{z}} \cdot \Psi_{0 \mathrm{j}} \cdot\right.$ Vento $\left.270^{\circ}\right)$

$N_{d}=1,4 \cdot(2047,70+1511,00)+1,4 \cdot(331,3+0,95 \cdot 1,142 \cdot 0,6 \cdot-200,80)$

$N_{d}=1,4 \cdot(3558,70)+1,4 \cdot(200,59)$

$N_{d}=5263,01 k N$

Tabela 7.14. Força normal de cálculo de $1^{a}$ ordem.

\begin{tabular}{|c|c|c|c|c|}
\hline \multicolumn{5}{|c|}{ ESFORÇOS NORMAIS DE CÁLCULO DE 1a ORDEM (kN) } \\
\hline PILARES & COMB.1 & COMB.2 & COMB.3 & COMB.4 \\
\hline P1 & 4870,18 & 5614,56 & 6021,68 & 5277,30 \\
\hline P2 & 9384,06 & 9780,68 & 9591,40 & 9194,78 \\
\hline P3 & 9591,40 & 9780,68 & 9384,20 & 9194,78 \\
\hline P4 & 6021,68 & 5614,56 & 4870,18 & 5277,30 \\
\hline P5 & 12621,84 & 12888,26 & 13130,88 & 12864,60 \\
\hline P6 & 26001,36 & 25982,88 & 26207,44 & 26225,92 \\
\hline P7 & 26207,44 & 25982,88 & 26001,36 & 26225,92 \\
\hline P8 & 13130,88 & 12888,26 & 12621,84 & 12864,60 \\
\hline P9 & 4776,10 & 5100,20 & 5341,28 & 5017,18 \\
\hline P10 & 5838,00 & 7424,90 & 7078,12 & 5491,22 \\
\hline P11 & 5963,86 & 7644,56 & 8562,40 & 6881,70 \\
\hline P12 & 8562,40 & 7644,56 & 5963,86 & 6881,70 \\
\hline P13 & 7078,12 & 7424,90 & 5838,00 & 5491,22 \\
\hline P14 & 5341,28 & 5100,20 & 4776,10 & 5017,18 \\
\hline
\end{tabular}


Tabela 7.15. Força normal de cálculo com efeitos de $2^{a}$ ordem global $\left(0,95 \gamma_{z}\right)$.

\begin{tabular}{|c|c|c|c|c|c|c|c|c|c|c|c|c|}
\hline \multicolumn{13}{|c|}{ FORÇA NORMAL DE CÁLCULO NA BASE DO PILAR COM EFEITOS DE 2a ORDEM GLOBAL (kN) } \\
\hline \multirow{2}{*}{ ILARES } & \multicolumn{3}{|c|}{ СОМв. 1} & \multicolumn{3}{|c|}{ СОМв. 2} & \multicolumn{3}{|c|}{ СОМв. 3} & \multicolumn{3}{|c|}{ СОМB. 4} \\
\hline & GAMA-Z & AVt & DELTA & GAMA-Z & FAVt & -DELTA & GAMA-Z & FAVt & P-DELTA & GAMA-Z & FAVt & TA \\
\hline P1 & & 324,12 & & 5628,99 & 5628,99 & 641,58 & 6067,88 & 6067,88 & 106,10 & 5263,01 & 01 & 5250 \\
\hline $\mathbf{P 2}$ & 9375,80 & 9375,80 & 9369,36 & 9805,60 & 9805,60 & 9827,58 & 9599,66 & 9599,66 & 9606,10 & 9169,86 & 9169,86 & 9147,88 \\
\hline P3 & 9599,66 & 9599,66 & 9606,10 & 9805,60 & 9805,60 & 9827,58 & 9375,80 & 9375,80 & 9369,36 & 9169,86 & 9169,86 & 9147,88 \\
\hline P4 & & 6067,74 & 6106,10 & & 5628,84 & & & 4824,12 & & & & \\
\hline P5 & 2601,40 & 12601,40 & 12585,02 & 12889,24 & 12889,24 & 12890,08 & 13151,32 & 13151,32 & 13167,84 & 12863,62 & 12863,62 & 12862,64 \\
\hline P6 & 5993,10 & 25993,10 & 25986,52 & 25972,52 & 25972,52 & 25963,42 & 26215,56 & 26215,56 & 26222,28 & 26236,28 & 26236,28 & 26245,24 \\
\hline P7 & 26215,56 & 26215,56 & 26222,28 & 25972,52 & 25972,52 & 25963,42 & 25993,10 & 25993,10 & 25986,52 & 26236,28 & 26236,28 & 26245,24 \\
\hline P8 & 13151,32 & 13151,32 & 13167,84 & 12889,24 & 12889,24 & 12890,08 & 12601,40 & 12601,40 & 12585,02 & 12863,62 & 12863,62 & 12862,64 \\
\hline P9 & & 4753,56 & 4735,22 & & & & & & 5382,16 & 5013,68 & 5013,68 & 5010,46 \\
\hline P10 & 5788,44 & 5788,44 & 5747,14 & 7507,08 & & 7568,68 & 7127,68 & 7127,68 & 7168,98 & 5409,04 & 5409,04 & 5347,44 \\
\hline P11 & 5859,98 & 5859,98 & 5766,18 & 7677,04 & 7677,04 & 7705,74 & 8666,42 & 8666,42 & 8760,08 & 6849,36 & 6849,36 & 6820,66 \\
\hline P12 & 8666,42 & 8666,42 & 8760,08 & 7677,04 & 7677,04 & 7705,74 & 5859,98 & 5859,98 & 5766,18 & 6849,36 & 6849,36 & 6820,66 \\
\hline P13 & 7127,68 & 7127,68 & 7168,98 & 7507,08 & 7507,08 & 7568,68 & 5788,44 & 5788,44 & 5747,14 & 5409,04 & 5409,04 & 5347,44 \\
\hline P14 & 5363,96 & 5363,96 & 5382,16 & 5103,70 & 5103,70 & 5106,92 & 4753,56 & 4753,56 & 4735,22 & 5013,68 & 5013,68 & 5010,46 \\
\hline
\end{tabular}

Comparando-se os esforços obtidos por $\gamma_{\mathrm{z}}$ e $F A V t$, idênticos neste caso, com os do processo P-Delta, pode-se perceber que $50 \%$ do total de esforços, para todos os pilares, estão acima dos obtidos pelo P-Delta, e 50\% estão abaixo, ou seja, 28 esforços estão acima e 28 abaixo, isso porque se tem, para cada combinação, 14 pilares, ou seja, 14 esforços para cada combinação, com um total de 56 esforços.

Em relação aos valores obtidos pelo P-Delta, dos que ficaram abaixo, eles estão em média 0,16\% menores, e dos que ficaram acima, 0,60\% maiores. Com isso pode-se concluir que os esforços aproximados estão muito próximos dos obtidos pelo processo P-Delta, mais refinado.

Realizando-se novamente a análise, agora com o valor integral do $\gamma_{\mathrm{z}}$ obtém-se os resultados mostrados na tabela 7.16. 
Tabela 7.16. Força normal de cálculo com efeitos de $2^{a}$ ordem global $\left(\gamma_{z}\right)$.

\begin{tabular}{|c|c|c|c|c|c|c|c|c|c|c|c|c|}
\hline \multicolumn{13}{|c|}{ FORÇA NORMAL DE CÁLCULO NA BASE DO PILAR COM EFEITOS DE 2a ORDEM GLOBAL (kN) } \\
\hline \multirow{2}{*}{ PILARES } & \multicolumn{3}{|c|}{ СОМв. 1} & \multicolumn{3}{|c|}{ СОМв. 2} & \multicolumn{3}{|c|}{ СОМв. 3} & \multicolumn{3}{|c|}{ СОМв. 4} \\
\hline & GAMA-Z & FAVt & P-DELTA & GAMA-Z & FAVt & P-DELTA & GAMA-Z & FAVt & P-DELTA & GAMA-Z & FAVt & P-DELTA \\
\hline P1 & 4792,62 & 4792,62 & 4785,76 & 5638,50 & 5638,50 & 5641,58 & 6100,50 & 6100,50 & 6106,10 & 5253,36 & 5253,36 & 5250,28 \\
\hline $\mathbf{P 2}$ & 9369,92 & 9369,92 & 9369,36 & 9822,40 & 9822,40 & 9827,58 & 9605,54 & 9605,54 & 9606,10 & 9153,20 & 9153,20 & 9147,88 \\
\hline P3 & 9605,54 & 9605,54 & 9606,10 & 9822,40 & 9822,40 & 9827,58 & 9369,92 & 9369,92 & 9369,36 & 9153,20 & 9153,20 & 9147,88 \\
\hline P4 & 6100,50 & 6100,50 & 6106,10 & 5638,50 & 5638,50 & 5641,58 & 4792,62 & 4792,62 & 4785,76 & 5253,36 & 5253,36 & 4785,76 \\
\hline P5 & 12586,98 & 12586,98 & 12585,02 & 12889,94 & 12889,94 & 12890,08 & 13165,74 & 13165,74 & 13167,84 & 12862,92 & 12862,92 & 12862,64 \\
\hline P6 & 25987,22 & 25987,22 & 25986,52 & 25965,66 & 25965,66 & 25963,42 & 26221,44 & 26221,44 & 26222,28 & 26243,14 & 26243,14 & 26245,24 \\
\hline P7 & 26221,44 & 26221,44 & 26222,28 & 25965,66 & 25965,66 & 25963,42 & 25987,22 & 25987,22 & 25986,52 & 26243,14 & 26243,14 & 26245,24 \\
\hline P8 & 13165,74 & 13165,74 & 13167,84 & 12889,94 & 12889,94 & 12890,08 & 12586,98 & 12586,98 & 12585,02 & 12862,92 & 12862,92 & 12862,64 \\
\hline P9 & 4737,46 & 4737,46 & 4735,22 & 5106,08 & 5106,08 & 5106,92 & 5380,06 & 5380,06 & 5382,16 & 5011,30 & 5011,30 & 5010,46 \\
\hline P10 & 5753,02 & 5753,02 & 5747,14 & 7562,24 & 7562,24 & 7568,68 & 7163,10 & 7163,10 & 7168,98 & 5353,88 & 5353,88 & 5347,44 \\
\hline P11 & 5791,52 & 5791,52 & 5766,18 & 7698,74 & 7698,74 & 7705,74 & 8740,48 & 8740,48 & 8760,08 & 6827,52 & 6827,52 & 6820,66 \\
\hline P12 & 8740,48 & 8740,48 & 8760,08 & 7698,74 & 7698,74 & 7705,74 & 5785,92 & 5785,92 & 5766,18 & 6827,52 & 6827,52 & 6820,66 \\
\hline P13 & 7163,10 & 7163,10 & 7168,98 & 7562,24 & 7562,24 & 7568,68 & 5753,02 & 5753,02 & 5747,14 & 5353,88 & 5353,88 & 5347,44 \\
\hline P14 & 5380,06 & 5380,06 & 5382,16 & 5106,08 & 5106,08 & 5106,92 & 4737,46 & 4737,46 & 4735,22 & 5011,30 & 5011,30 & 5010,46 \\
\hline
\end{tabular}

Em comparação análoga à anterior, pode-se perceber que também $50 \%$ do total de esforços nos pilares estão acima e 50\%, abaixo dos obtidos pelo P-Delta, ou seja, 28 esforços acima e 28 abaixo.

Em relação aos valores referentes ao P-Delta, os que ficaram abaixo são $0,03 \%$ menores, e os que ficaram acima, $0,44 \%$ maiores. Com isso pode-se afirmar que os esforços de segunda ordem global obtidos com $\gamma_{\mathrm{z}}$, para este exemplo, também são melhores que os relativos a $0,95 \gamma_{\mathrm{z}}$, pois os valores acima e abaixo são mais próximos dos obtidos com o P-Delta.

São considerados, agora, os momentos fletores na base do pilares. São mostrados na tabela 7.17 os momentos fletores de cálculo de $1^{\text {a }}$ ordem, e na tabela 7.18, os valores, em módulo, dos momentos finais na base para apenas 14 pilares, por conta da simetria já mencionada, sendo esses momentos relativos à direção mais rígida de cada pilar. Os cálculos dos esforços finais serão realizados, em detalhes, somente para o pilar P1, para todas as combinações. 
COMB. 1: Peso próprio + carga perm. + carga acid. + 0,6 vento $0^{\circ}$ $M_{d}=\gamma_{\mathrm{g}} \cdot(P P+C P)+\gamma_{\mathrm{q}} \cdot\left(C A+0,95 \gamma_{\mathrm{z}} \cdot \Psi_{0 \mathrm{j}} \cdot\right.$ Vento $\left.0^{0}\right)$

$M_{d}=1,4 \cdot(-13,70-12,10)+1,4 \cdot(-3,80+0,95 \cdot 1,137 \cdot 0,6 \cdot 400,10)$

$M_{d}=1,4 \cdot(-25,80)+1,4 \cdot(255,50)$

$M_{d}=321,58 \mathrm{kN} \cdot \mathrm{m}$

COMB. 2: Peso próprio + carga perm. + carga acid. + 0,6 vento $90^{\circ}$ $M_{d}=\gamma_{\mathrm{g}} \cdot(P P+C P)+\gamma_{\mathrm{q}} \cdot\left(C A+0,95 \gamma_{\mathrm{z}} \cdot \Psi_{0 \mathrm{j}} \cdot\right.$ Vento $\left.90^{0}\right)$

$M_{d}=1,4 \cdot(-13,70-12,10)+1,4 \cdot(-3,80+0,95 \cdot 1,142 \cdot 0,6 \cdot 0,80)$

$M_{d}=1,4 \cdot(-25,80)+1,4 \cdot(-3,28)$

$M_{d}=-40,71 \mathrm{kN} \cdot \mathrm{m}$

COMB. 3: Peso próprio + carga perm. + carga acid.I + 0,6 vento $180^{\circ}$ $M_{d}=\gamma_{\mathrm{g}} \cdot(P P+C P)+\gamma_{\mathrm{q}} \cdot\left(C A+\Psi_{0 \mathrm{j}} \cdot 0,95 \gamma_{\mathrm{z}} \cdot\right.$ Vento $\left.180^{\circ}\right)$

$M_{d}=1,4 \cdot(-13,70-12,10)+1,4 \cdot(-3,80+0,95 \cdot 1,137 \cdot 0,6 \cdot-400,10)$

$M_{d}=1,4 \cdot(-25,80)+1,4 \cdot(-263,10)$

$M_{d}=-404,46 \mathrm{kN} . \mathrm{m}$

COMB. 4: Peso próprio + carga perm. + carga acid. + 0,6 vento $270^{\circ}$

$M_{d}=\gamma_{\mathrm{g}} \cdot(P P+C P)+\gamma_{\mathrm{q}} \cdot\left(C A+\Psi_{0 \mathrm{j}} \cdot 0,95 \gamma_{\mathrm{z}} \cdot\right.$ Vento $\left.270^{\circ}\right)$

$M_{d}=1,4 \cdot(-13,70-12,10)+1,4 \cdot(-3,80+0,95 \cdot 1,142 \cdot 0,6 \cdot-0,80)$

$M_{d}=1,4 \cdot(-25,80)+1,4 \cdot(-4,32)$

$M_{d}=-42,17 \mathrm{kN} \cdot \mathrm{m}$ 
Tabela 7.17. Momento fletor de cálculo de $1^{\mathrm{a}}$ ordem.

\begin{tabular}{|c|c|c|c|c|}
\hline \multicolumn{5}{|c|}{ MOMENTOS FLETORES DE CÁLCULO DE 1a ORDEM (kN.m) } \\
\hline PILARES & COMB.1 & COMB.2 & COMB.3 & COMB.4 \\
\hline P1 & 294,70 & 40,74 & 377,44 & 42,00 \\
\hline P2 & 2288,16 & 2,80 & 2285,08 & 0,28 \\
\hline P4 & 2285,08 & 2,80 & 2288,16 & 0,28 \\
\hline P5 & 377,44 & 40,74 & 294,70 & 42,00 \\
\hline P6 & 23,10 & 836,08 & 40,46 & 818,86 \\
\hline P7 & 11,76 & 3104,50 & 74,20 & 3042,06 \\
\hline P8 & 44,20 & 3104,64 & 11,76 & 3042,20 \\
\hline P9 & 30,46 & 836,22 & 23,10 & 818,86 \\
\hline P10 & 63,70 & 238,98 & 64,40 & 26,18 \\
\hline P11 & 1284,92 & 15,26 & 1258,60 & 11,06 \\
\hline P12 & 1258,60 & 15,26 & 1284,92 & 11,06 \\
\hline P13 & 64,40 & 238,98 & 63,70 & 367,08 \\
\hline P14 & 367,08 & 32,34 & 308,70 & 26,18 \\
\hline
\end{tabular}

Tabela 7.18. Momento fletor de cálculo com efeitos de $2^{a}$ ordem global $\left(0,95 \gamma_{z}\right)$.

\begin{tabular}{|c|c|c|c|c|c|c|c|c|c|c|c|c|}
\hline \multicolumn{13}{|c|}{ MOMENTO FLETOR DE CÁLCULO COM EFEITOS DE 2a ORDEM GLOBAL (kN.m) } \\
\hline \multirow{2}{*}{ PILARES } & \multicolumn{3}{|c|}{ СОМв. 1} & \multicolumn{3}{|c|}{ СОМв. 2} & \multicolumn{3}{|c|}{ СОМв. 3} & \multicolumn{3}{|c|}{ СОМв. 4} \\
\hline & GAMA-Z & FAVt & P-DELTA & GAMA-Z & FAVt & P-DELTA & GAMA-Z & FAVt & P-DELTA & GAMA-Z & FAVt & P-DELTA \\
\hline P1 & 321,58 & 321,58 & 329,15 & 40,71 & 40,71 & 40,77 & 404,46 & 404,46 & 411,15 & 42,17 & 42,17 & 41,99 \\
\hline $\mathbf{P 2}$ & 2471,06 & 2471,06 & 2539,59 & 2,91 & 2,91 & 2,69 & 2468,05 & 2468,05 & 2535,65 & 0,10 & 0,10 & 0,32 \\
\hline $\mathbf{P 3}$ & 2468,05 & 2468,05 & 2535,65 & 2,86 & 2,86 & 2,65 & 2471,04 & 2471,04 & 2539,57 & 0,14 & 0,14 & 0,35 \\
\hline P4 & 404,35 & 404,35 & 411,17 & 40,70 & 40,70 & 40,78 & 321,58 & 321,58 & 329,14 & 42,07 & 42,07 & 42,00 \\
\hline P5 & 25,70 & 25,70 & 21,76 & 906,42 & 906,42 & 928,45 & 43,01 & 43,01 & 38,91 & 889,13 & 889,13 & 911,34 \\
\hline P6 & 15,13 & 15,13 & 11,14 & 3365,78 & 3365,78 & 3455,82 & 77,59 & 77,59 & 73,77 & 3303,33 & 3303,33 & 3393,82 \\
\hline P7 & 77,67 & 77,67 & 73,85 & 3365,82 & 3365,82 & 3455,86 & 15,23 & 15,23 & 11,24 & 3303,38 & 3303,38 & 3393,88 \\
\hline P8 & 43,06 & 43,06 & 38,96 & 906,51 & 906,51 & 928,54 & 25,69 & 25,69 & 21,74 & 889,14 & 889,14 & 911,36 \\
\hline P9 & 335,66 & 335,66 & 341,57 & 32,58 & 32,58 & 32,66 & 394,16 & 394,16 & 399,38 & 25,90 & 25,90 & 25,83 \\
\hline P10 & 63,69 & 63,69 & 63,56 & 264,73 & 264,73 & 269,88 & 64,41 & 64,41 & 64,60 & 392,88 & 392,88 & 398,27 \\
\hline P11 & 1386,70 & 1386,70 & 1421,25 & 15,44 & 15,44 & 15,60 & 1360,38 & 1360,38 & 1393,41 & 10,88 & 10,88 & 10,74 \\
\hline P12 & 1360,37 & 1360,37 & 1393,41 & 15,46 & 15,46 & 15,60 & 1386,70 & 1386,70 & 1421,25 & 10,88 & 10,88 & 10,74 \\
\hline P13 & 64,47 & 64,47 & 64,60 & 264,73 & 264,73 & 269,88 & 63,69 & 63,69 & 63,56 & 392,88 & 392,88 & 398,27 \\
\hline P14 & 394,14 & 394,14 & 399,38 & 32,56 & 32,56 & 32,65 & 335,68 & 335,68 & 341,59 & 25,90 & 25,90 & 25,83 \\
\hline
\end{tabular}


Comparando-se os esforços obtidos por $\gamma_{z}$ e FAVt, idênticos neste caso, com os relativos ao P-Delta, pode-se perceber que apenas $32 \%$ do total de esforços, para todos os pilares, estão acima dos obtidos pelo P-Delta, e 68\%, abaixo, ou seja, 18 esforços estão acima e 38 abaixo. Em relação aos valores obtidos pelo P-Delta, dos que ficaram abaixo, eles são em média 5,76\% menores, e dos que ficaram acima, 9,16\% maiores.

Se em vez de $0,95 \gamma_{\mathrm{z}}$ fosse considerado o valor integral de $\gamma_{\mathrm{z}}$ para majoração dos esforços horizontais, obter-se-iam os resultados mostrados na tabela 7.19, consideração que também vale para o FAVt.

Tabela 7.19. Momento fletor de cálculo com efeitos de $2^{\mathrm{a}}$ ordem global $\left(\gamma_{\mathrm{z}}\right)$.

\begin{tabular}{|c|c|c|c|c|c|c|c|c|c|c|c|c|}
\hline \multicolumn{9}{|c|}{ MOMENTO FLETOR DE CÁLCULO COM EFEITOS DE 2a ORDEM GLOBAL (kN.m) } \\
\hline \multirow{2}{*}{ PILARES } & \multicolumn{3}{|c|}{ COMB. 1 } & \multicolumn{3}{c|}{ COMB. 2 } & \multicolumn{3}{c|}{ COMB. 3 } & \multicolumn{3}{c|}{ COMB. 4 } \\
\cline { 2 - 14 } & GAMA-Z & FAVt & P-DELTA & GAMA-Z & FAVt & P-DELTA & GAMA-Z & FAVt & P-DELTA & GAMA-Z & FAVt & P-DELTA \\
\hline P1 & 340,75 & 340,75 & 329,15 & 40,64 & 40,64 & 40,77 & 423,50 & 423,50 & 411,15 & 42,11 & 42,11 & 41,99 \\
\hline P2 & 2601,40 & 2601,40 & 2539,59 & 2,98 & 2,98 & 2,69 & 2598,39 & 2598,39 & 2535,65 & 0,03 & 0,03 & 0,32 \\
\hline P3 & 2598,39 & 2598,39 & 2535,65 & 2,93 & 2,93 & 2,65 & 2601,38 & 2601,38 & 2539,57 & 0,07 & 0,07 & 0,35 \\
\hline P4 & 423,51 & 423,51 & 411,17 & 40,67 & 40,67 & 40,78 & 340,73 & 340,73 & 329,14 & 42,11 & 42,11 & 42,00 \\
\hline P5 & 27,52 & 27,52 & 21,76 & 953,58 & 953,58 & 928,45 & 44,81 & 44,81 & 38,91 & 936,29 & 936,29 & 911,34 \\
\hline P6 & 17,58 & 17,58 & 11,14 & 3540,96 & 3540,96 & 3455,82 & 80,04 & 80,04 & 73,77 & 3478,51 & 3478,51 & 3393,82 \\
\hline P7 & 80,12 & 80,12 & 73,85 & 3541,01 & 3541,01 & 3455,86 & 17,68 & 17,68 & 11,24 & 3478,57 & 3478,57 & 3393,88 \\
\hline P8 & 44,87 & 44,87 & 38,96 & 953,68 & 953,68 & 928,54 & 27,51 & 27,51 & 21,74 & 936,31 & 936,31 & 911,36 \\
\hline P9 & 354,93 & 354,93 & 341,57 & 32,76 & 32,76 & 32,66 & 413,41 & 413,41 & 399,38 & 25,73 & 25,73 & 25,83 \\
\hline P10 & 63,67 & 63,67 & 63,56 & 282,00 & 282,00 & 269,88 & 64,48 & 64,48 & 64,60 & 410,14 & 410,14 & 398,27 \\
\hline P11 & 1459,19 & 1459,19 & 1421,25 & 15,57 & 15,57 & 15,60 & 1432,87 & 1432,87 & 1393,41 & 10,77 & 10,77 & 10,74 \\
\hline P12 & 1432,87 & 1432,87 & 1393,41 & 15,57 & 15,57 & 15,60 & 1459,21 & 1459,21 & 1421,25 & 10,77 & 10,77 & 10,74 \\
\hline P13 & 64,48 & 64,48 & 64,60 & 282,00 & 282,00 & 269,88 & 63,66 & 63,66 & 63,56 & 410,14 & 410,14 & 398,27 \\
\hline P14 & 413,41 & 413,41 & 399,38 & 32,75 & 32,75 & 32,65 & 354,93 & 354,93 & 341,59 & 25,73 & 25,73 & 25,83 \\
\hline
\end{tabular}

Comparando-se os esforços obtidos por $\gamma_{z}$ e $F A V t$, idênticos neste caso, com os relativos ao P-Delta, pode-se perceber que $82 \%$ dos esforços estão acima dos referentes ao P-Delta, e 18\% estão abaixo, ou seja, 46 estão acima e 16 abaixo. Em relação aos obtidos pelo P-Delta, dos que ficaram abaixo, eles são em média 10,90\% menores, e dos que ficaram acima, 6,56\% maiores.

Neste caso também se nota que os esforços abaixo dos obtidos com o P-Delta se distanciaram um pouco mais do que no caso anterior. Porém a quantidade desses que ficaram abaixo foi reduzida de $68 \%$ para $10 \%$ do total. 
Pode-se assim concluir que para os momentos fletores também se obtém melhores resultados com a majoração dos esforços horizontais pelo valor integral de $\gamma_{z}$.

\subsubsection{ALTERNATI VA PARA CONSI DERAR A NÃO-LI NEARI DADE FÍ SI CA}

Como já se sabe, pode-se considerar um valor único para a rigidez em pilares e vigas, igual a 0,7 EI, somente quando a estrutura de contraventamento for composta exclusivamente por vigas e pilares e $\gamma_{\mathrm{z}} \leq 1,3$.

Como essas exigências são atendidas pelo exemplo em questão, esta alternativa pode ser considerada. Os respectivos resultados são mostrados na tabela 7.20.

Tabela 7.20. Parâmetros de estabilidade para rigidez 0,7 EI em pilares e vigas.

\begin{tabular}{|c|c|c|c|c|}
\hline \multicolumn{5}{|c|}{ PARÂMETRO DE ESTABILIDADE } \\
\hline Ang. & $\boldsymbol{\alpha}$ & GAMA-Z & FAVt & RM2M1 \\
\hline $0^{\circ}$ & 0,601 & 1,096 & 1,096 & 1,097 \\
\hline $90^{\circ}$ & 0,660 & 1,108 & 1,108 & 1,109 \\
\hline $180^{\circ}$ & 0,601 & 1,096 & 1,096 & 1,097 \\
\hline $270^{\circ}$ & 0,660 & 1,108 & 1,108 & 1,109 \\
\hline
\end{tabular}

Utilizando-se esta alternativa, a edificação passou a ser considerada de nós fixos nas direções de $0^{\circ}$ e $180^{\circ}$, pois o valor de $\gamma_{z}$ resultou menor que 1,1 .

Os valores de $\gamma_{\mathrm{z}}$ e FAVt também são quase iguais aos obtidos por P-Delta. Os valores de $\alpha$ são os mesmos da tabela 7.13 e indicam que a edificação é de nós móveis em todas as direções. Porém, como já foi dito, atualmente considerase que as análises feitas pelo processo aproximado $\gamma_{\mathrm{z}}$ geram resultados melhores. Dessa maneira, estes é que são levados em conta na análise. 



\section{CONCLUSÕES}

Foi comentado neste trabalho que, para a correta análise de segunda ordem global em edifício com estrutura de concreto armado, deve-se atentar para um aspecto importante: o concreto não é um material de comportamento linear. Ele possui comportamento puramente não-linear, portanto as nãolinearidades física e geométrica devem ser consideradas para que se obtenham bons resultados, condizentes com a realidade.

Para a análise da estabilidade global, estão disponíveis alguns parâmetros: $\alpha, \gamma_{z}$, FAVt e RM2M1. O parâmetro $\alpha$ apenas avalia a estabilidade do edifício, classificando-o como de nós fixos ou de nós móveis. O $\gamma_{z}$, além de propiciar a mesma classificação anterior, também permite estimar os esforços de segunda ordem. O FAVt possui as mesmas funções do $\gamma_{z}$, sendo que a única diferença está na maneira como a parcela do momento de segunda ordem é calculada, parcela essa em que se consideram os deslocamentos horizontais devidos às cargas verticais.

E por último tem-se o $R M 2 M 1$, gerado por meio do processo P-Delta, que apenas avalia a estabilidade do edifício. Ele corresponde a nada mais que a porcentagem dos efeitos de segunda ordem em relação aos de primeira. Por essa razão o seu cálculo é posterior à análise de segunda ordem. Vale lembrar que, por meio dessa análise, obtêm-se diretamente os esforços finais $\left(1^{a}+2^{a}\right.$ ordem), isso porque o processo P-Delta consiste em uma análise não-linear. Dentro do Sistema TQS, há dois métodos de cálculo para o P-Delta, o Convencional e o de Dois Passos, sendo este último o método utilizado neste trabalho.

Também foi comentado que há alguns fatores que influenciam diretamente na estabilidade dos edifícios, entre os quais: as ações atuantes, sendo que a horizontal em nada influencia e somente a vertical tem influência direta; a rigidez; as análises com redistribuição de esforços; a interação solo-estrutura e o modelo estrutural adotado. 
O segundo exemplo, no item 4.2.5.6 deste trabalho, mostrou que ao se refinar o modelo estrutural, em que foi flexibilizada a ligação viga-pilar, ou seja, utilizando-se molas, os valores de $\gamma_{z}$ foram alterados, resultando maiores. A seguir, apresentam-se as conclusões obtidas com as análises numéricas. Em item posterior encontram-se sugestões para novas pesquisas.

\subsection{CONCLUSÕES DAS ANÁLI SES NUMÉRICAS}

Para os exemplos de 1 a 7, foram avaliados a estabilidade global e os esforços de segunda ordem gerados pelos métodos aproximados. Serão comentadas as características e os resultados relativos a cada exemplo.

\subsubsection{EXEMPLO 1}

Este exemplo é um edifício de 14 pavimentos totalmente simétrico (página 116). Em relação à estabilidade global, foram obtidos bons resultados com os coeficientes aproximados, em comparação com o $R M 2 M 1$, gerado pelo processo P-Delta. Eles indicaram que a edificação é de nós móveis em todas as direções.

Em relação à análise de segunda ordem global, os resultados relativos à majoração dos esforços de primeira ordem por $\gamma_{z}$ ou $F A V t$ foram melhores que os majorados por $0,95 \gamma_{z}$ ou $0,95 F A V t$, lembrando que neste exemplo simétrico os valores de $\gamma_{z}$ e FAVt são idênticos.

Ao se considerar a rigidez alternativa 0,7 EI para levar em conta a nãolinearidade física, a edificação ficou mais rígida, com redução dos parâmetros de estabilidade.

\subsubsection{EXEMPLO 2}

Este também é um edifício de 14 pavimentos, mas que possui excentricidade devida ao balanço (Página 127). Em relação à estabilidade global, os resultados dos coeficientes aproximados foram bons em comparação com $R M 2 M 1$ e indicaram que a edificação é de nós móveis em todas as direções. Porém, na direção onde a excentricidade tem influência direta, os resultados do FAVt foram melhores que os do $\gamma_{z}$, lembrando que neste exemplo os valores de $\gamma_{z}$ e FAVt não são idênticos, devido à excentricidade. 
Em relação à análise de segunda ordem global, os resultados obtidos pela majoração dos esforços de primeira ordem por $\gamma_{z}$ ou FAVt também foram melhores que os majorados por $0,95 \gamma_{z}$ ou $0,95 F A V t$. Como neste caso os valores dos dois coeficientes não são iguais na direção da excentricidade, em relação aos esforços normais, resultaram valores majorados por $\gamma_{z}$ pouca coisa mais a favor da segurança que os majorados por FAVt. Em relação aos momentos fletores aconteceu o contrário, ou seja, os esforços majorados por FAVt foram pouca coisa mais a favor da segurança que os majorados por $\gamma_{z}$.

Para este exemplo também se observou que, ao se considerar 0,7 EI, a edificação ficou mais rígida, reduzindo os valores dos parâmetros de estabilidade.

\subsubsection{EXEMPLO 3}

Este edifício de 10 pavimentos é totalmente simétrico, com lajes nervuradas (página 140). Em relação à estabilidade global, os resultados foram quase iguais aos relativos a RM2M1, e a edificação foi classificada como de nós fixos nas direções de $0^{\circ}$ e $180^{\circ}$, e de nós móveis nas direções de $90^{\circ}$ e $270^{\circ}$.

Portanto, a análise de segunda ordem só foi realizada nas direções de $90^{\circ}$ e $270^{\circ}$. Os resultados obtidos pela majoração dos esforços de primeira ordem por $\gamma_{z}$ ou FAVt novamente foram melhores que os majorados por $0,95 \gamma_{z}$ ou $0,95 F A V t$, lembrando que neste exemplo os valores de $\gamma_{z}$ e FAVt são idênticos.

Ao se considerar a alternativa 0,7 EI, a edificação tendeu a ficar mais rígida, reduzindo os valores dos parâmetros de estabilidade, que ficaram abaixo dos limites. Portanto, sendo utilizada essa rigidez única, a análise de segunda ordem não seria necessária em nenhuma direção.

\subsubsection{EXEMPLO 4}

Este edifício, também de 10 pavimentos com lajes nervuradas, é totalmente simétrico e possui núcleo rígido na escada e no elevador (página 150). Em relação à estabilidade global, os resultados foram ótimos, pois os valores dos coeficientes aproximados foram idênticos ao do RM2M1. Porém, esses resultados, em torno de 1,04, ficaram abaixo do limite, o que indica que a estrutura é de nós fixos em todas as direções. Portanto, não é necessário considerar efeitos de segunda ordem. 
Para este exemplo, não se pôde considerar 0,7 EI, pois a estrutura de contraventamento não é formada exclusivamente por vigas e pilares.

\subsubsection{EXEMPLO 5}

Este edifício de 10 pavimentos é totalmente simétrico, com lajes maciças (página 153). Em relação à estabilidade global, obtiveram-se bons resultados dos coeficientes aproximados, comparando-os com RM2M1. Porém, todos ficaram abaixo do limite 1,10, indicando nós fixos em todas as direções. Portanto, também não é necessário considerar efeitos de segunda ordem.

Também para este exemplo a alternativa 0,7 EI conduziu a uma estrutura mais rígida, reduzindo os valores dos parâmetros de estabilidade.

\subsubsection{EXEMPLO 6}

Este edifício de 10 pavimentos com lajes maciças também é totalmente simétrico e possui núcleos rígidos na escada e no elevador (página 157). Em relação à estabilidade global, obtiveram-se ótimos resultados, pois os valores dos coeficientes aproximados foram idênticos ao $R M 2 M 1$. Porém, os resultados, em torno de 1,04, ficaram abaixo do limite, o que indica que a estrutura é de nós fixos em todas as direções. Portanto, não é necessário considerar efeitos de segunda ordem.

Para este exemplo, não se pôde considerar a alternativa 0,7 EI, pelos mesmos motivos do exemplo anterior, pois a estrutura de contraventamento não é formada exclusivamente por vigas e pilares.

\subsubsection{EXEMPLO 7}

Este edifício é de 22 pavimentos e também é totalmente simétrico, com lajes maciças (página 159). Em relação à estabilidade global, os resultados foram quase iguais aos relativos a $R M 2 M 1$, e a edificação foi classificada como de nós móveis em todas as direções. Portanto, a análise de segunda ordem foi realizada em todas elas. 
Os resultados obtidos pela majoração dos esforços de primeira ordem por $\gamma_{z}$ ou FAVt novamente foram melhores que os majorados por $0,95 \gamma_{z}$ ou $0,95 F A V t$, lembrando que neste exemplo os valores de $\gamma_{z}$ e $F A V t$ também são idênticos.

Ao se considerar a alternativa 0,7 EI, a edificação também tendeu a ficar mais rígida, reduzindo os valores dos parâmetros de estabilidade, que ficaram abaixo dos limites em duas direções. Portanto, sendo utilizada essa rigidez única, a análise de segunda ordem não seria necessária nestas direções.

\subsubsection{CONSI DERAÇÕES FI NAIS DAS ANÁLI SES}

Dos resultados obtidos para todos os exemplos, pode-se concluir que a utilização de apenas $\gamma_{z}$ como majorador de esforços para a obtenção dos esforços de segunda ordem gera resultados muito melhores que o emprego de $0,95 \gamma_{z}$. Como já foi comentado no capítulo 2, muitos outros trabalhos já chegaram à mesma conclusão. Portanto, recomenda-se que na próxima revisão da NBR 6118:2003 seja levado em consideração o resultado deste trabalho e dos outros nele citados.

Em relação ao FAVt, como já foi visto no capítulo 2, ele é o fator de amplificação de esforços horizontais ou de vento, ou seja, é o coeficiente utilizado para a obtenção dos esforços de segunda ordem pela majoração dos esforços horizontais de primeira ordem. Seus resultados foram muito bons em comparação com os do processo P-Delta. Porém, neste trabalho a maioria dos edifícios analisados era simétrica nas duas direções em planta, resultando $\gamma_{z} \mathrm{e}$ FAVt idênticos.

Nos exemplos também se tentou avaliar a sua possível condição como parâmetro de estabilidade, comparando-o com outros parâmetros já conhecidos. Porém, com poucos exemplos, não é possível afirmar que ele seja um bom avaliador da estabilidade global. Mais edifícios devem ser analisados.

A não consideração dos esforços de segunda ordem quando eles são menores que $10 \%$ dos de primeira poderia ser abandonada, pois hoje, na era da informática, a dificuldade de se considerar ou não tais esforços é a mesma.

Se o motivo de se manter tal consideração for economia, destaca-se que dessa forma é ignorada uma análise estrutural mais correta e mais segura. Ressalta-se que, com o processo P-Delta, os esforços de segunda ordem sempre são considerados, mesmo quando menores que $10 \%$ dos de primeira ordem. 
A utilização de núcleos rígidos nos exemplos 4 e 6, ambos edifícios de 10 pavimentos, com certeza foi um exagero com relação à estabilidade do edifício, pois percebeu-se que, nos exemplos 3 e 5, apenas os pórticos de pilares e vigas já eram suficientes. Os resultados de $\gamma_{z}$ para esses exemplos 4 e 6 foram muito baixos, em torno de 1,04. Portanto, confirmou-se que núcleos rígidos não são necessários para garantir a estabilidade de edificações consideradas "baixas". Eles fazem grande diferença na análise de edifícios altos.

Tanto nos edifícios altos quanto nos mais baixos, os núcleos rígidos permitem a redução da seção transversal dos demais pilares. Sob este aspecto, eles teriam sentido também nos edifícios mais baixos se levassem a uma economia do custo global da estrutura.

Concluiu-se, também, que ao se utilizar a alternativa para consideração da não-linearidade física aproximada, com rigidez 0,7 EI para vigas e pilares, as estruturas tenderam a ficar mais rígidas, podendo resultar estruturas de nós fixos em vez de nós móveis, o que permitiria dispensar a análise de segunda ordem.

\subsection{SUGESTÕES PARA NOVAS PESQUISAS}

Seria muito importante fazer um estudo da análise de segunda ordem global considerando a interação solo-estrutura, variando-se o sistema estrutural dos edifícios.

Outra sugestão seria estudar a rigidez de vigas e pilares em edifícios com menos de quatro pavimentos, obtendo-se, assim, resultados que possam até viabilizar a consideração do coeficiente $\gamma_{z}$ também para esses casos.

Pode-se também realizar um estudo comparativo da utilização exclusiva de vigas e pilares para a estrutura de contraventamento e a utilização de núcleos rígidos, comparando as condições construtivas e econômicas e como os parâmetros de estabilidade se comportam.

Por fim, pode-se avaliar como os parâmetros de estabilidade se comportam em casos com grandes vigas de transição e com torção significativa em torno do eixo vertical do edifício. 


\section{REFERÊNCI AS BI BLI OGRÁFI CAS}

ASSOCIAÇÃO BRASILEIRA DE NORMAS TÉCNICAS (1988). Forças devidas ao vento em edificações, NBR 6123, Rio de Janeiro, RJ.

ASSOCIAÇÃO BRASILEIRA DE NORMAS TÉCNICAS (1980). Cargas para o cálculo de estruturas de edificações, NBR 6120, Rio de Janeiro, RJ.

ASSOCIAÇÃO BRASILEIRA DE NORMAS TÉCNICAS (2003). Ações e segurança nas estruturas - Procedimento, NBR 8681, Rio de Janeiro, RJ.

ASSOCIAÇÃO BRASILEIRA DE NORMAS TÉCNICAS (2003). Projeto de estruturas de concreto - Procedimento, NBR 6118, Rio de Janeiro, RJ.

BUENO, M. M. E. (2009). Avaliação dos parâmetros de instabilidade global em estruturas de concreto armado. Dissertação de Mestrado em Estruturas e Construção Civil, Publicação E. DM-002A/09, Departamento de Engenharia Civil e Ambiental, Universidade de Brasília, Brasília, 88p.

CAMPOÓ, L. B., CORRÊA, M. R. S.; RAMALHO, M. A. (2005). Efeitos de segunda ordem em edifícios de alvenaria estrutural. In: Revista Minerva: Pesquisa e Tecnologia, v.2, n.2.

CARMO, R. M. S. (1995). Efeitos de segunda ordem em edifícios usuais de concreto armado. 112p. Dissertação (Mestrado) - Escola de Engenharia de São Carlos, Universidade de São Paulo, São Carlos, 1995.

CARVALHO, R. C. (1994). Análise não-linear de pavimentos de edifícios de concreto através da analogia de grelha. Tese (Doutorado) - Escola de Engenharia de São Carlos, Universidade de São Paulo, São Carlos, 1994.

CARVAlHO, R. C.; PINHeiro, L. M. (2009). Cálculo e detalhamento de estruturas usuais de concreto armado. Editora Pini, v.2, São Paulo, SP, 2009. 
CICOLIN, L. A. B. (2007). Estabilidade em edifícios de concreto armado com pavimentos em lajes planas. Dissertação (Mestrado) - Centro de ciências exatas e de tecnologia, Universidade Federal de São Carlos, São Carlos, 2007.

CORRÊA, M. R. S. (1991). Aperfeiçoamento de modelos usualmente empregados no projeto de sistemas estruturais de edifícios. 331p. Tese (Doutorado) - Escola de Engenharia de São Carlos, Universidade de São Paulo, São Carlos, 1991.

COVAS, N. (2009). Esclarecimentos sobre o parâmetro FAVt. [mensagem pessoal]. Mensagem recebida de <Nelson@tqs.com.br> em 20 de outubro de 2009.

DELALIBERA, R. G. et al. (2005). Estabilidade global de edifícios de concreto armado: análise dos métodos P- $\Delta$ e $\gamma_{z}$ considerando a deformabilidade da fundação. In: Congresso Brasileiro do Concreto, 47., Recife. Anais... Instituto Brasileiro do Concreto, São Paulo, 2005.

FONTANA, L. A. (2006). Avaliação da não-linearidade física na estabilidade global de edifícios de concreto armado. Dissertação (Mestrado) Faculdade de Engenharia Civil, Arquitetura e Urbanismo da Universidade Estadual de Campinas, Campinas, 2006.

FONTES, F. F. (2005). Análise estrutural de elementos lineares segundo a NBR 6118:2003. Dissertação (Mestrado) - Escola de Engenharia de São Carlos, Universidade de São Paulo, São Carlos, 2005.

FRANÇA, R. L. S. (1991). Contribuição ao estudo dos efeitos de segunda ordem em pilares de concreto armado. Tese (doutorado) - Departamento de Engenharia de Estruturas e Fundações, EPUSP, São Paulo, SP, 1991.

FRANCO, M. (1985). Problemas de estabilidade nos edifícios de concreto armado. In: Reunião Anual do Ibracon: Colóquio sobre Estabilidade Global das Estruturas de Concreto Armado, São Paulo, 1985. Anais...

FRANCO, M.; VASCONCELOS, A. C. (1991). Practical assessment of second order effects in tall buildings. Colloquium on the CEB-FIP MC 90, COPPE/UFRJ, Rio de Janeiro, RJ. 
FUSCO, P. B. (1976). Estruturas de concreto: fundamentos do projeto estrutural. Editora McGraw Hill, São Paulo, SP, 1976.

GAIOTTI, R.; SMITH, B. S. (1989). P-Delta analysis of building structures. Journal of Structural Engineering. p.755-770. New York, 1989.

GONÇALVES, R. M. et al. (2007). Ação do vento nas edificações: teoria e exemplos. EESC-USP, São Carlos, SP, 2007.

IBRACON (2007). Comentários técnicos e exemplos de aplicação da NB-1. IBRACON, São Paulo, 2007.

KIMURA, A. E. (2007). I nformática aplicada em estruturas de concreto armado: cálculos de edifícios com o uso de sistemas computacionais. Editora Pini, São Paulo, 2007.

KIMURA, A. E. (2010). Pilares. Notas de aula. Pós-graduação em Projeto de Estruturas de Concreto para Edifícios. Faculdade de Engenharia São Paulo, São Paulo, 2010.

LIMA, J. S. (2001). Verificações da punção e da estabilidade global de edifícios de concreto: desenvolvimento e aplicação de recomendações normativas. 225p. Dissertação (Mestrado) - Escola de Engenharia de São Carlos, Universidade de São Paulo, São Carlos, 2001.

LIMA, J. S.; GUARDA, M. C. C. (1999). Utilização do coeficiente $\gamma_{z}$ como majorador de efeitos de primeira ordem em edifícios altos. In: Congresso Brasileiro do Concreto, 41., Salvador. Anais... Instituto Brasileiro do Concreto, São Paulo, 1999.

LOPES, A. P., SANTOS; G. O.; SOUZA, A. L. A. C. (2005). Estudo sobre diferentes métodos de análise p-delta. In: Congresso Brasileiro do Concreto, 47., Olinda. Anais... Instituto Brasileiro do Concreto, São Paulo.

MARIN, M. C. (2009). Contribuição à análise da estabilidade global de estruturas em concreto pré-moldado de múltiplos pavimentos. $213 p$. Dissertação (Mestrado) - Escola de Engenharia de São Carlos, Universidade de São Paulo, São Carlos, 2009. 
MEDEIROS, S. R. P. (1999). Módulo TQS para análise não-linear geométrica de pórticos espaciais. J ornal TQS News, n.11, São Paulo, SP.

MEDEIROS, S. R. P.; FRANÇA, R. L. S. (1989). Um programa para análise nãolinear em microcomputadores. In: Simpósio EPUSP sobre Estruturas de Concreto, 1989., São Paulo. Adendo aos Anais... Escola Politécnica da USP, São Paulo.

OLIVEIRA, P. H. A. S. (2004). Processo aproximado para a consideração da não-linearidade física de pilares em concreto armado. Dissertação (Mestrado) - Departamento de Engenharia de Estruturas e Fundações, Escola Politécnica da Universidade de São Paulo, São Paulo, 2004.

OLIVEIRA, R. S. (1997). Análise de pavimentos de edifícios de concreto armado com a consideração da não-linearidade física. 123p. Dissertação (Mestrado) - Escola de Engenharia de São Carlos, Universidade de São Paulo, São Carlos, 1997.

OLIVEIRA, R. S. (2001). Análise de pavimentos de edifícios de concreto armado com a consideração da não-linearidade física - modelagem e metodologia de aplicação a projetos. 197p. Tese (Doutorado) - Escola de Engenharia de São Carlos, Universidade de São Paulo, São Carlos, 2001.

PINTO, R. S. (1997). Não-linearidade física e geométrica no projeto de edifícios usuais de concreto armado. 108p. Dissertação (Mestrado) Escola de Engenharia de São Carlos, Universidade de São Paulo, São Carlos, 1997.

PINTO, R. S. (2002). Análise não-linear das estruturas de contraventamento de edifícios em concreto armado. 189p. Tese (Doutorado) - Escola de Engenharia de São Carlos, Universidade de São Paulo, São Carlos, 2002.

PINTO, R. S., CORRÊA, M. R. S.; RAMALHO, M. A. (2005). Utilização do parâmetro $\gamma_{z}$ para estimar esforços de segunda ordem em edifícios de concreto armado. In: Revista I BRACON de Estruturas, v.1, n.2.

PROENÇA, S. P. B. (2010). Análise não-linear de estruturas. Notas de aula. Escola de Engenharia de São Carlos, Universidade de São Paulo, São Carlos, 2010. 
SILVA, R. M. (1996). Análise não-linear de pórticos planos de concreto armado: modelagem numérica e avaliação dos métodos aproximados. Tese (Doutorado) - Escola de Engenharia de São Carlos, Universidade de São Paulo, São Carlos, 1996.

TQS INFORMÁTICA (2002). Desenvolvimento. Jornal TQS News, n.16, São Paulo, 2002.

TQS INFORMÁTICA (2009-a). Manual do usuário: dominando os sistemas CAD/ TQS - visão geral e exemplo completo. TQS Informática, v.2, São Paulo, 2009.

TQS INFORMÁTICA (2009-b). Manual do usuário: dominando os sistemas CAD/ TQS - análise estrutural. TQS Informática, v.3, São Paulo, 2009.

TQS INFORMÁTICA (2010-a). Desenvolvimento. Jornal TQS News, n.30, São Paulo, 2010.

TQS INFORMÁTICA (2010-b). Desenvolvimento. Jornal TQS News, n.31, São Paulo, 2010.

VASCONCELOS, A. C. (2000). Em que casos não se deve aplicar o processo simplificado do $\gamma_{z}$ para determinação dos efeitos de $2^{a}$ Ordem? Artigo Biblioteca Digital TQS, São Paulo, 2000.

VASCONCELOS, A. C. (2003). O engenheiro de estruturas se beneficia com o computador? In: Jornal TQS News, n.18, São Paulo, 2003.

ZUMAETA MONCAYO, W. J. (2009). Estabilidade global de pórticos tridimensionais com variação da ligação viga-pilar em estruturas prémoldadas. Seminário da Disciplina SET-5861 (Estruturas de Concreto PréMoldado), Escola de Engenharia de São Carlos, Universidade de São Paulo, São Carlos, 2009. 

Este apêndice é voltado aos iniciantes nos sistemas CAD/TQS versão 15.5. Apresenta-se onde foram editados, dentro do sistema TQS, os principais critérios para se realizar a análise estrutural, relacionados à estabilidade global. Será mostrado em detalhes onde e como são alterados os seguintes parâmetros:

$>$ Coeficiente de arrasto do vento (Ca);

$>$ Coeficientes $\gamma_{f}$ e $\gamma_{f 3}$;

> Imperfeições geométricas globais (Desaprumo);

> Coeficientes para consideração aproximada da não-linearidade física;

$>$ Esforços para cálculo do Gama-z;

> Consideração do Gama-z na transferência de esforços;

> Cargas verticais para cálculo dos momentos de segunda ordem;

> Deslocamentos horizontais devidos às cargas verticais;

> Número mínimo de pisos para aplicação do Gama-z;

$>$ Coeficiente para classificar a deslocabilidade da estrutura;

> Dados referentes ao processo P-Delta;

$>$ Fator de engastamento parcial de vigas;

> Flexibilização das ligações viga-pilar;

> Limites dos deslocamentos horizontais do edifício;

> Fator MULAXI, que amplia a rigidez axial dos pilares, para correção dos diagramas de momentos fletores do pórtico, considerando, assim, os efeitos construtivos.

\section{A.1 COEFICI ENTE DE ARRASTO (Ca)}

O coeficiente de arrasto, como já foi estudado no capítulo 5, influencia diretamente na força do vento que atua sobre o edifício. Ao se iniciar um edifício novo, este critério pode ser editado no ícone mostrado na figura A.1.

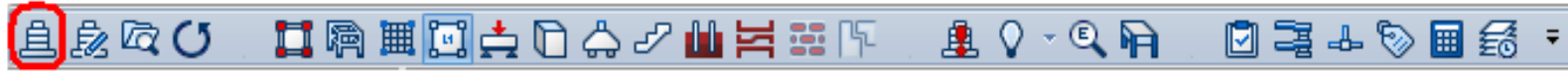

Figura A.1. Ícone para criar edifício novo. 
Ao se clicar nesse ícone, abre-se a janela apresentada na figura A.2: digita-se o nome do edifício, por exemplo, Monte Verde, e clica-se em OK.

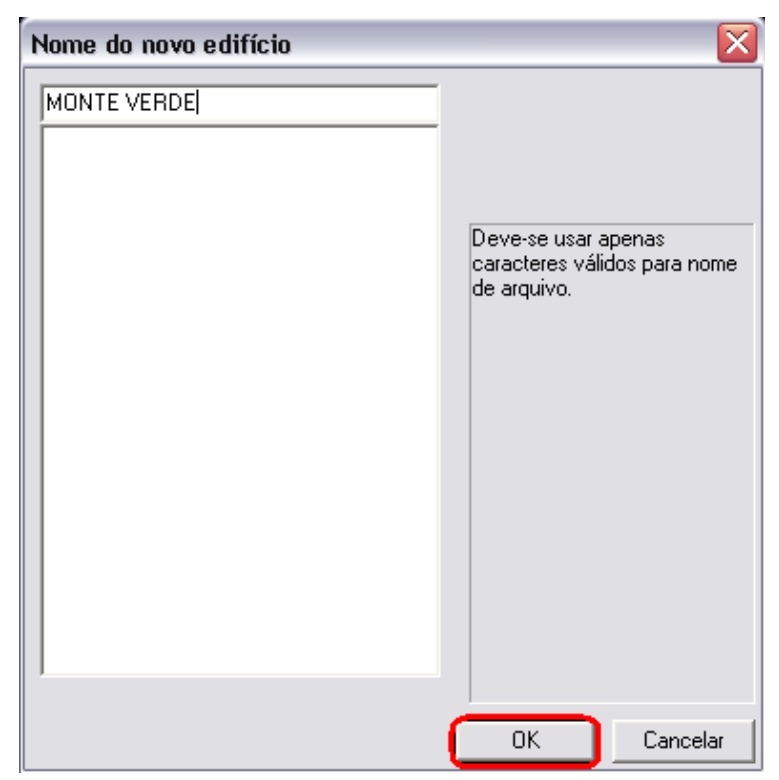

Figura A.2. Nome do novo edifício.

Nesta outra janela (figura A.3), podem-se observar várias abas principais como: Gerais, Modelo, Pavimentos, Materiais, Cobrimentos, Cargas e Critérios. Portanto, clica-se na aba Cargas, como indicado em vermelho na figura A.3.

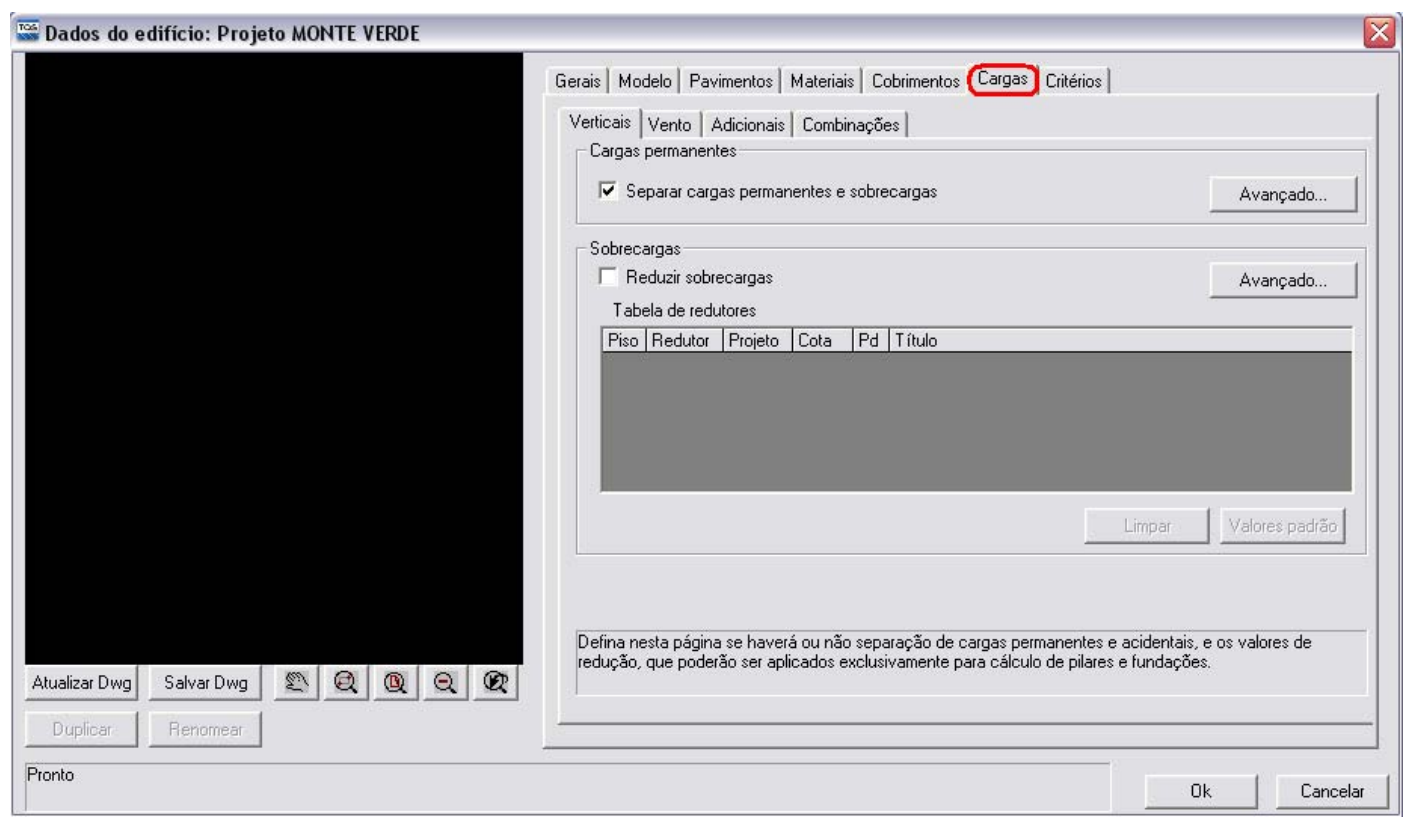

Figura A.3. Aba Cargas.

Neste exemplo, deve ficar claro que somente está sendo mostrado onde se deve alterar o coeficiente de arrasto, e não entrar em detalhes sobre a criação do edifício como um todo. 
Continuando o exemplo, na figura A.4 há quatro subabas: Verticais, Vento, Adicionais e Combinações. Portanto, clica-se na subaba Vento, contornada por linha vermelha.

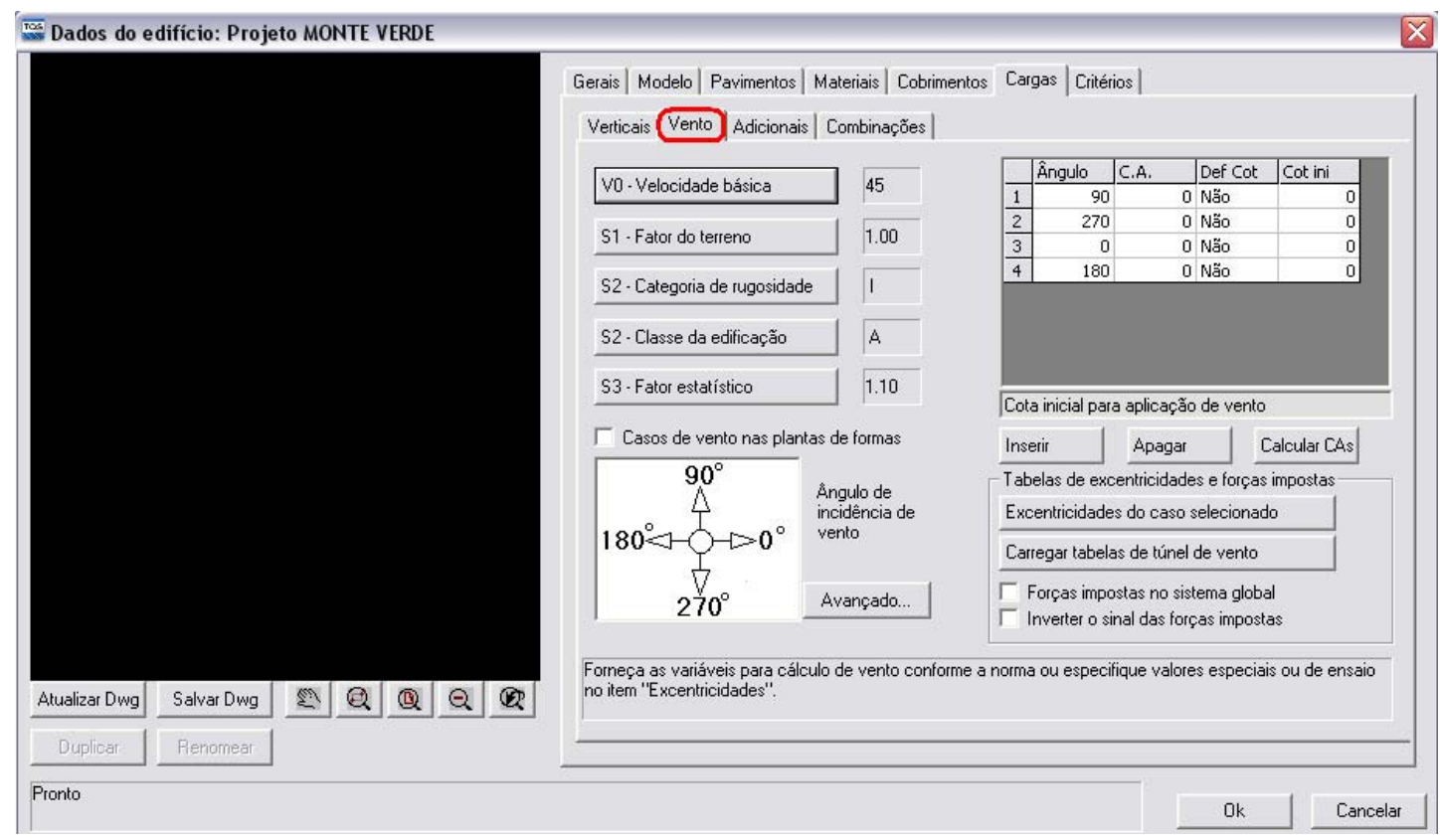

Figura A.4. Subaba Vento.

Pode-se observar que os dados na coluna C.A. estão zerados (figura A.5) para todos os ângulos. Portanto, podem-se atribuir valores previamente calculados.

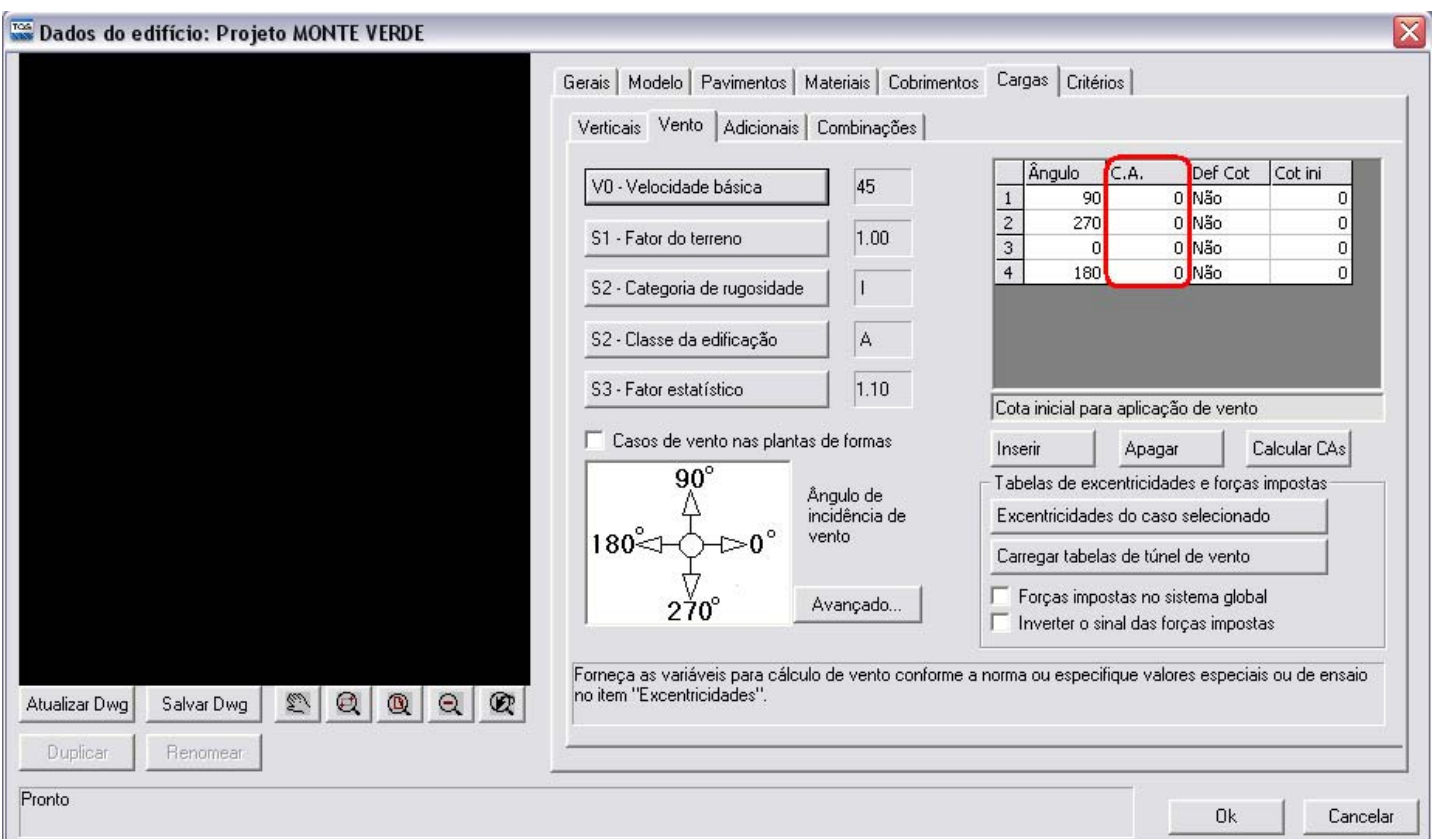

Figura A.5. Coluna dos coeficientes de arrasto. 
Esses coeficientes também podem ser calculados automaticamente pelo Sistema, mas, para isso, a planta de forma já deve estar bem definida no modelador estrutural. Neste caso, o edifício já foi criado. Então se deve clicar em "editar edifício", para se ter novamente acesso às janelas de dados do edifício.

Para mostrar como se pode calcular automaticamente, supõe-se que a estrutura já foi lançada no modelador. Neste caso, clica-se em "editar edifício", o que é feito por meio do ícone indicado na figura A.6.

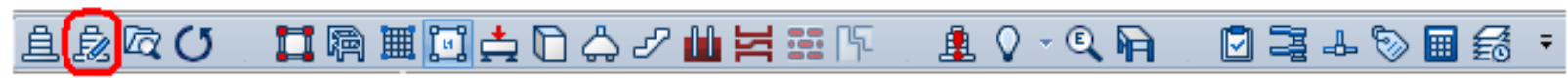

Figura A.6. Ícone para editar edifício.

Repete-se a mesma rotina anterior, pois ao clicar em "editar edifício", tem-se acesso às mesmas janelas que quando se clica em edifício novo. Então se clica no botão calcular CAs, (figura A.7).

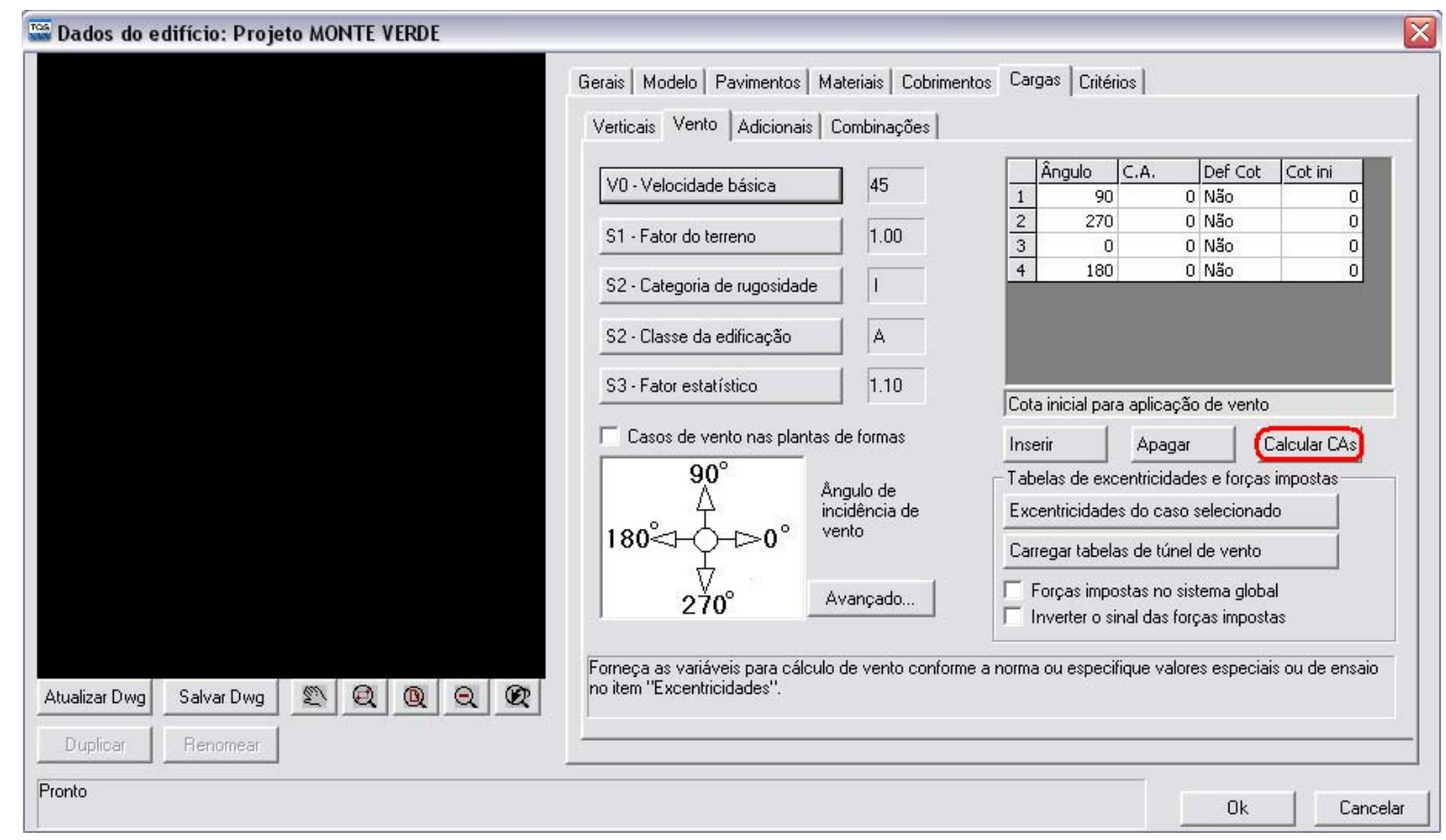

Figura A.7. Ícone Calcular CAs.

Nesta nova janela (figura A.8), primeiramente escolhe-se baixa ou alta turbulência do vento, depois se clica em estimar. É aqui que o Sistema vai procurar as formas lançadas no modelador e estimar suas dimensões e altura com vento, para o cálculo do adequado coeficiente de arrasto. 


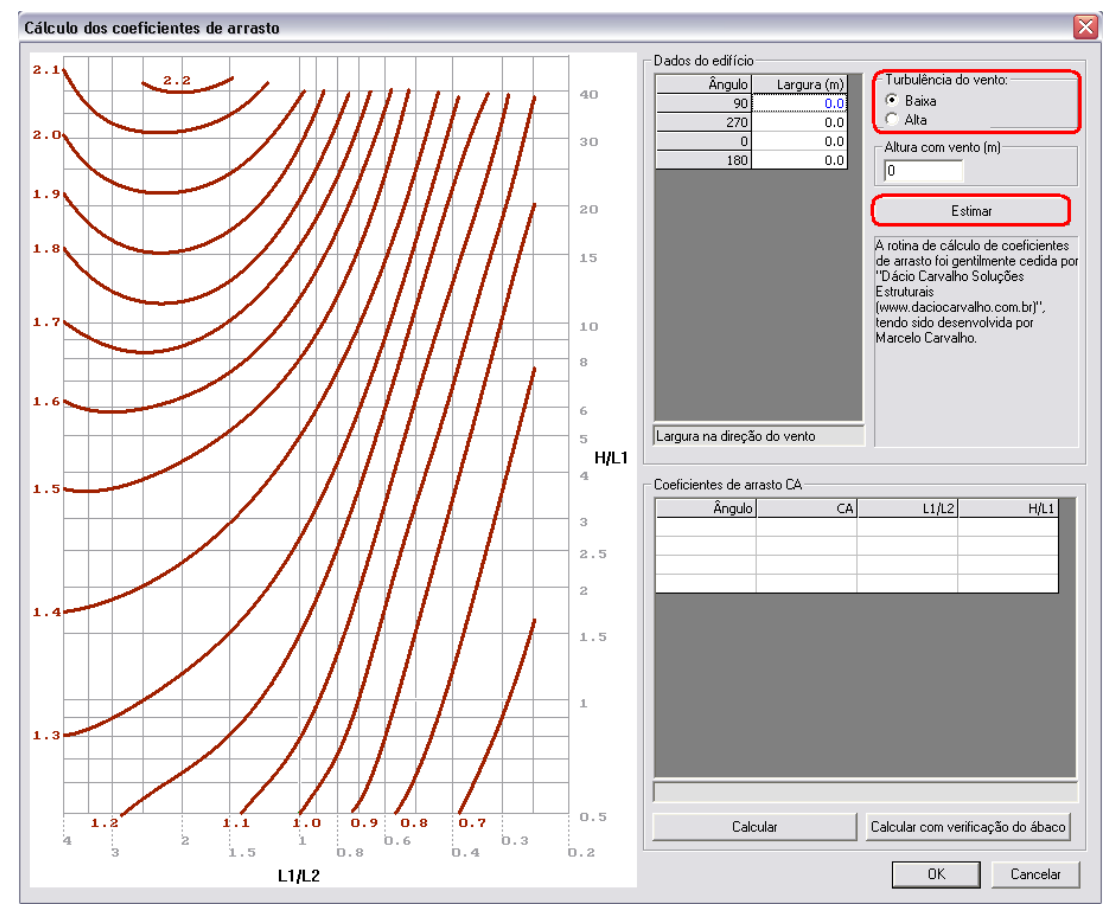

Figura A.8. Cálculo automático dos coeficientes de arrasto.

$\mathrm{Na}$ figura A.9, encontram-se circulados em vermelho os dados que foram estimados pelo Sistema. No exemplo mostrado aqui, esses dados estão zerados, pois como foi citado anteriormente, está sendo considerado que a estrutura foi lançada previamente.

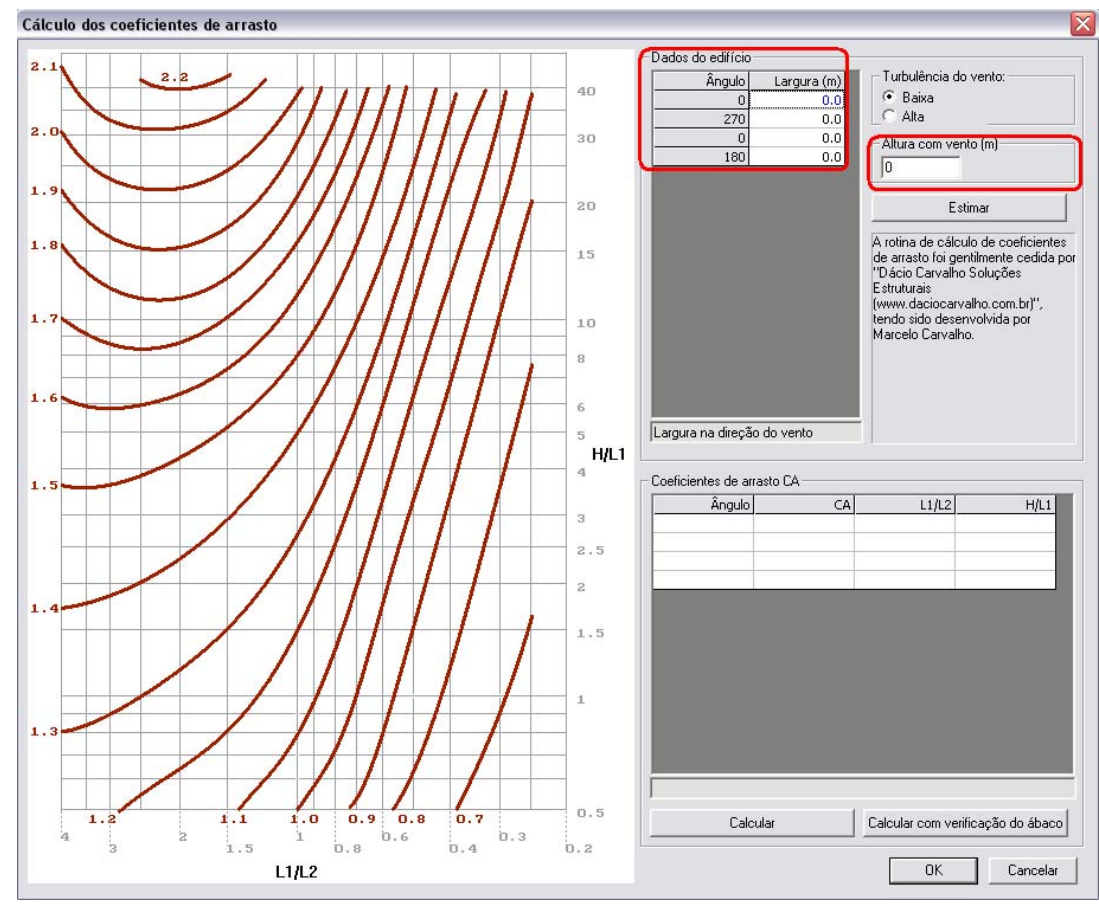

Figura A.9. Dados estimados. 
Portanto, de posse dos dados estimados, clica-se em Calcular, que está circulado em vermelho na figura A.10.

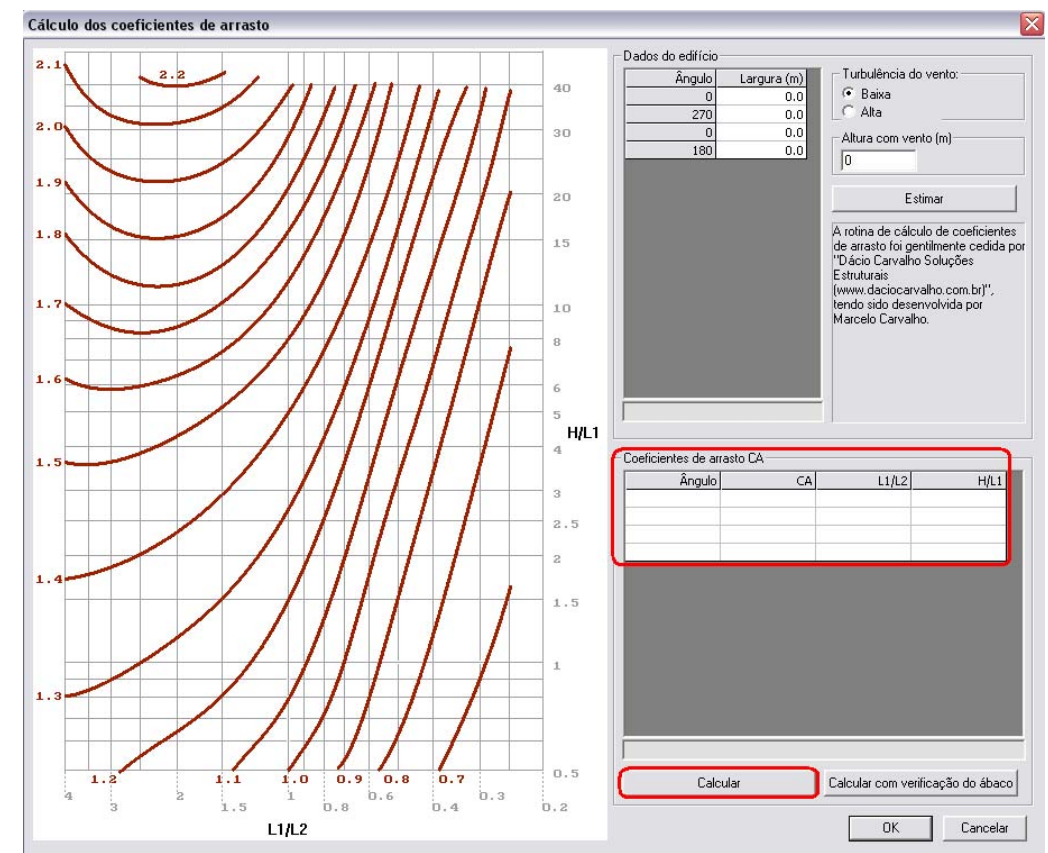

Figura A.10. Coeficientes de arrasto calculados automaticamente.

Ainda na figura A.10, pode-se ver também uma tabela com todos os dados relacionados ao coeficiente de arrasto, que foram calculados automaticamente. $\mathrm{E}$ em seguida, clica-se em OK (figura A.11).

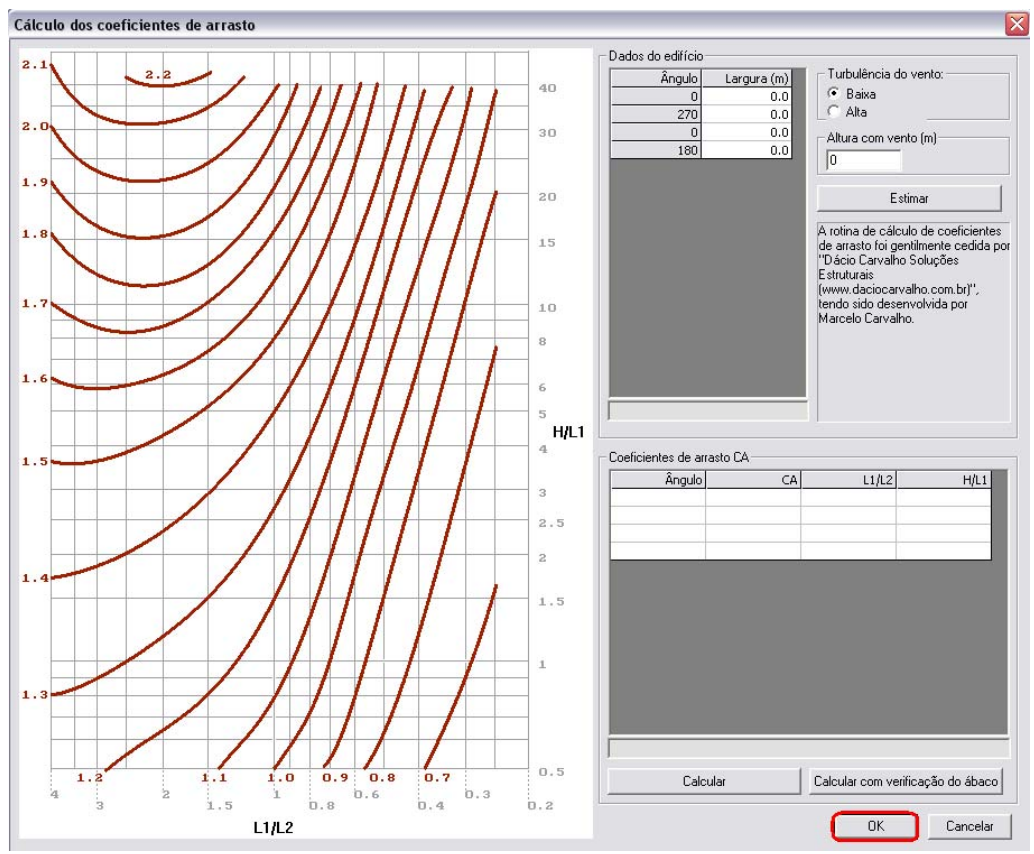

Figura A.11. Coeficientes de arrasto calculados. 
Após clicar em OK, volta-se para a janela da subaba "Vento" (figura A.12) e toda a coluna C.A., circulada em vermelho, estará preenchida com seus respectivos valores, logicamente os mesmos mostrados na tabela circulada em vermelho na figura A.10.

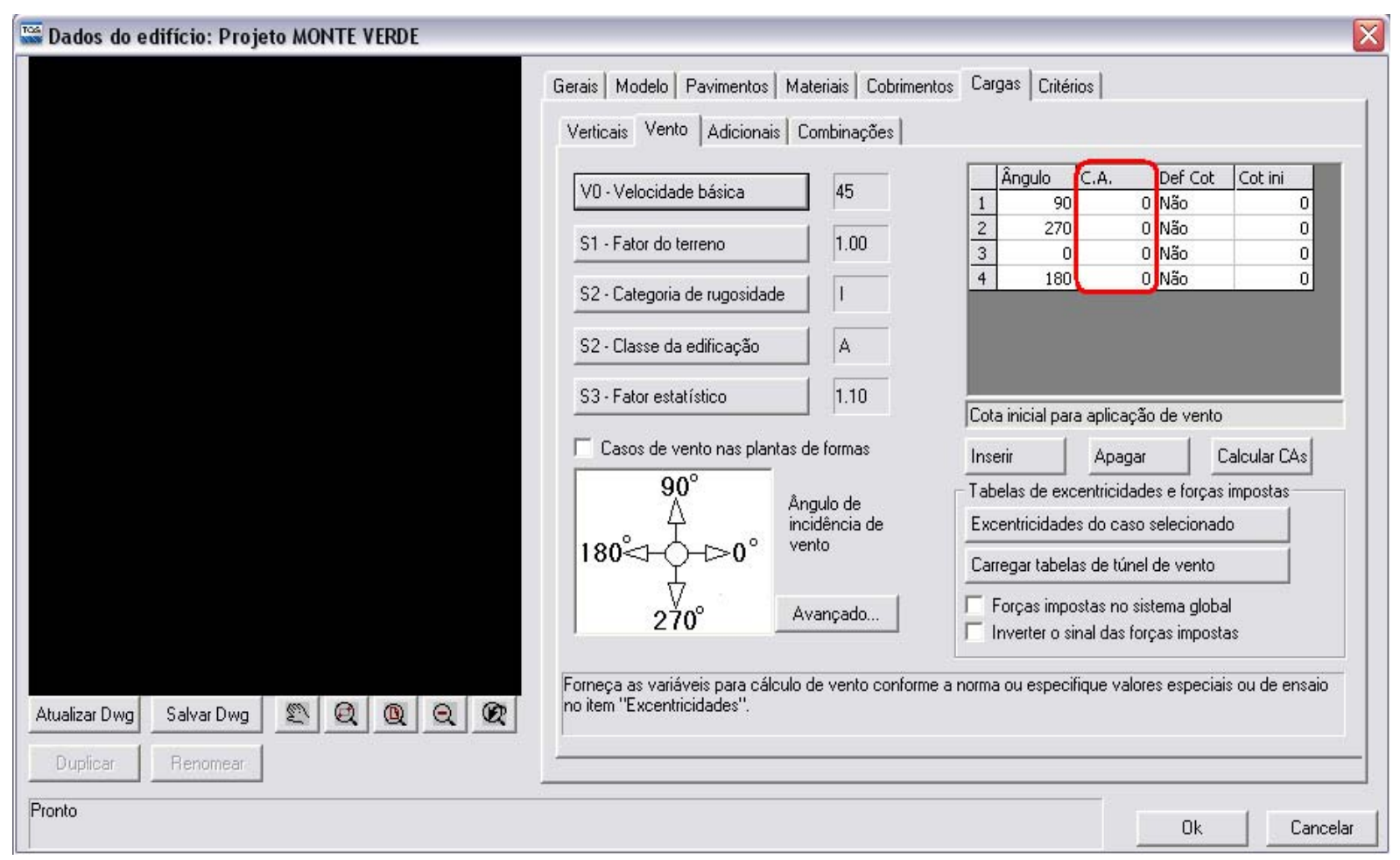

Figura A.12. Coeficientes de arrasto calculados.

\section{A. 2 COEFICI ENTES $\gamma_{f}$ E $\gamma_{f 3}$}

Os coeficientes $\gamma_{f}$ e $\gamma_{f 3}$, como já foram estudados no capítulo 2, dentro do sistema CAD/TQS eles podem ser editados na aba Verticais.

Para se ter acesso a essa aba, primeiramente clica-se em editar edifício (figura A.13).

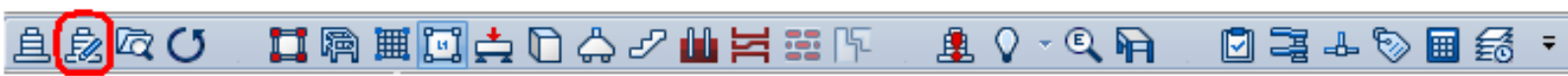

Figura A.13. Ícone para editar edifício. 
Com isso tem-se acesso à janela dados do edifício (figura A.14). Nessa janela devem ser clicadas: a aba Cargas, a subaba Verticais e o botão "Avançado".

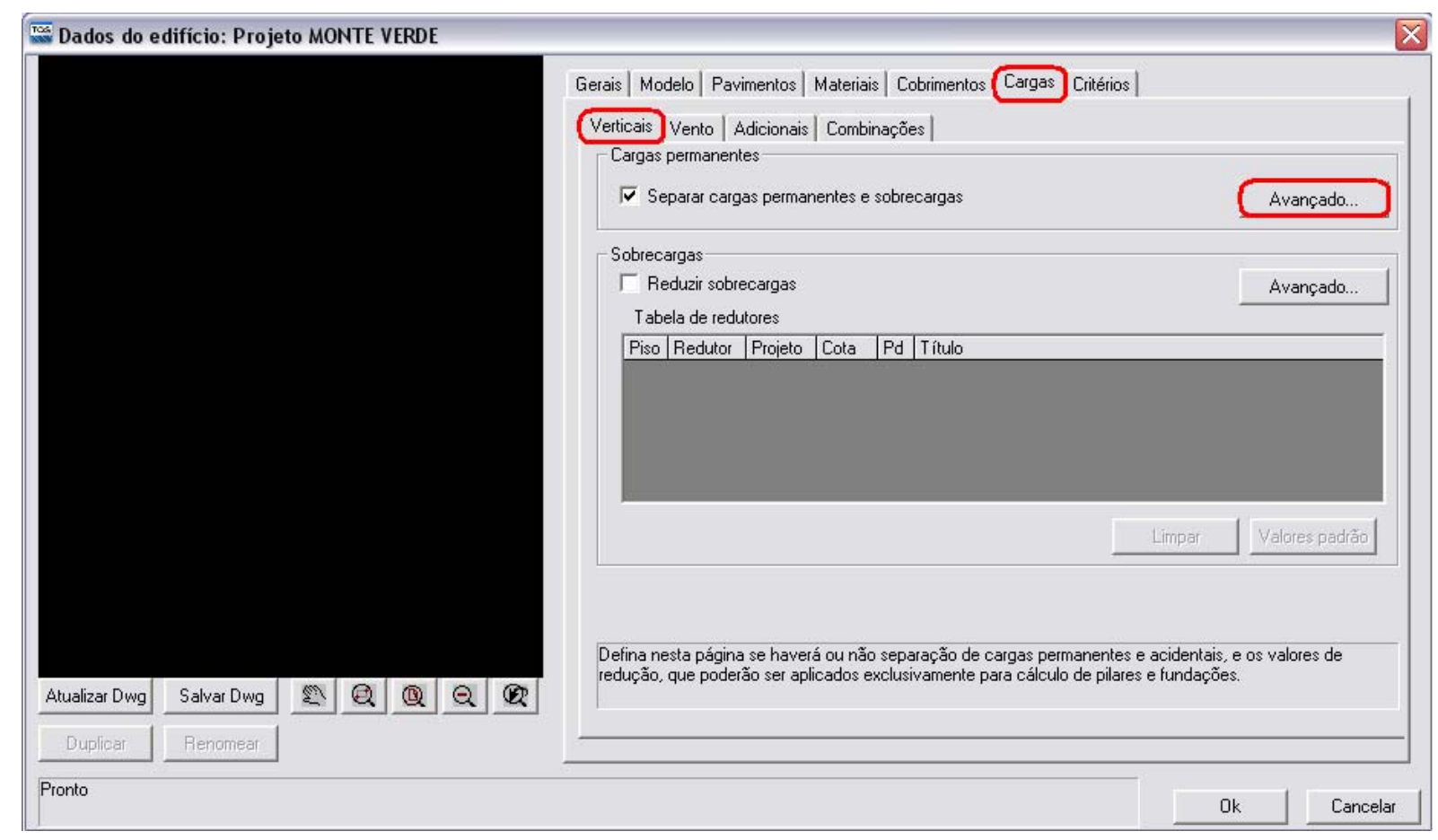

Figura A.14. Botão "Avançado".

Na próxima janela (figura A.15), há o campo para se alterarem os valores de $\gamma_{f}$, separadamente para peso próprio e para cargas permanentes, e de $\gamma_{f 3}$.

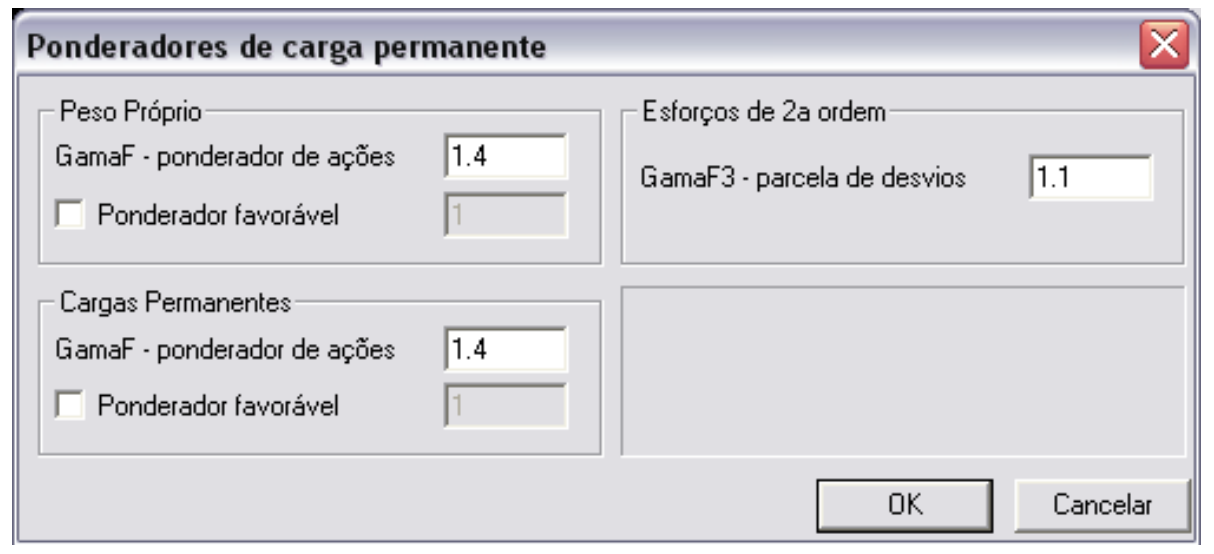

Figura A.15. Coeficientes $\gamma_{f}$ e $\gamma_{f 3}$. 


\section{A.3 I MPERFEI ÇÕES GEOMÉTRI CAS GLOBAI S (DESAPRUMO)}

As imperfeições geométricas globais, como já foram estudadas no capítulo 5, são levadas em conta com a consideração do desaprumo global, e dentro do sistema CAD/TQS tal desaprumo pode ser inserido na aba Desaprumo.

Para se ter acesso a ela, primeiramente clica-se em editar edifício (figura A.16).

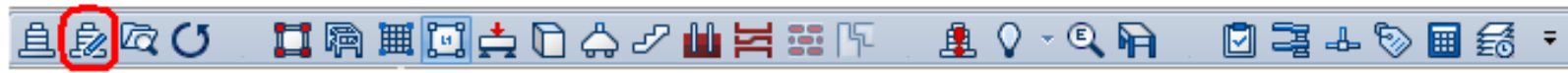

Figura A.16. Ícone para editar edifício.

Em seguida, clicam-se nas abas Cargas > Adicionais > Desaprumo (figura A.17).

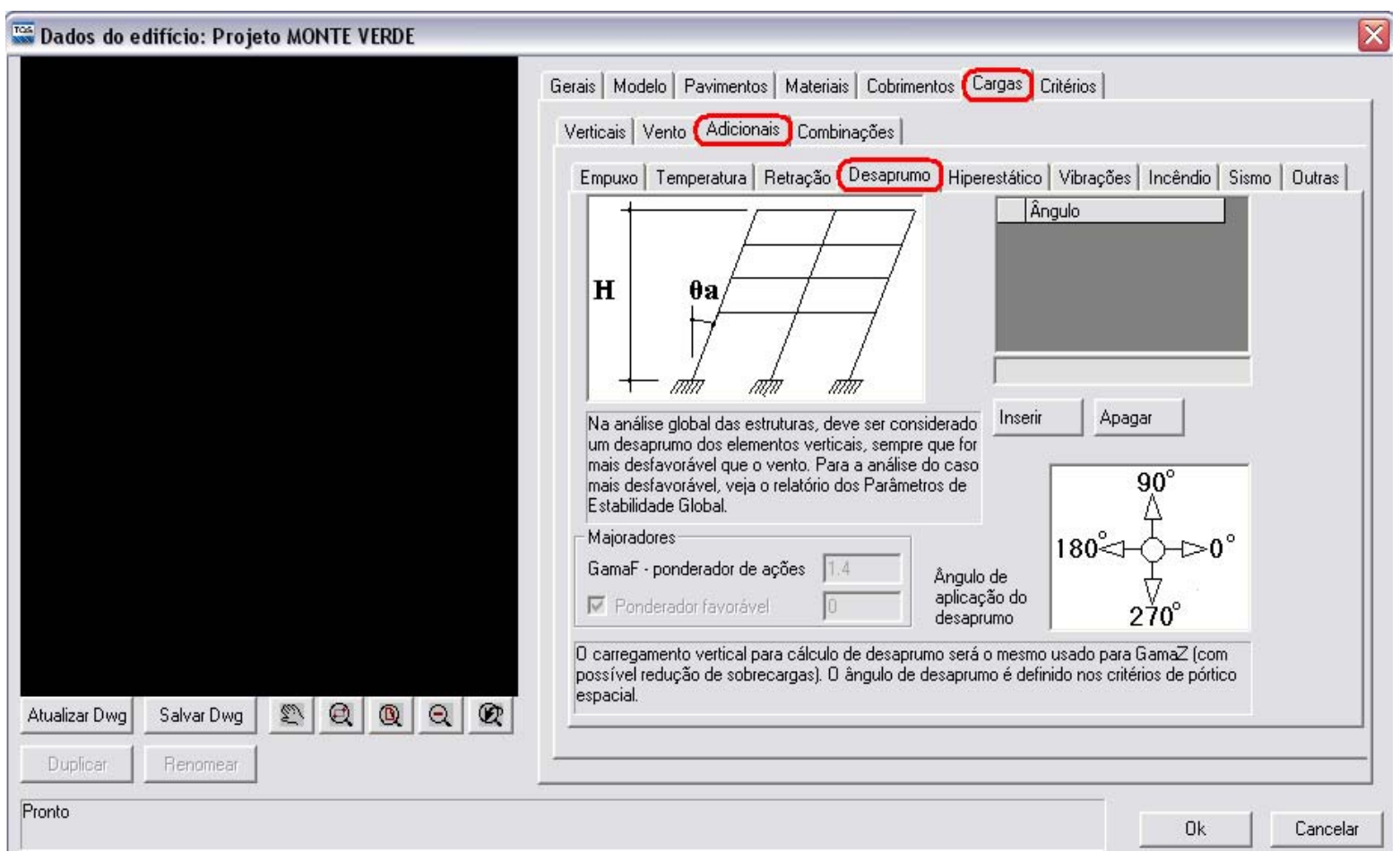

Figura A.17. Desaprumo

$\mathrm{Na}$ janela Desaprumo, clica-se em Inserir para escolher em quais direções o desaprumo será considerado. A figura A.18 mostra que foi inserido desaprumo nas quatro direções: $90^{\circ}, 270^{\circ}, 0^{\circ}$ e $180^{\circ}$. Os sentidos estão na mesma janela, indicados na legenda, logo abaixo do botão Inserir. 


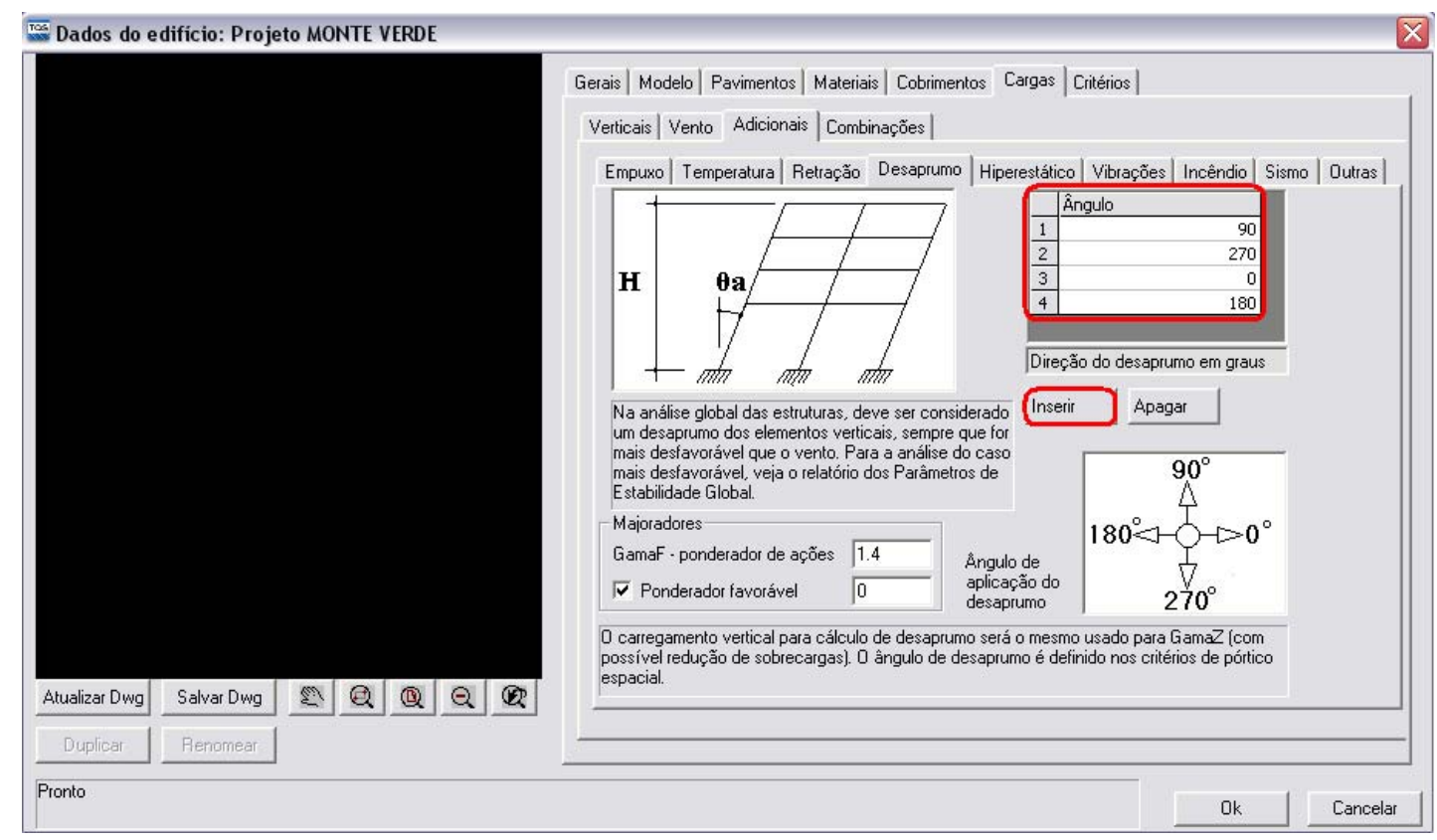

Figura A.18. Botão "Inserir".

O ângulo de inclinação $\theta_{a}$ do desaprumo global pode ser alterado na aba Estabilidade global dos critérios gerais do pórtico-TQS. Para se ter acesso, primeiramente clica-se em Sistemas > Pórtico-TQS (figura A.19).

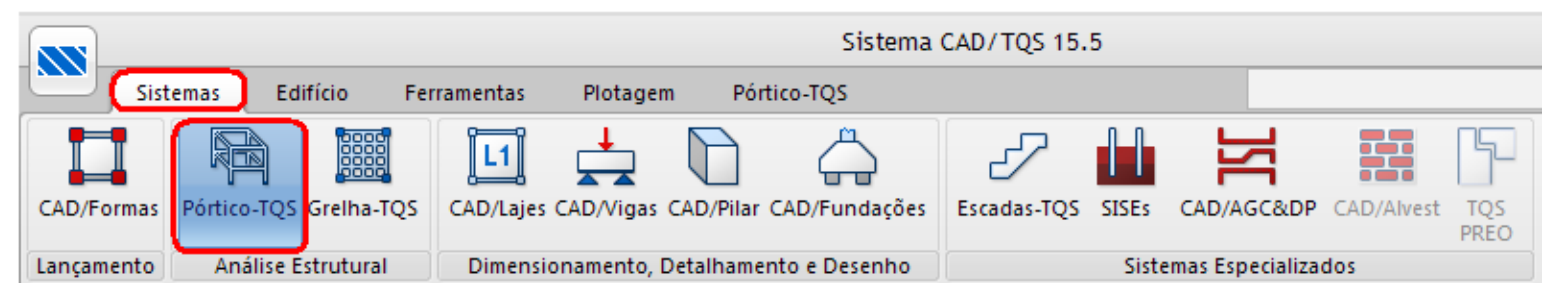

Figura A.19. Ícone Pórtico-TQS.

Dentro dos critérios do Pórtico-TQS, clica-se nos botões Critérios > Critérios Gerais (figura A.20).

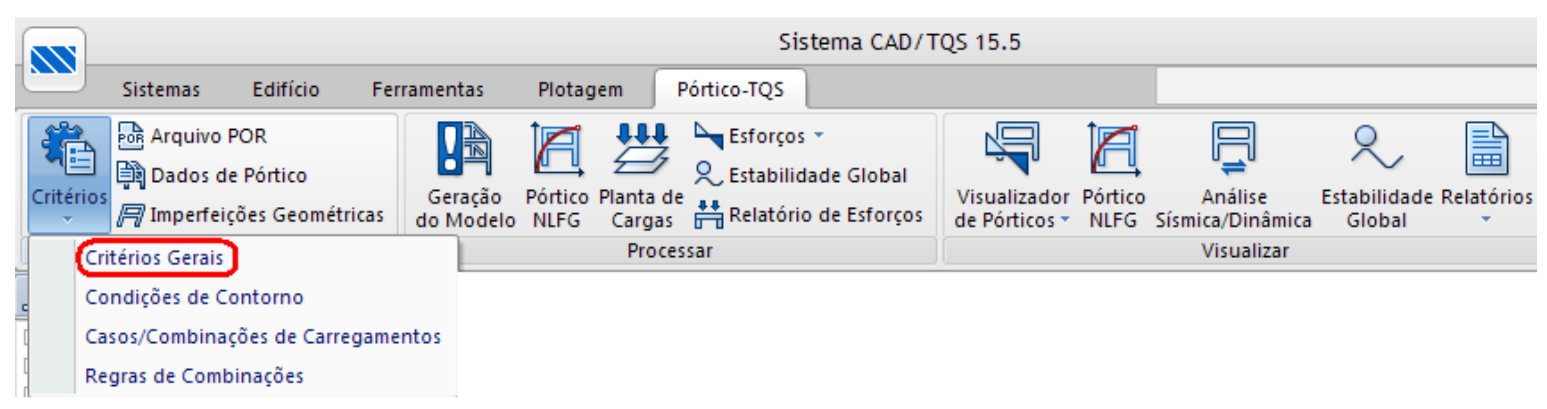

Figura A.20. Critérios gerais do Pórtico-TQS. 
Ao clicar em Critérios Gerais surge a janela indicada na figura A.21: clicase em OK.

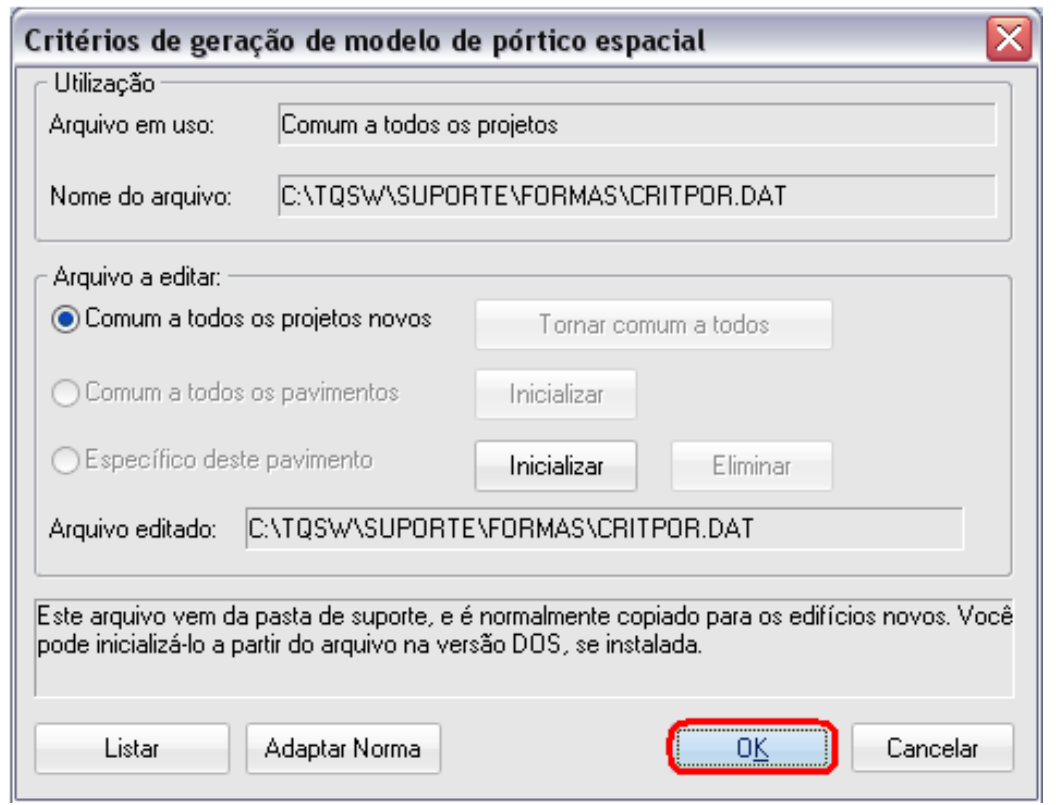

Figura A.21. Critérios de geração de modelo de pórtico espacial.

Entra-se na aba Estabilidade Global e clica-se em Consideração de imperfeições globais (figura A.22).

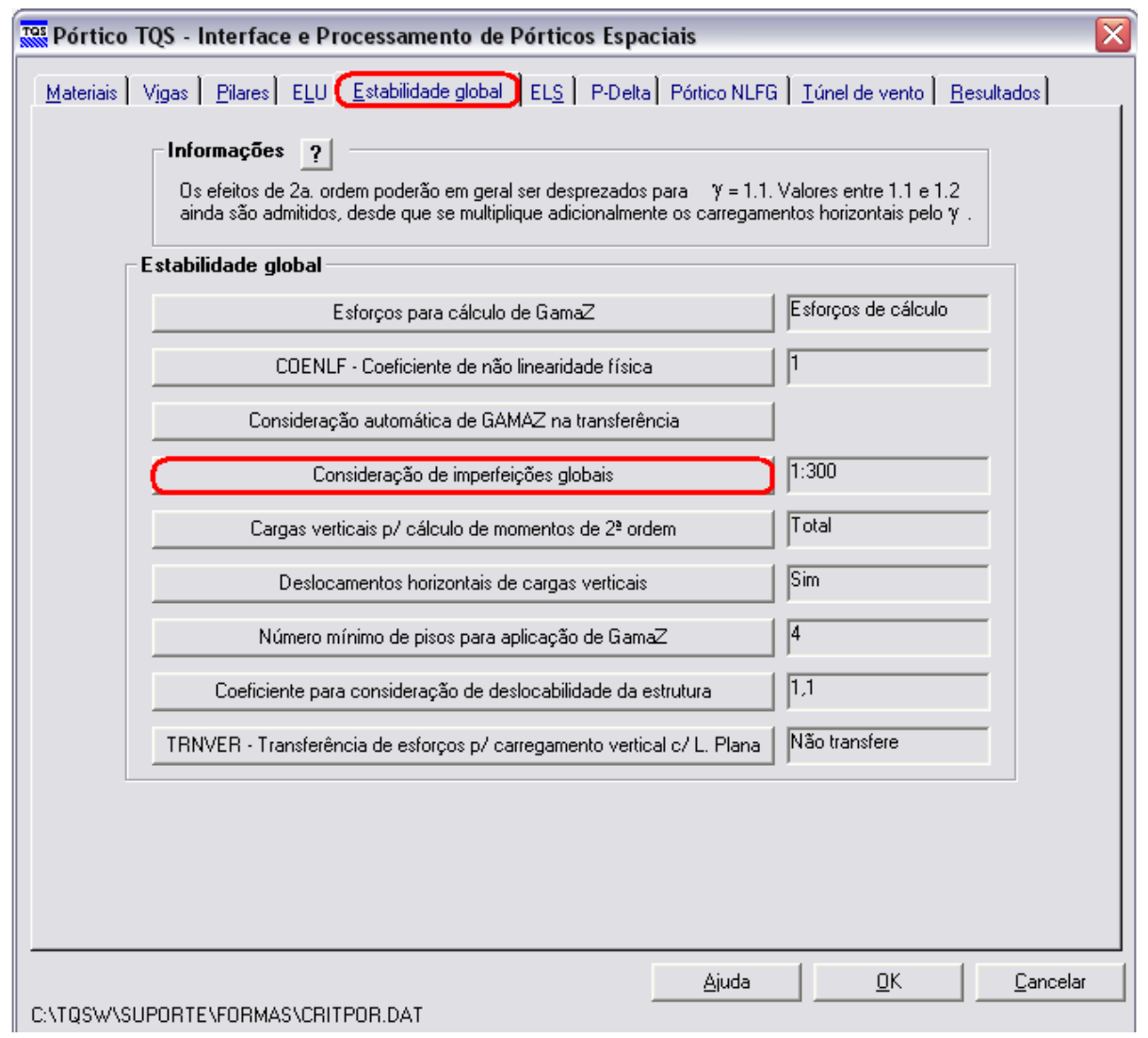

Figura A.22. Consideração de imperfeições globais. 
Em seguida, na janela da figura A.23, pode-se alterar a razão de desaprumo, ou seja, o ângulo de inclinação $\theta_{a}$ medido em radianos.

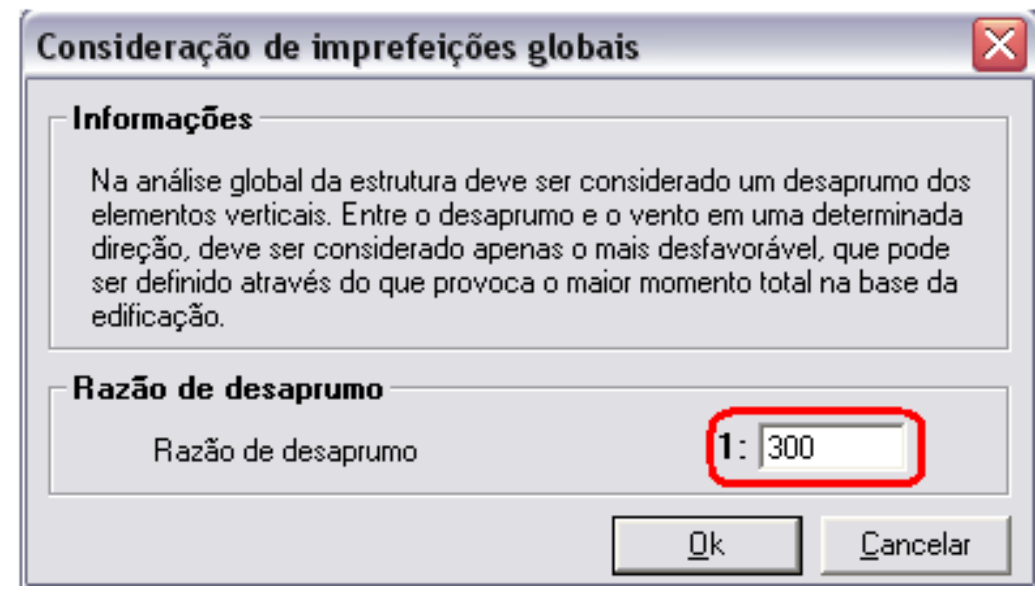

Figura A.23. Janela de consideração de imperfeições globais.

\section{A.4 COEFI CI ENTES PARA CONSI DERAÇÃO DA NÃO-LI NEARI DADE Fí SI CA}

Os coeficientes para consideração da não-linearidade física podem ser alterados na aba ELU ou na relativa à Estabilidade Global, dos critérios gerais do pórtico-TQS. Para se ter acesso, primeiramente clica-se em Sistemas > PórticoTQS (figura A.24).

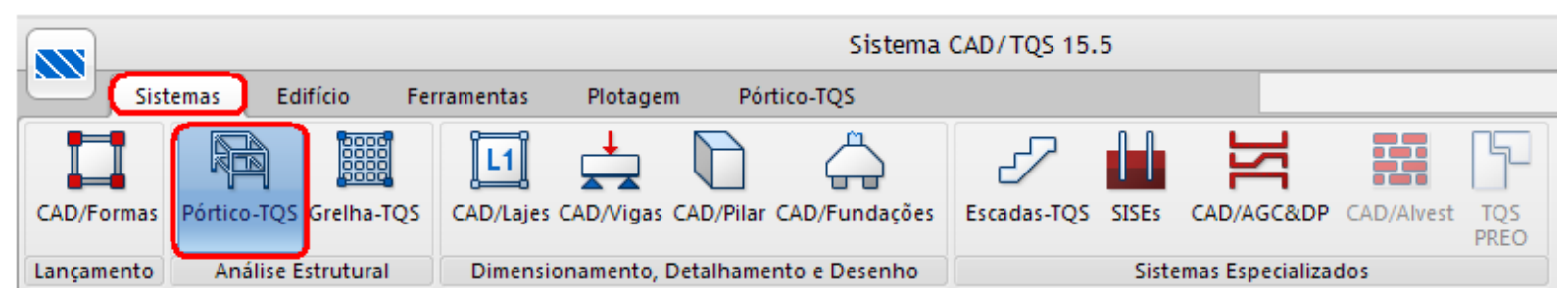

Figura A.24. Ícone Pórtico-TQS.

Dentro dos critérios do Pórtico-TQS, clica-se nos botões Critérios > Critérios Gerais (figura A.25).

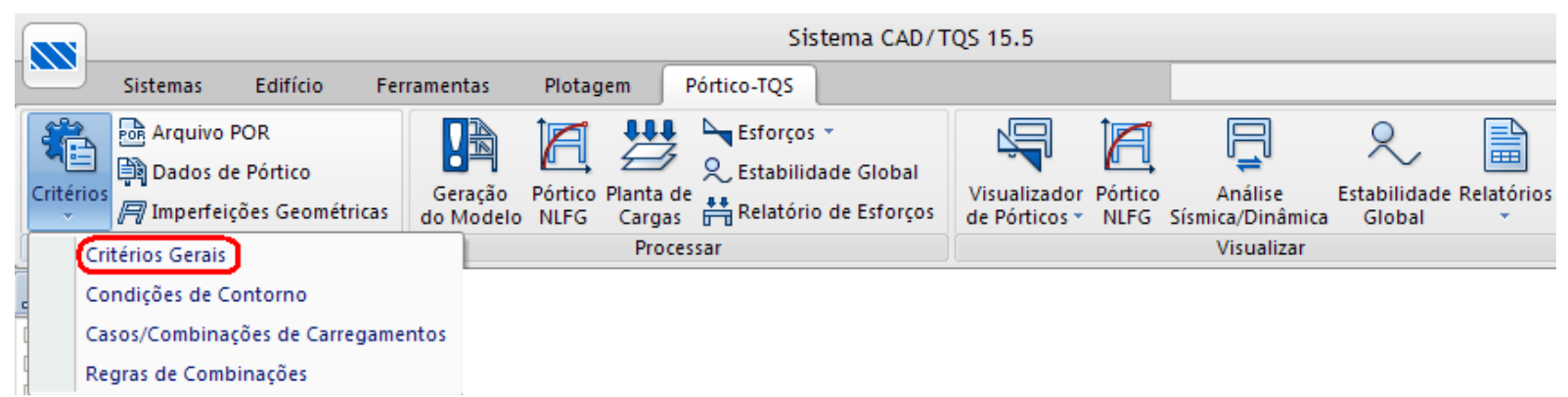

Figura A.25. Critérios gerais do Pórtico-TQS. 
Ao clicar em Critérios Gerais, aparece a janela da figura A.26: clica-se em OK.

\begin{tabular}{|c|c|c|c|c|}
\hline \multicolumn{4}{|c|}{ Critérios de geração de modelo de pórtico espacial } & $x$ \\
\hline \multicolumn{5}{|c|}{ Utilização } \\
\hline Arquivo em uso: & \multicolumn{4}{|c|}{ Comum a todos os projetos } \\
\hline Nome do arquivo: & \multicolumn{4}{|c|}{ C:\TQSW $\backslash S U P O R T E \backslash F O R M A S \backslash C R I T P O R . D A T$} \\
\hline \multicolumn{5}{|c|}{ Arquivo a editar: } \\
\hline \multicolumn{2}{|c|}{ Comum a todos os projetos novos } & Tornar & a todos & \\
\hline \multicolumn{2}{|c|}{ Comum a todos os pavimentos } & Inicializar & & \\
\hline \multicolumn{2}{|c|}{ Específico deste pavimento } & Inicializar & Eliminar & \\
\hline \multicolumn{5}{|c|}{ Arquivo editado: C:\TQSW } \\
\hline \multicolumn{5}{|c|}{$\begin{array}{l}\text { Este arquivo vem da pasta de suporte, e é normalmente copiado para os edifícios novos. Vocế } \\
\text { pode inicializá-lo a partir do arquivo na versão } D 0 S \text {, se instalada. }\end{array}$} \\
\hline Listar & Adaptar Norma & & $\mathrm{OK}$ & Cancelar \\
\hline
\end{tabular}

Figura A.26. Critérios de geração de modelo de pórtico espacial.

Na aba ELU, pode-se atribuir coeficientes diferentes para vigas e pilares (figura A.27).

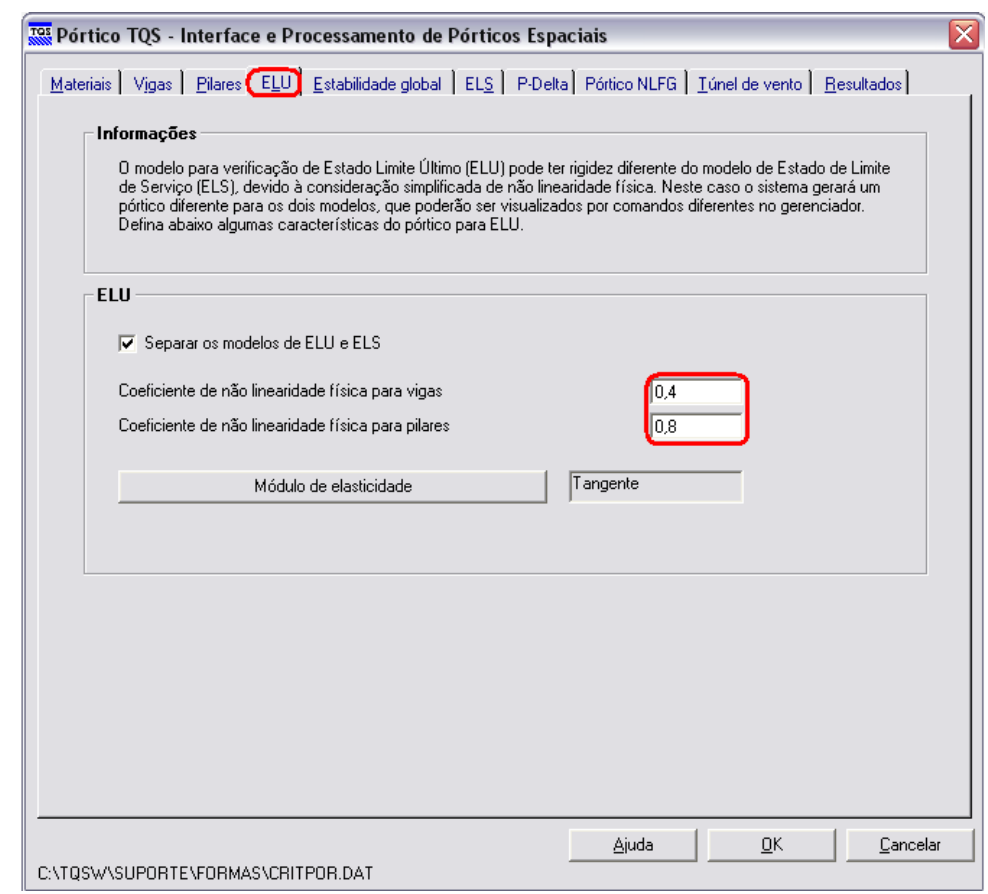

Figura A.27. Coeficientes de não-linearidade física diferenciados.

Também se podem alterar esses coeficientes na aba Estabilidade global, desde que não tenham sido alterados na opção anterior, ou seja, que nessa opção anterior estejam igual a 1 para vigas e pilares. Então, clica-se em "COENLF - Coeficiente de não-linearidade física" (figura A.28). 


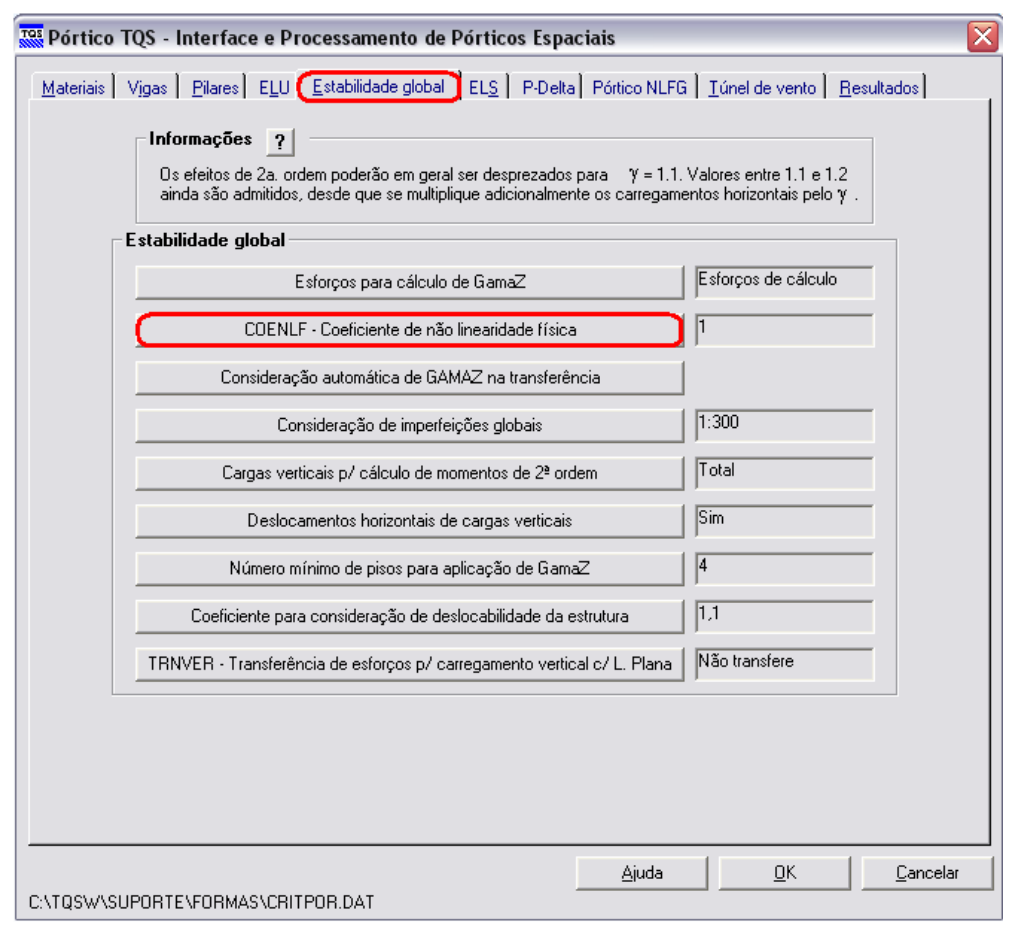

Figura A.28. COENLF - Coeficiente de não-linearidade física.

Na janela "COENLF - Coeficiente de não-linearidade física", pode-se alterar o valor desse coeficiente, sendo ele o mesmo para vigas e pilares (figura A.29).

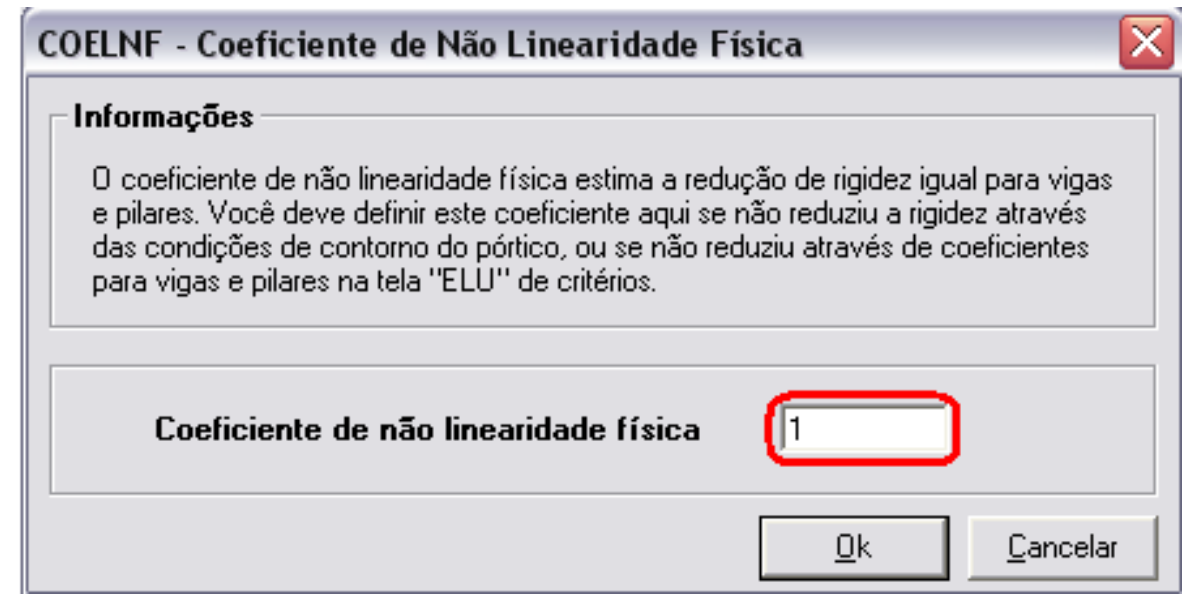

Figura A.29. Coeficiente de não-linearidade física único para vigas e pilares.

\section{A.5 ESFORÇOS PARA CÁLCULO DO GAMA-Z}

Os esforços para cálculo do Gama-z podem ser de cálculo ou os característicos, e essa opção é feita na aba Estabilidade Global dos critérios gerais do pórtico-TQS. Para se ter acesso, primeiramente clica-se em Sistemas > Pórtico-TQS (figura A.30). 


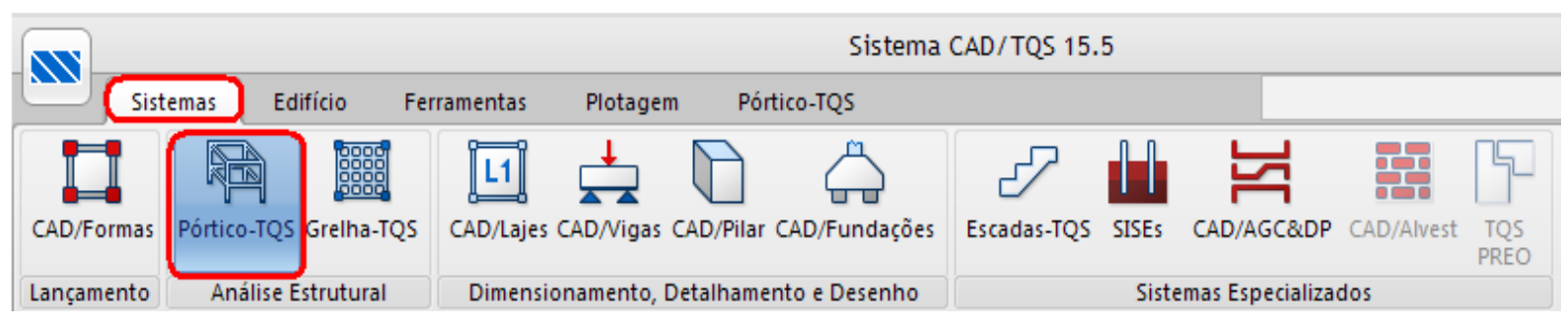

Figura A.30. Ícone Pórtico-TQS.

Dentro dos critérios do Pórtico-TQS, clica-se nos botões Critérios > Critérios Gerais (figura A.31).

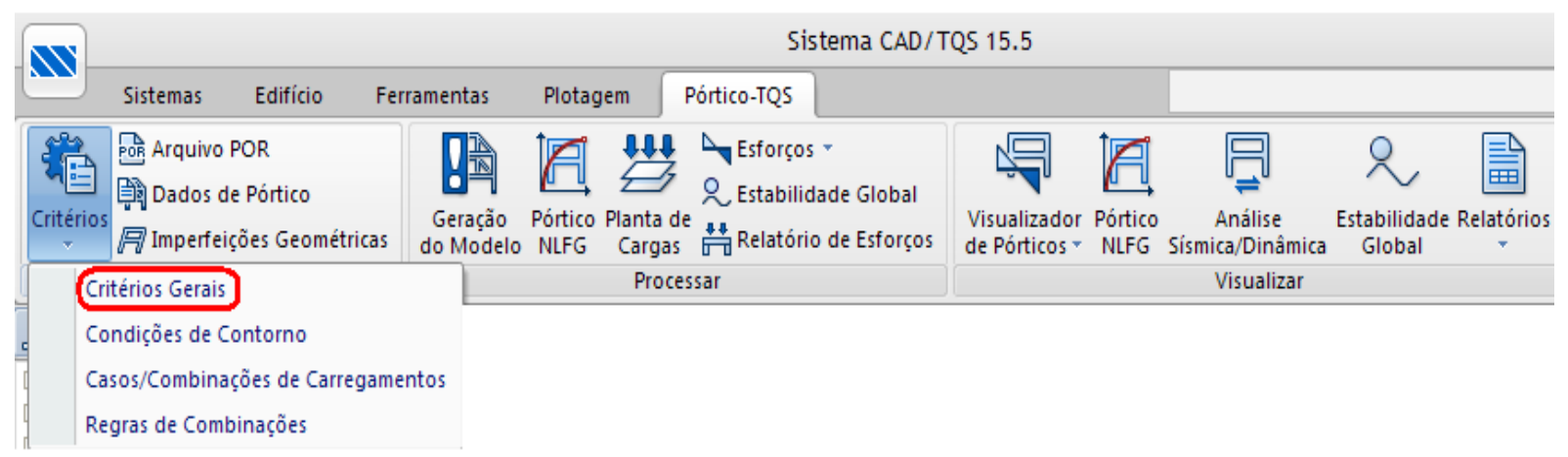

Figura A.31. Critérios gerais do Pórtico-TQS.

Ao clicar em Critérios Gerais, aparece a janela da figura A.32: clica-se em OK.

\begin{tabular}{|c|c|c|}
\hline \multicolumn{3}{|c|}{ Critérios de geração de modelo de pórtico espacial } \\
\hline \multicolumn{3}{|c|}{ Utilização } \\
\hline Arquivo em uso: & \multicolumn{2}{|c|}{ Comum a todos os projetos } \\
\hline Nome do arquivo: & \multicolumn{2}{|c|}{ C:ITQSWISUPORTE\FORMAS\CRITPOR.DAT } \\
\hline \multicolumn{3}{|l|}{ Arquivo a editar: } \\
\hline Comum a todos os projetos novos & Tornar comum a todos & \\
\hline Comum a todos os pavimentos & Inicializar & \\
\hline Específico deste pavimento & Inicializar & \\
\hline \multicolumn{3}{|c|}{ Arquivo editado: C:TTQSW $\backslash$ SUPORTE YFORMAS\CRITPOR.DAT } \\
\hline \multicolumn{3}{|c|}{$\begin{array}{l}\text { Este arquivo vem da pasta de suporte, e é normalmente copiado para os edifícios novos. Vocế } \\
\text { pode inicializá-lo a partir do arquivo na versão DOS, se instalada. }\end{array}$} \\
\hline Adaptar Norma & OK & Cancelar \\
\hline
\end{tabular}

Figura A.32. Critérios de geração de modelo de pórtico espacial. 
Na aba Estabilidade global, clica-se em "Esforços para cálculo de Gama-z" (figura A.33).

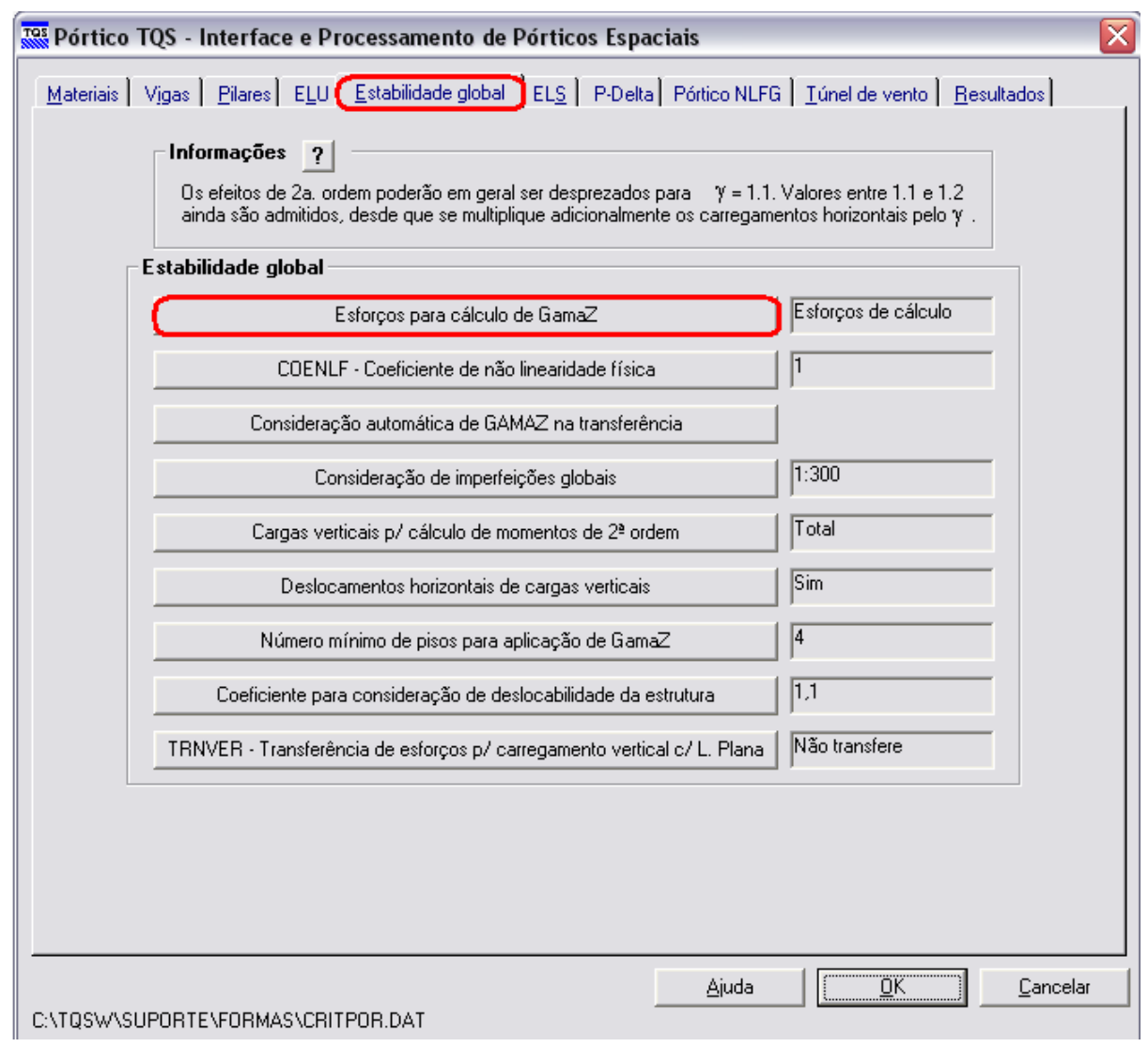

Figura A.33. Esforços para cálculo de Gama-z.

Na janela "Esforços para cálculo de Gama-z", faz-se a opção de considerar esforços característicos ou de cálculo (figura A.34).

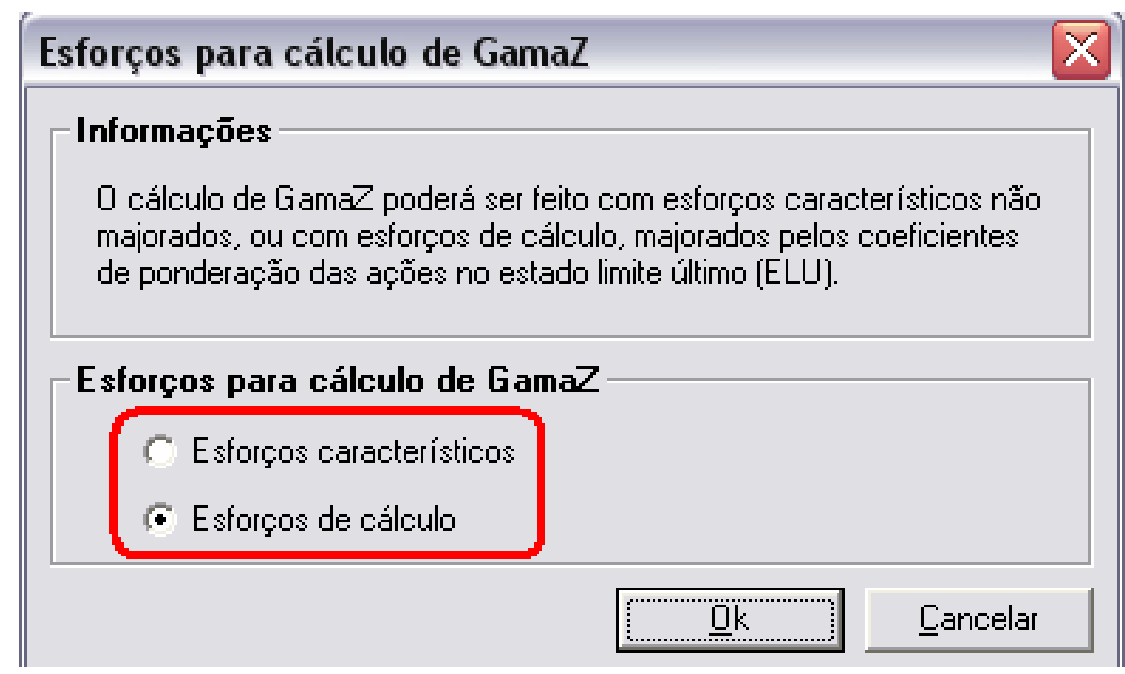

Figura A.34. Esforços para cálculo de Gama-z. 


\section{A.6 CONSI DERAÇÃO DO GAMA-Z NA TRANSFERÊNCI A DE ESFORÇOS}

Os critérios para consideração do Gama-z na transferência de esforços podem ser alterados na aba Estabilidade Global dos critérios gerais do PórticoTQS. Para se ter acesso, primeiramente clica-se em Sistemas > Pórtico-TQS (figura A.35).

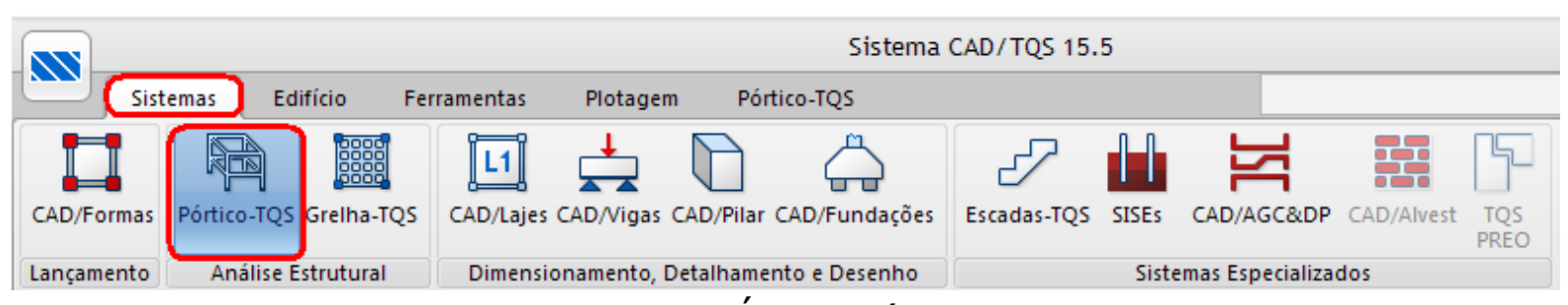

Figura A.35. Ícone Pórtico-TQS.

Dentro dos critérios do Pórtico-TQS, clica-se nos botões Critérios > Critérios Gerais (figura A.36).

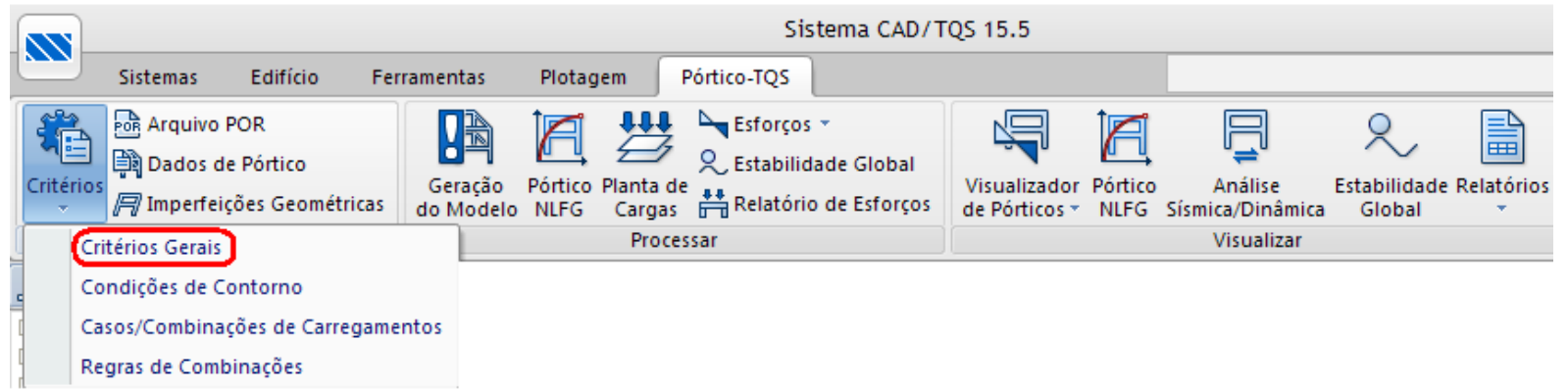

Figura A.36. Critérios gerais do Pórtico-TQS.

Ao clicar em Critérios Gerais, aparece a janela da figura A.37: clica-se em OK.

\begin{tabular}{|c|c|c|}
\hline \multicolumn{3}{|c|}{ Critérios de geração de modelo de pórtico espacial } \\
\hline \multicolumn{3}{|l|}{ Utilização- } \\
\hline \multicolumn{3}{|c|}{ Comum a todos os projetos } \\
\hline Nome do arquivo: & \multicolumn{2}{|c|}{ C:TQSWMSUPORTE\FORMAS\CRITPOR.DAT } \\
\hline \multicolumn{3}{|l|}{ Arquivo a editar: } \\
\hline Comum a todos os projetos novos & Tornar comum a todos & \\
\hline Comum a todos os pavimentos & Inicializar & \\
\hline Específico deste pavimento & Inicializar & \\
\hline Arquivo editado: C:ITQSW & \multicolumn{2}{|c|}{ C:ITQSW SSUPORTEYFORMASSCRITPOR.DAT } \\
\hline \multicolumn{3}{|c|}{$\begin{array}{l}\text { Este arquivo vem da pasta de suporte, e é normalmente copiado para os edifícios novos. Vocề } \\
\text { pode inicializá-lo a partir do arquivo na versão } \mathrm{DOS} \text {, se instalada. }\end{array}$} \\
\hline Adaptar Norma & OKK & Cancelar \\
\hline
\end{tabular}

Figura A.37. Critérios de geração de modelo de pórtico espacial. 
Na aba Estabilidade global, clica-se em "Consideração automática de Gama-z na transferência" (figura A.38).

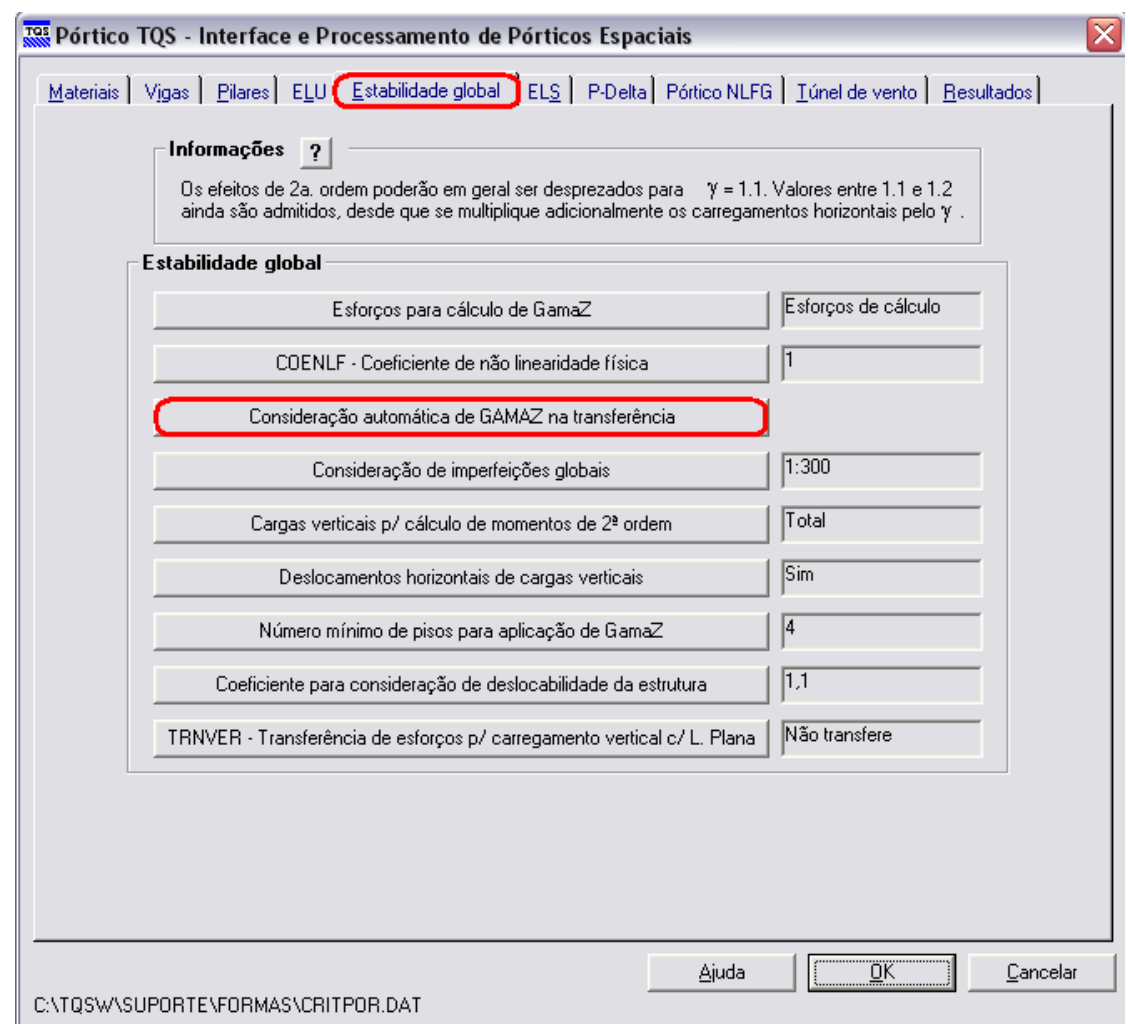

Figura A.38. Consideração automática de Gama-z na transferência de esforços.

Na janela "Consideração automática de Gama-z na transferência", opta-se por Não ou Sim. Se for adotada a alternativa Sim, pode-se alterar o valor do multiplicador e dos limites Mínimo e Máximo (figura A.39).

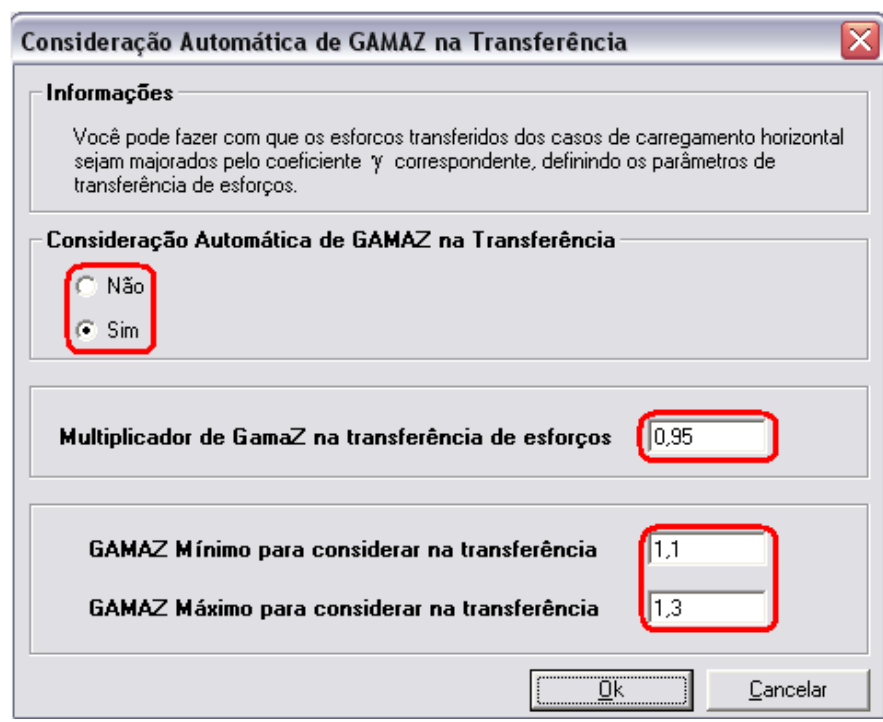

Figura A.39. Consideração automática de Gama-z na transferência de esforços. 


\section{A.7 CARGAS VERTI CAIS PARA CÁlCULO DOS MOMENTOS DE 2ạ ORDEM}

As cargas verticais para cálculo dos momentos de $2^{a}$ ordem podem ser consideradas reduzidas ou não, opção que é feita na aba Estabilidade Global dos critérios gerais do Pórtico-TQS. Para se ter acesso, primeiramente clica-se em Sistemas > Pórtico-TQS (figura A.40).

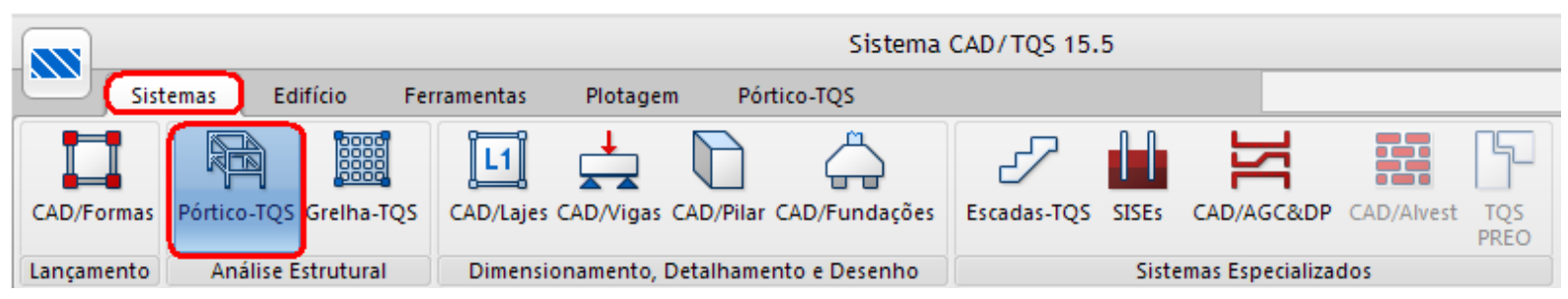

Figura A.40. Ícone Pórtico-TQS.

Dentro dos critérios do Pórtico-TQS, clica-se nos botões Critérios > Critérios Gerais (figura A.41).

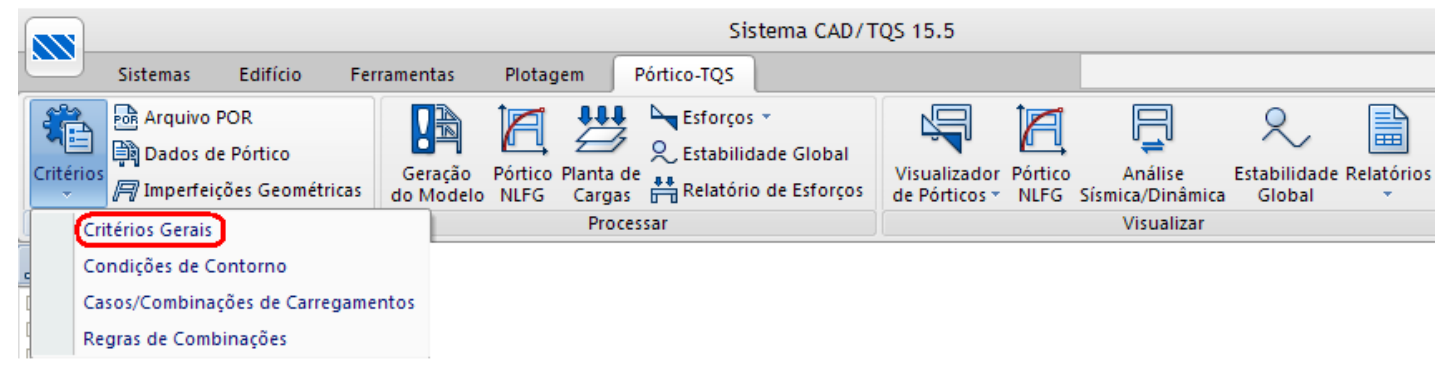

Figura A.41. Critérios gerais do Pórtico-TQS.

Ao clicar em Critérios Gerais, surge a janela indicada na figura A.42: clicase em OK.

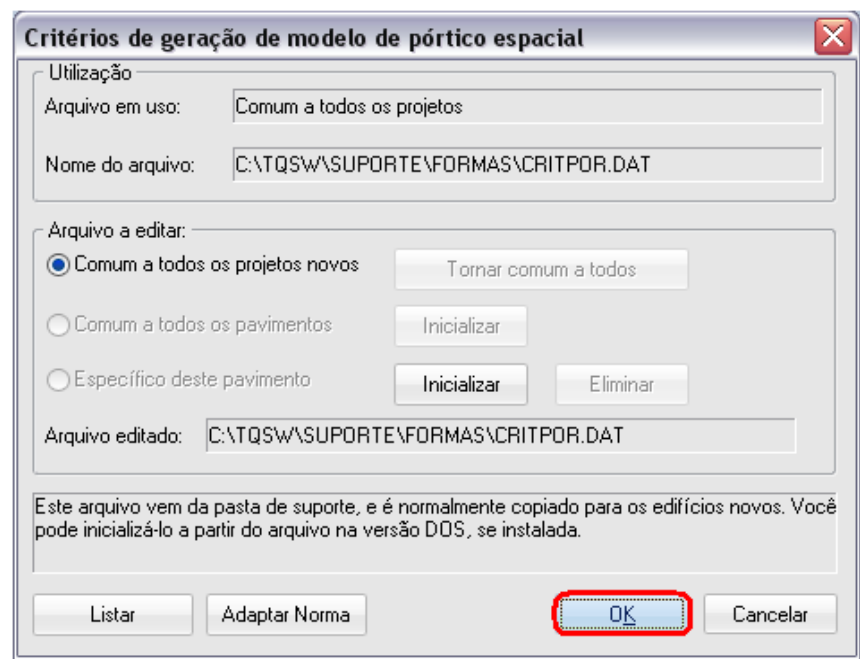

Figura A.42. Critérios de geração de modelo de pórtico espacial. 
Na aba Estabilidade global, clica-se em "Cargas verticais para cálculo de momentos de $2^{a}$ ordem" (figura A.43).

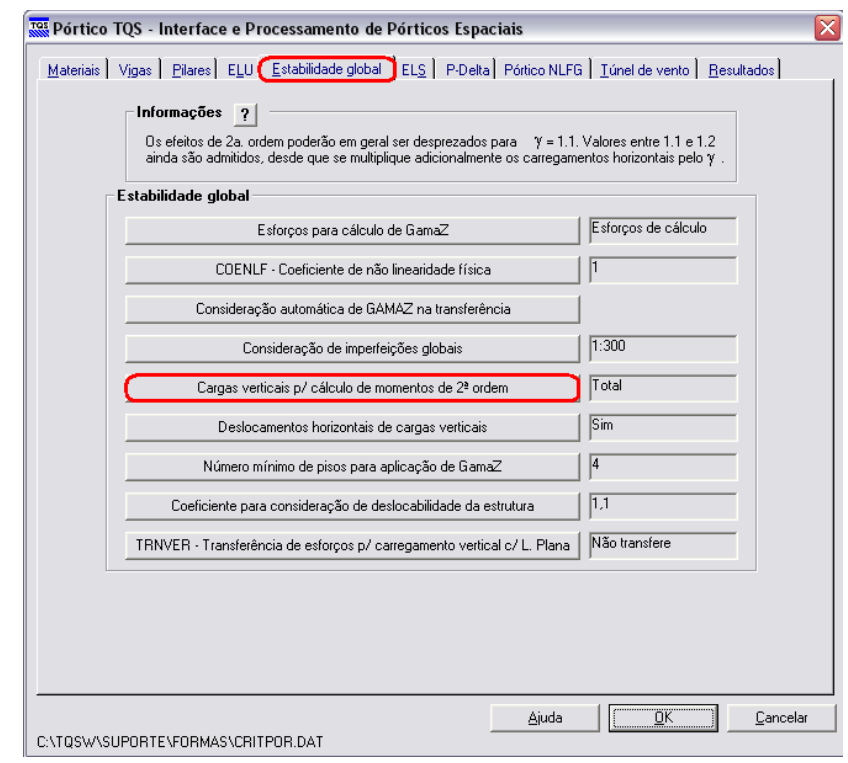

Figura A.43. Cargas verticais para cálculo de momentos de segunda ordem.

Na janela "Cargas verticais para cálculo de momentos de 2a ordem", optase por utilizar o carregamento Total ou Com redução (figura A.44).

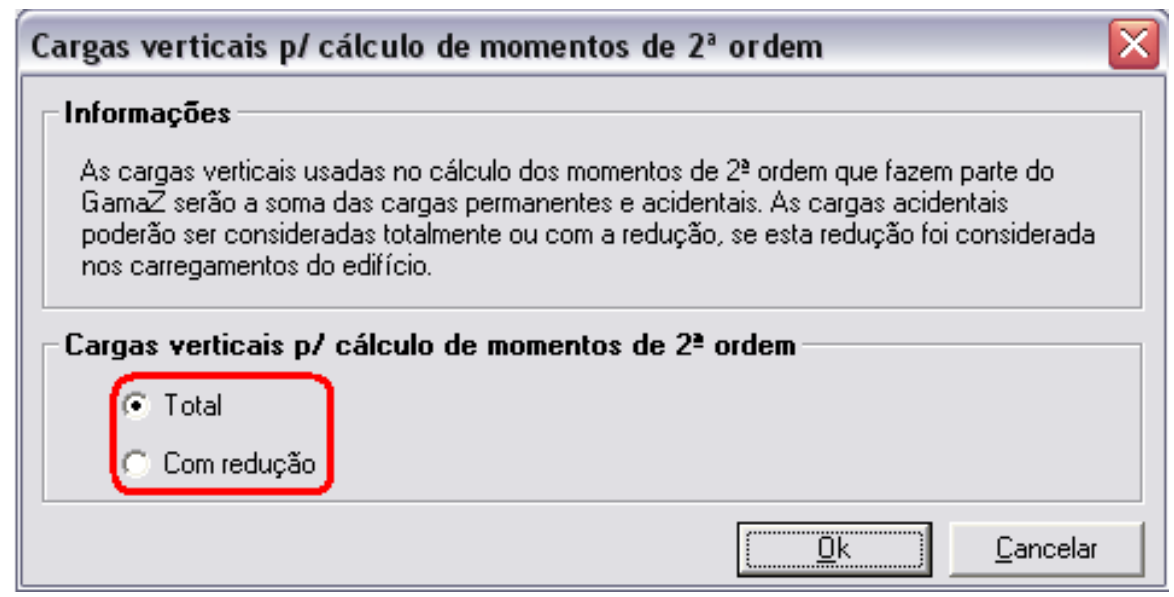

Figura A.44. Cargas verticais para cálculo de momentos de segunda ordem.

\section{A.8 DESLOCAMENTOS HORIZONTAIS DEVI DOS A CARGAS VERTI CAIS}

No cálculo de Gama-z, os deslocamentos horizontais de cargas verticais podem ser considerados ou não, opção que é feita na aba Estabilidade Global dos critérios gerais do Pórtico-TQS. Para se ter acesso, primeiramente clica-se em Sistemas > Pórtico-TQS (figura A.45). 


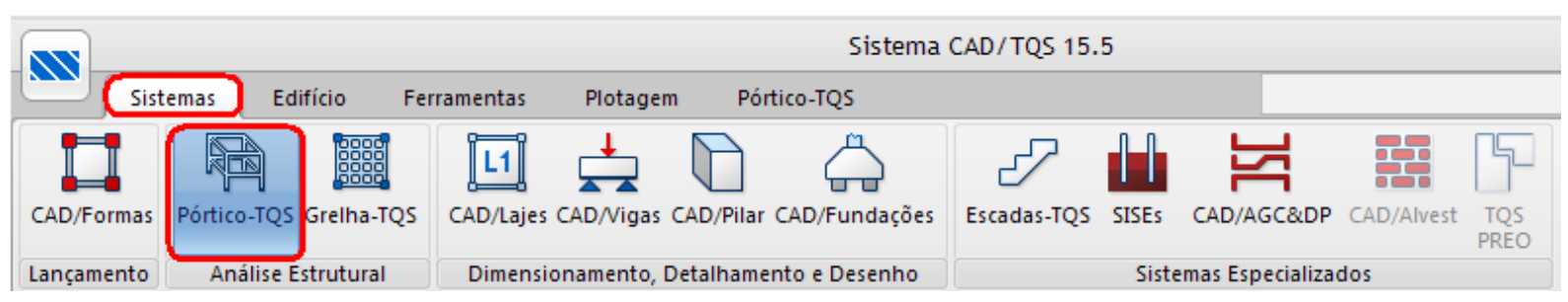

Figura A.45. Ícone Pórtico-TQS.

Dentro dos critérios do Pórtico-TQS, clica-se nos botões Critérios > Critérios Gerais (figura A.46).

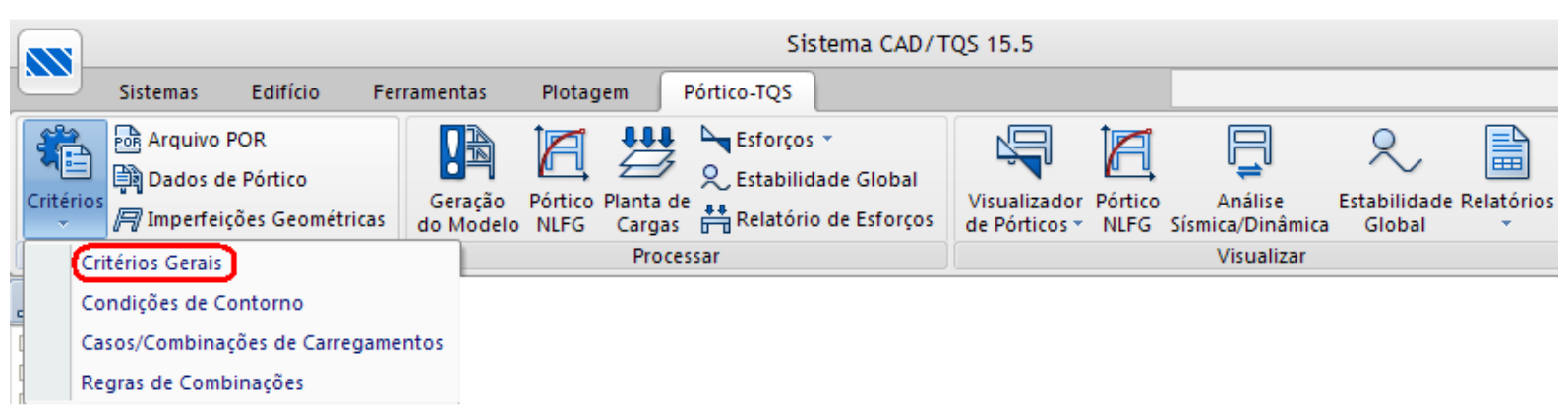

Figura A.46. Critérios gerais do Pórtico-TQS.

Ao clicar em Critérios Gerais surge a janela mostrada na figura A.47: clicase em OK.

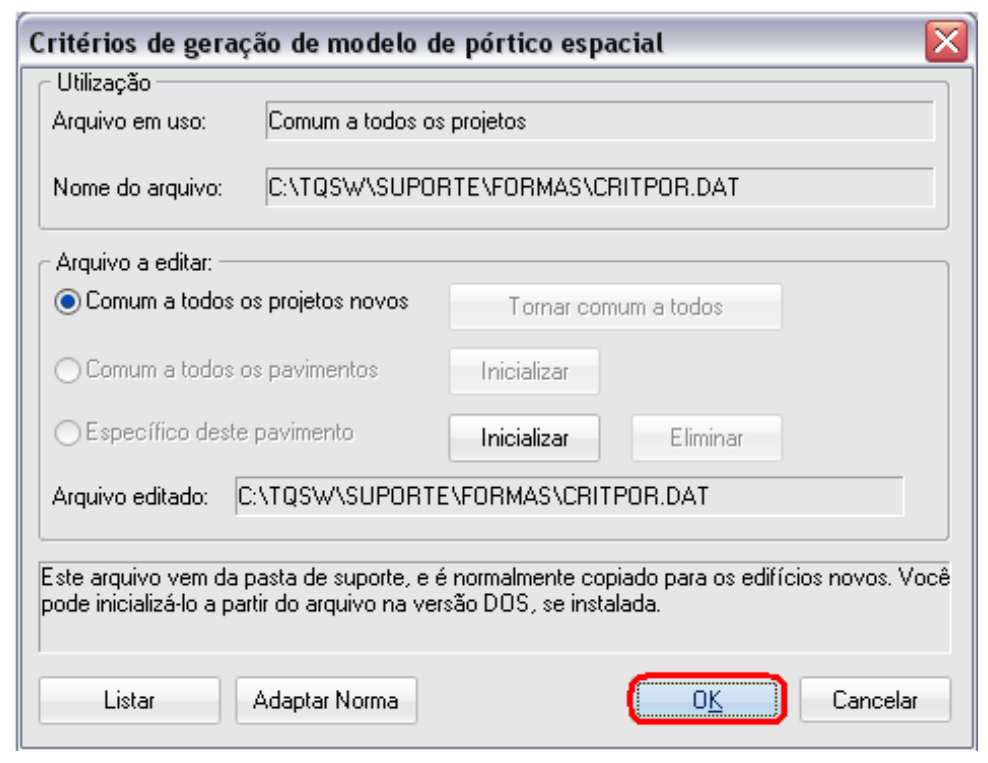

Figura A.47. Critérios de geração de modelo de pórtico espacial. 
$\mathrm{Na}$ aba Estabilidade global, clica-se em "Deslocamentos horizontais de cargas verticais" (figura A.48).

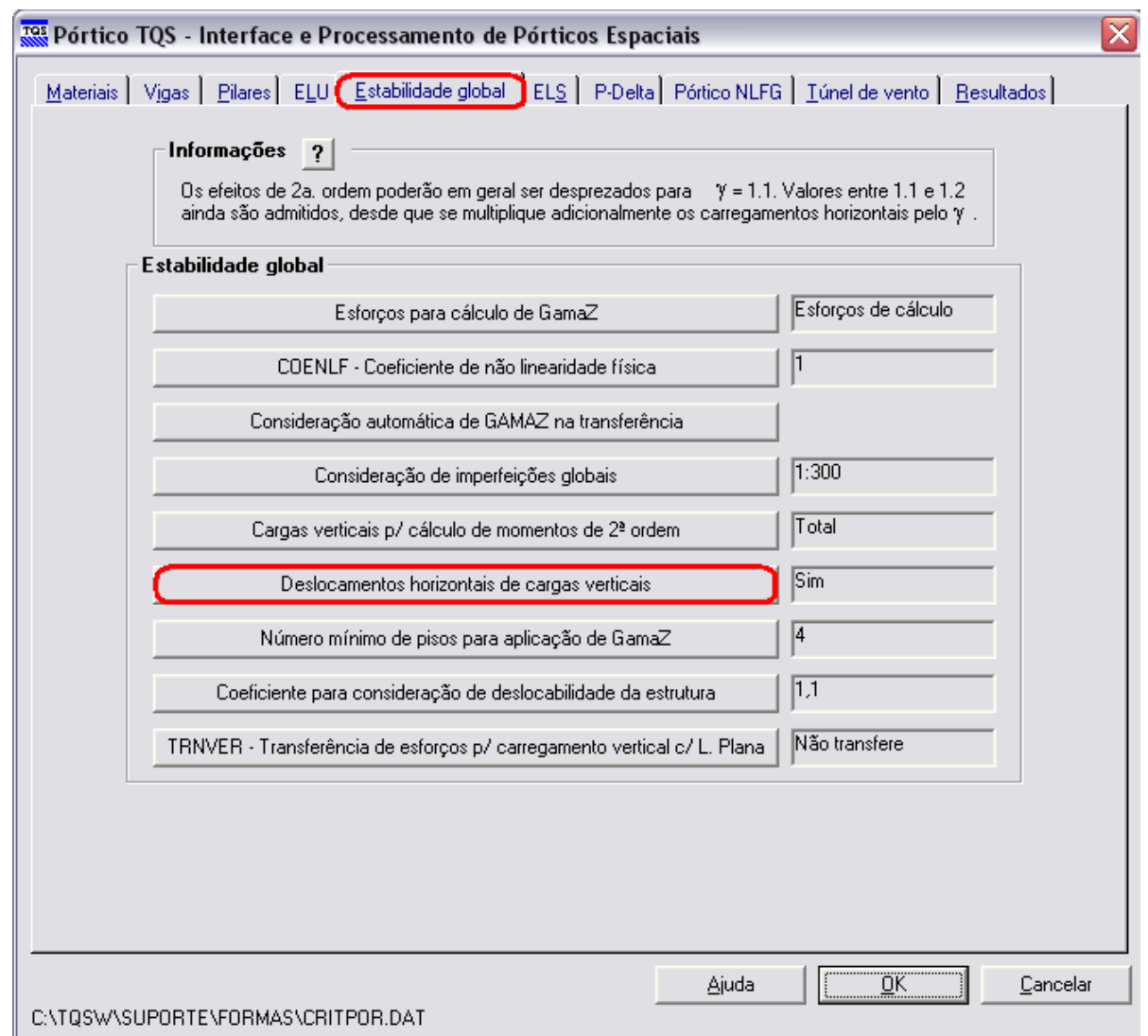

Figura A.48. Deslocamentos horizontais de cargas verticais.

$\mathrm{Na}$ janela "Deslocamentos horizontais das cargas verticais", opta-se por considerar esses deslocamentos ou não. Se a escolha for "Sim", podem ser usados fatores de redução diferentes para deslocamentos por peso próprio e por outras cargas permanentes (figura A.49).

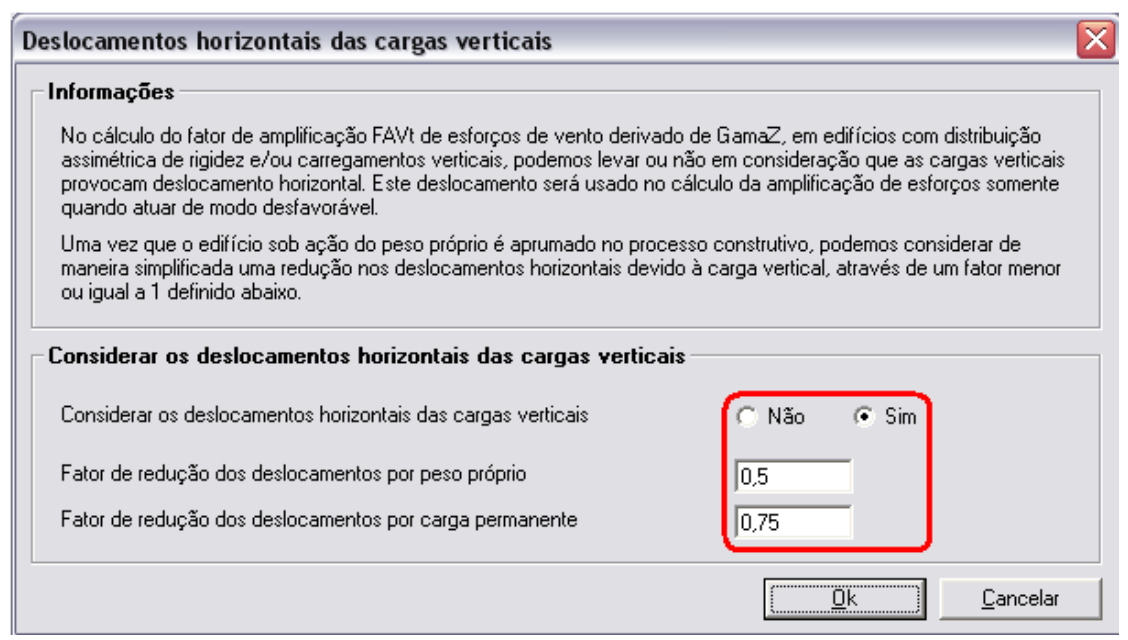

Figura A.49. Deslocamentos horizontais das cargas verticais. 


\section{A.9 NÚMERO MÍ NI MO DE PI SOS PARA APLI CAÇÃo DE GAMA-Z}

O número mínimo de pisos para a aplicação do Gama-z pode ser alterado na aba Estabilidade Global dos critérios gerais do Pórtico-TQS. Para se ter acesso, primeiramente clica-se em Sistemas > Pórtico-TQS (figura A.50).

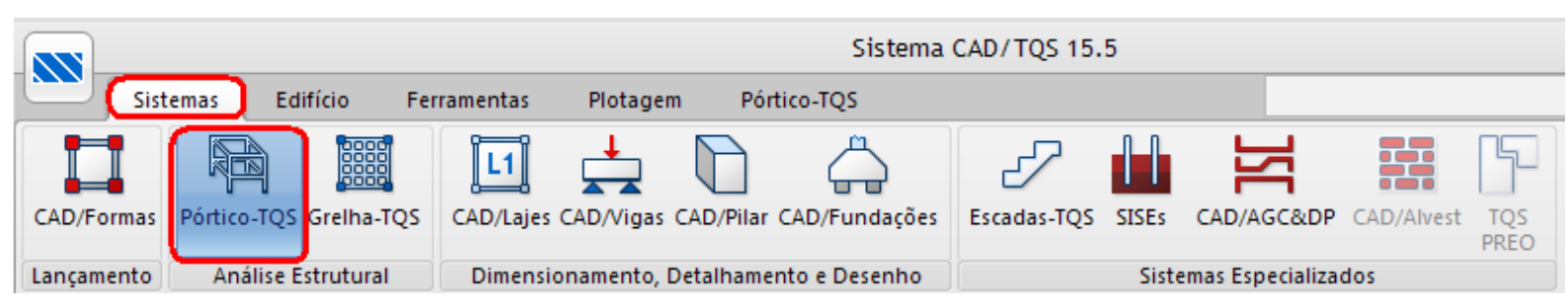

Figura A.50. Ícone Pórtico-TQS.

Dentro dos critérios do Pórtico-TQS, clica-se em Critérios > Critérios Gerais (figura A.51).

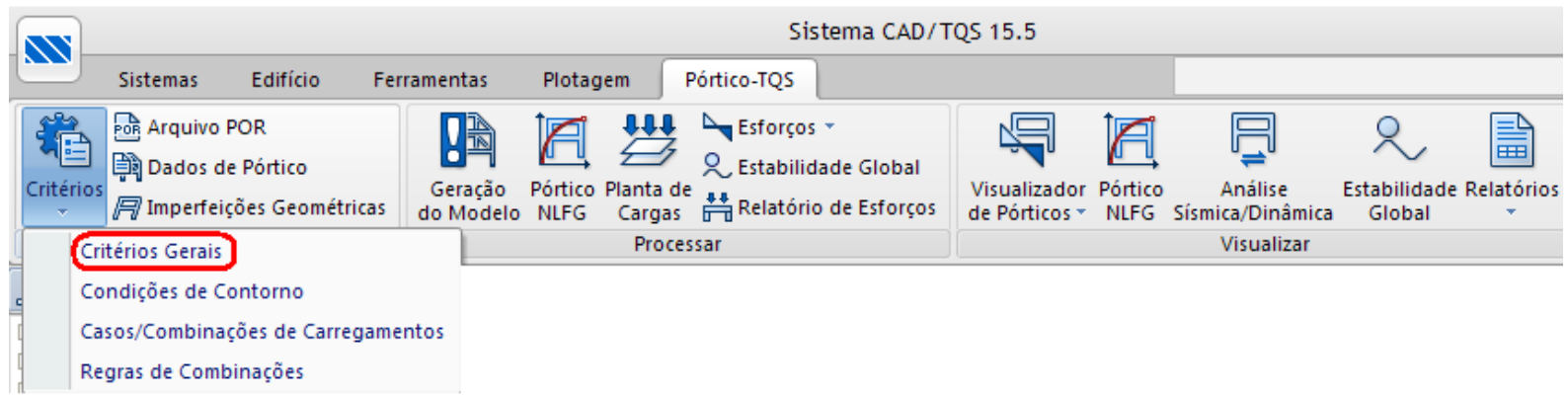

Figura A.51. Critérios gerais do Pórtico-TQS.

Ao clicar em Critérios Gerais, aparece a janela da figura A.52: clica-se em OK.

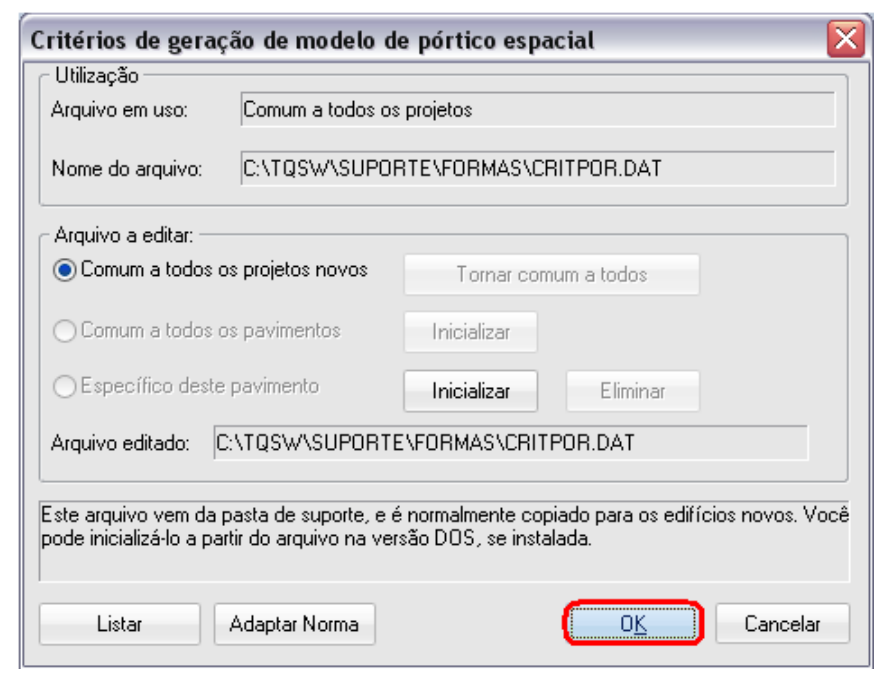

Figura A.52. Critérios de geração de modelo de pórtico espacial. 
Na aba Estabilidade global, clica-se em "Número mínimo de pisos para aplicação de Gama-z" (figura A.53).

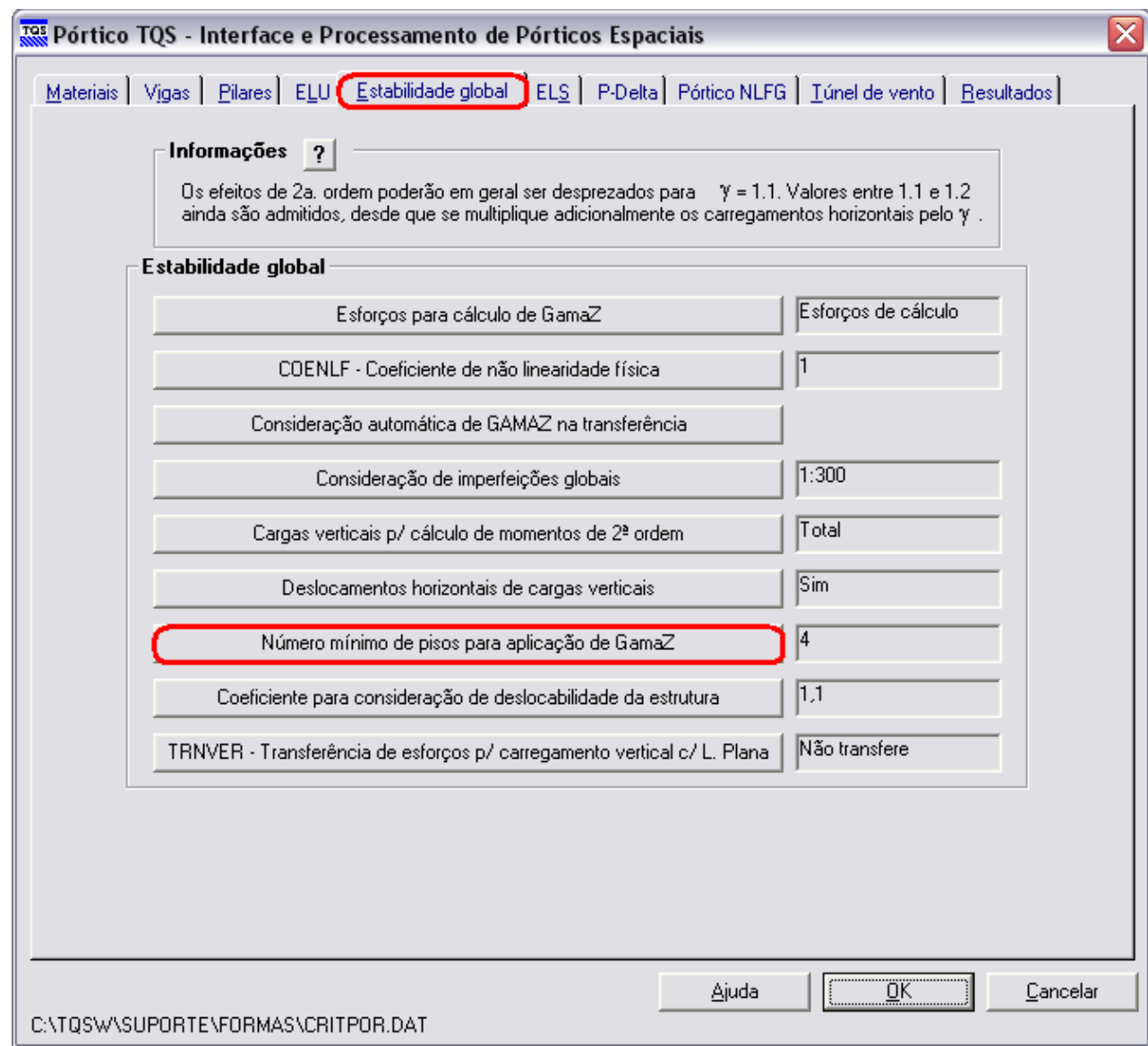

Figura A.53. Número mínimo de pisos para aplicação de Gama-z.

Na janela "Número mínimo de pisos para aplicação de Gama-z", pode-se escolher a partir de quantos pisos pode ser considerado o valor de Gama-z, para avaliar a estabilidade global (figura A.54).

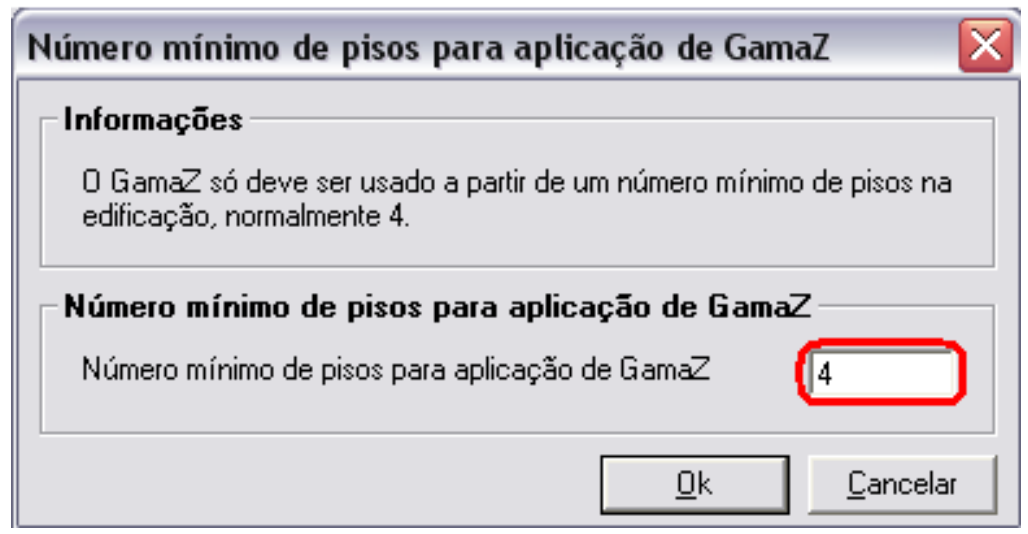

Figura A.54. Número mínimo de pisos para aplicação de Gama-z. 


\section{A.10 COEFI CI ENTE PARA CLASSI FI CAR A DESLOCABI LI DADE}

O coeficiente para classificar a estrutura, em deslocável ou não, pode ser alterado na aba Estabilidade Global dos critérios gerais do Pórtico-TQS. Para se ter acesso, primeiramente clica-se em Sistemas > Pórtico-TQS (figura A.55).

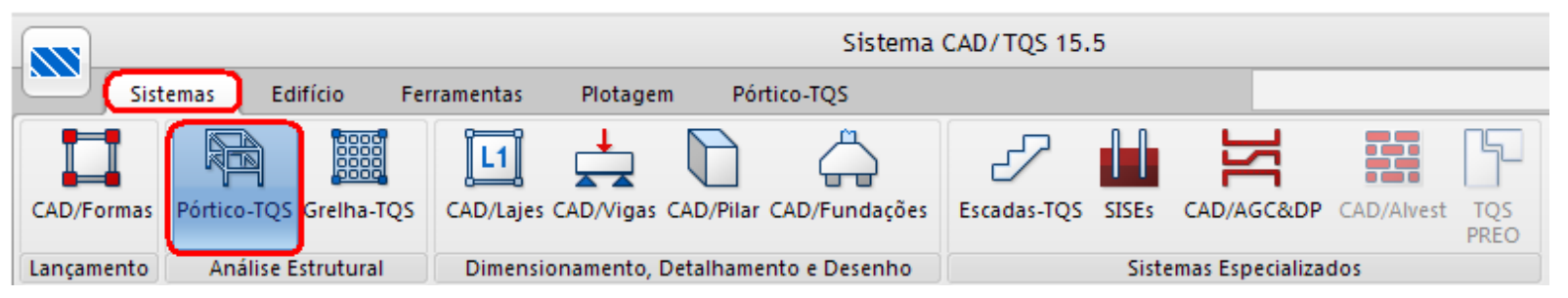

Figura A.55. Ícone Pórtico-TQS.

Dentro dos critérios do Pórtico-TQS, clica-se em Critérios > Critérios Gerais (figura A.56).

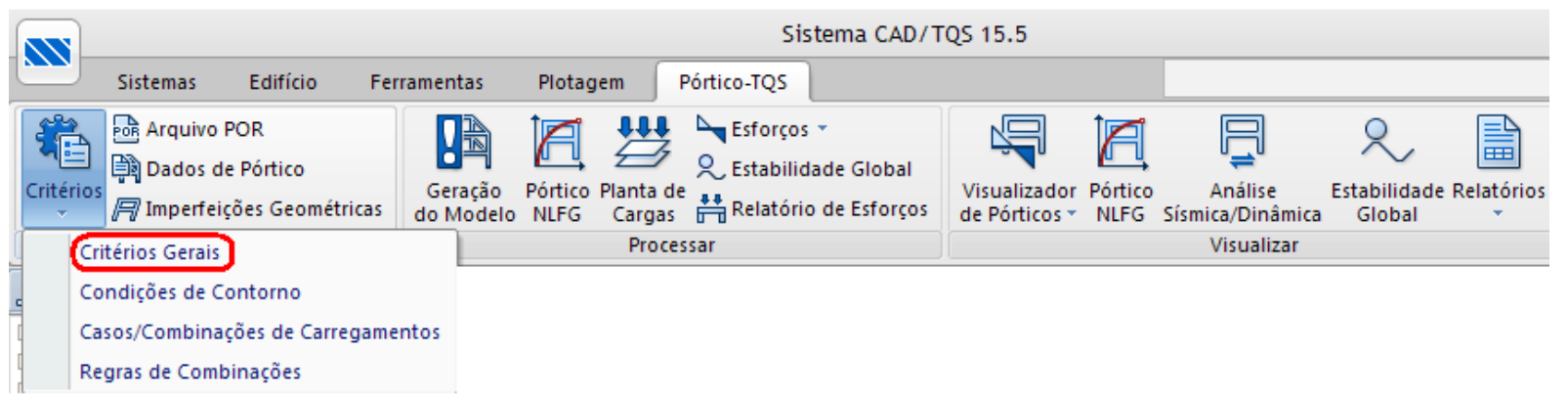

Figura A.56. Critérios gerais do Pórtico-TQS.

Ao clicar em Critérios Gerais, aparece a janela da figura A.26: clica-se em OK.

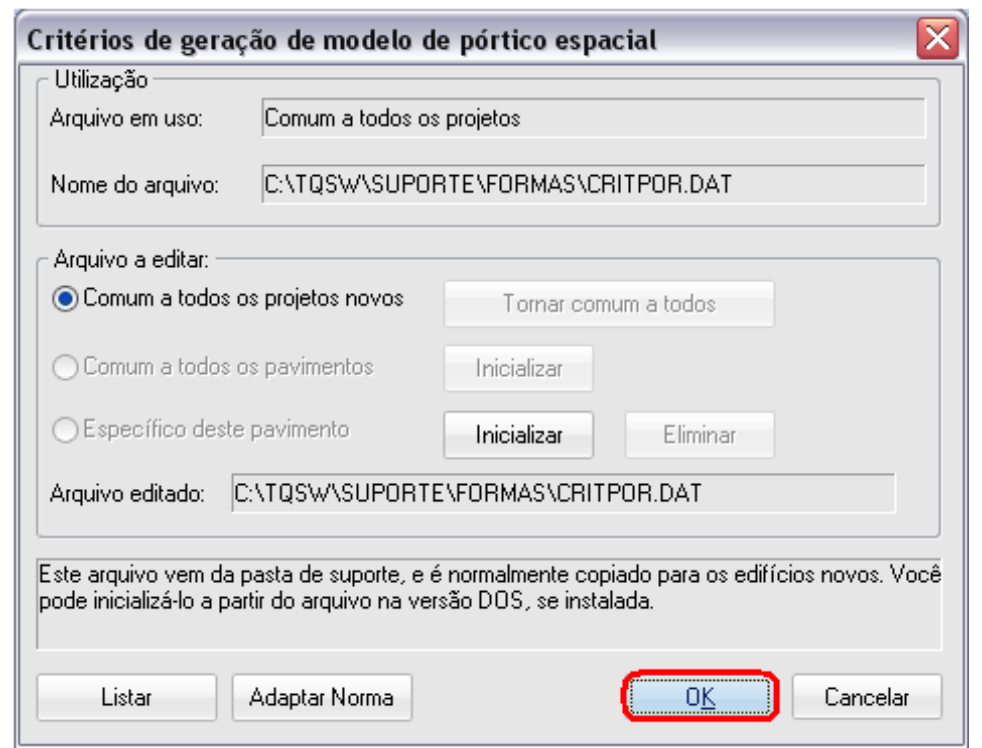

Figura A.57. Critérios de geração de modelo de pórtico espacial. 
$\mathrm{Na}$ aba Estabilidade global, clica-se em "Coeficiente para consideração de deslocabilidade da estrutura" (figura A.58).

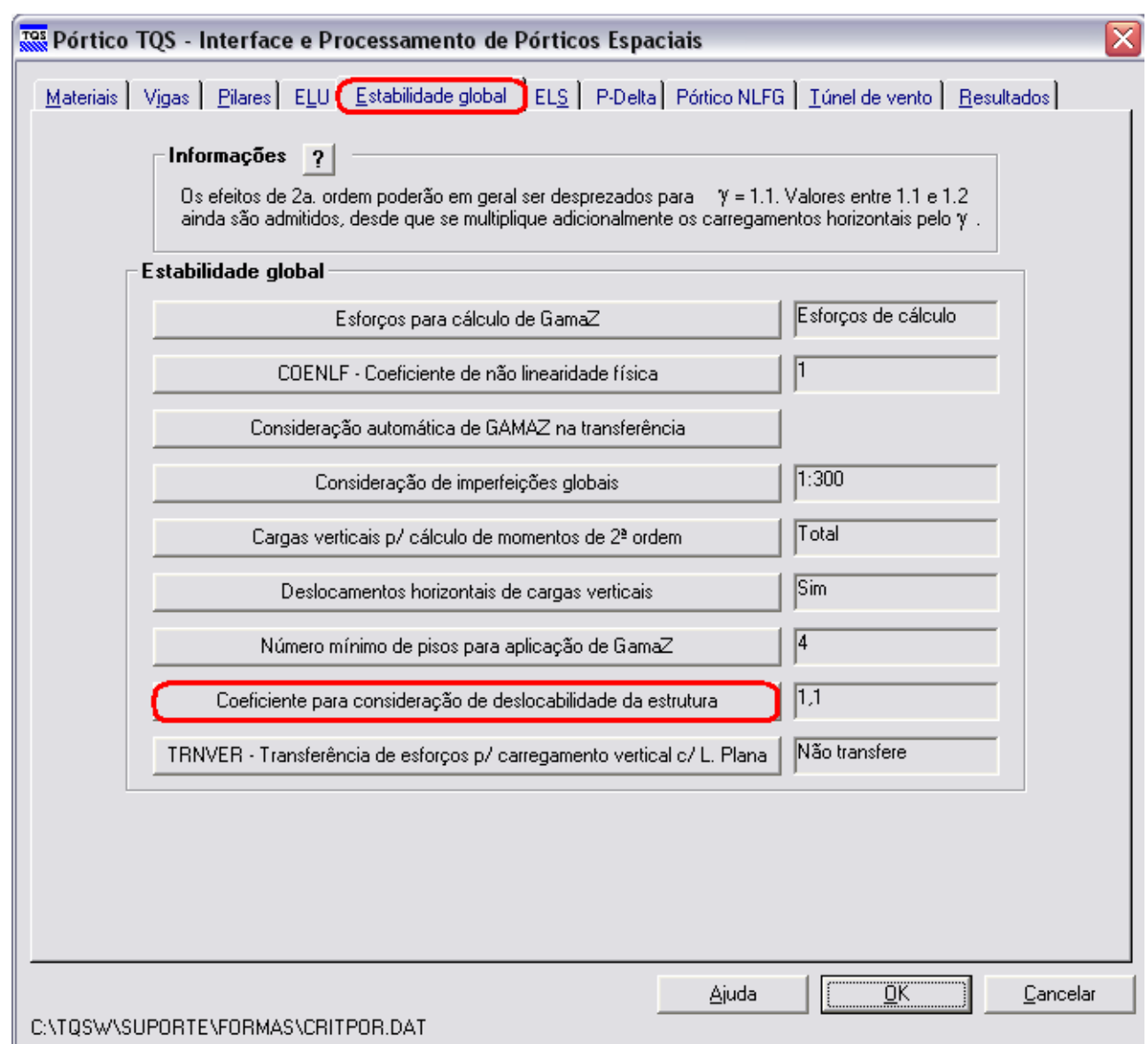

Figura A.58. Coeficiente para consideração de deslocabilidade da estrutura.

Na janela "Coeficiente para consideração de deslocabilidade da estrutura", pode-se optar por utilizar o parâmetro FAVt ou o Gama-z (figura A.59).

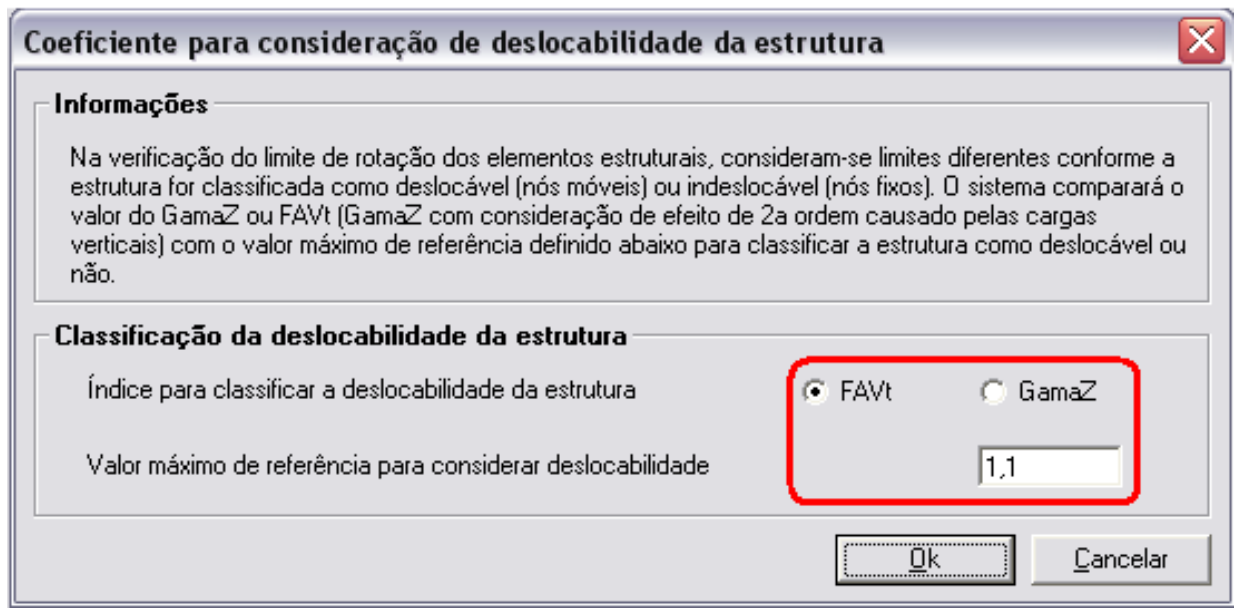

Figura A.59. Coeficiente para consideração de deslocabilidade da estrutura. 


\section{A.11 DADOS REFERENTES AO PROCESSO P-DELTA}

Os dados referentes ao processo P-Delta podem ser alterados na aba P-Delta dos critérios gerais do Pórtico-TQS. Para se ter acesso, primeiramente clica-se em Sistemas > Pórtico-TQS (figura A.60).

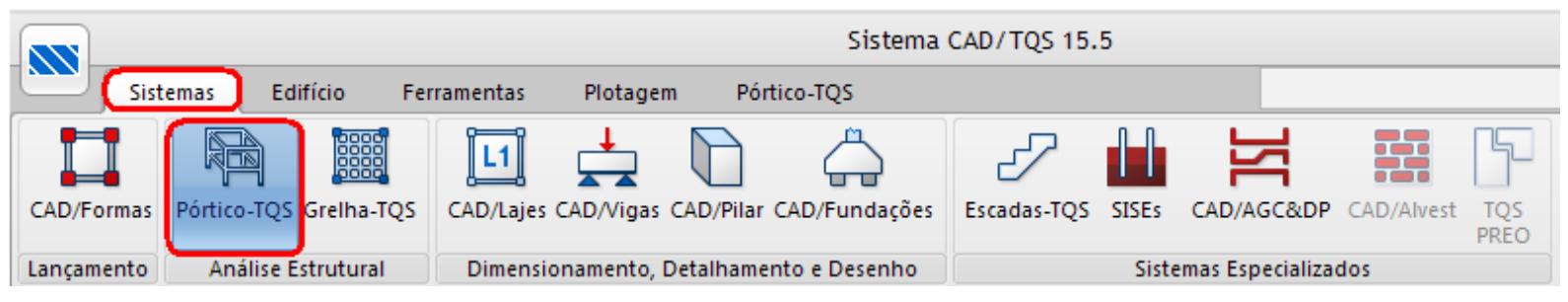

Figura A.60. Ícone Pórtico-TQS.

Dentro dos critérios do Pórtico-TQS, clica-se em Critérios > Critérios Gerais (figura A.61).

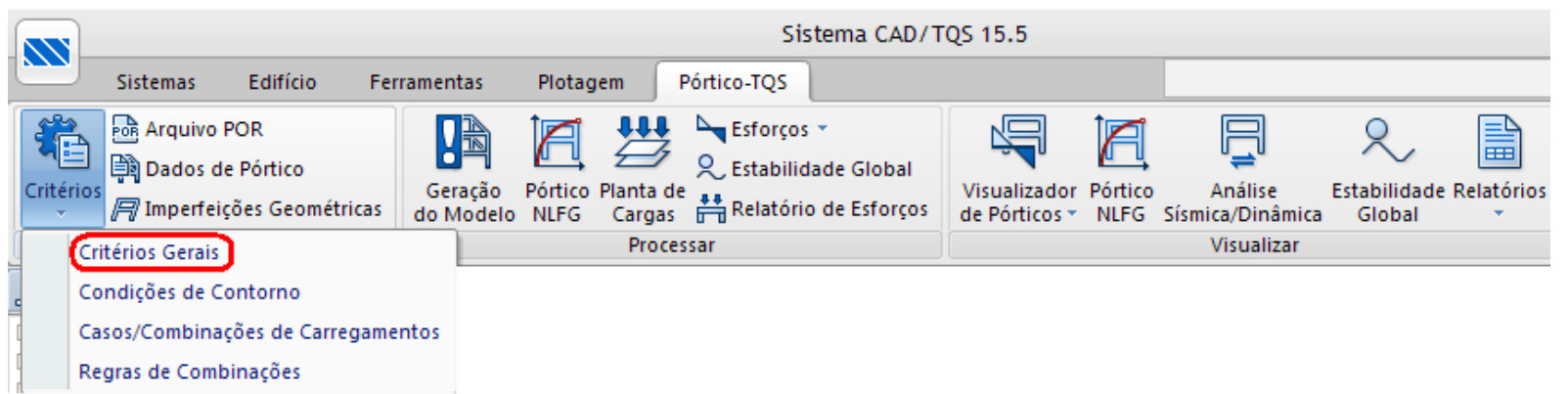

Figura A.61. Critérios gerais do Pórtico-TQS.

Ao clicar em Critérios Gerais, aparece a janela da figura A.62: clica-se em OK.

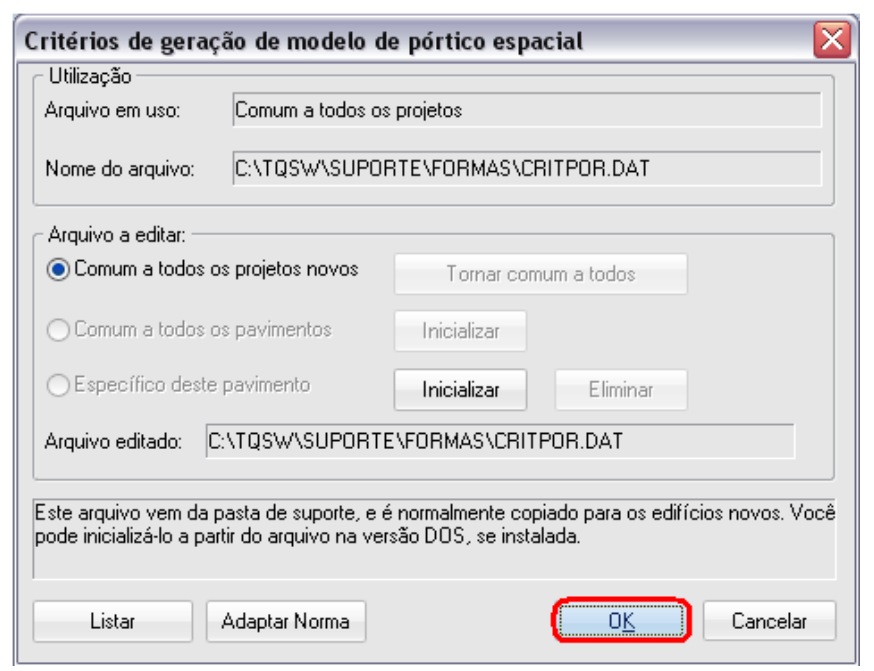

Figura A.62. Critérios de geração de modelo de pórtico espacial. 
$\mathrm{Na}$ aba P-Delta dos critérios gerais do Pórtico-TQS (figura A.63), pode-se observar que podem ser alterados: o número máximo de iterações, a tolerância relativa e um multiplicador de esforços pós-análise. É nessa aba, também, que se pode considerar a matriz $\mathrm{K}_{\mathrm{l}}$ ou não, matriz essa que leva em conta as forças devidas a deslocamento nodal horizontal, e que foi mencionada no capítulo 3.

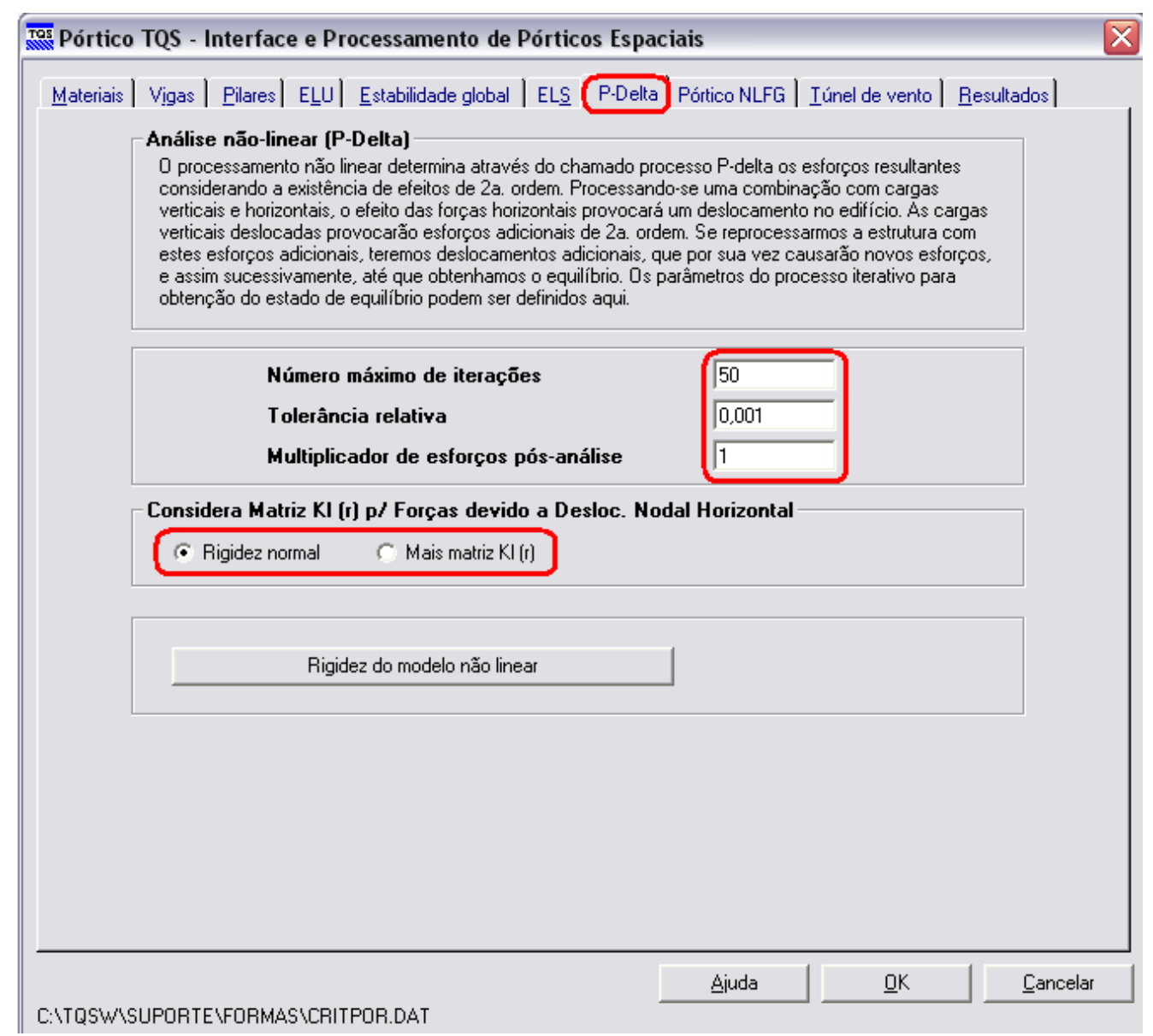

Figura A.63. P-delta.

Na figura A.64, ainda na aba P-Delta dos critérios gerais do Pórtico-TQS, pode-se observar que há um botão chamado "Rigidez do modelo não-linear". É aqui que se faz a opção para que a análise seja realizada pelo processo P-Delta convencional ou pelo processo P-Delta em dois passos. Esses dois processos já foram estudados no capítulo 3.

$\mathrm{Na}$ figura A.65, pode-se observar um resumo dos dois processos de análise e as opções "não" ou "sim" para calcular com o efeito P-Delta de dois passos. 


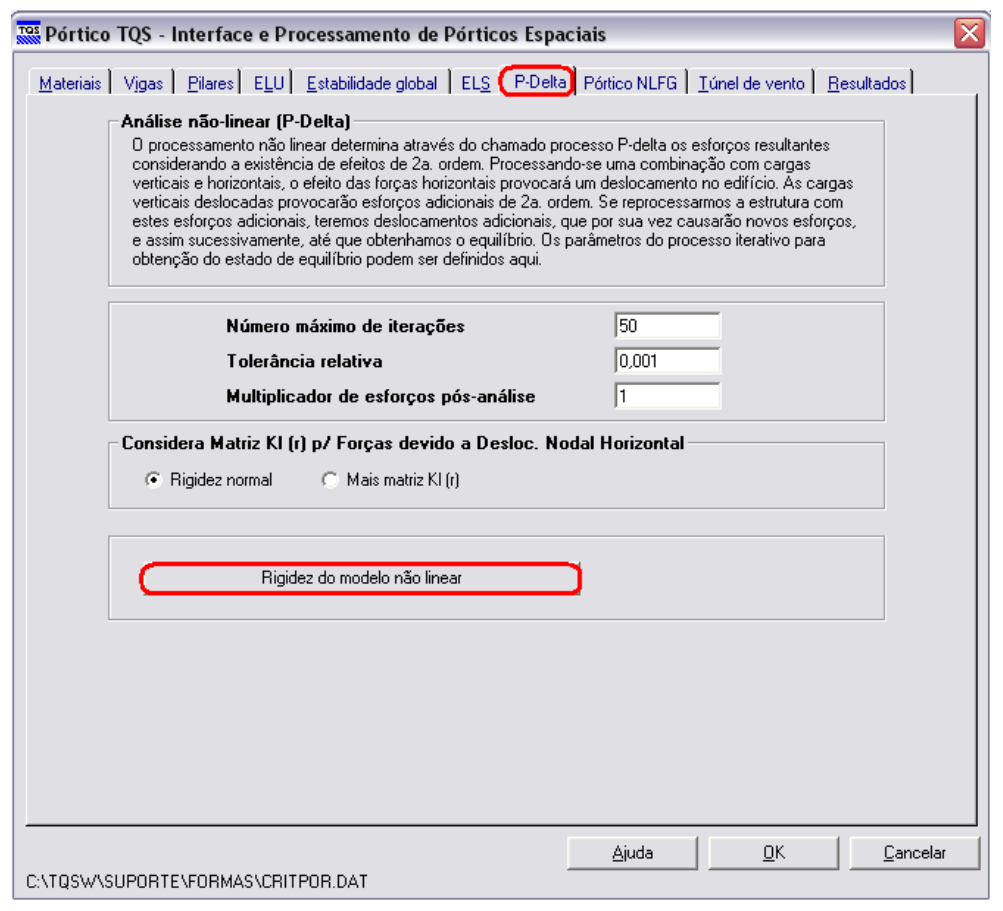

Figura A.64. Rigidez do modelo não-linear.

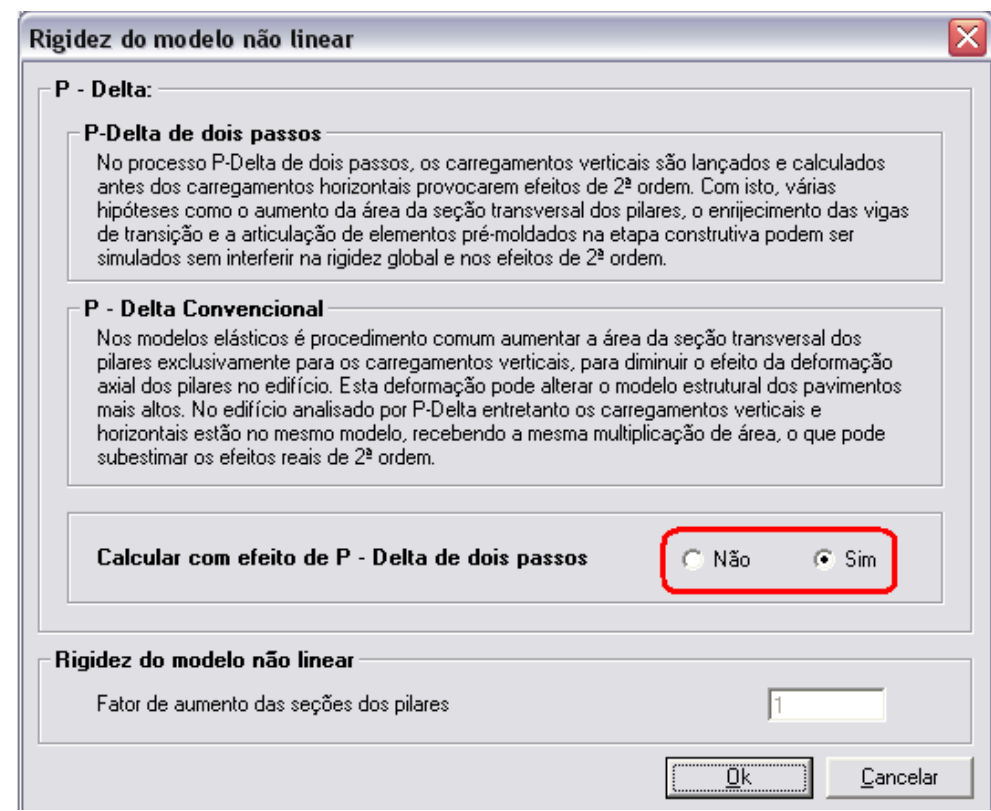

Figura A.65. Rigidez do modelo não-linear.

\section{A.12 FATOR DE ENGASTAMENTO PARCIAL DE VIGAS}

O fator de engastamento de vigas pode ser alterado na aba Vigas, dos critérios gerais do Pórtico-TQS. Para se ter acesso, primeiramente clica-se em Sistemas > Pórtico-TQS (figura A.66). 


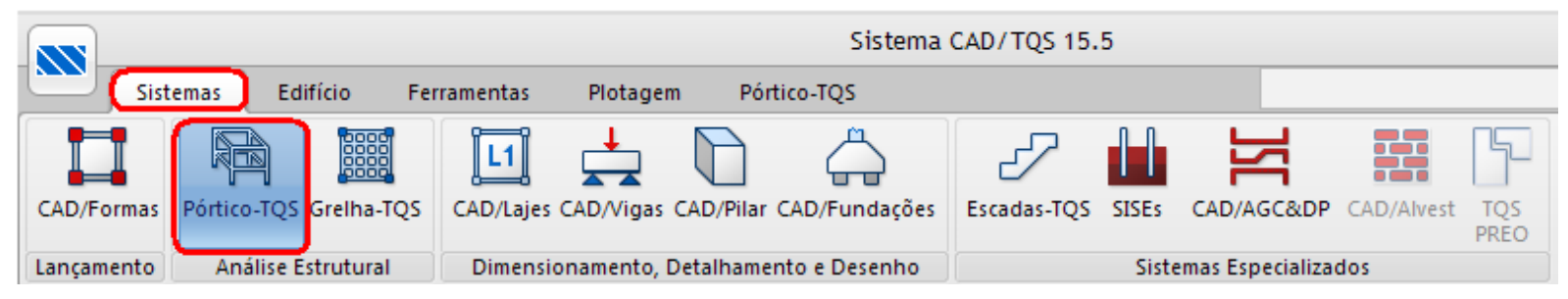

Figura A.66. Ícone Pórtico-TQS.

Dentro dos critérios do Pórtico-TQS, clica-se em Critérios > Critérios Gerais (figura A.67).

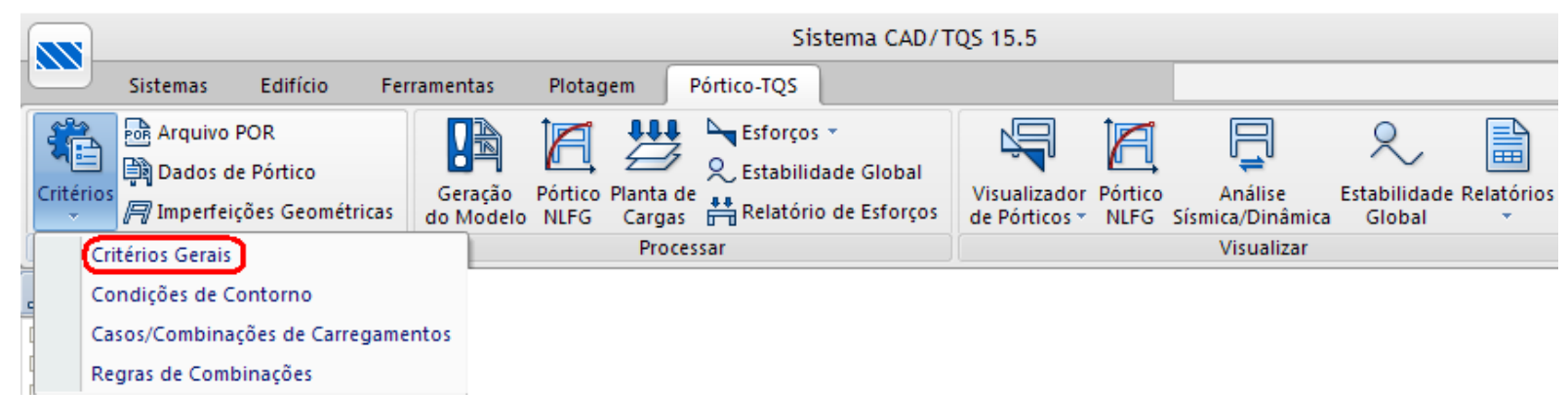

Figura A.67. Critérios gerais do Pórtico-TQS.

Ao clicar em Critérios Gerais, chega-se à janela da figura A.68. Clica-se em OK.

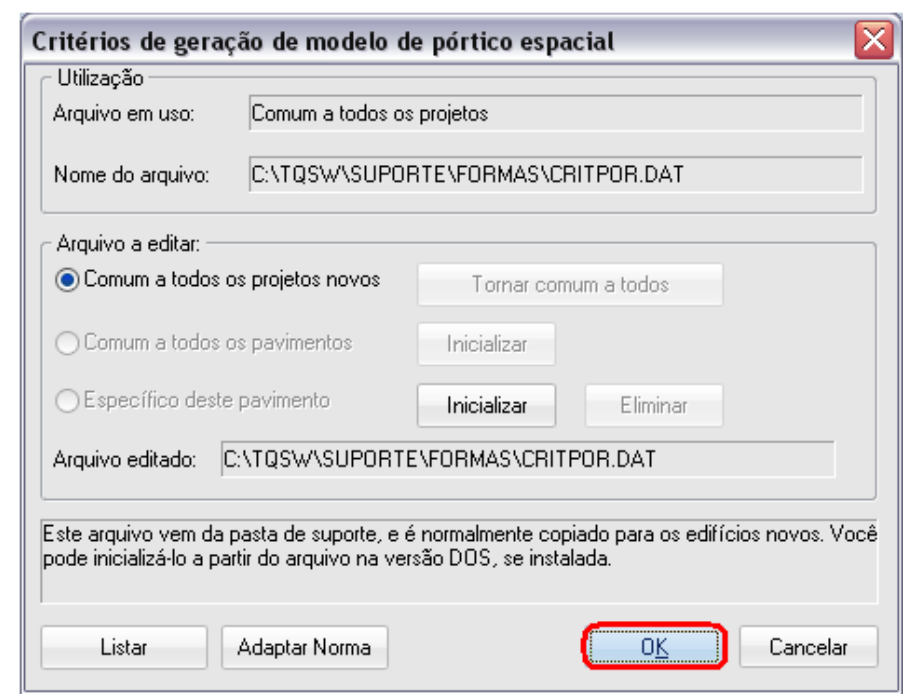

Figura A.68. Critérios de geração de modelo de pórtico espacial.

$\mathrm{Na}$ aba Vigas, clica-se em "ENGVIG - Fator de engastamento parcial de vigas" (figura A.69). 


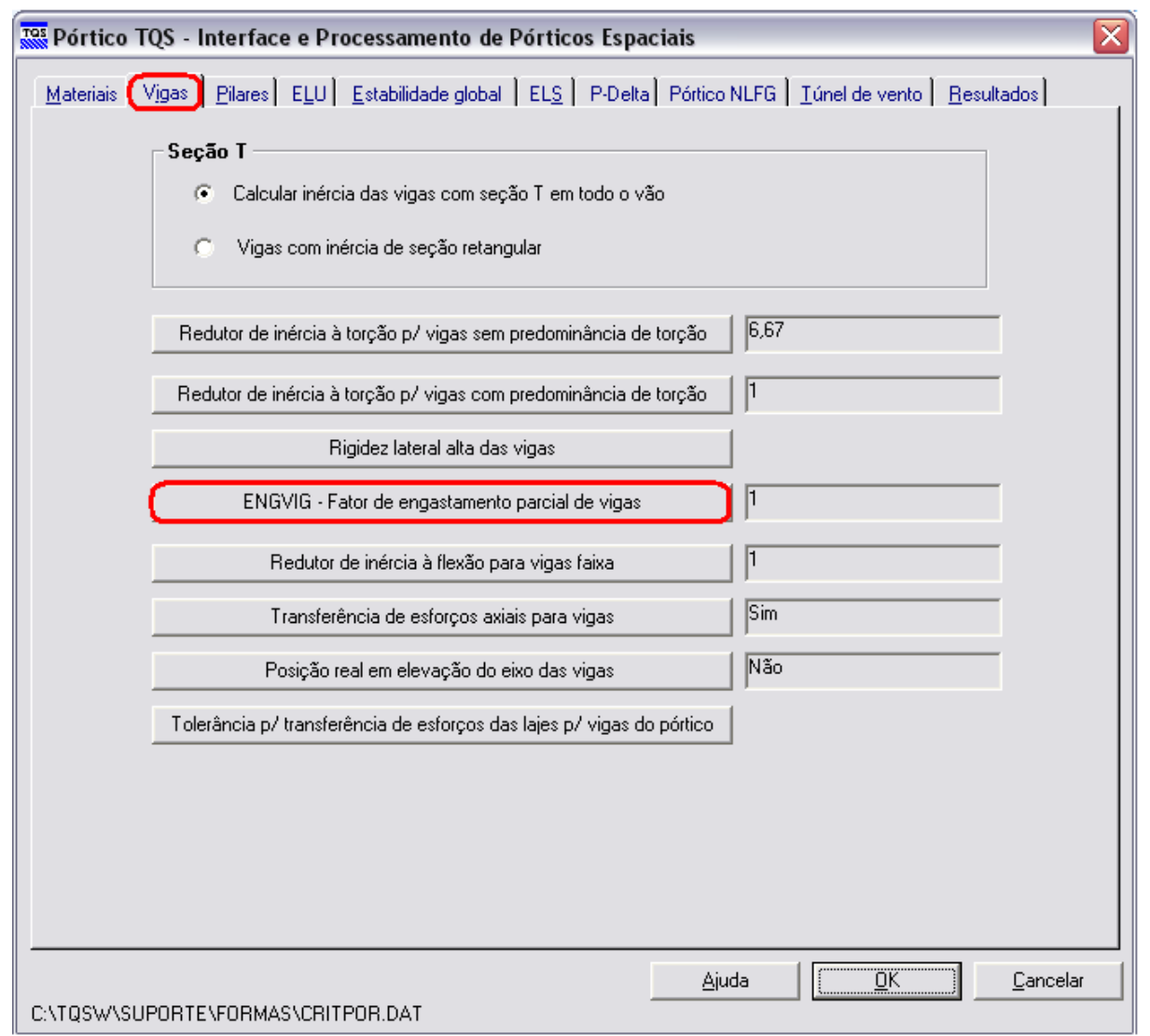

Figura A.69. ENGVIG - Fator de engastamento parcial de vigas.

Nessa janela, o fator "ENGVIG" pode variar de 0 (ligação articulada) a 1 (ligação rígida) (figura A.70).

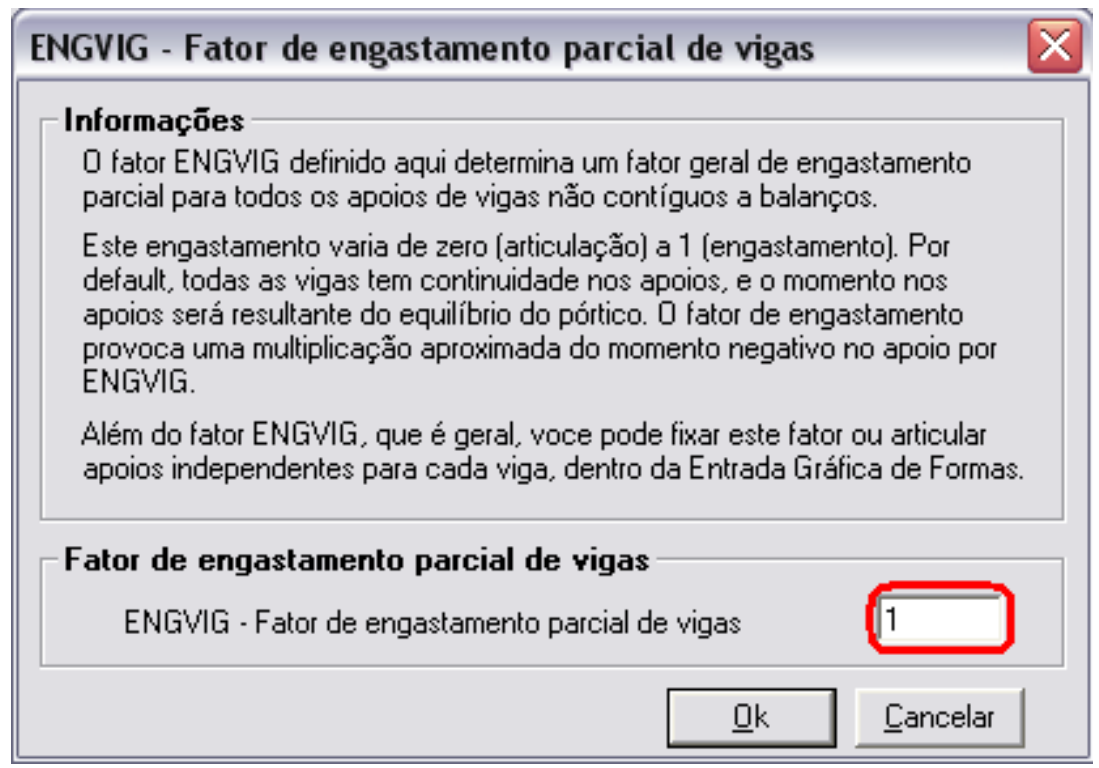

Figura A.70. Valor do fator de engastamento parcial de vigas. 


\section{A.13 FLEXI BI LI ZAÇÃO DAS LI GAÇÕES VI GA-PI LAR}

A flexibilização das ligações viga-pilar pode ser ativada na aba Pilar, dos critérios gerais do Pórtico-TQS. Para se ter acesso, primeiramente clica-se em Sistemas > Pórtico-TQS (figura A.71).

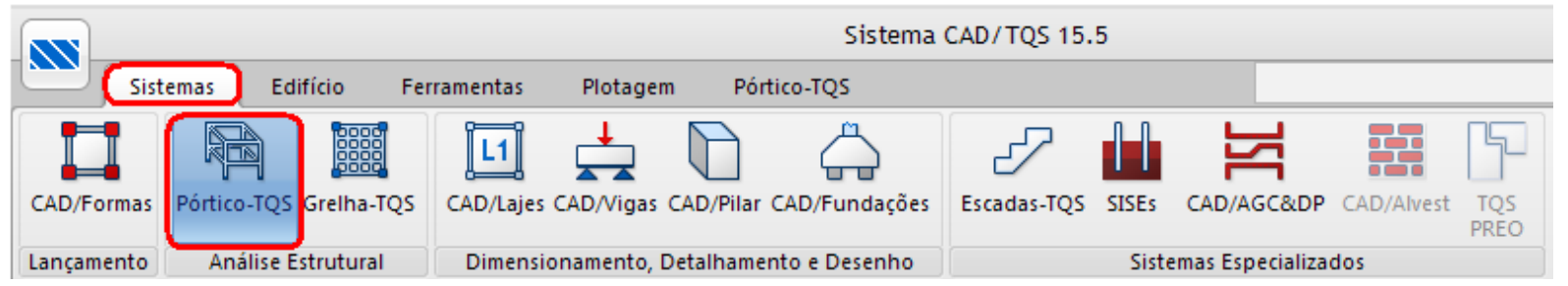

Figura A.71. Ícone Pórtico-TQS.

Dentro dos critérios do Pórtico-TQS, clica-se em Critérios > Critérios Gerais (figura A.72).

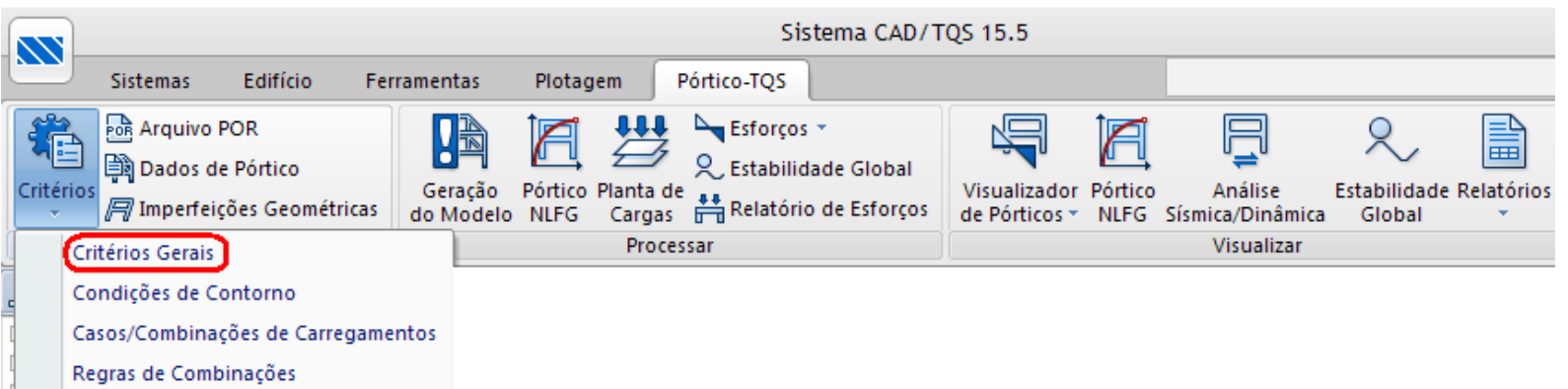

Figura A.72. Critérios gerais do Pórtico-TQS.

Ao clicar em Critérios Gerais, aparece a janela da figura A.73: clica-se em OK.

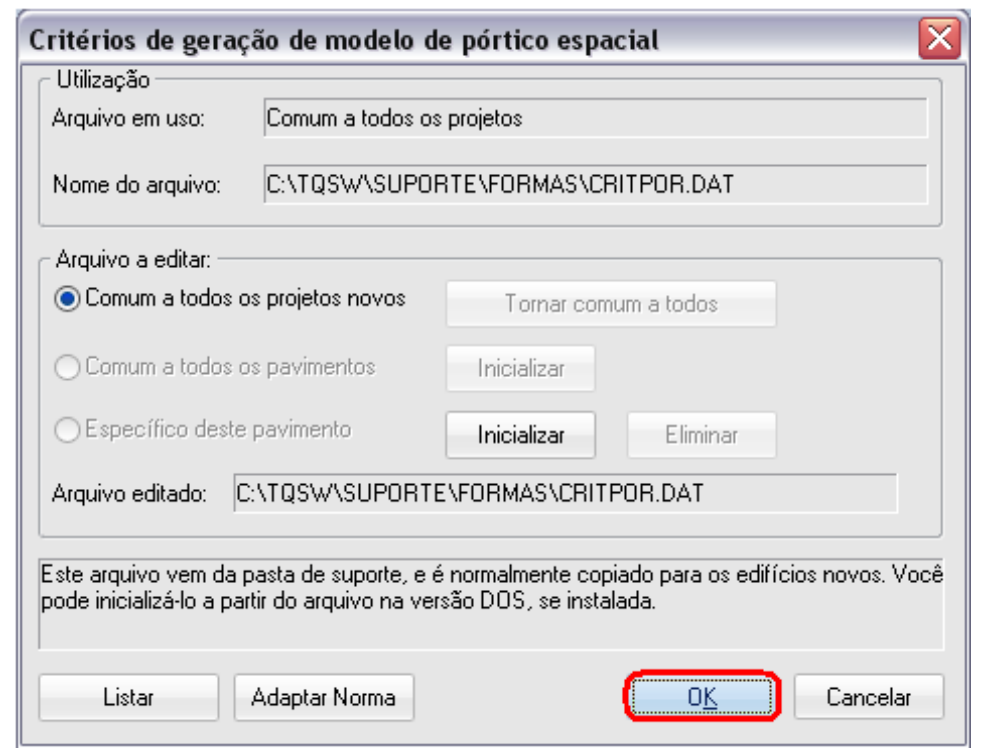

Figura A.73. Critérios de geração de modelo de pórtico espacial. 
Na aba Pilares, clica-se em "Flexibilização das ligações viga-pilar" (figura A.74).

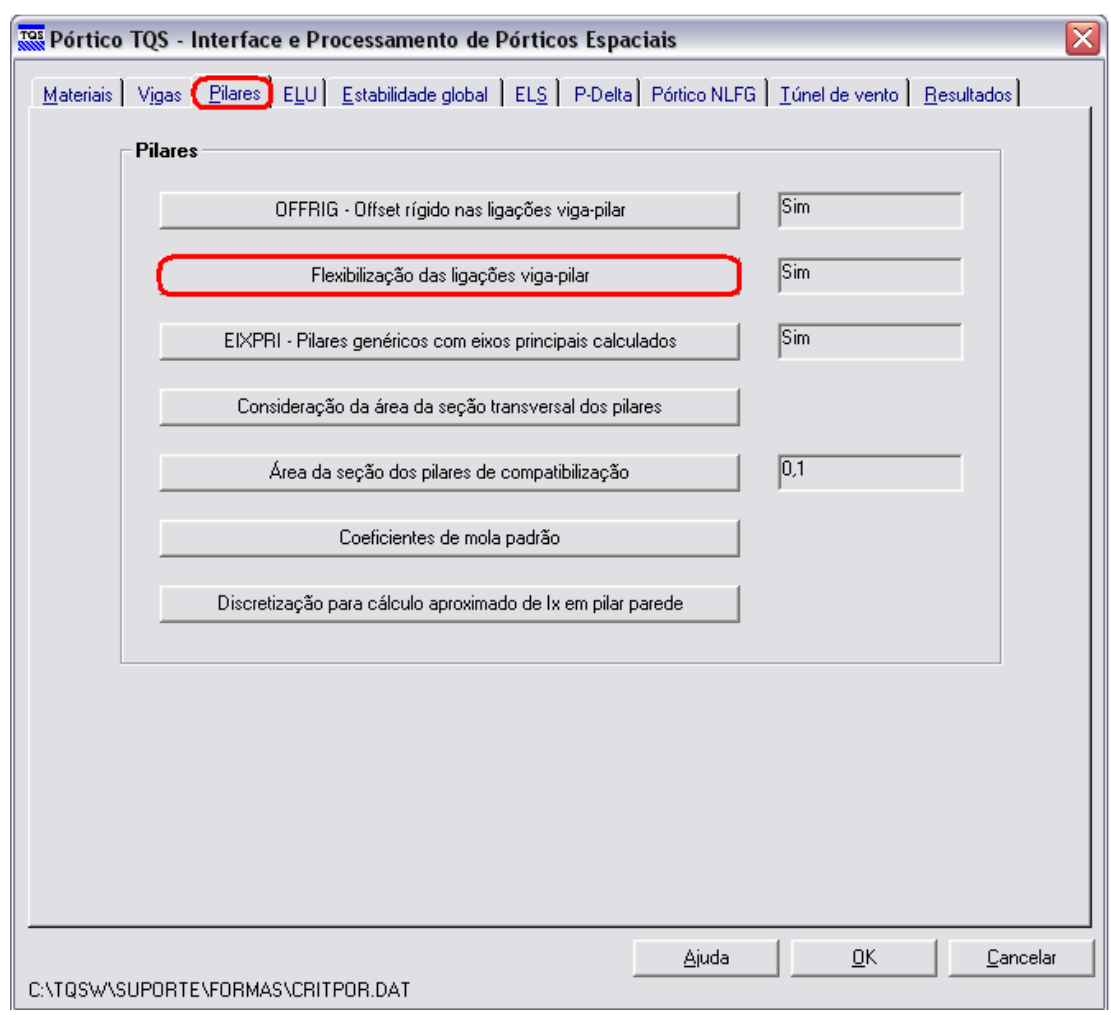

Figura A.74. Flexibilização das ligações viga-pilar.

Nessa janela, a flexibilização pode ser ativada ou não, e também podem ser alterados os coeficientes REDMOL e LEPMOL (figura A.75).

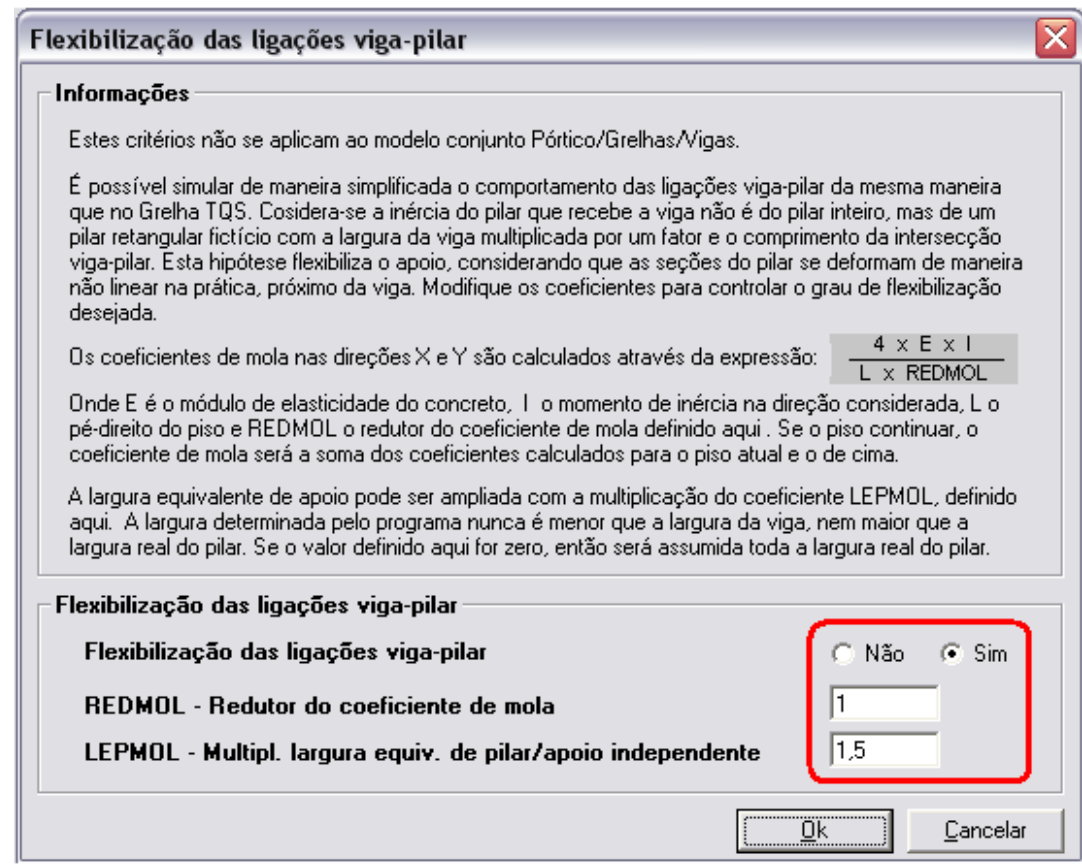

Figura A.75. Janela da flexibilização das ligações viga-pilar. 


\section{A.14 LI MITES DOS DESLOCAMENTOS HORI ZONTAIS DO EDI FÍ CIO}

Os limites dos deslocamentos horizontais do edifício podem ser alterados na aba ELS dos critérios gerais do Pórtico-TQS. Para se ter acesso, primeiramente clica-se em Sistemas > Pórtico-TQS (figura A.76).

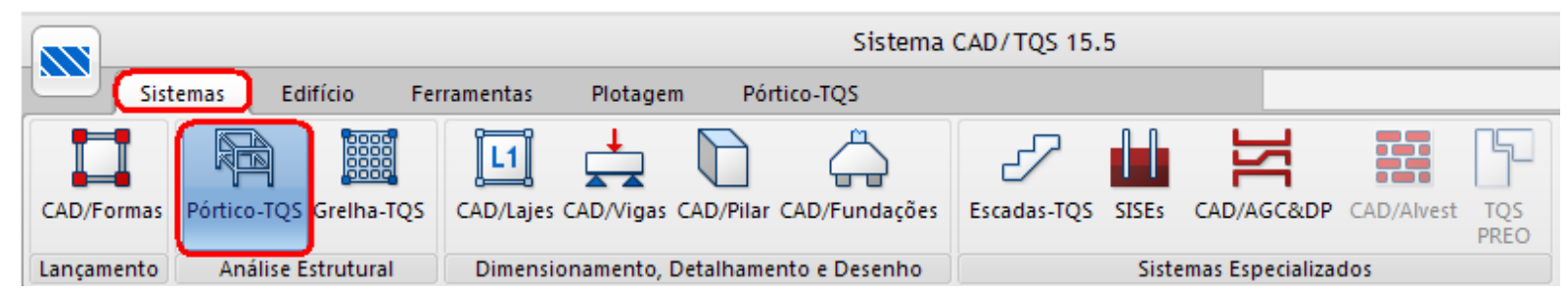

Figura A.76. Ícone Pórtico-TQS.

Dentro dos critérios do Pórtico-TQS, clica-se em Critérios > Critérios Gerais (figura A.77).

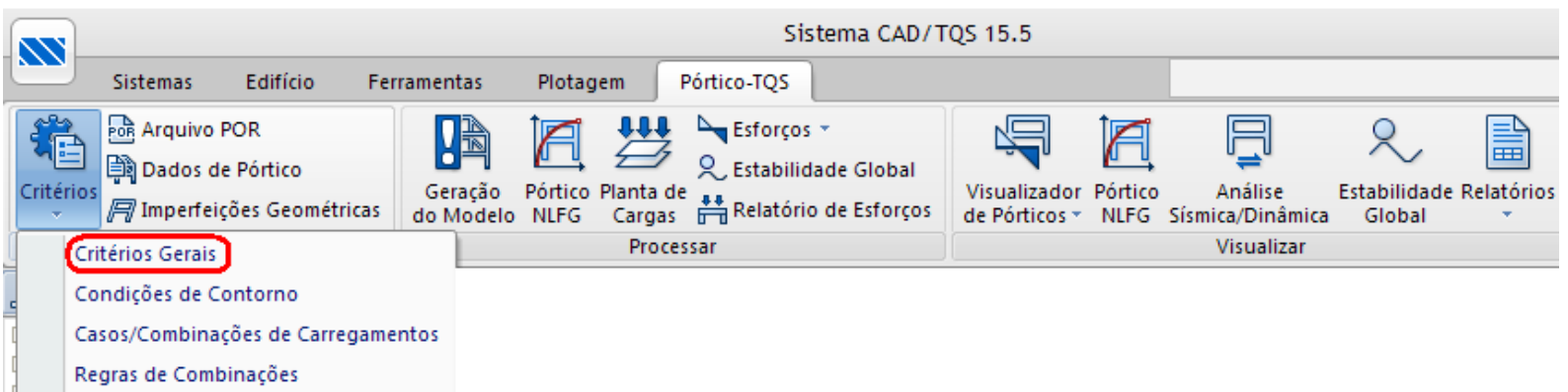

Figura A.77. Critérios gerais do Pórtico-TQS.

Ao clicar em Critérios Gerais, tem-se a janela da figura A.78. Clica-se em OK.

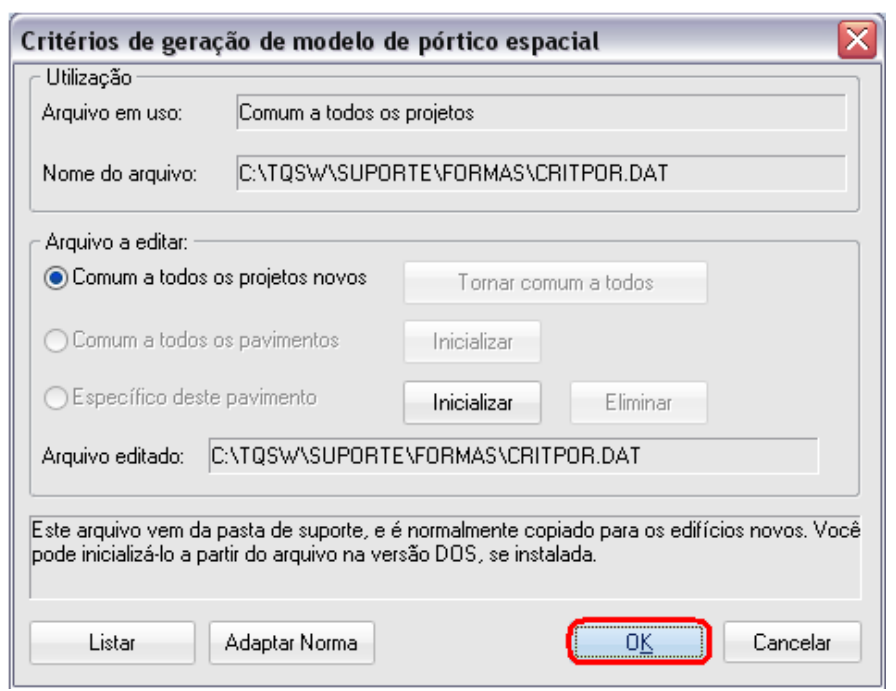

Figura A.78. Critérios de geração de modelo de pórtico espacial. 
Na aba ELS, pode-se alterar o valor dos deslocamentos máximos (figura A.79).

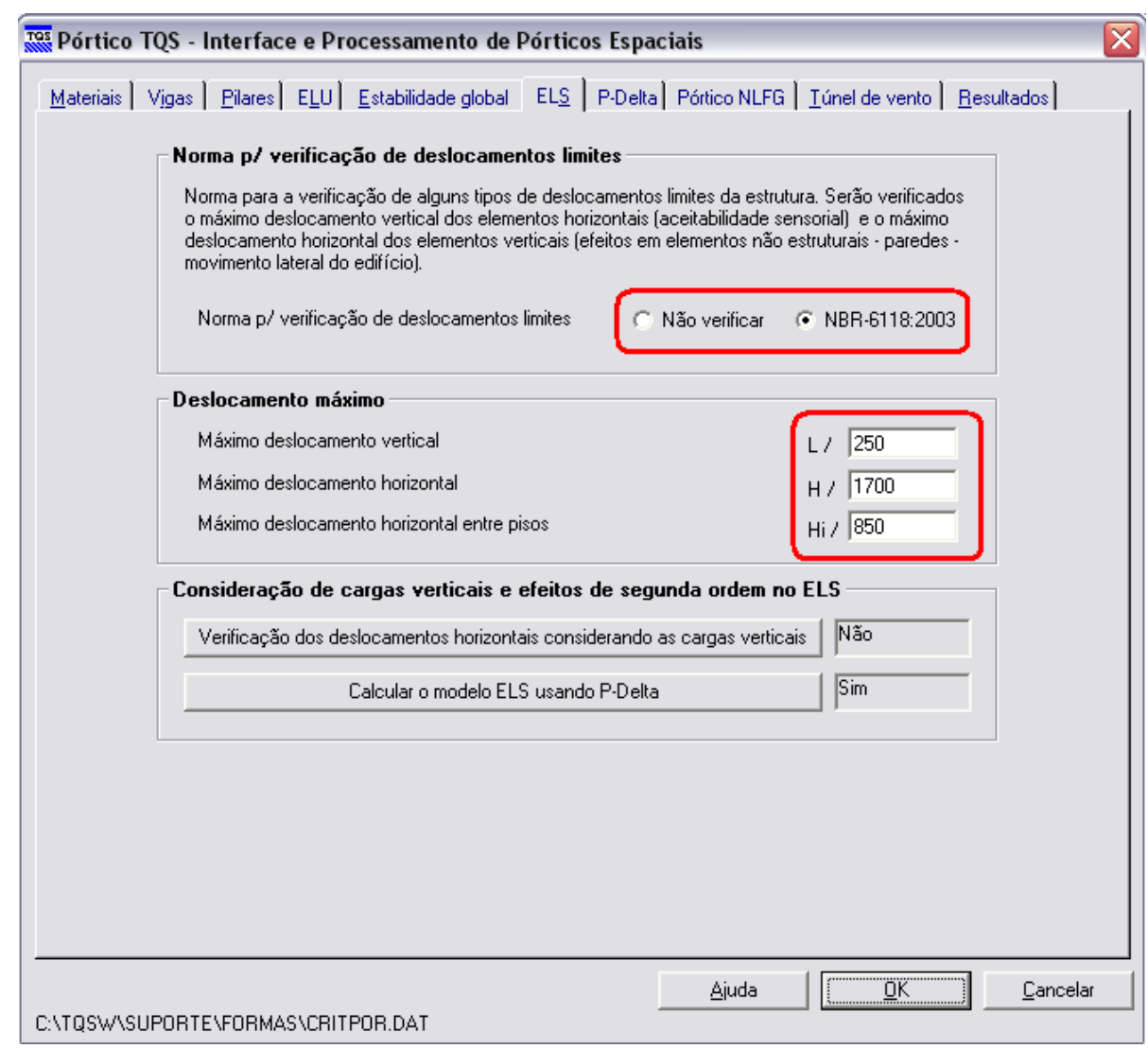

Figura A.79. Deslocamentos máximo.

\section{A.15 FATOR MULAXI}

O fator MULAXI, como já foi comentado no início deste Apêndice, amplia a rigidez axial dos pilares, para correção dos diagramas de momentos fletores do pórtico, considerando, assim, os efeitos construtivos.

Ele pode ser alterado na aba Pilar dos critérios gerais do Pórtico-TQS. Para se ter acesso a essa aba, primeiramente clica-se em Sistemas > Pórtico-TQS (figura A.80).

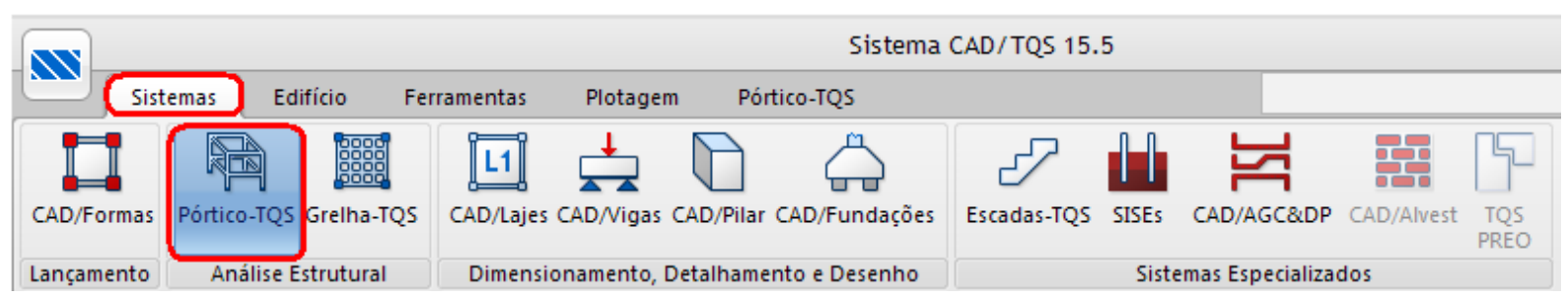

Figura A.80. Ícone Pórtico-TQS. 
Dentro dos critérios do Pórtico-TQS, clica-se em Critérios > Critérios Gerais (figura A.81).

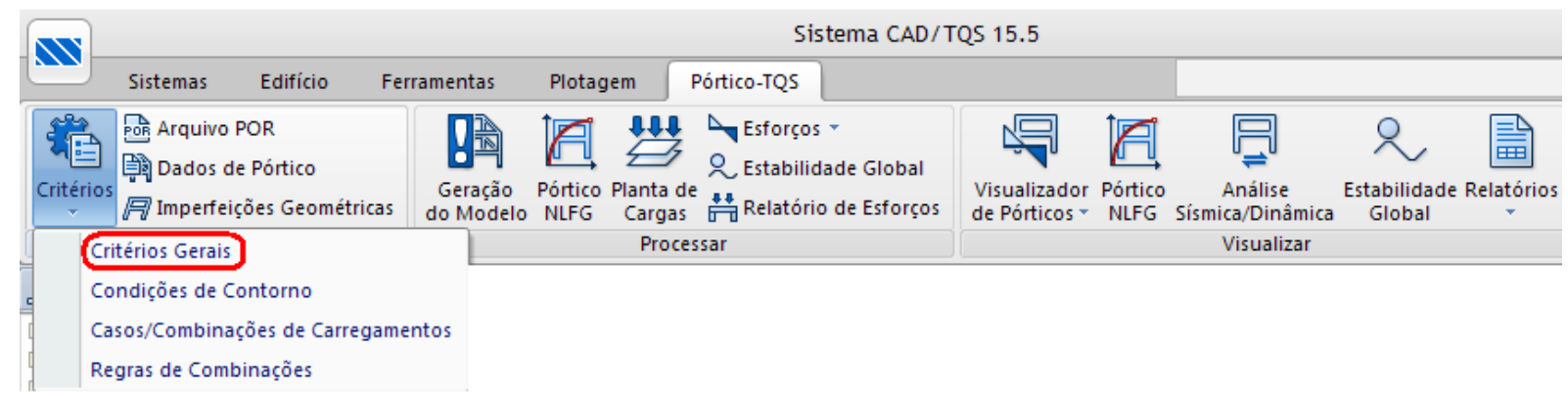

Figura A.81. Critérios gerais do Pórtico-TQS.

Ao clicar em Critérios Gerais, surge a janela indicada na figura A.82. Clicase em OK.

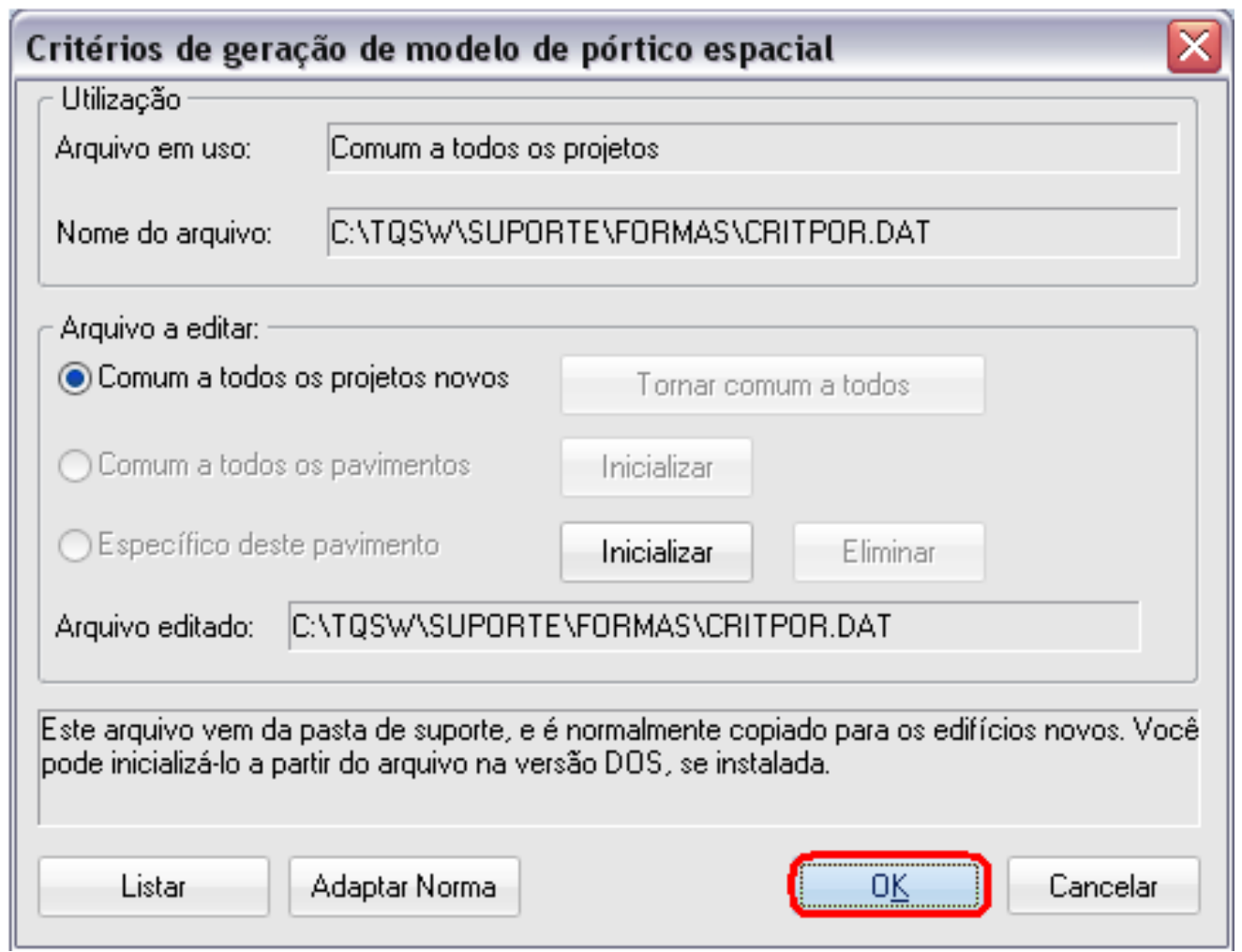

Figura A.82. Critérios de geração de modelo de pórtico espacial.

Na aba Pilares, clica-se em "Consideração da área da seção transversal dos pilares" (figura A.83). 


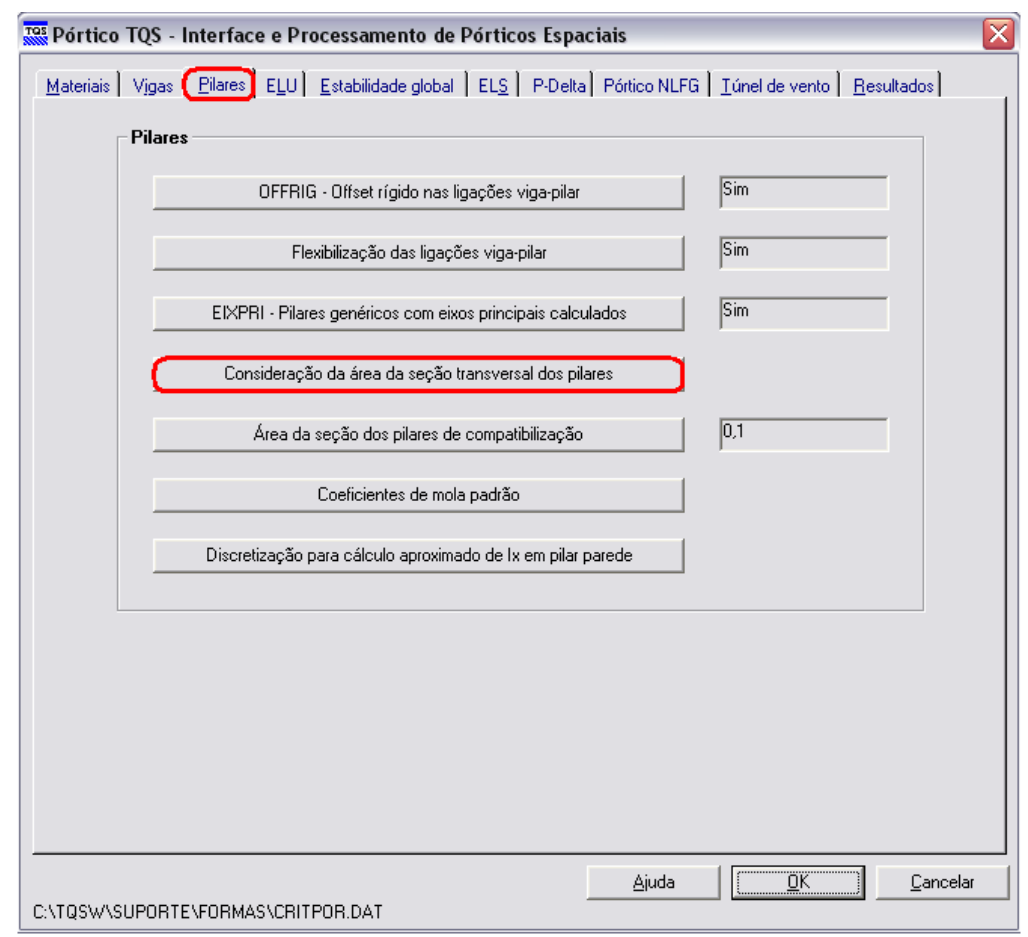

Figura A.83. Consideração da área da seção transversal dos pilares.

Na janela "Consideração da área da seção transversal dos pilares", podese alterar o valor do fator MULAXI (figura A.84).

\begin{tabular}{|c|c|}
\hline Consideração da Área da Seção Transversal dos Pilares & \\
\hline Informaçōes & \\
\hline $\begin{array}{l}\text { A geração do modelo de pórtico espacial de edifícios altos com consideração da } \\
\text { seções transversais leva à deformação axial por carga vertical maior dos pilares d } \\
\text { área de seção transversal, com consequente redistribuição de esforços para outr }\end{array}$ & $\begin{array}{l}\text { a área real das } \\
\text { de maior carga por } \\
\text { tros pilares. }\end{array}$ \\
\hline $\begin{array}{l}\text { Este efeito é tanto maior quanto mais assimétrica for a distribuição de cargas e de } \\
\text { no pórtico. Nos casos extremos, os pórticos podem sofrer torção excessiva devid } \\
\text { com o eventual surgimento de momentos positivos em apoios de vigas, devido ao } \\
\text { apoio. }\end{array}$ & $\begin{array}{l}\text { de seções de pilares } \\
\text { do à carga vertical, } \\
\text { aos recalques de }\end{array}$ \\
\hline $\begin{array}{l}\text { Para muitos calculistas, esta consideração de deformação axial é conservadora. } \\
\text { argumentos apontados, pode-se considerar a acomodação da estrutura durante } \\
\text { nivelamento progressivo dos pisos. Por outro lado, terminada a construção, haver } \\
\text { adicional devido às sobrecargas e outras cargas acidentais. Por isso, a área de to } \\
\text { multiplicada por um fator (MULAXI), se este parâmetro estiver ligado. }\end{array}$ & $\begin{array}{l}\text { Dentre os } \\
\text { a construção, com } \\
\text { erá deformação } \\
\text { todos os pilares será }\end{array}$ \\
\hline $\begin{array}{l}\text { O fator MULAXI é aplicado exclusivamente nos carregamentos verticais. Nos car } \\
\text { inércia à flexão das vigas de transição é multiplicada por um fator (dados do edif́ } \\
\text { botão 'Vigas de transição/tirantes", valor padrão 10.0), o MULAXI utilizado é mai } \\
\text { último. }\end{array}$ & $\begin{array}{l}\text { íregamentos onde a } \\
\text { ício, aba "Modelo", } \\
\text { aior ou igual a este }\end{array}$ \\
\hline Aumenta Área da Seção Transversal dos Pilares & \\
\hline$C$ Area real das barras & \\
\hline - Area das barras multiplicada pelo fator MULAXI & $?$ \\
\hline MULAXI & \\
\hline Fator MULAXI de aumento da seção dos pilares & 3 \\
\hline Eliminar MULAXI dos carregamentos $\mathrm{c} /$ vigas de transição $\mathrm{c} /$ inércia normal & Nã̃o \\
\hline$\underline{\mathrm{Ok}}$ & Cancelar \\
\hline
\end{tabular}

Figura A.84. Fator MULAXI. 



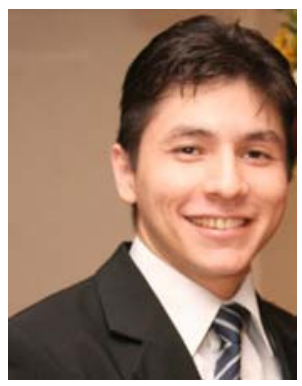

Winston Junior Zumaeta Moncayo

Engenheiro Civil pela Universidade Federal do Amazonas, UFAM, em 2008, e Licenciado em Matemática pela mesma Instituição, no mesmo ano. Mestre em Engenharia Civil (Engenharia de Estruturas) pela Escola de Engenharia de São Carlos da Universidade de São Paulo, EESC-USP, em 2011. Nessa mesma Instituição, também em 2011, iniciou Curso de Doutorado em Engenharia Civil (Engenharia de Estruturas), sendo que, em novembro de 2010, já tinha concluído todos os créditos em disciplinas, necessários para o doutorado, faltando apenas o exame de qualificação e a defesa da Tese. Paralelamente a essas atividades, concluiu o curso de Especialização (Mestrado Lato Sensu) em Projeto de Estruturas de Concreto para Edifícios, na Faculdade de Engenharia São Paulo, FESP, curso ministrado em parceria com a ABECE e a TQS Informática, faltando apenas a defesa do TCC, prevista para maio de 2011. Neste curso, além de projetos de concreto armado, trabalhou com projetos de concreto protendido, concreto pré-moldado e alvenaria estrutural. No curso de graduação em Engenharia Civil, foi homenageado como melhor aluno da turma. Foi monitor de Resistência dos Materiais e de Teoria das Estruturas. No curso de Matemática, participou do programa de aperfeiçoamento de professores de Matemática do Ensino Médio. De fevereiro de 2008 a fevereiro de 2009, trabalhou com projetos de estruturas de concreto para edifícios, utilizando os sistemas CAD/TQS. Durante o mestrado, participou do Programa de Aperfeiçoamento de Ensino - PAE, nas disciplinas de graduação da EESC-USP: Estruturas de Concreto Armado I e II. No período de 12 de agosto a 7 de outubro de 2010, ministrou sete palestras na disciplina de pós-graduação Instabilidade de Elementos e Estruturas de Concreto. Desde 23 de março de 2011, é representante da TQS Informática na cidade de Manaus. 